Portland State University

PDXScholar

\title{
Comparing the Promise and Reality of E-Scooters: a Critical Assessment of Equity Improvements and Mode-Shift
}

Michael Glenn McQueen

Portland State University

Follow this and additional works at: https://pdxscholar.library.pdx.edu/open_access_etds

Part of the Transportation Commons, and the Urban Studies and Planning Commons Let us know how access to this document benefits you.

\section{Recommended Citation}

McQueen, Michael Glenn, "Comparing the Promise and Reality of E-Scooters: a Critical Assessment of Equity Improvements and Mode-Shift" (2020). Dissertations and Theses. Paper 5565.

https://doi.org/10.15760/etd.7439

This Thesis is brought to you for free and open access. It has been accepted for inclusion in Dissertations and Theses by an authorized administrator of PDXScholar. Please contact us if we can make this document more accessible: pdxscholar@pdx.edu. 
Comparing the Promise and Reality of E-Scooters:

A Critical Assessment of Equity Improvements and Mode-Shift

by

Michael Glenn McQueen

A thesis submitted in partial fulfillment of the requirements for the degree of

Master of Science

in

Civil and Environmental Engineering

Thesis Committee:

Kelly J. Clifton, Chair John MacArthur

Christopher Monsere

Liming Wang

Portland State University

2020 
(C) 2020 Michael Glenn McQueen 


\section{Abstract}

In just three years, e-scooters have substantially disrupted and altered the urban mobility landscape. Throughout this period, they have been commonly touted as part of a larger micromobility solution that promises to erase equity barriers and solve the firstmile/last-mile problem. However, few studies in the nascent e-scooter literature have considered these claims. In this study, we surveyed students at Portland State University ( $n=1,968$ ) about the role that e-scooters, among other modes, played in meeting their general and university-related travel needs. We then estimated models that incorporated demographics, travel behavior, and latent attitudes distilled using exploratory factor analysis (EFA). These models were used to assess the current performance of e-scooters in meeting equity and mode-shift goals.

We first estimated ordinal logit models to understand the relationship of these factors to the stated number of trips taken in the 7 days prior to the survey by escooter, car, bike, and MAX light rail. Perceived propensity to switch to using e-scooter, car, bike, or MAX light rail modes for commuting to the university should their present primary commute mode became unavailable. We also designed and implemented a stated choice experiment (SCE) consisting of several hypothetical scenarios of a commute to PSU. In the SCE, students were given a three-mode labelled set consisting of car, bike, and e-scooter + MAX choices. The experiment choice sets were designed using a D-Efficient method. In order to understand the relationship of travel time and 
cost in addition to the other covariates on mode choice, we estimated a multinomial logit (MNL) model from the experiment data. We used this model to perform a thorough sensitivity analysis to uncover the most impactful factors that encourage firstmile/last-mile e-scooter usage. Additionally, we used the model to generate catchment area maps for e-scooter/MAX multimodal trips in the Portland area based on the most probable mode choice at every point in the city.

In addition to the models, we asked students to indicate barriers that actively prevented them from using non-auto modes more often. We mapped out barrier "hotspots" in order to understand the current travel realities of the city.

Results were mixed in indicating that e-scooters bring about racial and gender equity in transportation. Additionally, we found that there was no place in the city where taking an e-scooter to connect with MAX to travel to PSU was more preferable (utilitarian) than taking a bike or private car, on average. This suggests that e-scooters are currently not a practical solution to the first-mile/last-mile problem. However, our findings revealed "dials" that can be tweaked through policy measures in order to promote this kind of use. Overall, our critical analysis of the implementation of escooters suggests that their promise is overstated, at least without substantial policy changes to encourage desired use cases. 
Dedication

To our shared future. 


\section{Acknowledgements}

First and foremost, I want to recognize the loving support of lan McQueen throughout this and countless other challenging journeys. I am immensely grateful for the unending grace and patience he has shown while my energies were focused on this endeavor, and I am looking forward to being more present in our next chapter. I want to thank my advisor, Dr. Kelly J. Clifton, for originally convincing me to move to Portland and for proving to me that I worry too much. Her expertise, non-anxious presence, and self-described bad jokes were just what I needed to accomplish this undertaking. I also want to thank John MacArthur for giving me countless opportunities to learn and apply an incredible number of new skills throughout our research together. Additionally, I am grateful to him for letting me borrow his hot-rod e-bike - for research purposes, of course. Thanks to Dr. Christopher Monsere and Dr. Liming Wang for agreeing to participate on my committee. Your comments and input have been extremely valuable. I appreciate the help of Dr. Kristina Currans in the early stages of defining this project, despite the fact that I was not even a student at her university. I am grateful for the tutelage of Dr. Jason Newsom, who single-handedly managed to teach me a solid foundational understanding of statistics, skills which I hope were put to good use in this research. Thanks to my classmates, colleagues, and concurrent friends Gabby AbouZeid, Katherine Keeling, Jaime Orrego-Oñate, George Palmiter, Jaclyn Schaefer, and Baxter Shandobil, who all humored me with shared enthusiasm for this work and were kind enough to test out the survey, sometimes on more than one occasion. For these 
same reasons I am also grateful to my mother, who was particularly gifted at spotting missing punctuation and faulty parallelisms in the survey draft - thank you! I have special appreciation for Clint Culpepper and lan Stude at Transportation \& Parking Services, who trusted me enough to help me reach the entire student body of Portland State University for this study. I would like to recognize Dr. Jack Horne, creator of the choiceDes R package, who took time out of his day on several occasions to answer my naïve questions about statistics. I am so grateful for the trust and support of the Federal Highway Administration's (FHWA) Dwight D. Eisenhower Transportation Fellowship Program (DDETFP), the National Institute for Transportation and Communities (NITC), and Young Professionals in Transportation (YPT) both of which provided me with substantial grants that enabled me to complete my studies with a relatively low financial burden. Lastly, I would like to recognize in writing the contribution of my feline friend Zoë towards my general state of mental well-being, despite the fact that I know she has better things to do than read this thesis. 
Table of Contents

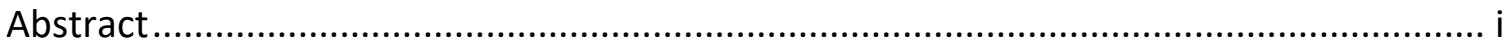

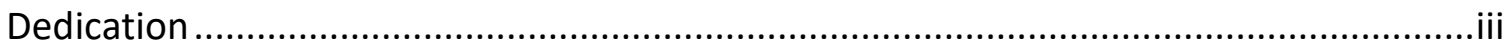

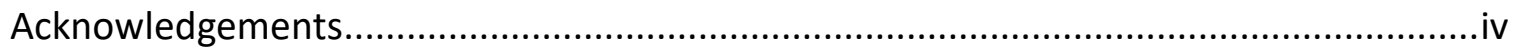

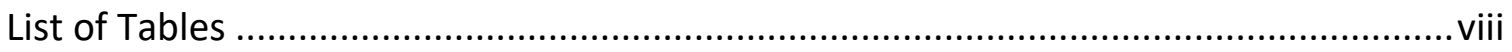

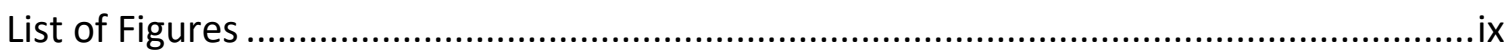

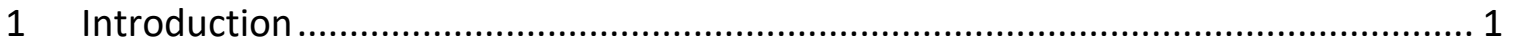

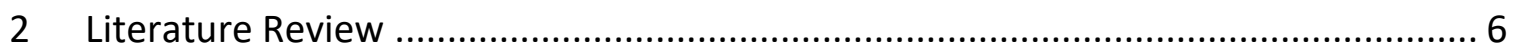

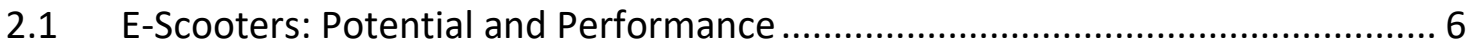

2.2 Approach and Contribution.................................................................... 10

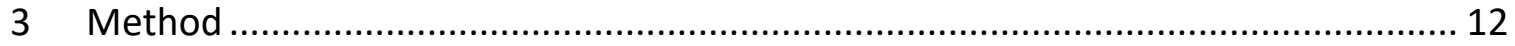

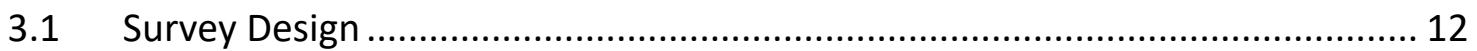

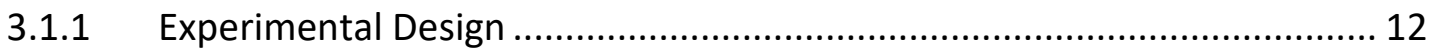

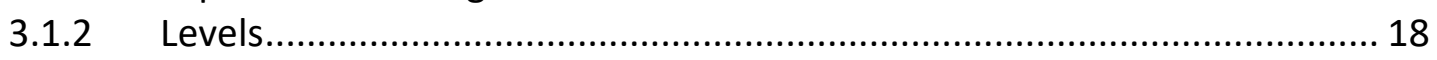

3.1.3 Mode Attitudes and Decision Factors................................................... 22

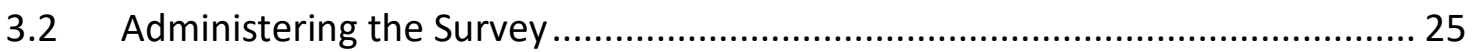

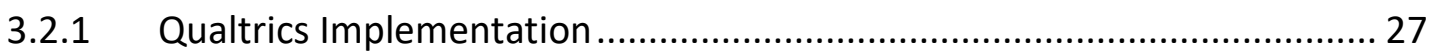

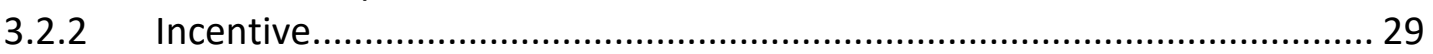

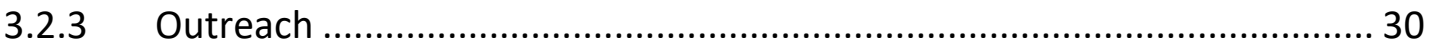

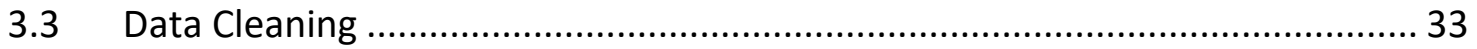

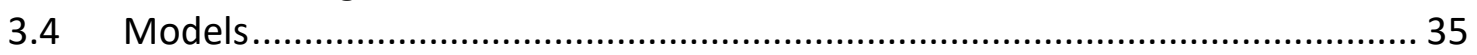

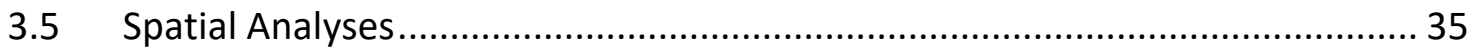

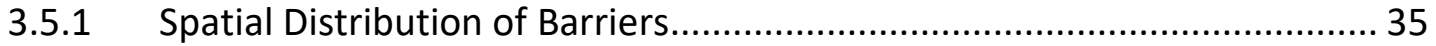

3.5.2 Spatial Implementation of MNL Results ............................................. 38

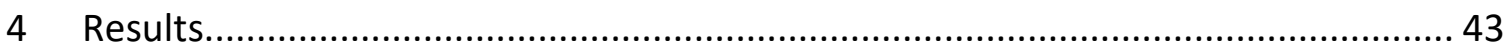

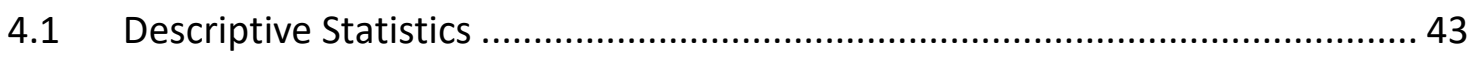

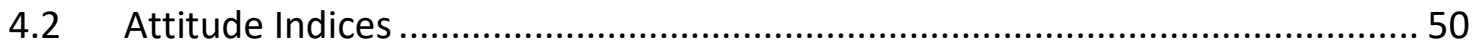

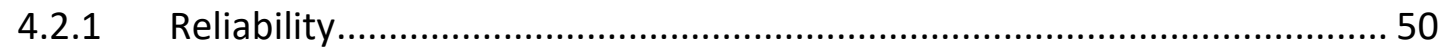

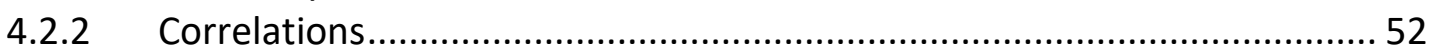

4.2.3 Indices Calculated Using Item Sums and Means .................................... 54

4.2.4 Principal Components Analysis (PCA) and Exploratory Factor Analysis (EFA) 54

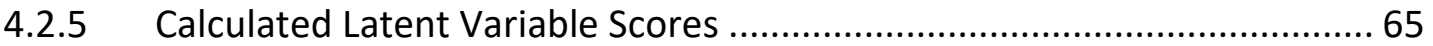

4.2.6 Structural Equation Modelling (SEM) .......................................................6 66

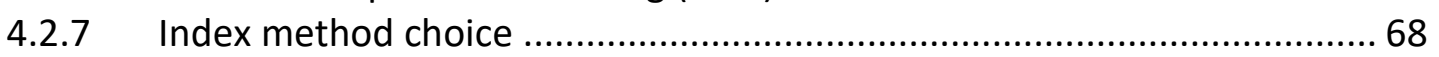

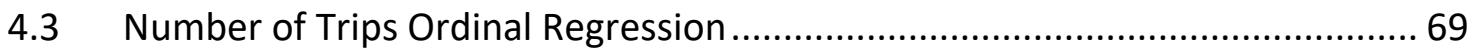

4.4 Propensity to Switch Linear Regression .................................................... 84 
4.5 Stated Choice Experiment MNL Regression............................................... 100

4.6 Spatial Distribution of Mode Use Barriers ..................................................... 108

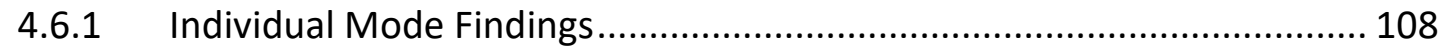

4.6.2 Comparison of Similar Barriers Across Modes ....................................... 113

4.7 MNL Sensitivity Analysis and Visualization .............................................. 119

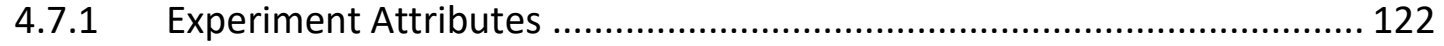

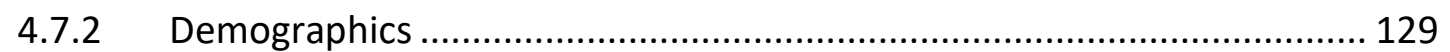

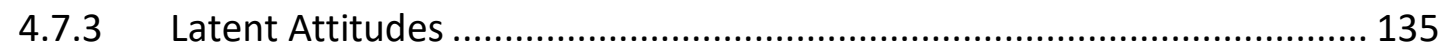

4.7.4 Example of obtaining "good" first-mile ridership.................................. 142

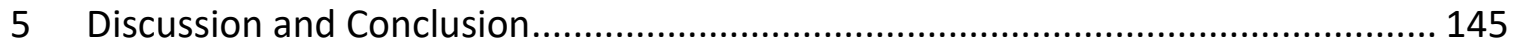

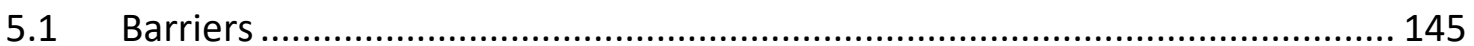

5.2 General Model Findings - Travel behavior, routine, built environment, and

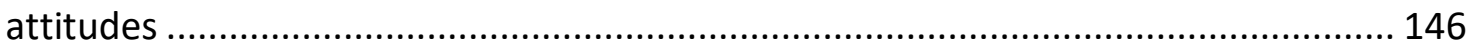

$5.3 \quad$ E-Scooter Specific Findings................................................................... 150

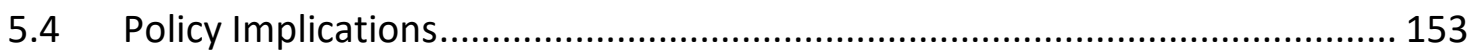

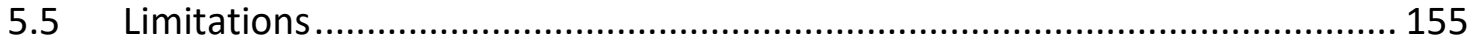

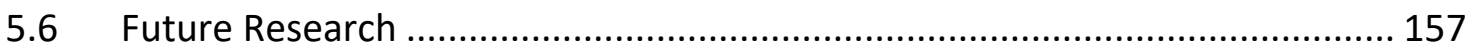

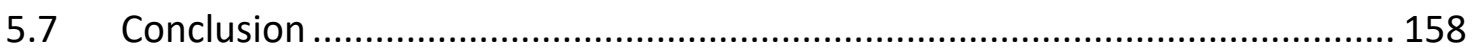

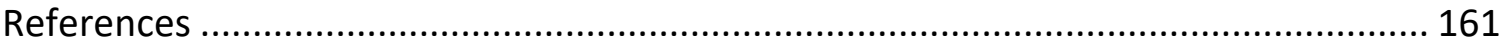

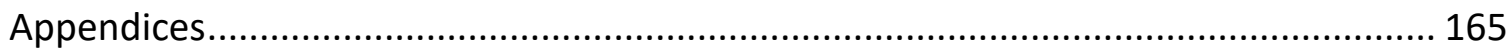

A. Pearson Correlations of Scale Items ........................................................... 166

B. Full Latent Variable Estimation Method Comparisons ................................. 172

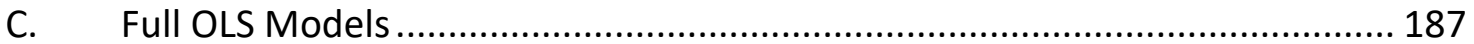

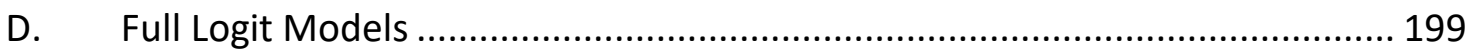

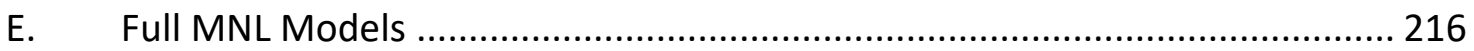

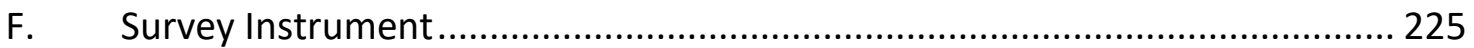


List of Tables

Table 1: Level Selection and Justification ................................................................. 21

Table 2: Attitudinal Likert Scale Questions (Please indicate to what extent you agree or disagree with the following statements:) ....................................................................... 23

Table 3: Mode Choice Decision Factor Questions (How important are each of the following issues in choosing your means of transportation to PSU?) .............................. 24

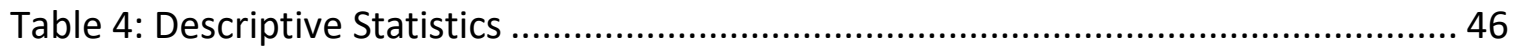

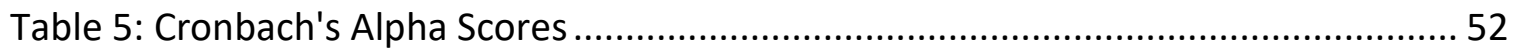

Table 6: MAX Attitude Items, Pearson Correlations ....................................................... 53

Table 7: Descriptive Statistics, Calculated Index Values .............................................. 54

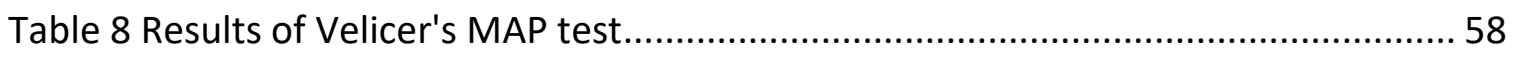

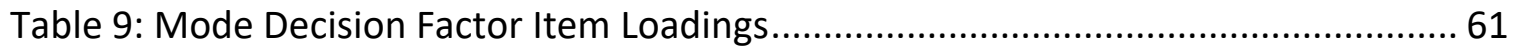

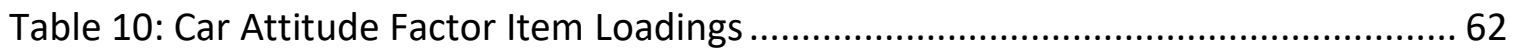

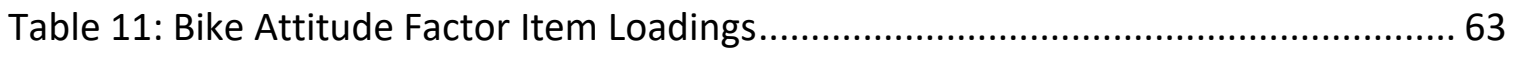

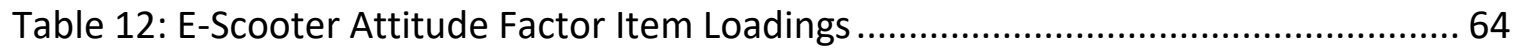

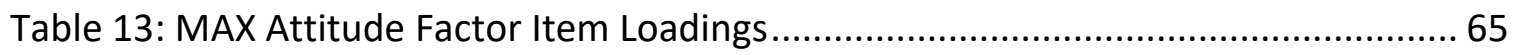

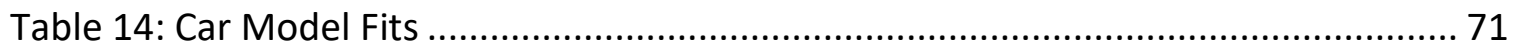

Table 15: Car Trips Ordinal Logit Regression Models (sig. predictors only) .................... 72

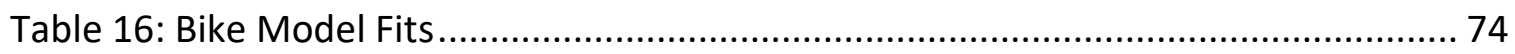

Table 17: Bike Trips Ordinal Logit Regression Models (sig. predictors only)................... 75

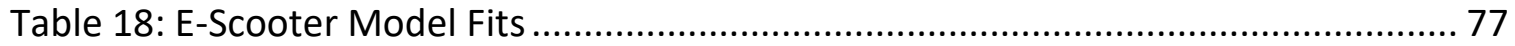

Table 19: E-Scooter Trips Ordinal Logit Regression Models (sig. predictors only) ........... 78

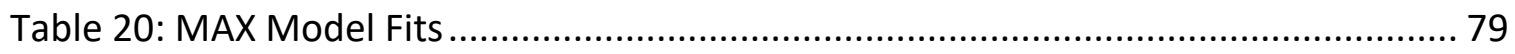

Table 21: MAX Trips Ordinal Logit Regression Models (sig. predictors only) ................... 80

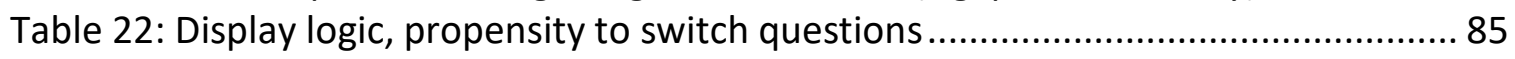

Table 23: Propensity to Switch to Car OLS Regression Models (sig. predictors only) ...... 87

Table 24: Propensity to Switch to Bike OLS Regression Models (sig. predictors only) .... 90

Table 25: Propensity to Switch to E-Scooter OLS Regression Models (sig. predictors only)

.

Table 26: Propensity to Switch to MAX OLS Regression Models (sig. predictors only) ... 97

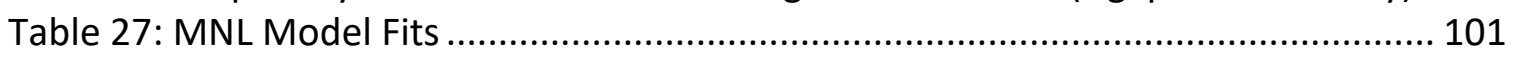

Table 28: Stated Choice Experiment MNL Model (sig. predictors only)....................... 103 
List of Figures

Figure 1: An Assortment of E-Scooters (Photo sourced under the Pixabay License) ......... 1

Figure 2: Distribution of survey responses by date ...................................................... 26

Figure 3: Stated Choice Experiment Survey Format, Computer..................................... 28

Figure 4: Stated Choice Experiment Survey Format, Mobile Device (note that question is

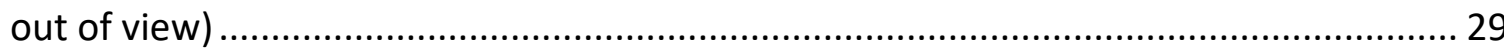

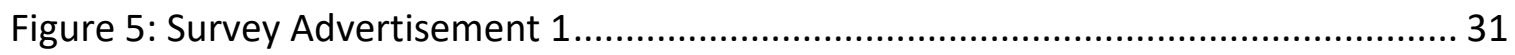

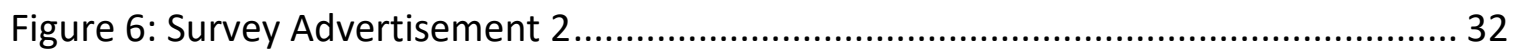

Figure 7: Approximate locations of geocoded responses within the Portland Metro Area

Figure 8: Raw Count Distribution of Responses

Figure 9: Raw Ratio Distribution of Responses............................................................. 36

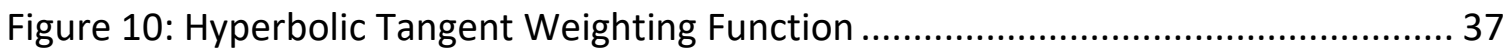

Figure 11: Weighted Ratio Distribution of Responses.................................................. 38

Figure 12: Test point generation, snapping, and nearest neighbor analysis................... 39

Figure 13: Estimated Travel Times and Speeds of the last 4 miles of I-84 WB using loop

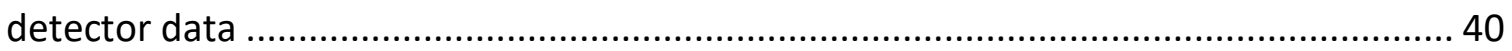

Figure 14: PCA Scree Plots (blue solid), Kaiser-Guttman Criterion (red dotted), and

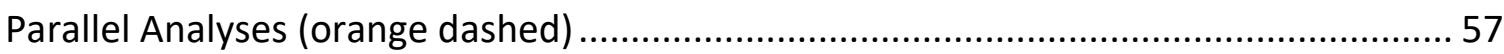

Figure 15: PCA (top) and EFA (bottom) path diagram framework ................................ 59

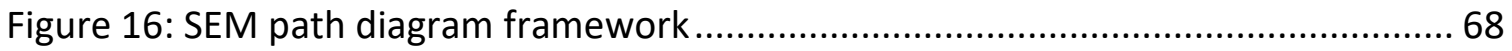

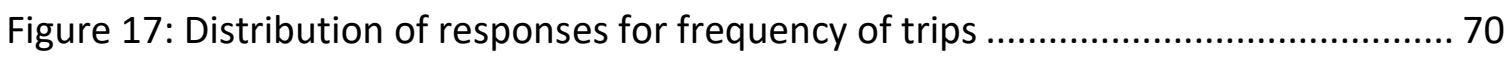

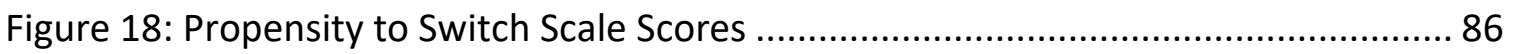

Figure 19: Bike Neighborhood Barriers: I'm afraid that my bike will be stolen ............. 108

Figure 20: E-Scooter Neighborhood Barriers: I can't count on an e-scooter being around

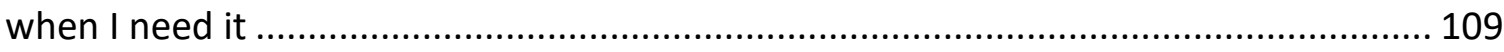

Figure 21: E-Scooter Neighborhood Barriers: I live outside of an e-scooter service area

Figure 22: E-Scooter Personal Barriers: I have never tried riding an e-scooter before . 110

Figure 23: MAX Neighborhood Barriers: I live too far from a MAX station.................... 111

Figure 24: MAX Neighborhood Barriers: There is not a safe way for me to walk or bike to

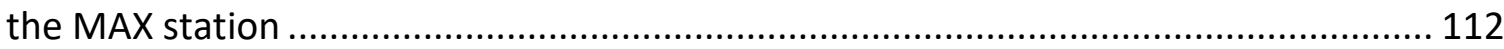

Figure 25: MAX Personal Barriers: MAX does not go where I need to go ...................... 113

Figure 26: E-Scooter Neighborhood Barriers: Too much traffic .................................. 113

Figure 27: Bike Neighborhood Barriers: Too much traffic .......................................... 114

Figure 28: Bike Neighborhood Barriers: Not enough bike lanes or trails..................... 115

Figure 29: E-Scooter Neighborhood Barriers: Not enough dedicated lanes to ride in... 115

Figure 30: Bike Personal Barriers: I don't want to ride a bike when the weather is bad 115

Figure 31: E-Scooter Personal Barriers: I don't want to ride an e-scooter when the

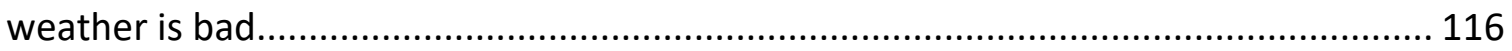

Figure 32: Bike Personal Barriers: Bikes are too slow ............................................ 117 
Figure 33: E-Scooter Personal Barriers: E-Scooters are too slow ............................... 117

Figure 34: MAX Personal Barriers: MAX is too slow ................................................... 117

Figure 35: Bike Personal Barriers: I can't afford to buy a bike ................................... 118

Figure 36: Bike Personal Barriers: I can't afford maintenance costs for a bike............. 118

Figure 37: E-Scooter Personal Barriers: I can't afford to ride e-scooters regularly ........ 119

Figure 38: MAX Personal Barriers: MAX is too expensive .......................................... 119

Figure 39: Mode Catchment Areas, Current Conditions ............................................ 121

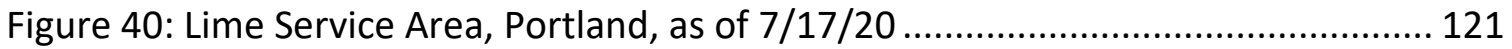

Figure 41: E-Scooter Travel Time Sensitivity Analysis............................................. 123

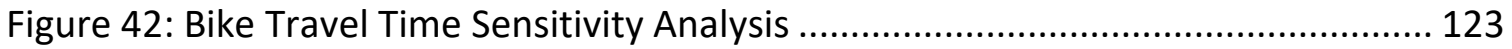

Figure 43: Car Travel Time Sensitivity Analysis ....................................................... 124

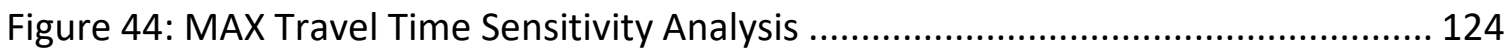

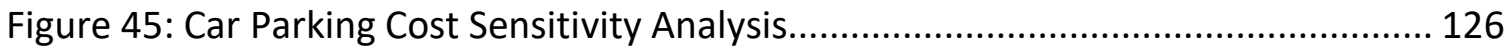

Figure 46: Mode Catchment Areas, Medium Parking Increase .................................. 126

Figure 47: Mode Catchment Areas, Large Parking Increase ....................................... 127

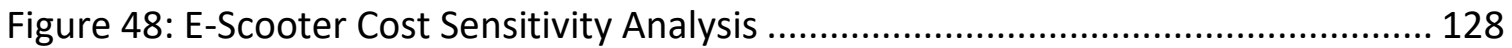

Figure 49: Mode Catchment Areas, Free E-Scooters .............................................. 128

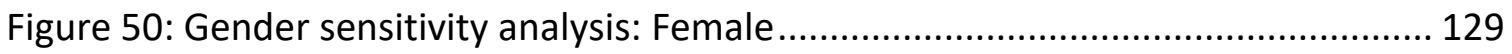

Figure 51: Mode Catchment Areas, Female Travelers ............................................. 130

Figure 52: Mode Catchment Areas, Male Travelers ................................................. 130

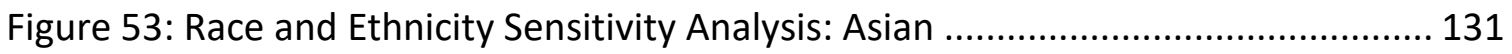

Figure 54: Race and Ethnicity Sensitivity Analysis: Black....................................... 132

Figure 55: Race and Ethnicity Sensitivity Analysis: Hispanic or Latinx/Latino/Latina .... 132

Figure 56: Mode Catchment Areas, Asian Travelers................................................ 133

Figure 57: Mode Catchment Areas, Black Travelers .................................................. 133

Figure 58: Mode Catchment Areas, Hispanic or Latinx Travelers................................... 134

Figure 59: Mode Catchment Areas, White Travelers ............................................... 134

Figure 60: Latent Attitude Sensitivity Analysis: Bike ............................................... 135

Figure 61: Mode Catchment Areas, Travelers with low Bike Attitude ........................... 136

Figure 62: Mode Catchment Areas, Travelers with high Bike Attitude ......................... 136

Figure 63: Latent Attitude Sensitivity Analysis: Car .................................................... 137

Figure 64: Mode Catchment Areas, Travelers with low Car Attitude........................... 137

Figure 65: Mode Catchment Areas, Travelers with high Car Attitude .......................... 138

Figure 66: Latent Attitude Sensitivity Analysis: E-Scooter........................................ 139

Figure 67: Mode Catchment Areas, Travelers with low E-Scooter Attitude .................. 139

Figure 68: Mode Catchment Areas, Travelers with high E-Scooter Attitude ................. 140

Figure 69: Latent Attitude Sensitivity Analysis: MAX .............................................. 141

Figure 70: Mode Catchment Areas, Travelers with low MAX Attitude ......................... 141

Figure 71: Mode Catchment Areas, Travelers with high MAX Attitude ......................... 142

Figure 72: Mode Catchment Areas, Medium parking cost increase and free E-Scooters 
Figure 73: Mode Catchment Areas, Medium parking cost increase and free E-Scooters, detail

Figure 74: Mode Catchment Areas, Medium parking cost increase, free E-Scooters, MAX Publicity, E-Scooter Publicity 144 Figure 75: Mode Catchment Areas, Medium parking cost increase, free E-Scooters, MAX Publicity, E-Scooter Publicity, Gateway detail 


\section{Introduction}

Shared e-scooters arrived in the United States in 2017, largely to the surprise of city officials and residents alike. These two-wheeled, lightweight electric vehicles (Figure 1) quickly became popular among urbanites. Although not quite as popular as ride-hailing services, e-scooters quickly outpaced carsharing at an adoption rate of $3.6 \%$ in the first 12 months, as defined by the number of people who have ever used the services (Populus 2018). The transportation community presently suggests that the best use case for e-scooters is short trips such as those between 0.5 to 3 miles (Smith and Schwieterman 2018; ITDP 2018). Because of this, it appears unlikely that e-scooters could provide significant automobile replacement for lengthier trips, for example, those that travel between outer lying neighborhoods and downtown. Consequently, the better solution to replacing automobile trips for this segment of travel may still be traditional transit when considering the required spatial reach.

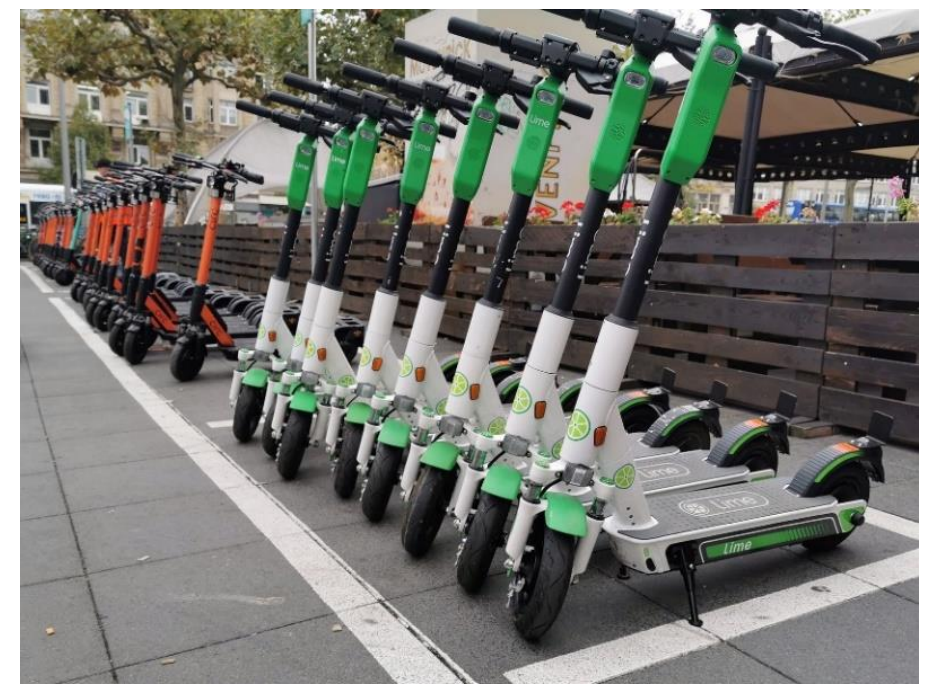

Figure 1: An Assortment of E-Scooters (Photo sourced under the Pixabay License) 
However, despite the promising space, environment, and equity benefits of transit, most transportation professionals agree that transit has an access problem (Zarif, Pankratz, and Kelman 2019). According to the Transit Capacity and Quality of Service Manual, $75 \%-80 \%$ of passengers will walk 0.25 miles or less to access bus stops, the equivalent of a 5-minute walk. Transit passengers do seem willing to go farther to access rapid transit, as more than $50 \%$ of passengers will walk more than 0.5 miles in this case (Transportation Research Board 2013). This leaves a large swath of potential transit riders, both those that have the option to take other modes and those that do not, out of reach from quality transit systems. This may especially be the case in areas where networks are less dense. As a result, frequent and reliable transit service becomes less useful to those who live too far away to walk to a stop (Levinson, Marshall, and Axhausen 2017). The term "first-mile/last-mile problem" has been coined to describe this common barrier in transit planning. Several solutions have been proposed over the years in order to encourage mode shift away from automobiles, including improved bicycle and bike share access (Zuo et al. 2020), park and rides (Levinson, Marshall, and Axhausen 2017), and dedicated autonomous shuttles (Yap, Correia, and van Arem 2016). The success of these solutions, however, may be limited by traveler stamina, geometric limits, and technology readiness, respectively. Additionally, the electrified nature and different form factor of e-scooters may be attracting people who have never used shared active transportation before (PBOT 2018). It follows that e-scooters could 
be a potential first-mile/last-mile solution that overcomes these challenges while simultaneously extending transit station catchment areas beyond the limits of walking.

In addition to environmental and vehicle miles travelled (VMT) reduction outcomes, transportation researchers and professionals have noted that e-scooters could also advance transportation equity by increasing access to transit for underserved communities (Zarif, Pankratz, and Kelman 2019). Transit is essential for low-income community members who cannot afford personal vehicles to access jobs and services, yet low-income neighborhoods quite often lack adequate transit access and service (Fleming 2018).

Although the potential of e-scooters seems promising, few studies in the nascent e-scooter literature have considered these claims. In this thesis, we assess the performance of e-scooters as it pertains to equity and last-mile/first-mile usage and compare it to their frequently stated promise.

We begin with a literature review outlining the presently sparse body of knowledge surrounding e-scooters and their potential to decrease mobility disparities among different genders, races and ethnicities, incomes, and abilities. We also summarize findings showing that travel behavior habits and perceptions of transportation modes influence usage of emerging modes, including e-scooters.

Next, we discuss the design of a stated choice experiment of transportation modes that was incorporated into the survey created for this study. We explain the data cleaning process that resulted in an original dataset of 1,968 valid responses. We then 
walk through the process used to generate models describing what influenced stated mode trip frequency in the previous seven days, propensity to switch to another mode for commuting to PSU if the respondent's primary mode became unavailable, and transportation mode choice in the stated choice experiment.

In the results section, we use descriptive statistics to show who responded to the survey. We explain how the survey results were used to estimate values for latent mode attitude and decision factors that were later used as covariates in the models. We then display and discuss the results of various ordinary least squares, ordered logit, binomial logit, and multinomial logit models of three dependent variables from the survey. Next, we provide a spatial analysis of barriers preventing respondents from using non-auto modes more frequently. We also perform a sensitivity analysis of the multinomial logit model generated from the stated choice experiment. Concurrently, the model is applied spatially to the Portland area. This analysis shows where each mode is the most preferable, given the trip attributes from thousands of test locations around the city.

We conclude with a discussion of the findings, beginning with the proliferation of barriers to usage of non-auto modes. We assess the effects of each set of covariates, including travel behavior, built environment, and mode attitudes in the models. We then assess the effects of sociodemographic factors in the models, allowing us to speak directly to the potential of e-scooters to reduce transportation inequities in gender, race and ethnicity, income, and ability. Our results indicate that this potential is likely overrated in some measures and non-existent in others. Additionally, we found that 
entrenched car users were less likely to choose non-auto options including e-scooters.

Lastly, we provide a discussion of policy implications, study limitations, and future research. 


\section{Literature Review}

In this section, we will briefly discuss the existing nascent literature surrounding escooters with regards to equity issues, the first-mile/last-mile problem, and utility. Next, we will describe our novel contribution and approach to these topics.

\subsection{E-Scooters: Potential and Performance}

Of the few studies considering e-scooter mobility, most tend to focus on potential reach without considering other mediating factors that may impact routine use. For example, researchers in Chicago (Smith 2020) found that e-scooters would enable 24$29 \%$ of transit trips to be quicker thanks to improved last-mile/first-mile access. EScooters would also make $12.3 \%$ more jobs reachable within a 30 -minute commute and over $20 \%$ within a one -hour commute compared to transit and walking alone. Yet, this modeled potential does not consider the impact of price, e-scooter availability, sociodemographics, or latent attitudes.

Meanwhile, concerns about the life cycle emissions and longevity of e-scooters have also arisen, bringing to light the limits of their net environmental benefits if more automobile trips are not replaced (Hollingsworth, Copeland, and Johnson 2019; Schuller and Aboukrat 2019). Despite calls to subsidize and harness e-scooters in our cities (ITDP 2018; Zarif, Pankratz, and Kelman 2019; Smith and Schwieterman 2018), how realistic is it that e-scooter and transit multimodal trips could replace a substantial number of automobile trips? 
Early observations of the naturalistic use of e-scooters tell a less optimistic story. The results of PBOT's (2018) first e-scooter pilot program and survey have been widely cited, saying that $18.82 \%$ of surveyed Portland riders took an e-scooter instead of a personal automobile and $15.37 \%$ replaced a ride in a taxi, Uber, or Lyft, compared to $3.97 \%$ that replaced a transit trip. However, the largest portion of replaced trips would have been taken by walking (36.51\%). Additionally, only $5.69 \%$ of respondents primarily used e-scooters to get to or from transit. These findings are tempered, however, by the fact that e-scooters seemed to be attracting a large portion of users who had never previously used bikeshare. In a study of three large French cities (6t 2019), e-scooters were also more frequently used to substitute not only walking trips (47\%), but also transit (29\%) and biking (10\%) trips, compared to personal automobile trips (3\%). In total, $15 \%$ of trips were multimodal, consisting of an e-scooter and transit connection. Thus, the present environmental impact of e-scooters due to mode shift is lackluster. EScooters may not be affecting a more substantial shift to transit through first-/last-mile connections compared to what has been suggested.

The outcomes of e-scooter equity goals are also mixed. On the one hand, communities of color have been shown to hold largely favorable views of e-scooters (74\% of people of color in Portland expressed support for e-scooters when surveyed). Portland also requires a certain share of e-scooters to be made available in underserved areas. However, East Portlanders and Black Portlanders expressed concern for traffic safety, racial profiling, and harassment while riding e-scooters (PBOT 2018). These risks 
and barriers could be preventing communities of color from being able to realize new accessibility benefits from e-scooters.

There are also mixed findings surrounding the potential for e-scooters to enable greater gender parity in active transportation, contrasting the gender gap that is currently observed in cycling (Broach and Dill 2016). Clewlow (2019) found that slightly more women than men held favorable views of e-scooters in a national survey. Additionally, Eccarius and Lu (2020) found that females appeared more likely than males to adopt and maintain e-scooter use in Taiwan based on stated usage levels, among other factors. Yet, the French study (6t 2019) observed an overrepresentation of male riders in their survey. Of the women that were surveyed, $65 \%$ had reservations about the safety of using an e-scooter compared to $48 \%$ of men. In a blog post, Dill (2019) wrote that the PBOT (2018) e-scooter pilot survey data also displayed a wide gender gap in respondents. Male riders were overrepresented (64\%) compared to female riders (34\%). Additionally, men tended to indicate that they rode e-scooters more frequently during the week than women.

Low-income communities may also be negatively impacted by the price of e-scooter systems. Smith and Schwieterman (2018) suggest that e-scooter trips over three miles are too expensive to be competitive with other modes. In France, price was the most commonly cited barrier to using e-scooters (6t 2019). In Portland, Black Portlanders and East Portlanders expressed that cost was prohibitive to their use of e-scooters. Additionally, low-income plans appeared to be underpromoted and under-utilized, 
despite the fact that people living on low incomes tended to hold positive views of escooters (66\%). In response, ITDP (2018) has suggested that cities should subsidize escooters in order to make them more accessible and so that they are used to connect with transit. Charlotte, North Carolina, has tried a similar technique by dynamically pricing their e-scooters such that parking downtown is higher than in low-density areas and areas adjacent to transit lines, but it has not yet been reported if this technique has successfully encouraged first-mile and last-mile usage (Goodman et al. 2019).

In addition to the burdens faced by members of diverse sociodemographic groups, built environment factors may also contribute to the level of uptake of e-scooters. Users prefer riding on low-speed streets or bike lanes (6t 2019; PBOT 2018), which is also the preference of city officials (Goodman et al. 2019). Greater availability of bike lanes could consequently attract more e-scooter traffic (Zou et al. 2020), and thus a lack of bike lanes could stifle latent demand.

Habit and routine may play supporting roles in the uptake of e-scooters. Asgari and Jin (2020) observed that existing travel habits acted as a barrier toward mode shift to emerging mobility options such as AVs and shared mobility services. This was especially the case for private vehicle drivers and passengers. However, disutility factors, such as parking cost and travel time, helped to break the power of these habits. Habit and disutility have seen little study in relation to e-scooters, though it is possible that these factors could have similar impacts, as e-scooters fit within the realm of emerging 
mobility. Eccarius and Lu (2020) also agree that existing mobility habits may play an important role when it comes to e-scooter use.

Personal priorities and attitudes towards modes may also contribute to the uptake of e-scooters. Research has shown that transport priorities, such as exercise, convenience, and environmental impact contribute to the explained variance of choice models in addition to attitudes towards specific modes (Egset and Nordfjærn 2019). A study specific to e-scooters used factor analysis and structural equation modelling (SEM) to find that perceived compatibility with e-scooters influenced the level of intention and stage of behavioral change towards using them (Eccarius and Lu 2020).

\subsection{Approach and Contribution}

Due to the novel nature of e-scooters, there have been few studies to date that compare the purported potential of e-scooters to the realities of how they are currently being used and perceived. It has been said that e-scooters enable and encourage greater mobility among diverse sociodemographic groups and can act as a practical and popular first-mile/last-mile solution, but are e-scooters delivering on these expectations? Additionally, how do travel habits and latent personal priorities and attitudes contribute to e-scooter use?

In this study, we set out to use a variety of factors to model past and future use of e-scooters among the Portland State University (PSU) student body, including sociodemographic indicators, latent mode attitudes, and transportation priorities. First, we model the number of e-scooter trips within the past week and compare to other 
modes using ordered and binary logit models. We explore how factors impact the propensity for commuters to switch to using an e-scooter compared to other modes should their existing primary mode for commuting become unavailable using ordinary least squares linear models. We use the city of Portland as a case study to observe the spatial extent to which personal and neighborhood factors limit the use of e-scooters, bikes, and light rail transit. Finally, we explore the relative utility (preferability) of taking multimodal e-scooter and transit trips to PSU relative to a car or bike trip using a stated choice experiment and the resulting multinomial logit (MNL) model. The goal of this study is to fill a research gap that exists surrounding the current performance and optimal use cases of e-scooters in order to better inform future transportation policy. 


\section{Method}

In this section, we explain the process used to design the survey instrument, including the discrete choice experiment used to build the MNL model. Next, we detail how the survey was administered to the PSU student body. Lastly, we summarize how the data was cleaned and analyzed.

\subsection{Survey Design}

We began this research by defining the questions that we wanted to explore and by designing a survey instrument that would help us to answer these questions. Namely, we were curious to understand which values, perceptions, demographics, and transportation mode attributes influenced mode choice and usage frequency of PSU students. We especially wanted to explore what influenced PSU students to use escooters. We chose three main dependent variables that would help us to answer these questions: frequency of trips by mode in the previous seven days, a 10-point scale on which the respondent rated their propensity to switch to a specific different mode if their primary mode of transportation to PSU became unavailable, and the choice of a set of three transportation modes for getting to PSU from a hypothetical location given combinations of various attribute levels. This last dependent variable was part of a discrete choice experiment, whose design is detailed in section 3.1.1.

\subsubsection{Experimental Design}

One of the main goals of this study was to determine the impact that specific attributes of trips of various transportation modes would have on the probability of 
selecting a specific mode from a set of mode alternatives. This is known as a labelled discrete choice experiment, or a discrete choice experiment with alternatives that are named in order to capture the attitudes that respondents have regarding that choice without having to describe the choices with additional generic attributes. Attributes that are not implied by the label could include anything from travel time and cost to weather conditions and proportion of a route with low-stress bike lanes.

As the literature surrounding e-scooters, especially as a first-/last-mile solution, is sparse, we decided to use a relatively simple set of alternatives, attributes, and levels for the experiment. This was also done to simplify the survey design and to reduce potential fatigue experienced by the respondents. We selected three modes (car, bike, and e-scooter + MAX). We consciously chose MAX as the sole transit mode to be combined with a first-mile e-scooter leg for multimodal trips to PSU. The MAX system has low network coverage and limited station access due to wide stop spacing, however it offers faster travel times compared to bus for those that live far from the city center. Additionally, respondents may be more willing to take a multimodal trip that encompasses frequent service and reliable travel times as a result of dedicated right-ofway. It is already suggested that riders are willing to walk further to access this type of transit compared to less utilitarian transit options (Transportation Research Board 2013). As it also turned out, the largest portion of students indicated that MAX was already their primary mode of transportation to PSU. For car, we included three attributes: drive time, parking cost, and walk time (from a parking spot to a PSU campus 
location). For bike, we included only bike time, leaving the cost at $\$ 0$ and the walk time at 0 mins for all choice sets. We did this to mimic the circumstances of a personal bike that could be parked outside of any campus building. For e-scooter + MAX, we included walk time (to arrive at an e-scooter), time riding the e-scooter to a MAX station, escooter trip cost, time riding the MAX to PSU, and MAX ticket cost. We chose to leave out wait time from the e-scooter + MAX mode for simplicity. In addition, we assumed that users choosing this mode would plan their trips using widely available transit realtime location information to minimize any potential wait time upon arriving at a MAX station via e-scooter. In total, this design included nine attributes across three modes. This aligns with the recommendation of Louviere et al. $(2000,103)$ who suggest no greater than ten attributes for this type of experiment. For additional simplicity, we assigned each attribute a set of equally-spaced low, medium, and high levels. Level selection is discussed further in section 3.1.2.

Given this set of attributes and levels, our next step was to design a suite of choice sets to present to the respondents in the experiment portion of the survey. There are several ways to accomplish this, and the procedure that we used paralleled the process outlined by Louviere et al. $(2000,83-96)$.

In any discussion of design of experiments, it is often useful to begin by considering full factorial designs. These designs effectively provide a set of all possible combinations of levels. Given our experiment design so far, we could calculate the number of total choice combinations using the following expression: 
9 attributes, 3 levels each $=3^{9}=19,683$ choice sets

This all-inclusive yet long experiment design guarantees that the effects of all attributes could be measured independently. Additionally, this design provides the opportunity to estimate all possible interaction effects between attributes.

Unfortunately, this complete design, containing every possible combination, conflicts with the practical expectations of experiment participants. Although it would be ideal to have respondents answer each of 19,683 choice sets to obtain the clearest picture about what influences mode choice, realistically this task is not at all feasible. A different solution was necessary.

Continuing the discussion of classical experimental design methods, the next step in the process would be to consider a fractional factorial design. In this design, the researcher takes the full factorial design and selects only a portion of the choice sets. The choice sets are selected such that the main effects and lower order interactions of interest between the attributes can still be measured. Although these designs do lose some statistical information, the majority of statistical information of interest can still be maintained if the design is performed correctly. Hensher et al. $(2005,152-53)$ extend this discussion by additionally stating that when these fractional factorial designs are orthogonal (the columns sum to zero when using effects coding) the attributes are statistically independent and therefore uncorrelated. However, orthogonal fractional factorial designs do not necessarily impart the maximum information possible about the parameters of the attributes in the choice task. To tackle this issue, a new class of 
designs has been introduced to pursue this optimization, called optimal or statistically efficient designs.

Optimal designs are statistically efficient, but they are likely to have correlations between the parameters of the experiment. Thus, the researcher has to make a tradeoff between information efficiency and statistical independence. Besides, three level fractional factorial designs can add complexity, as the researcher must choose which interactions are important to analyze up front, risking obscuring interactions that were not chosen for analysis. Additionally, they require more runs than a more common twolevel design (NIST/SEMATECH 2013, sec. 5.3.3.10.). Thus, classical designs may not work best in our application, as they would require too many treatment combinations in order to preserve more than a few interaction effects (NIST/SEMATECH 2013, sec. 5.5.1.), especially considering that we were not expecting to initially obtain more than 100 responses. Hensher et al. $(2005,152-53)$ carry on to note that the literature has tended towards designs that maximize the determinant of the variance-covariance matrix of the model to be estimated, known as D-optimal designs. The same task can also be accomplished by minimizing the determinant of the inverse of the variancecovariance matrix, a value often called the D-error. Minimizing the D-error will result in a design that also minimizes the errors surrounding the estimated parameters. Additionally, D-optimal designs leave open the possibility of analyzing interactions between the design attributes without having to make decisions to exclude some up front (NIST/SEMATECH 2013, sec. 5.5.2.1.). Due to the uncertainty during the design 
phase that we had surrounding the total number of respondents we would obtain and the availability of a user-friendly R (R Core Team 2020) package, we decided to design the choice experiment using a D-optimal design.

D-optimal designs are generated using an iterative computer algorithm, of which several exist. We used the R package choiceDes (Horne 2018) that extends the $R$ package AlgDesign (Wheeler 2019) that makes use of the Federov algorithm (Fedorov 1972). As described by Reliasoft's reliawiki.org (2017, chap. 12) and Wheeler (2019), the Federov algorithm improves a design of an experiment with each iteration by tracking the amount of change in the determinant of the variance-covariance matrix with each step. The algorithm calculates all of the possible changes in this value by swapping out each row in the current optimal design with every row in the candidate list, finding the maximum determinant change. The algorithm stops once the change is less than a predetermined small value, or in the case of the AlgDesign package, once the maximum iterations limit is reached.

In practice, we generated the design using the choiceDes R package (Horne 2018). Using the function dcm.design, we specified the number of attributes and levels for each attribute, the number of blocks, the number of choice sets in each block, and the number of repeats that the Federov and blocking algorithms should be performed in order to maximize the D-Efficiency of the final experiment design. (The default maximum number of iterations of 100 was used for each repeat.) Further, the dcm.design function in choiceDes used the optBlock function in AlgDesign to optimize 
the placement of the candidate set produced by the Federov algorithm within the specified number of blocks.

\subsubsection{Levels}

Hensher et al. $(2005,105-9)$ suggest that level selection must be done with care such that choice sets are believable to the respondents. This can be done by examining the experiences of the target respondent group with the attributes in question. Additionally, it is useful to include values outside of the observed range in order to accurately model effects of hypothetical levels. Again, these hypothetical levels must also be considered as believable in order for the respondent to take the survey seriously. To this end, we used existing information about the PSU student community, Portland's geography, and transportation cost structures to inform the selection of levels for the experiment.

For the car mode, we used the AASHTO walking speed and Portland block size to calculate the time required to walk distances of 0,2 , and 4 blocks from the parked car. We determined drive time levels based on typical pre-COVID-19 pandemic weekday travel times along I-84, I-5, and I-405 between Gateway Transit Center and PSU. We established parking cost levels based on the $\$ 7.09$ per weekday calculated rate from the 2019-2020 student parking permit general rate of $\$ 390$ per term.

For the bike mode, we estimated a general range of bike travel times that could replace MAX trips from the east side of Portland. 
For the e-scooter + MAX mode, we used the AASHTO walking speed and Portland block size to calculate the time required to walk distances of 0,2 , and 4 blocks, just as we had done for the car mode and in line with the finding that $55 \%$ of users in France walked less than 5 minutes to reach an e-scooter (6t 2019). We decided on e-scooter travel time levels of 5, 10, and 15 minutes to approximate the amount of time people might be willing to spend scooting to and from a MAX station. As was also found in France, the median e-scooter trip travel time was 11 minutes, with $55 \%$ of trips taking less than 15 minutes (6t 2019). We established MAX travel time levels based on the fact that the median MAX door-to-door transportation time for PSU students is $46-60$ minutes, as found in the 2019 version of the annual PSU Student Transportation survey. Since this is door-to-door travel time, the actual ride time is likely to be shorter, and therefore we assigned levels between 25 and 35 minutes. This is representative of a MAX trip between the Gateway Transit Center and PSU, which is 30 minutes. For the escooter cost, we calculated that the original typical Portland e-scooter rate of $\$ 1.00$ to unlock plus $\$ 0.15$ per minute (PBOT n.d.) leads to trips costing $\$ 1.75$ to $\$ 3.25$ for trips between 5 and 10 minutes. We simplified this price structure in the experiment by providing flat trip fees between $\$ 0.50$ and $\$ 3.00$. With this method, we were able to provide a range of "cheap" and "expensive" cost per minute rates, even though there were only three flat rate cost levels. Finally, we established the MAX ticket cost levels based on the $\$ 1.25$ Honored Citizen reduced fare that many PSU students are able to use, the $\$ 2.50$ current regular fare, and a $\$ 3.75$ hypothetical increased fare. Levels that 
are outside the current state of mode cost (including $\$ 0.50$ e-scooter rides and $\$ 3.75$ transit fares) are needed to inform the model. These levels reduce the amount extrapolation required of the model when interpreting results, as extrapolation is not a best statistical application of the models we generated.

We performed several pilot runs of the survey with the help of classmates, colleagues, and family members. The feedback from these pilots confirmed that most of the levels were received as realistic except for the e-scooter costs. Initially, they were perceived by some as being too high altogether. Consequently, we lowered the escooter costs to make them more realistic for the final version of the survey. The finalized levels and their sources are summarized in Table 1. 
Table 1: Level Selection and Justification

\begin{tabular}{|c|c|c|c|c|c|}
\hline Mode & Attribute & Low & Medium & High & Source: \\
\hline \multirow{3}{*}{ రั } & $\begin{array}{l}\text { Walking } \\
\text { Time }\end{array}$ & 0 mins & 2 mins & 4 mins & $\begin{array}{l}\text { AASHTO walking speed and Portland city } \\
\text { block size ( } 3.5 \mathrm{ft} / \mathrm{s} \text { and } 200 \mathrm{ft} \text { ), so } \\
\text { equivalent walking times for } 0,2 \text {, and } 4 \\
\text { blocks }\end{array}$ \\
\hline & Drive Time & 25 mins & 35 mins & 45 mins & $\begin{array}{l}\text { Drive time from Gateway Transit Center } \\
\text { is typically } 20-40 \text { mins on weekday } \\
\text { mornings from Google Maps. }\end{array}$ \\
\hline & $\begin{array}{l}\text { Parking } \\
\text { Cost }\end{array}$ & $\$ 7$ & $\$ 11$ & $\$ 15$ & $\begin{array}{l}19-20 \text { Term Rate for Students, General: } \\
\$ 390 \text {. For } 11 \text {-week term and } 5 \text { days per } \\
\text { week, this works out to } \$ 7.09 \text { per day. }\end{array}$ \\
\hline$\frac{\ddot{v}}{\ddot{\bar{m}}}$ & Bike time & 25 mins & 35 mins & 45 mins & $\begin{array}{l}\text { Estimate of range of bike times. Biking } \\
\text { from Gateway transit center to PSU is } 45 \\
\text { mins. }\end{array}$ \\
\hline \multirow{5}{*}{ 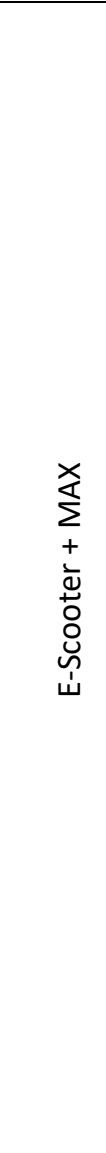 } & $\begin{array}{l}\text { Walking } \\
\text { Time }\end{array}$ & 0 mins & 2 mins & 4 mins & $\begin{array}{l}\text { AASHTO walking speed and Portland city } \\
\text { block size ( } 3.5 \mathrm{ft} / \mathrm{s} \text { and } 200 \mathrm{ft} \text { ), so } 0,2 \text {, } \\
\text { and } 4 \text { blocks }\end{array}$ \\
\hline & $\begin{array}{l}\text { E-Scooter } \\
\text { Time }\end{array}$ & 5 mins & 10 mins & 15 mins & $\begin{array}{l}\text { Estimate of range of e-scooter times for } \\
\text { connecting with MAX. }\end{array}$ \\
\hline & MAX Time & 25 mins & 30 mins & 35 mins & $\begin{array}{l}\text { From } 2019 \text { PSU student transportation } \\
\text { survey, median and mode total time for } \\
\text { those that take MAX at least once per } \\
\text { week is between } 46-60 \text { mins (total door } \\
\text { to door time). A MAX trip from Gateway } \\
\text { Transit Center is } 31 \text { mins. }\end{array}$ \\
\hline & $\begin{array}{l}\text { E-Scooter } \\
\text { Cost }\end{array}$ & $\$ 0.50$ & $\$ 1.75$ & $\$ 3.00$ & $\begin{array}{l}\text { From city of Portland, scooters typically } \\
\text { cost } \$ 1.00 \text { to unlock plus } \$ 0.15 \text { per } \\
\text { minute. For } 5 \text { to } 15 \text {-minute trips, this } \\
\text { ranges between } \$ 1.75 \text { and } \$ 3.25 \text {. The } \\
\text { flat rate range was designed to capture } \\
\text { information about both cheap and } \\
\text { expensive cost/minute rates, outside } \\
\text { what is currently offered by scooter } \\
\text { companies. }\end{array}$ \\
\hline & MAX Cost & $\$ 1.25$ & $\$ 2.50$ & $\$ 3.75$ & $\begin{array}{l}\text { The typical cost of a one-way transit } \\
\text { ticket in Portland is } \$ 2.50 \text {. However, } \\
\text { reduced fares are offered to low-income } \\
\text { and disabled residents for } \$ 1.25 \text {. Many } \\
\text { PSU students take advantage of this } \\
\text { discounted rate. } \$ 3.75 \text { was included to } \\
\text { capture the effect of an increased fare. }\end{array}$ \\
\hline
\end{tabular}




\subsubsection{Mode Attitudes and Decision Factors}

In order to capture and control for attitudinal covariates that would help explain mode choice and usage, we created a suite of 5-point Likert scale questions to ask the respondents about their perceptions of car, bike, e-scooter, and MAX modes. These questions are displayed in Table 2. 
Table 2: Attitudinal Likert Scale Questions (Please indicate to what extent you agree or disagree with the following statements:)

\begin{tabular}{|c|c|c|c|c|}
\hline Mode: & Car & Bike & E-Scooter & MAX \\
\hline \multirow{10}{*}{ 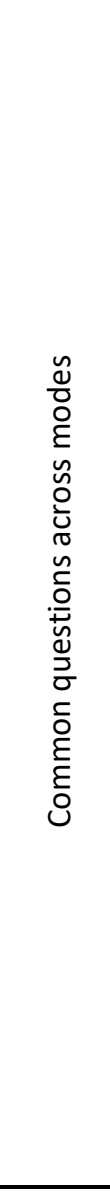 } & I enjoy driving & I enjoy riding a bike & $\begin{array}{l}\text { I enjoy riding an e- } \\
\text { scooter }\end{array}$ & I enjoy riding MAX \\
\hline & I feel safe in a car & $\begin{array}{l}\text { I feel safe riding a } \\
\text { bike }\end{array}$ & $\begin{array}{l}\text { I feel safe riding an } \\
\text { e-scooter }\end{array}$ & I feel safe riding $M A X$ \\
\hline & Driving is cool & Riding a bike is cool & $\begin{array}{l}\text { Riding an e-scooter } \\
\text { is cool }\end{array}$ & Riding MAX is cool \\
\hline & - & $\begin{array}{l}\text { I consider myself a } \\
\text { bike commuter }\end{array}$ & $\begin{array}{l}\text { I am an e-scooter } \\
\text { commuter }\end{array}$ & $\begin{array}{l}\text { I am a transit } \\
\text { commuter }\end{array}$ \\
\hline & - & $\begin{array}{l}\text { Most cyclists ride } \\
\text { recklessly }\end{array}$ & $\begin{array}{l}\text { Most e-scooter users } \\
\text { ride recklessly }\end{array}$ & - \\
\hline & $\begin{array}{l}\text { I feel comfortable } \\
\text { riding in a car } \\
\text { (Temperature, seat, } \\
\text { space, etc.) }\end{array}$ & - & - & $\begin{array}{l}\text { I feel comfortable } \\
\text { while riding MAX } \\
\text { (Temperature, seat, } \\
\text { space, etc.) }\end{array}$ \\
\hline & - & $\begin{array}{l}\text { I will not ride } \\
\text { somewhere if there } \\
\text { are no bike lanes }\end{array}$ & $\begin{array}{l}\text { I will not ride } \\
\text { somewhere if there } \\
\text { are no dedicated } \\
\text { lanes }\end{array}$ & - \\
\hline & - & $\begin{array}{l}\text { Cyclists cause unsafe } \\
\text { situations for } \\
\text { pedestrians }\end{array}$ & $\begin{array}{l}\text { E-Scooter users } \\
\text { cause unsafe } \\
\text { situations for } \\
\text { pedestrians }\end{array}$ & - \\
\hline & $\begin{array}{l}\text { I think that cars are } \\
\text { harmful to the } \\
\text { environment }\end{array}$ & $\begin{array}{l}\text { I think that riding a } \\
\text { bike helps the } \\
\text { environment }\end{array}$ & $\begin{array}{l}\text { I think that riding an } \\
\text { e-scooter helps the } \\
\text { environment }\end{array}$ & $\begin{array}{l}\text { I think that riding } \\
\text { MAX helps the } \\
\text { environment }\end{array}$ \\
\hline & Cars are convenient & Bikes are convenient & $\begin{array}{l}\text { E-Scooters are } \\
\text { convenient }\end{array}$ & MAX is convenient \\
\hline \multirow{3}{*}{ 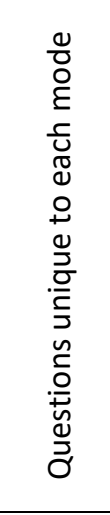 } & $\begin{array}{l}\text { Even if I get delayed } \\
\text { by traffic, I'd still } \\
\text { prefer to take a car }\end{array}$ & I am a bike advocate & $\begin{array}{l}\text { I would use an e- } \\
\text { scooter more often if } \\
\text { I knew there was } \\
\text { always one available } \\
\text { close by }\end{array}$ & $\begin{array}{l}\text { I am glad to have the } \\
\text { time to do other } \\
\text { things while riding } \\
\text { MAX }\end{array}$ \\
\hline & $\begin{array}{l}\text { I don't mind } \\
\text { searching for a } \\
\text { parking spot }\end{array}$ & & E-Scooters are ugly & $\begin{array}{l}\text { MAX comes } \\
\text { frequently enough } \\
\text { for me to use it } \\
\text { spontaneously }\end{array}$ \\
\hline & & & & $\begin{array}{l}\text { Transit is primarily } \\
\text { for people with } \\
\text { lower incomes }\end{array}$ \\
\hline
\end{tabular}


In addition to these mode-specific perception questions, we also asked respondents to identify items that were important in their transportation mode choice decision for getting to PSU. These transportation mode choice priorities were also asked about using 5-point Likert scale questions, displayed in Table 3. Most of these questions were adapted from Egset and Nordfjærn (2019), who were interested in understanding the effects of latent transportation decision factors on students' use of active and public transport to and from Norwegian universities.

Table 3: Mode Choice Decision Factor Questions (How important are each of the following issues in choosing your means of transportation to PSU?)

\begin{tabular}{|l|}
\hline Mode choice decision factors: \\
\hline Obtaining exercise or physical activity \\
\hline My physical ability \\
\hline Opportunity to shower at destination \\
\hline Arriving on time to destination \\
\hline Frequency of transit departures \\
\hline Flexible time of departure \\
\hline Travel cost/price \\
\hline Travel time \\
\hline Flexible travel route \\
\hline Personal safety and security \\
\hline Traffic safety \\
\hline The current weather conditions \\
\hline $\begin{array}{l}\text { My personal impact on the } \\
\text { environment (carbon footprint) }\end{array}$ \\
\hline $\begin{array}{l}\text { The opportunity to do other things } \\
\text { while traveling }\end{array}$ \\
\hline Physical comfort while traveling \\
\hline
\end{tabular}

As was done in Egset and Nordfjærn (2019), we distilled these sets of attitudinal questions to a smaller number of factors using exploratory factor analysis (EFA). These 
index factors were then used as covariates in the regression models. This process and the results are detailed in section 4.2 .

\subsection{Administering the Survey}

In this section, we outline how the survey was constructed and administered. We applied for and obtained Human Research Protection Program (HRPP) authorization from PSU's Institutional Review Board (IRB) in order to perform this study. It should be noted that although the survey was administered between February 28, 2020 and March 13, 2020, the majority of complete responses were received on March 4 and March 5 (see Figure 2). This was before Oregon announced a state of emergency due to the COVID-19 global pandemic (March 8) and a subsequent stay at home order (March 23). Therefore, we assume that the results of this research reflect pre-COVID-19 travel behavior. 


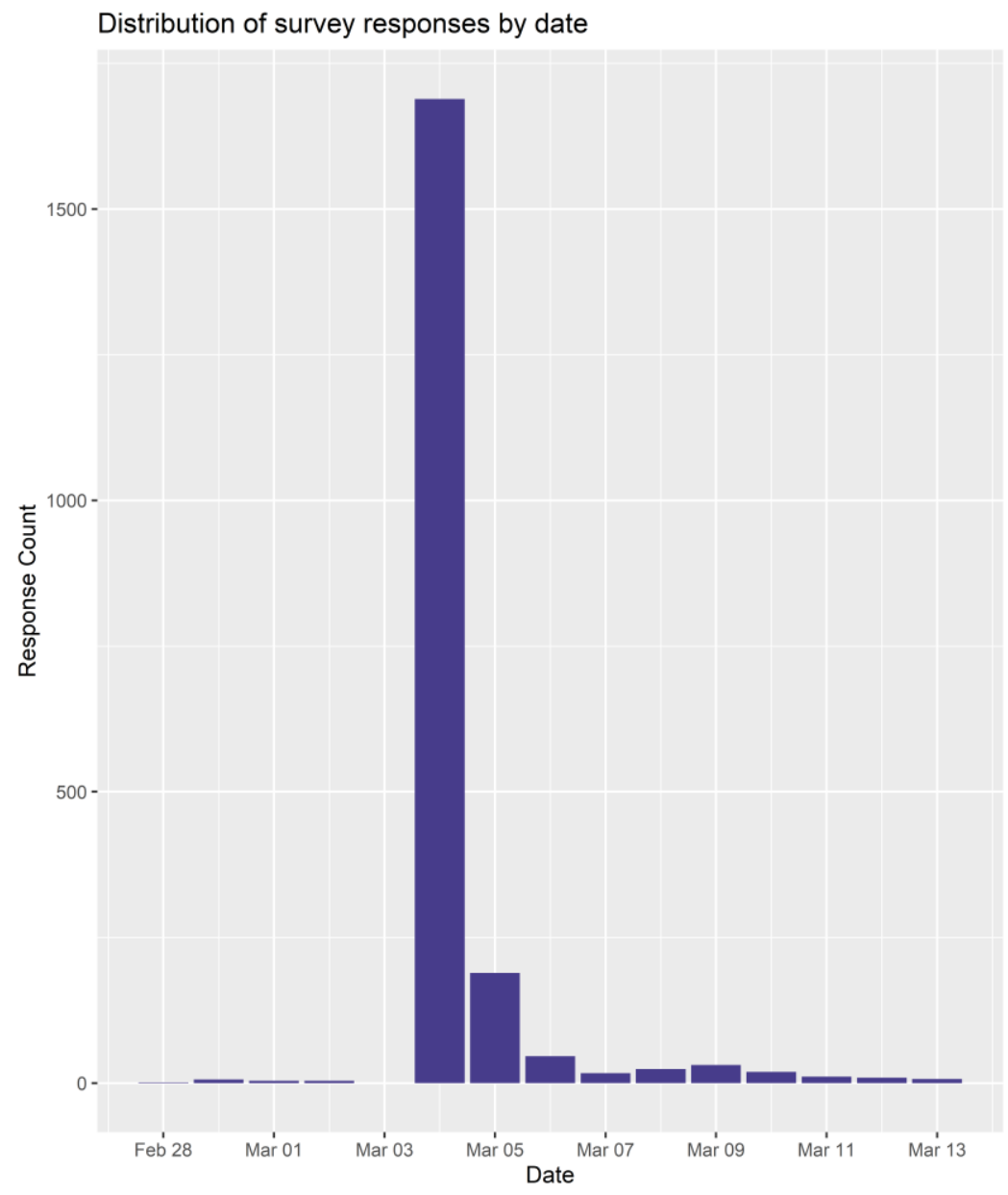

Figure 2: Distribution of survey responses by date 


\subsubsection{Qualtrics Implementation}

We constructed the survey using the Qualtrics Experience Manager online platform. Qualtrics was chosen simply because we already had free access to it as PSU researchers. It provided intuitive tools for writing and formatting of most questions, managing responses, and exporting data to formats that are readily accessible by both SPSS and R. We randomized most response choices within questions in order to avoid response order bias. We required responses on Q2 (accepting the terms of informed consent) and the stated choice experiment questions (Q38 to Q61) only. The survey instrument is provided in Appendix F.

Unfortunately, Qualtrics was not an ideal system for administering a stated choice experiment, as there was no question layout that allowed for the creation of formattable tables containing the attribute levels for each choice set. To get around this limitation, we developed an $\mathrm{R}$ code that constructed html code for these attribute level tables. The R code took the survey design generated previously by the choiceDes package, applied the level labels, inserted the category headers and units, and exported the html table code to separate text files for each question. Then, we manually copied and pasted the html code from these output files into Qualtrics. The html code was inserted using the "source" button in the Rich Text Editor for each response of a single answer horizontal multiple-choice question with three choices. This process was repeated for each of the 24 unique choice sets. The resulting formatted questions are shown in Figure 3 (computer) and Figure 4 (mobile device). As shown in the figures, we 
included columns that contain the total cost and time in order to ease the cognitive burden on the respondent when considering the tradeoffs of each alternative.

Based upon these attributes, which one of the three transportation options to PSU do you prefer?

Note that the attributes will change each time.

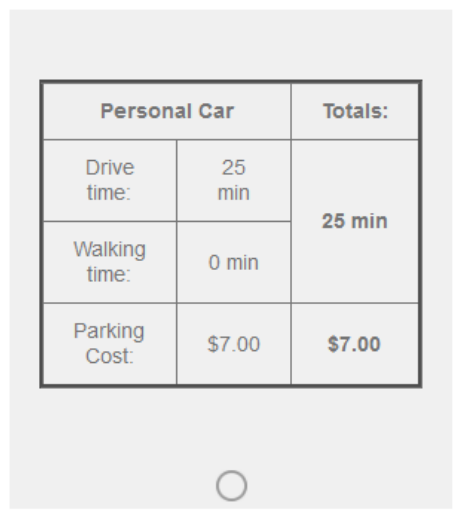

\begin{tabular}{|c|c|c|}
\hline \multicolumn{2}{|c|}{ Bike } & \multirow{2}{*}{ Totals: } \\
\cline { 1 - 2 } $\begin{array}{c}\text { Walking } \\
\text { time: }\end{array}$ & $\begin{array}{c}0 \\
\text { min }\end{array}$ & $\begin{array}{c}35 \\
\text { mins }\end{array}$ \\
\cline { 1 - 2 } $\begin{array}{c}\text { Bike } \\
\text { time: }\end{array}$ & $\begin{array}{c}35 \\
\text { min }\end{array}$ & \\
\cline { 1 - 2 } Cost: & Free & Free \\
\hline
\end{tabular}

\begin{tabular}{|c|c|c|}
\hline \multicolumn{2}{|c|}{ E-Scooter + MAX } & Totals: \\
\hline $\begin{array}{l}\text { Walking } \\
\text { time: }\end{array}$ & $2 \min$ & \multirow{3}{*}{$47 \mathrm{~min}$} \\
\hline $\begin{array}{c}\text { E-Scooter } \\
\text { time: }\end{array}$ & $\begin{array}{l}10 \\
\min \end{array}$ & \\
\hline MAX time: & $\begin{array}{l}35 \\
\mathrm{~min}\end{array}$ & \\
\hline $\begin{array}{c}\text { E-scooter } \\
\text { cost: }\end{array}$ & $\$ 1.75$ & \multirow[t]{2}{*}{$\$ 4.25$} \\
\hline MAX cost: & $\$ 2.50$ & \\
\hline
\end{tabular}

0

○

Figure 3: Stated Choice Experiment Survey Format, Computer 


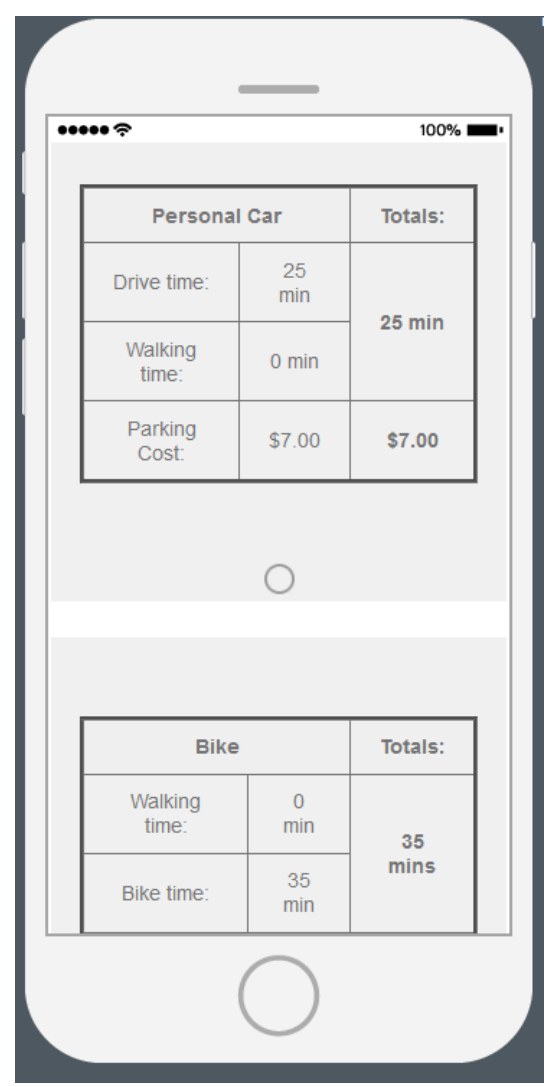

Figure 4: Stated Choice Experiment Survey Format, Mobile Device (note that question is out of view) The stated choice experiment questions were divided into four blocks of six questions by the choiceDes $\mathrm{R}$ package. The question order was randomized so that question order bias and fatigue bias could be reduced. Additionally, we used the "Evenly Present Elements" option within the Qualtrics block randomizer in order to ensure that the block response frequencies were as balanced as possible.

\subsubsection{Incentive}

As an incentive to participate in the survey, we offered respondents the opportunity to enter a raffle to win one of three $\$ 50$ Amazon gift cards. Upon completing the survey, respondents were provided a link to a separate Google Form in which they could submit their email address. Due to a lack of controls on the Google 
Form, some opportunistic respondents applied to the raffle more than once. We cleaned the email list using an $\mathrm{R}$ code to remove duplicate emails and usernames. Finally, we used a random number generator on random.org to select three respondents to receive the gift card. After list cleaning, we found that 2,017 unique participants had entered the raffle. (Of these, 45 participants had entered their email more than once, but their duplicate emails were removed.)

\subsubsection{Outreach}

We worked with PSU's Transportation \& Parking Services office to distribute the survey as part of their regular quarterly transportation options newsletter to students. This Winter quarter newsletter provided information regarding parking pass sales, Trimet's reduced fare program, and free rides on Biketown and Portland Streetcar for students. It was sent via email on February 28, 2020. The email was distributed to a list of all students that were currently enrolled and had a valid email address, a total of 19,943 recipients. The survey was advertised in the newsletter using the banner shown in Figure 5 which was located at the bottom of the email. 


\section{We want to hear from YOU! \\ Participate in a short survey about \\ your transportation choices to PSU. \\ Help inform PSU research and be entered into a raffle for one of three $\$ 50$ Amazon gift cards! \\ Your input matters!}

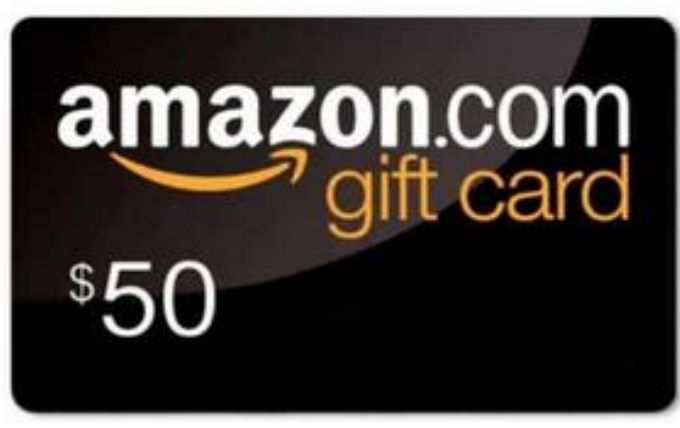

\section{Click here to learn more and take the survey.}

Figure 5: Survey Advertisement 1

Unfortunately, the link to the survey in the initial newsletter email was broken.

Despite this, fifteen respondents were able to correct the URL error and took the survey anyway. Thanks to quick work from Transportation \& Parking Services, a follow up correction email containing just the survey was sent out to the same distribution list on March 4, 2020. This email in its entirety is shown in Figure 6. Overall, $52.8 \%(10,537)$ of those emailed opened the message, and $25.0 \%(2,630)$ clicked through to the survey. The remaining 2,384 partial and complete responses were collected until the survey was closed on March 13, 2020. In total, we received 2,399 responses, of which 2,057 were complete. (In this case, complete means that the respondent reached the end of the survey, however they could have skipped some questions along the way). This represents a partial response rate of $12.0 \%$ and a full response rate of $10.3 \%$. When filtering out those who were distance learners and non-students, the valid responses came to 1,968 , representing a $9.9 \%$ valid response rate. 


\title{
Portland State Transportation \& Parking Services
}

\author{
Oops! We're sorry...
}

It's come to our attention that the link to the survery included in the Spring Term

Transportation Options email was broken. Apologies for the inconvenience!

\section{BUT DON'T MISS OUT!}

Complete this short survey about your transportation choices and be entered to win one of three

$\$ 50$ Amazon gift cards!

Your participation will help inform student research on campus!

Your input matters!

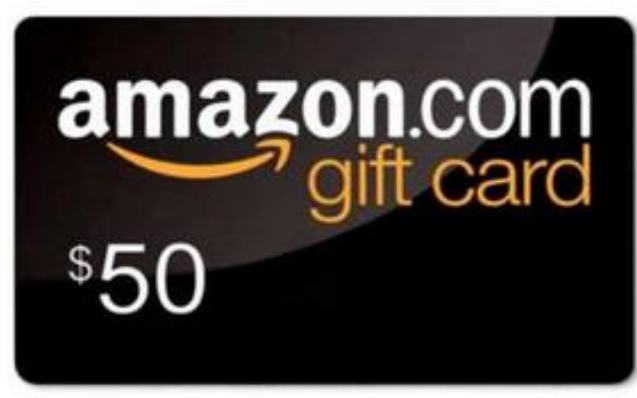

\section{COMPLETE THE SURVEY}

Figure 6: Survey Advertisement 2 


\subsection{Data Cleaning}

Although Qualtrics was mostly helpful in formatting the survey data for SPSS and $\mathrm{R}$, there were several persistent data formatting issues that needed to be resolved before the data could be analyzed. We cleaned the raw data output from Qualtrics using R. During this process, we filtered out responses that were not $100 \%$ completed $(n=$ 342). We also checked that no one under the age of 18 had responded to the survey, and found that no one under the age of 18 had responded. Next, we adjusted value codes and labels such that binary responses used 0 and 1 and other responses used consecutive numeric codes. During this process, questions with "NA" were assigned "-7 Refused" if they were skipped or "-1 Appropriate Skip" if the question was not displayed to the user due to skip logic applied in the Qualtrics survey. For example, respondents that indicated that they did not come to campus at least once per week did not see questions asking about their primary mode of transportation to PSU or how far they lived from PSU. So, these questions had "NA" responses replaced with "-1 Appropriate Skip" for these respondents. Respondents that were shown the question about their primary mode of transportation to PSU that did not respond had the "NA" replaced with

"-7 Refused." Additionally, we changed the value labels of the stated choice experiment questions (Q38 through Q61) from the html code for the attribute tables to just the mode alternative names (car, bike, e-scooter + MAX) for ease of analysis.

In preparation for the MNL regression model of the stated choice experiment data, we created a new data structure. Instead of each line representing one complete 
survey and one respondent, we lengthened the data such that each stated choice within each choice set had its own line (three lines per choice set). We then joined each respondent's other responses to each of these lines. After rearranging the data in this manner, each respondent had eighteen lines, three for each of the six stated choice experiment questions that they had answered.

Additionally, the survey asked respondents to indicate an intersection closest to their home using a text entry field. Due to the high volume of responses, we used the Google Maps Geocoding API to find latitude/longitude coordinates that could be used for further spatial analysis. 1,087 respondents provided a text response that was able to be parsed to a usable set of coordinates and lay within the Portland metro area. The approximate home locations of these respondents are displayed in Figure 7.

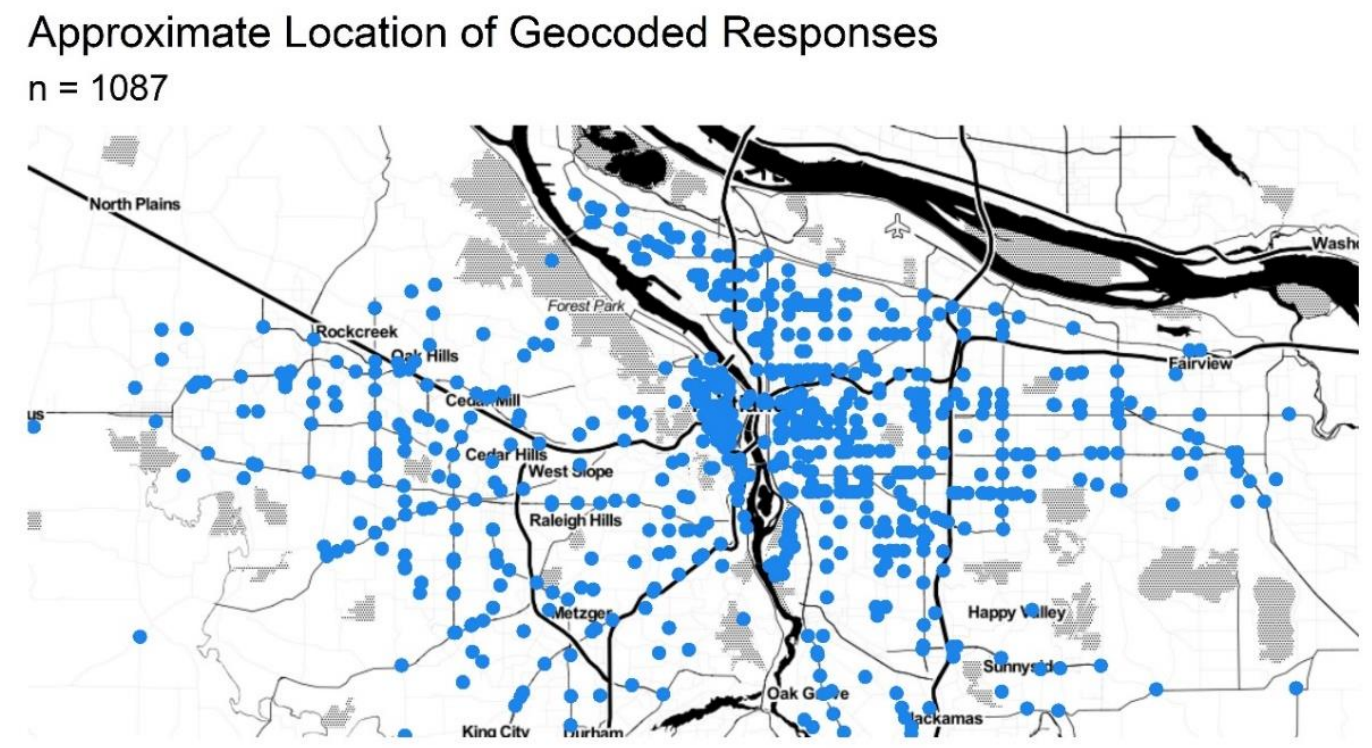

Figure 7: Approximate locations of geocoded responses within the Portland Metro Area 


\subsection{Models}

After data cleaning was complete, we used $\mathrm{R}$ to generate a variety of models from the survey data. These included ordinal logit models to explore the frequency of trips by mode in the previous seven days, ordinary least squares linear regression models to explore the propensity of respondents to switch to a different mode of transportation to PSU, and multinomial logit (MNL) models to analyze the results of the stated choice experiment. We used the MASS package (Venables and Ripley 2002) for ordinal logit model generation, the lavaan package (Rosseel 2012) for SEM propensity to switch score models, and the mnlogit (Hasan, Wang, and Mahani 2016) package for MNL models.

\subsection{Spatial Analyses}

We created several maps displaying results of the questions about transportation barriers using the respondents' closest intersection to their home, as ascertained using text responses and the Google Maps API. These maps were generated using several packages in R, including sf (Pebesma 2018), ggmap (Kahle and Wickham 2013), maptools (Bivand and Lewin-Koh 2020), nngeo (Dorman 2020), and ggsn (Baquero 2019).

\subsubsection{Spatial Distribution of Barriers}

Respondents were asked several questions to indicate neighborhood barriers and personal barriers that prevented them from using bike, MAX, or e-scooters more often. After plotting the geocoded home locations, we grouped the responses into equal area hexagons. An example of the raw counts of a barrier is shown in Figure 8. 
Bike Neighborhood Barriers

Too much traffic

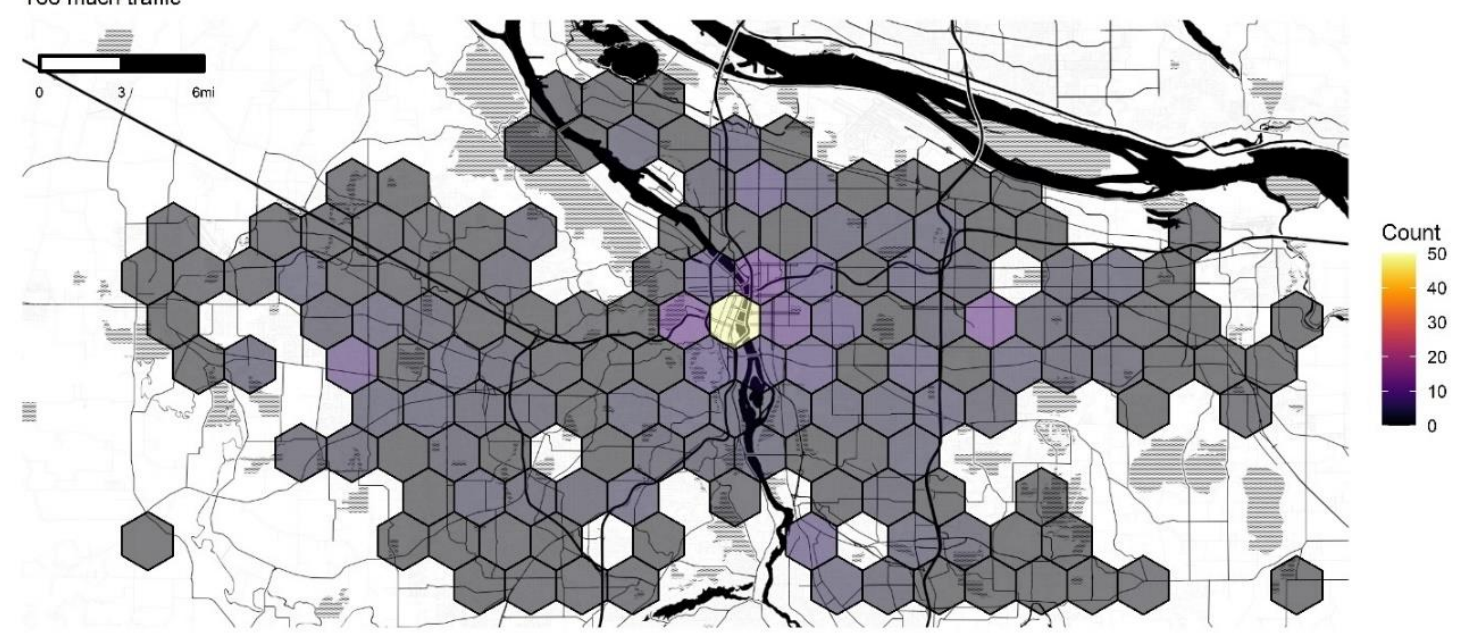

Figure 8: Raw Count Distribution of Responses

Next, in order to control for the fact that certain hexagons had many more

responses than others (namely the hexagon covering downtown), we calculated a ratio

for each hexagon of the number of respondents reported experiencing a barrier over

the total number of respondents located within that hexagon. An example of the results of this operation are shown in Figure 9.

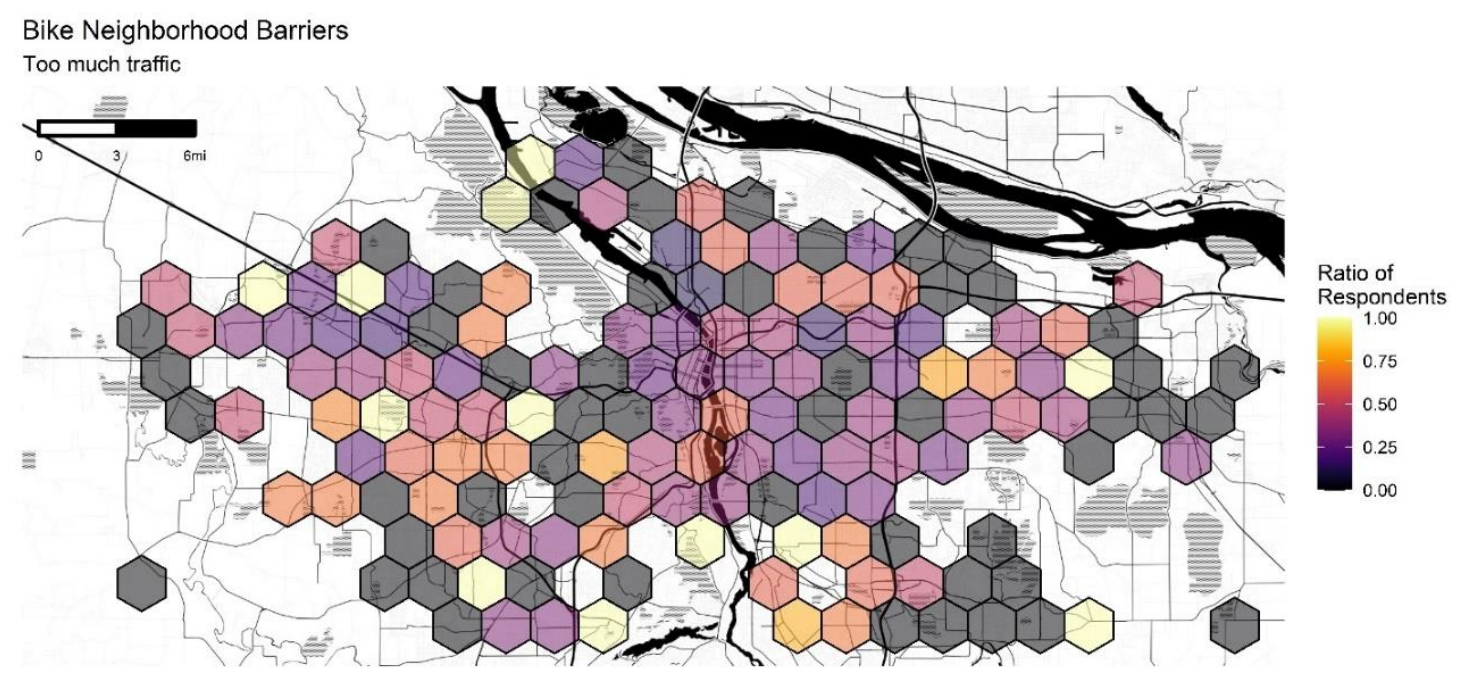

Figure 9: Raw Ratio Distribution of Responses 
Finally, in order to avoid over emphasizing hexagons with very few total respondents, we weighted the ratios using a transformed hyperbolic tangent curve shown in Figure 10. This curve was selected because it has a y value of 0 when $x$ (the count of respondents) is 0 , and a value close to 1 when $\mathrm{x}$ is large. The result of this final operation is shown in Figure 11. It can be seen that the outer lying hexagons are less emphasized because the total number of responses contained within them are smaller than the more centrally located hexagons. This technique is used to generate every map of barriers in the Results section.

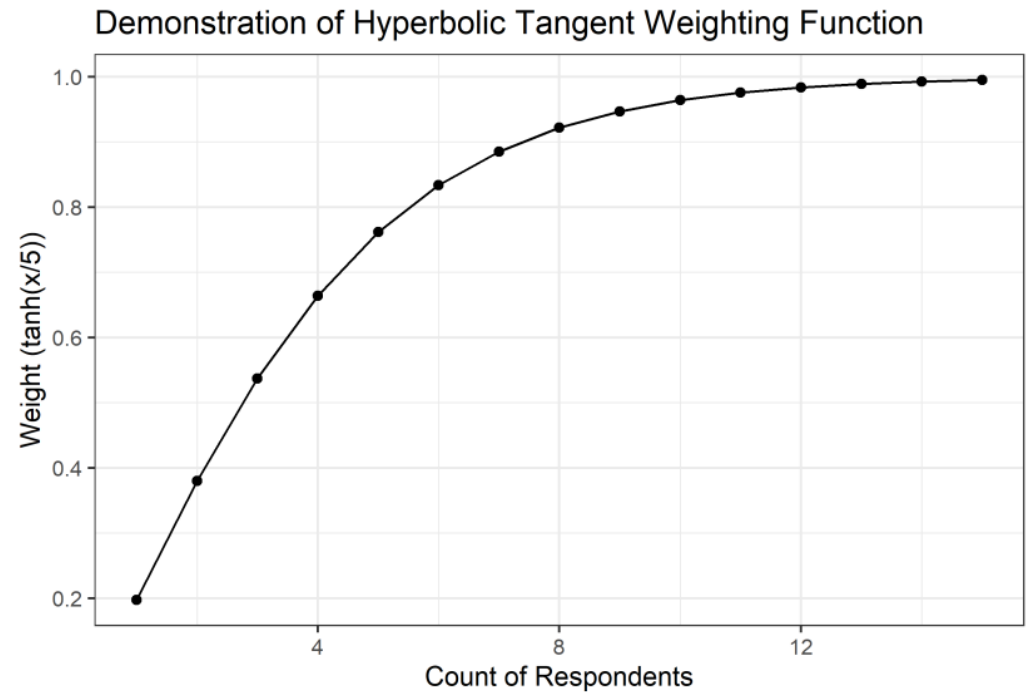

Figure 10: Hyperbolic Tangent Weighting Function 


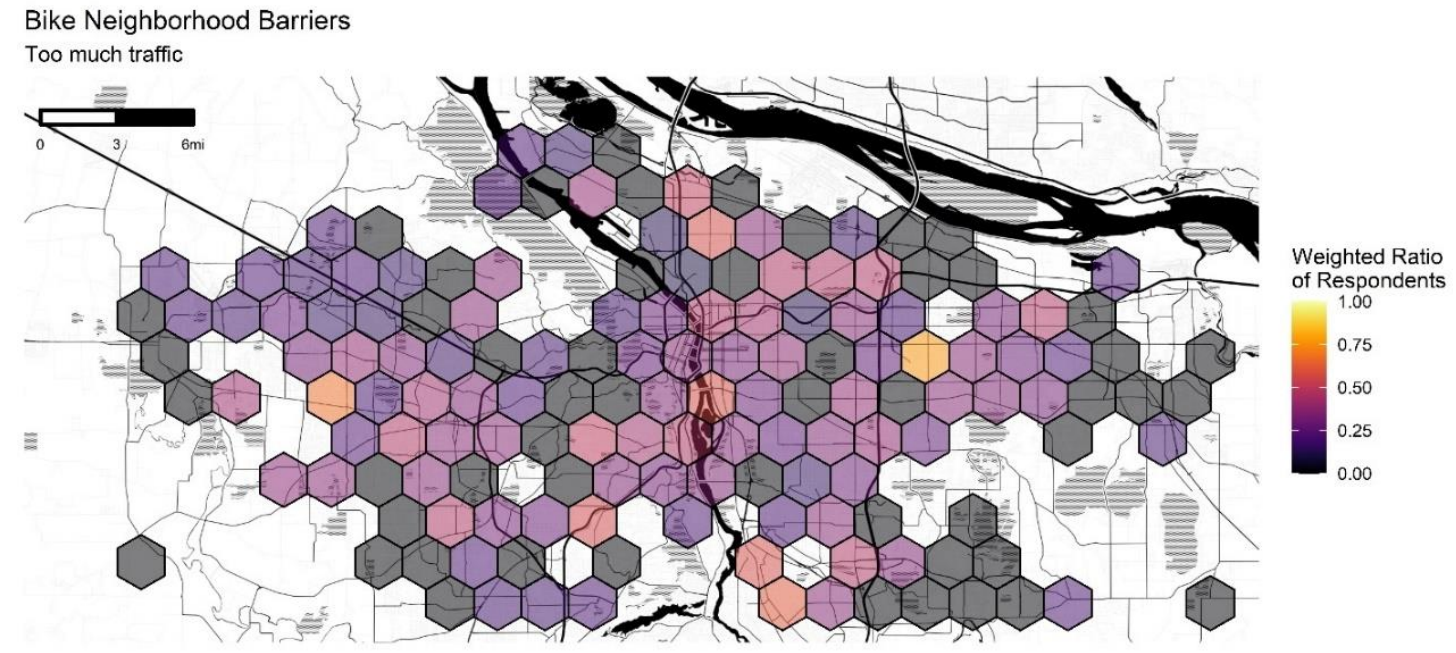

Figure 11: Weighted Ratio Distribution of Responses

\subsubsection{Spatial Implementation of MNL Results}

The second spatial analysis we performed involved applying the results of the MNL model estimated in section 4.5. This was accomplished in a series of steps. First, we selected a boundary box around the area we wished to test. Within this boundary box, we generated a set of regularly spaced "test points" in a grid pattern. Then, we snapped these points to the nearest point of the road network in the area. Next, we performed a nearest neighbor analysis to find the closest MAX stop to the test point. The results of the test point generation, test point snapping, and nearest neighbor analysis are shown in Figure 12. Black circles denote snapped test points, black lines denote the road network, orange lines denote the MAX network, white circles denote MAX stops, and blue lines show which MAX stop was determined to be the nearest neighbor of the test point to which it connects. For completeness, the nearest neighbor analysis also considered MAX stops that do not appear within the boundary box. 
Test point snapping and nearest MAX stop matching

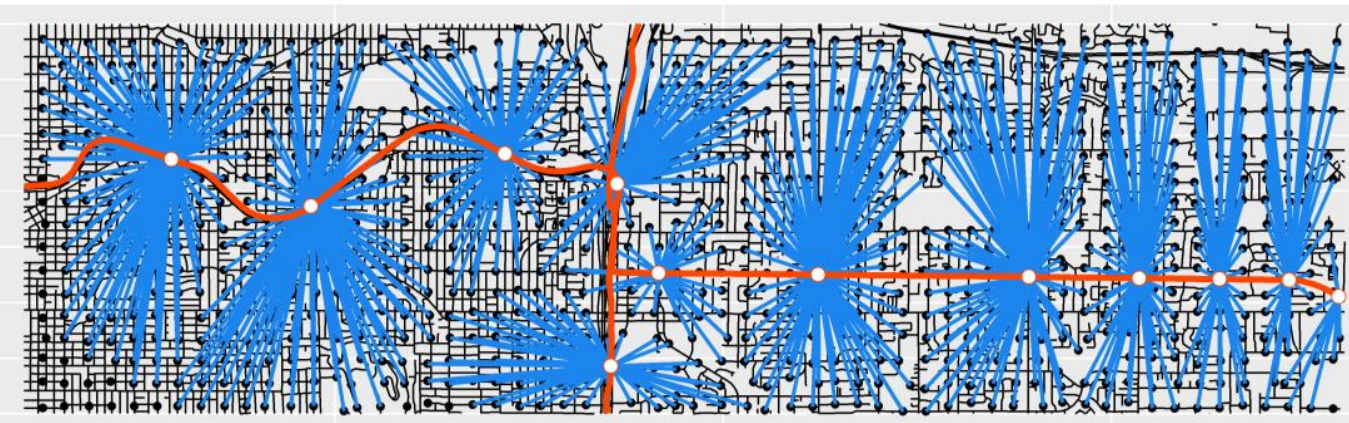

Figure 12: Test point generation, snapping, and nearest neighbor analysis

Next, we passed a set of queries to the Google Distance Matrix API to obtain

realistic travel times for each mode at each test point: car, MAX, bike, and e-scooter.

Each test point served as an origin, and the destination was either the PSU Recreation

Center (a centrally located building on campus) or the closest MAX station to the test

point. Car and bike travel times were estimated from the test point to PSU. MAX travel

times were obtained from each MAX stop to PSU. To simulate e-scooter travel times to

the closest MAX stop, a bicycle travel time was estimated and assumed to be similar to

the time it takes to travel by e-scooter. In order to ensure that the travel times were

realistic, we predicted the travel times in traffic at 8:00 AM on Thursday, July 23, 2020.

From past research, we have found Thursday to be among the busiest days of the week

and times in terms of traffic volumes. Figure 13 demonstrates traffic levels during a

typical Thursday on the last 4 miles of I-84 WB before the I-5 interchange. It should be

noted that the estimated travel times in Portland have gone down by $25-50 \%$ compared

to pre-COVID-19 pandemic levels. We thus tested travel times multiplied by both 1.25 
and 1.50 with marginal differences in results. It is unknown when travel times will return to their previous levels, however this rendered our model predictions as conservative.

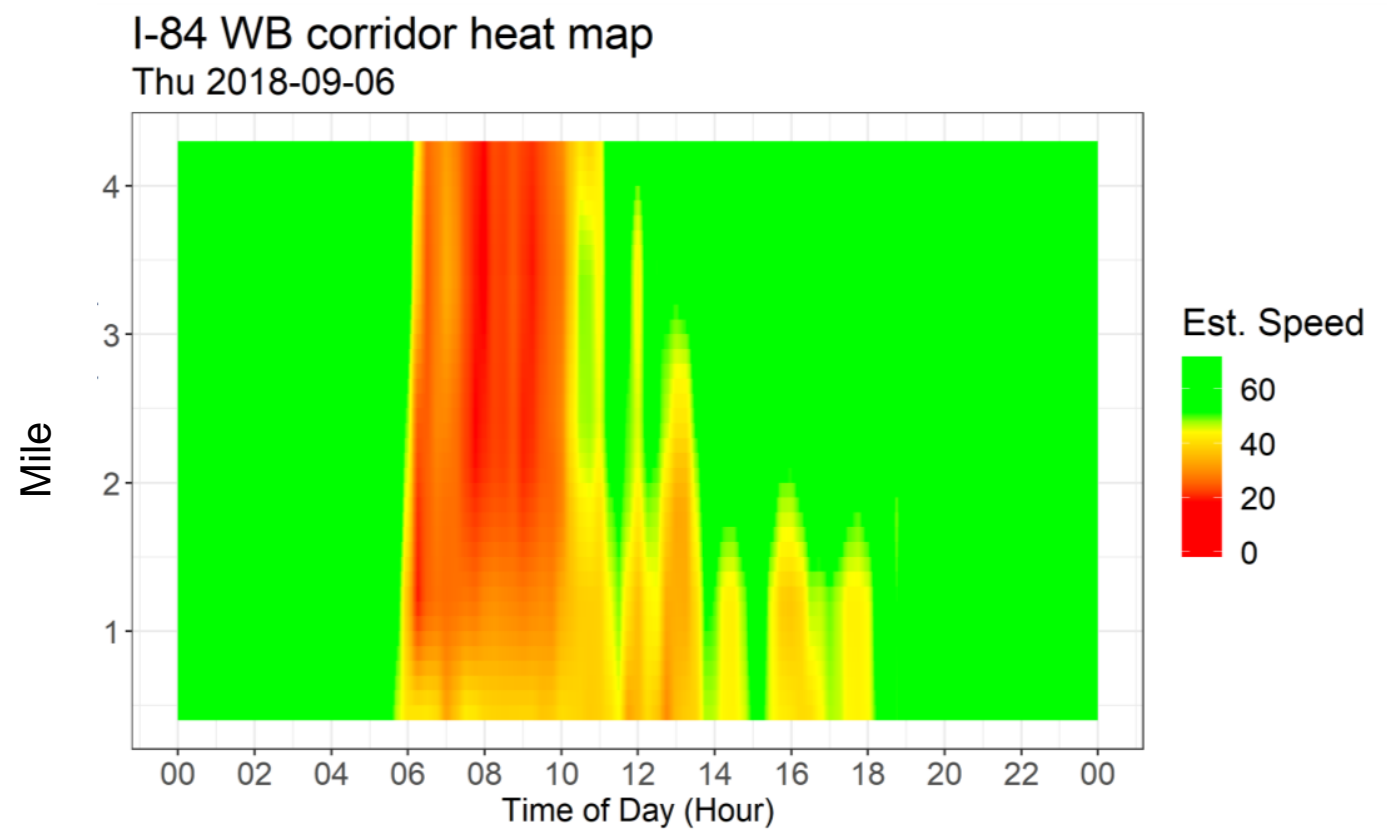

Figure 13: Estimated Travel Times and Speeds of the last 4 miles of I-84 WB using loop detector data Lastly, we joined the travel times estimated using the Google Distance Matrix API to the test points. Additionally, we calculated e-scooter trip cost using a flat rate plus per minute rate, similar to how e-scooter cost is calculated in the real world (for example, $\$ 1.00$ to unlock at $\$ 0.15 /$ minute). Other static parameters including car walk time, walk time to e-scooter, MAX cost, and parking cost were set manually and adjusted in order to observe impacts on mode choice probability.

Once the parameter values were set, we used the mnlogit package in $\mathrm{R}$ (Hasan, Wang, and Mahani 2016) to calculate the probability of choosing each of the three mode choices to get to PSU: bike, car, and e-scooter + MAX using the MNL model 
estimated from the stated choice experiment in section 4.5. The probabilities are calculated in the following manner:

As adapted in Aloulou (2018), the "utility" of each mode based on socioeconomic attributes, mode attributes, and environment attributes can be calculated using the deterministic equation:

$$
V_{i j}=\alpha_{0 j}+\sum_{k=1}^{K} \alpha_{j k} X_{i k}+\sum_{h=1}^{H} \beta_{h} W_{j h}+\sum_{m=1}^{M} \mu_{m} E_{j m}
$$

Where

- $V_{i j}$ is the estimated utility (in logits) for individual $i$ and mode $j$

- $\alpha_{0 j}$ is the alternative specific constant for mode $j$

- $\alpha_{j k}$ is the estimated parameter for the socioeconomic characteristic $k$ and mode $j$

- $X_{i k}$ is the value for individual $i$ and socioeconomic characteristic $k$ (such as gender or income)

- $\beta_{h}$ is the estimated parameter for mode attribute $\mathrm{h}$

- $W_{j h}$ is the value of mode attribute $h$ of mode $j$ (such as price or travel time)

- $\mu_{m}$ is the estimated parameter for factors of the environment of choice

- $E_{j m}$ is the value of environmental factor $m$ of mode $j$ (such as walk time to an escooter)

Next, a set of probabilities for choosing each of the three modes can be estimated

using the following equation:

$$
P_{j}=\frac{e^{V_{j}}}{1+\sum_{j=1}^{J} e^{V_{j}}}
$$

This means that the probability of choosing mode $j$ is the ratio of the exponentiated utilities of mode $j$ in $\{$ bike, e-scooter + MAX $\}$ over the sum of the exponentiated utilities. 
When calculating mode choice probabilities for the set of test points, we used mean values for all socioeconomic, behavioral, and attitudinal variables unless otherwise stated in the sensitivity analysis.

Using the probabilities of choosing each mode at each point, we used the akima $R$ package (Akima and Gebhardt 2020) to create three grids of regularly spaced tiles, one for each mode, with imputed probability values based on the probability values at the test points calculated using bilinear interpolation.

In the final processing step, these three grids of regularly spaced mode probability values, one for each mode, were coalesced such that the largest probability value was preserved for each tile. The "winning" mode corresponding to the largest probability was also preserved. These two pieces of information were used to inform the color ("winning" mode) and transparency (probability) of each tile on the map for visualization. 


\section{Results}

In this section, we provide the results of the models and spatial analyses and include brief interpretations.

\subsection{Descriptive Statistics}

As noted in section 3.2.3, we received 2,057 completed surveys. Of these, 89 respondents did not identify themselves as a student or did not indicate that they visited campus at least once per week. This left 1,968 valid responses after removing these respondents. The descriptive statistics of the remaining group are displayed in Table 4 and are compared to descriptive statistics from other university statistics where available.

The majority of respondents (53.6\%) identified as White only, similar to PSU's records for the 2020 Winter Term (54.2\%). American Indian or Alaska Native (0.6\%/1.1\%), Black or African American (1.9\%/3.5\%), and Hispanic or Latinx/Latino/Latina respondents (10.9\%/14.8\%) were somewhat underrepresented. Asian respondents (13.8\%/8.3\%) and respondents of more than one race or ethnicity (11.9\%/6.2\%) were somewhat over represented. Native Hawaiian or Pacific Islander respondents $(0.7 \% / 0.5 \%)$ were close to being equally represented in the survey.

Respondent reported age ranged between 18 and 99, with a mean of 25.6 and a standard deviation of 8 . (We suspect that the 99 reported age was not a true response, yet the next highest age reported was 73). Females were overrepresented in the survey (63\%/56\%) compared to males (30\%/44\%). This survey also represented students 
identifying as non-binary (4\%) or other (1\%), however PSU records do not provide a count of these gender identities for comparison.

A majority of respondents (69\%) reported being married or living with a partner. Most respondents (91\%) reported being responsible for 0 children. Additionally, most (60\%) reported having an income (either of the respondent or the respondent and partner) of less than $\$ 25,000$.

The majority of respondents reported being in a "good" state of health (37\%), which was the middle score on a 5-point Likert scale. $12 \%$ of respondents reported having a physical limitation that could make riding an e-scooter or bicycle difficult for them.

Of the respondents, $1 \%$ identified as being a faculty member, $7 \%$ identified as being a member of PSU staff, $1 \%$ identified as being a community member, and $1 \%$ identified as "other." Respondents traveled to campus an average of 4 days per week, $s d=1.6$, with a range between 1 and 7. On average, respondents lived 10.1 miles from campus, $s d=8.5$, however this scale was capped at 30 miles. 104 respondents $(5.3 \%)$ reported living 30 miles or more away from PSU. The most popular primary means of transportation to PSU was MAX (Light Rail) (28\%) followed by drive alone (26\%), bus (19\%), and walk/wheelchair (15\%). This is different than what was reported by the 2019 annual PSU transportation survey administered by Transportation \& Parking Services, however these discrepancies are likely caused by the fact that this question was asked in two different ways from our survey. When asked about what mode the respondent 
used to reach PSU on each day of the previous week, MAX was by far the most popular (81\%) followed by bus (6\%) and drive alone (5\%). When asked about which modes respondents had taken at any point in the previous month to reach PSU, MAX was again the most popular (34\%), followed by bus (16\%) and drive alone (11\%).

Overall, $84 \%$ of respondents had a driver's license, $74 \%$ had access to a car for travel to and from PSU, $24 \%$ had an e-scooter application installed on their phone. A majority (29\%) of respondents had taken $1-4$ car trips in the previous 7 days. A majority of respondents had taken 0 bike trips in the previous 7 days (89\%), 0 e-scooter trips in the last 7 days (93\%), and 0 MAX trips in the previous 7 days (40\%). 
Table 4: Descriptive Statistics

Descriptive statistics

$(n=1968)$

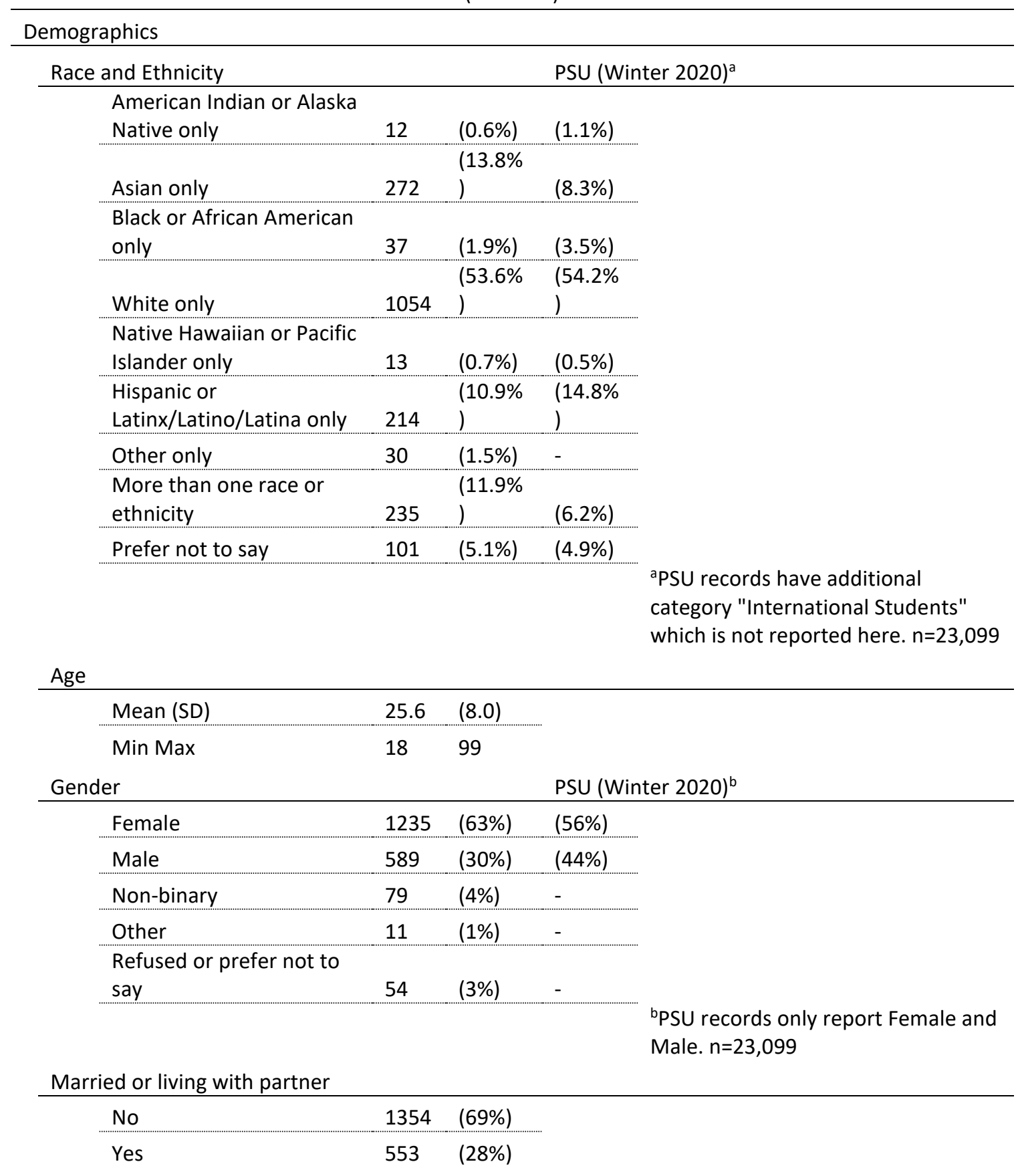


Number of children responsible

for

\begin{tabular}{lll}
\hline 0 & 1786 & $(91 \%)$ \\
\hline 1 & 82 & $(4 \%)$ \\
\hline 2 & 51 & $(3 \%)$ \\
\hline 3 & 18 & $(1 \%)$ \\
\hline $4+$ & 9 & $(0 \%)$ \\
\hline
\end{tabular}

Income of respondent and

partner

\begin{tabular}{lcc} 
Less than $\$ 25,000$ & 1172 & $(60 \%)$ \\
\hline$\$ 25,000-\$ 49,999$ & 280 & $(14 \%)$ \\
\hline$\$ 50,000-\$ 74,999$ & 151 & $(8 \%)$ \\
\hline$\$ 75,000-\$ 99,999$ & 79 & $(4 \%)$ \\
\hline$\$ 100,000-\$ 124,999$ & 44 & $(2 \%)$ \\
\hline $\begin{array}{l}\text { Greater than } \$ 125,000 \\
\text { Refused or prefer not to } \\
\text { say }\end{array}$ & 51 & $(3 \%)$ \\
\hline
\end{tabular}

Self-reported general state of health

\begin{tabular}{lcc} 
Poor & 45 & $(2 \%)$ \\
\hline Fair & 273 & $(14 \%)$ \\
\hline Good & 737 & $(37 \%)$ \\
\hline Very Good & 595 & $(30 \%)$ \\
\hline Excellent & 292 & $(15 \%)$
\end{tabular}

Has physical limitations that could make riding an e-scooter or bicycle difficult

\begin{tabular}{ccc}
\hline No & 1667 & $(88 \%)$ \\
Yes & 224 & $(12 \%)$ \\
\hline
\end{tabular}

Relationship to PSU

University Affiliation

\begin{tabular}{lcc} 
Student & 1968 & $(100 \%)$ \\
\hline Faculty & 19 & $(1 \%)$ \\
\hline Staff & 129 & $(7 \%)$ \\
\hline Community Member & 18 & $(1 \%)$ \\
\hline Other & 23 & $(1 \%)$
\end{tabular}

Days per week traveling to PSU

\begin{tabular}{lll} 
Mean (SD) & 4.0 & $(1.6)$ \\
\hline Min Max & 1 & 7
\end{tabular}




\begin{tabular}{|c|c|c|c|c|}
\hline $\begin{array}{l}\text { Primary Means of } \\
\text { Transportation to PSU }\end{array}$ & & & $\begin{array}{l}\text { PSU } \\
\text { (Fall }^{2019)^{c}}\end{array}$ & PSU (Fall 2019) ${ }^{d}$ \\
\hline Walk/Wheelchair & 289 & $(15 \%)$ & $(3 \%)$ & $(5 \%)$ \\
\hline Bike (bike that I own) & 42 & $(2 \%)$ & $(1 \%)$ & $(2 \%)$ \\
\hline Drive alone & 502 & $(26 \%)$ & $(5 \%)$ & $(11 \%)$ \\
\hline Bus & 373 & $(19 \%)$ & $(6 \%)$ & $(16 \%)$ \\
\hline MAX (Light Rail) & 542 & $(28 \%)$ & $(81 \%)$ & $(34 \%)$ \\
\hline Bike Share (BIKETOWN) & 2 & $(0 \%)$ & - & - \\
\hline $\begin{array}{l}\text { Shared E-Scooter (Lime, } \\
\text { Bolt, Skip, Bird) }\end{array}$ & 2 & $(0 \%)$ & $(0 \%)$ & $(1 \%)$ \\
\hline $\begin{array}{l}\text { Carpool (two or more } \\
\text { persons) }\end{array}$ & 78 & $(4 \%)$ & $(2 \%)$ & (5\%) \\
\hline $\begin{array}{l}\text { Dropped off } \\
\text { (Uber/Lyft/Taxi) }\end{array}$ & 9 & $(0 \%)$ & $(2 \%)$ & $(11 \%)$ \\
\hline Motorcycle/Moped & 4 & $(0 \%)$ & $(0 \%)$ & $(0 \%)$ \\
\hline Portland Streetcar & 82 & $(4 \%)$ & $(2 \%)$ & $(10 \%)$ \\
\hline Other & 43 & $(2 \%)$ & - & $\begin{array}{l}\text { (0\%) } \\
\text { "From the } 2019 \text { Transportation \& } \\
\text { Parking Services student survey, } \\
\text { "How did you travel to PSU each day } \\
\text { last week?", responses summed by } \\
\text { mode, } \\
\mathrm{n}=125 \text { to } n=851 \text { per day } \\
\text { dFrom the } 2019 \text { Transportation \& } \\
\text { Parking Services student survey, } \\
\text { "Which of the following } \\
\text { transportation modes have you used } \\
\text { in the past month to travel to PSU?", } \\
\mathrm{n}=2941\end{array}$ \\
\hline
\end{tabular}

Distance from Campus (mi) ${ }^{d}$

\begin{tabular}{lll} 
Mean (SD) & 10.1 & $(8.5)$ \\
\hline Min Max & 0 & 30
\end{tabular}

${ }^{\mathrm{d}} 30$ indicates $30+$ mi away

\begin{tabular}{lll}
\hline General Travel Behavior & & \\
\hline Has a Driver's License & & \\
\hline No & 306 & $(16 \%)$ \\
\hline $\begin{array}{l}\text { Yes } \\
\text { Has access to a personal car } \\
\text { to/from PSU }\end{array}$ & 1659 & $(84 \%)$ \\
\hline No & & \\
\hline Yes & 517 & $(26 \%)$ \\
\hline & 1451 & $(74 \%)$
\end{tabular}


Has e-scooter application installed on phone

$\begin{array}{lll}\text { No } & 1486 & (76 \%) \\ \text { Yes } & 478 & (24 \%)\end{array}$

Personal car trips in last 7 days

\begin{tabular}{|lll|}
\hline 0 trips & 489 & $(25 \%)$ \\
\hline $1-4$ trips & 579 & $(29 \%)$ \\
\hline $5-10$ trips & 437 & $(22 \%)$ \\
\hline$>10$ trips & 460 & $(23 \%)$ \\
\hline
\end{tabular}

Personal bike trips in last 7 days

\begin{tabular}{lll}
\hline 0 trips & 1755 & $(89 \%)$ \\
\hline $1-4$ trips & 118 & $(6 \%)$ \\
\hline $5-10$ trips & 38 & $(2 \%)$ \\
\hline$>10$ trips & 44 & $(2 \%)$
\end{tabular}

E-Scooter trips in last 7 days

\begin{tabular}{lcl}
\hline 0 trips & 1834 & $(93 \%)$ \\
\hline $1-4$ trips & 103 & $(5 \%)$ \\
\hline $5-10$ trips & 4 & $(0 \%)$ \\
\hline$>10$ trips & 4 & $(0 \%)$
\end{tabular}

MAX trips in last 7 days

\begin{tabular}{lcc}
\hline 0 trips & 792 & $(40 \%)$ \\
\hline $1-4$ trips & 601 & $(31 \%)$ \\
\hline $5-10$ trips & 370 & $(19 \%)$ \\
\hline$>10$ trips & 187 & $(10 \%)$ \\
\hline
\end{tabular}




\subsection{Attitude Indices}

As described in section 3.1.3, we asked respondents a series of 5-point Likert scale questions in order to assess their latent overall attitudes and perceptions of the four transportation modes that were presented in the stated preference experiment: car, bike, MAX, and e-scooter. Additionally, we asked another series of 5-point Likert scale questions regarding which decision factors were important in that respondent's mode decision for getting to PSU. It was important to measure these latent attitudes and decision factors to include as covariates in the models. In this section, we describe the process of determining that the level of internal reliability among all scale items is adequate. Additionally, we explain how we reduced each set of several items to estimates of one or multiple latent factors for ease of interpretation and reduction of multicollinearity.

\subsubsection{Reliability}

We initially assessed the internal reliability of each set of Likert scale items using Cronbach's Alpha (Cronbach 1951). This score is calculated using an estimate of the proportion of the observed score variance that is due to measurement error among the item set. It can be used to assess how well the scale in question is measuring a single construct. (Note that this is separate from assuming that the scales are unidimensional, which will be addressed in section 4.2.4.) In fact, where several constructs exist, the resulting Cronbach's Alpha for each construct may be lower. For this reason, the mode 
decision factor Cronbach's Alpha scores should be taken with a grain of salt, because these scales are designed to measure multiple constructs.

Before calculating the Cronbach's Alpha scores for each scale, we reversed the scores for items that were negatively worded, such as "Most e-scooter users ride recklessly." This was done to improve reliability and to increase the validity of indices generated using sums and averages. As expected, the reliability scores generally improved when these items were reversed.

The results of Cronbach's Alpha for each scale are summarized in Table 5. Scores under $\alpha^{a}$ denote Cronbach's Alpha with no items reversed or deleted. Scores in $\alpha^{b}$ were calculated after reversing negatively worded items. Finally, scores in $\alpha^{\mathrm{c}}$ were calculated after removing one item that improved the score the most. The final sum and average composites were calculated using the final scale with one item removed. None of the items in mode decision factors were reversed or deleted. A common rule of thumb proposed by Nunnally (1978) states that scores of 0.70 suggest modest reliability, however higher scores are desirable. All of the final scores fall well above the 0.70 modest reliability rule of thumb, suggesting that the remaining items present acceptable reliability. 
Table 5: Cronbach's Alpha Scores

\begin{tabular}{|l|l|l|l|l|l|}
\hline Scale & $\alpha^{\mathrm{a}}$ & Item(s) reversed & $\alpha^{\mathrm{b}}$ & Item(s) deleted & $\alpha^{\mathrm{c}}$ \\
\hline Car & 0.692 & Q15_7 & 0.764 & Q15_7 & 0.774 \\
\hline Bike & 0.549 & Q21_5, Q21_6, Q21_7 & 0.773 & Q21_6 & 0.790 \\
\hline E-Scooter & 0.498 & Q28_3, Q28_5, Q28_6, Q28_7 & 0.810 & Q28_6 & 0.828 \\
\hline MAX & 0.824 & Q34_10 & 0.844 & Q34_10 & 0.863 \\
\hline Mode Decision Factors & 0.820 & - & - & - & 0.820 \\
\hline
\end{tabular}

a (nothing reversed)

${ }^{b}$ (appropriate items reversed)

c (final)

\subsubsection{Correlations}

In addition to the complexity of interpretation of models making use of scales with several items, important correlations between scale items can also contribute to multicollinearity. We tested each set of items for correlations to demonstrate this. The Pearson correlation scores shown Table 6 indicate frequent significant medium $(>\approx 0.3)$ to large $(>\approx 0.5)$ correlations among scale items. These would cause multicollinearity issues without the implementation of comprehensive index scores or latent variable analysis. (The rest of the correlation tables for the other scales, including Car Attitude, Bike Attitude, E-Scooter Attitude, and Mode Decision Factors can be found in Appendix A). 
Table 6: MAX Attitude Items, Pearson Correlations

\begin{tabular}{|c|c|c|c|c|c|c|c|c|c|c|c|}
\hline & $\begin{array}{l}\text { Q34 } \\
ـ 1\end{array}$ & $\begin{array}{l}\text { Q34 } \\
2 \\
\end{array}$ & $\begin{array}{l}\text { Q34 } \\
-3\end{array}$ & $\begin{array}{l}\text { Q34 } \\
-4\end{array}$ & $\begin{array}{l}\text { Q34 } \\
-5\end{array}$ & $\begin{array}{l}\text { Q34 } \\
-6\end{array}$ & $\begin{array}{l}\text { Q34 } \\
-7\end{array}$ & $\begin{array}{l}\text { Q34 } \\
\quad 8\end{array}$ & $\begin{array}{l}\text { Q34 } \\
\quad 9\end{array}$ & $\begin{array}{l}\text { Q34_- } \\
10 r^{-}\end{array}$ & $\begin{array}{r}\text { Q34 } \\
111 \\
\end{array}$ \\
\hline $\begin{array}{l}\text { Q34_1 I enjoy riding } \\
\text { MAX }\end{array}$ & 1 & & & & & & & & & & \\
\hline $\begin{array}{l}\text { Q34_2 I feel safe riding } \\
\text { MAX }\end{array}$ & .608 & 1 & & & & & & & & & \\
\hline $\begin{array}{l}\text { Q34_3 I feel safe } \\
\text { waiting at the MAX } \\
\text { station }\end{array}$ & $\begin{array}{l}.537 \\
* *\end{array}$ & $\begin{array}{l}.738 \\
* *\end{array}$ & 1 & & & & & & & & \\
\hline $\begin{array}{l}\text { Q34_4 I feel } \\
\text { comfortable while } \\
\text { riding MAX } \\
\text { (Temperature, seat, } \\
\text { space, etc.) }\end{array}$ & $\begin{array}{l}.647 \\
* *\end{array}$ & $\begin{array}{l}.636 \\
* * \\
* \cdots \cdots\end{array}$ & $\begin{array}{l}.562 \\
* * \\
* * \cdots\end{array}$ & 1 & & & & & & & \\
\hline $\begin{array}{l}\text { Q34_5 I am a transit } \\
\text { commuter }\end{array}$ & $\begin{array}{l}.330 \\
* *\end{array}$ & $\begin{array}{l}.254 \\
* *\end{array}$ & $\begin{array}{l}.286 \\
* *\end{array}$ & $\begin{array}{l}.263 \\
* *\end{array}$ & 1 & & & & & & \\
\hline $\begin{array}{l}\text { Q34_6 I am glad to } \\
\text { have the time to do } \\
\text { other things while } \\
\text { riding MAX }\end{array}$ & $\begin{array}{l}.475 \\
* *\end{array}$ & $\begin{array}{l}.349 \\
* *\end{array}$ & $\begin{array}{l}.345 \\
* *\end{array}$ & $\begin{array}{l}.398 \\
* *\end{array}$ & $\begin{array}{l}.374 \\
* *\end{array}$ & 1 & & & & & \\
\hline $\begin{array}{l}\text { Q34_7 MAX comes } \\
\text { frequently enough for } \\
\text { me to use it } \\
\text { spontaneously }\end{array}$ & $\begin{array}{l}.346 \\
* *\end{array}$ & .291 & $\begin{array}{l}.329 \\
* *\end{array}$ & $\begin{array}{l}.324 \\
* *\end{array}$ & $\begin{array}{l}.310 \\
* *\end{array}$ & $\begin{array}{l}.338 \\
* *\end{array}$ & 1 & & & & \\
\hline $\begin{array}{l}\text { Q34_8 I think that } \\
\text { riding MAX helps the } \\
\text { environment }\end{array}$ & $\begin{array}{l}.383 \\
* *\end{array}$ & $\begin{array}{l}.307 \\
* *\end{array}$ & $\begin{array}{l}.261 \\
* *\end{array}$ & $\begin{array}{l}.322 \\
* *\end{array}$ & $\begin{array}{l}.202 \\
* *\end{array}$ & $\begin{array}{l}.404 \\
* *\end{array}$ & $\begin{array}{l}.293 \\
* *\end{array}$ & 1 & & & \\
\hline $\begin{array}{l}\text { Q34_9 Riding MAX is } \\
\text { cool }\end{array}$ & .622 & $\begin{array}{l}.461 \\
* *\end{array}$ & .397 & $\begin{array}{l}.477 \\
* *\end{array}$ & .201 & .409 & .270 & $\begin{array}{l}.431 \\
* *\end{array}$ & 1 & & \\
\hline $\begin{array}{l}\text { Q34_10r REVERSED } \\
\text { Transit is primarily for } \\
\text { people with lower } \\
\text { incomes }\end{array}$ & $\begin{array}{l}.131 \\
* *\end{array}$ & $\begin{array}{l}.124 \\
* *\end{array}$ & .127 & $\begin{array}{l}.090 \\
* * \\
* \ldots \ldots\end{array}$ & $\begin{array}{r}0.02 \\
8\end{array}$ & .091 & $\begin{array}{r}0.01 \\
4\end{array}$ & $\begin{array}{l}.171 \\
* *\end{array}$ & $\begin{array}{l}.152 \\
* *\end{array}$ & 1 & \\
\hline $\begin{array}{l}\text { Q34_11 MAX is } \\
\text { convenient }\end{array}$ & $\begin{array}{l}.460 \\
* *\end{array}$ & $\begin{array}{l}.358 \\
* * \\
\end{array}$ & $\begin{array}{l}.355 \\
* * \\
\end{array}$ & $\begin{array}{l}.413 \\
* *\end{array}$ & $\begin{array}{l}.417 \\
* *\end{array}$ & $\begin{array}{l}.439 \\
* * \\
\end{array}$ & $\begin{array}{l}.533 \\
* *\end{array}$ & $\begin{array}{l}.353 \\
* * \\
\end{array}$ & $\begin{array}{l}.371 \\
* * \\
\end{array}$ & $.046 *$ & 1 \\
\hline
\end{tabular}

$* *$. Correlation is significant at the

0.01 level (2-tailed).

*. Correlation is significant at the

0.05 level (2-tailed). 


\subsubsection{Indices Calculated Using Item Sums and Means}

For the mode attitudes, the remaining items that were not removed during the reliability analysis were grouped together to form index values that could be used as covariates in the models. Two sets of indices were calculated, one set was created by summing the remaining items, and the second set was created by averaging the remaining items. The descriptive statistics for these indices are shown in Table 7. Only one set of indices was used at a time when building models in order to avoid multicollinearity problems inherent with "double dipping".

Table 7: Descriptive Statistics, Calculated Index Values

\begin{tabular}{|l|r|r|r|r|r|}
\hline & N & Minimum & Maximum & Mean & Std. Deviation \\
\hline Car Attitude (Sum) & 1966 & 6 & 35 & 23.94 & 4.67 \\
\hline Bike Attitude (Sum) & 1957 & 1 & 44 & 28.17 & 5.60 \\
\hline E-Scooter Attitude (Sum) & 1944 & 1 & 48 & 26.92 & 6.41 \\
\hline MAX Attitude (Sum) & 1950 & 2 & 50 & 33.77 & 6.96 \\
\hline Car Attitude (Mean) & 1966 & 1 & 5 & 3.42 & 0.66 \\
\hline Bike Attitude (Mean) & 1957 & 1 & 4.89 & 3.14 & 0.61 \\
\hline E-Scooter Attitude (Mean) & 1944 & 1 & 5 & 2.71 & 0.63 \\
\hline MAX Attitude (Mean) & 1950 & 1 & 5 & 3.39 & 0.69 \\
\hline
\end{tabular}

\subsubsection{Principal Components Analysis (PCA) and Exploratory Factor Analysis (EFA)}

In addition to the non-refined index calculation methods of summing and averaging items within each scale discussed in section 4.2.3, we also calculated latent factor score estimates based on item loadings from an exploratory factor analysis (EFA). According to Fabrigar and Wegener $(2012,20)$, "factor analysis is used as a means of arriving at a more parsimonious representation of the underlying structure of 
correlations among a set of measured variables". It is a data reduction strategy that can be used to overcome multicollinearity problems and large numbers of items that may all capture the same underlying construct or constructs to similar or varying degrees.

EFA requires the researcher to decide at the start how many underlying factors exist within the scale in question. We informed this decision based on a preliminary principal component analysis (PCA) and several factor number determination tests and rules of thumb. Resulting latent factor scores can be less intuitive to interpret because they are standardized and no longer fall on the original 1-5 Likert scale that was used in the survey. However, they can represent latent factors more accurately than nonrefined methods, especially when scales exhibit multidimensionality. These latent factor scores can then be used as part of regression analyses (DiStefano, Zhu, and Mîndrilă 2009), which we develop in section 4.

To begin, we performed a PCA for each scale and plotted the resulting eigenvalues in Figure 14 (blue lines), called a "scree plot" (Cattell 1966). Each eigenvalue represents the portion of internal variance explained within each of the items on the scale. In PCA, there are as many calculated eigenvalues ("components") as scale items. The scree plot is used to visualize how many underlying components may be represented in the data. According to the scree test, the number of latent components is the number of eigenvalues that precedes the last major drop in value (the "elbow") (Fabrigar and Wegener 2012, chap. 3). It is difficult to interpret exactly what entails a "major drop," however this suggests 1 to 2 components for each scale in my data. Next, 
the oft-cited Kaiser-Guttman rule specifies that components with eigenvalues greater than one should be preserved (Fabrigar and Wegener 2012, chap. 3). We have overlaid a red line denoting a value of one in Figure 14 for easy visualization. This leads to a similar conclusion of one to three components on each scale.

Finally, we performed a parallel analysis for each scale. In this operation, eigenvalues are generated from a set of completely random data that contains the same number of observations and items as the dataset in question. These eigenvalues are compared to the eigenvalues of the real data, with the number of components retained equal to those whose eigenvalues are larger than the corresponding eigenvalues from the random data (Fabrigar and Wegener 2012, chap. 3). The parallel analysis eigenvalues are overlaid on the scree plots in orange in Figure 14. It has been suggested that parallel analysis is better than the simpler but flawed scree plot elbow test and Kaiser-Guttman rule (O'Connor 2000). For this reason, we have performed all three for comparison, yet the results are all very similar. 

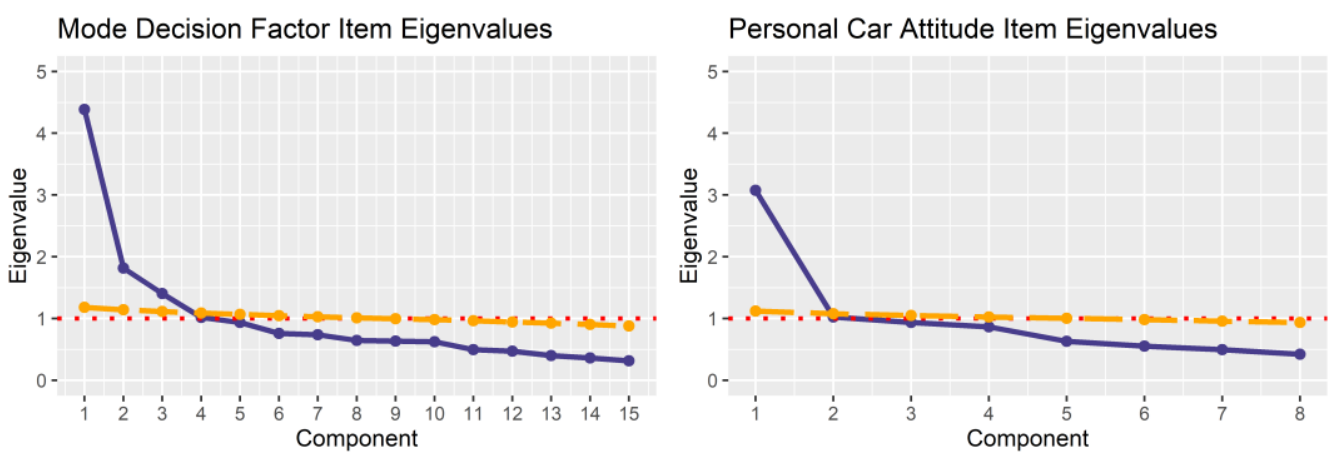

Bike Attitude Item Eigenvalues

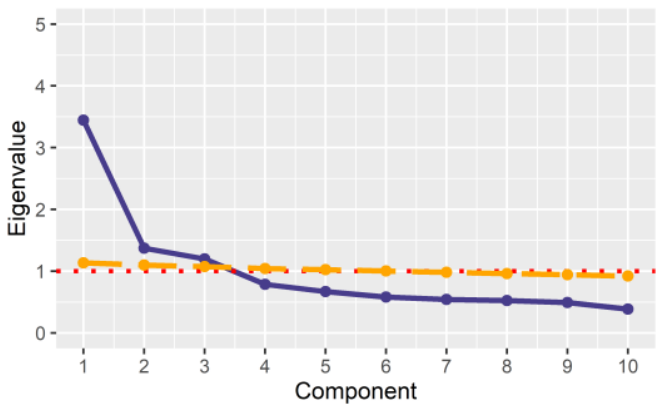

E-Scooter Attitude Item Eigenvalues

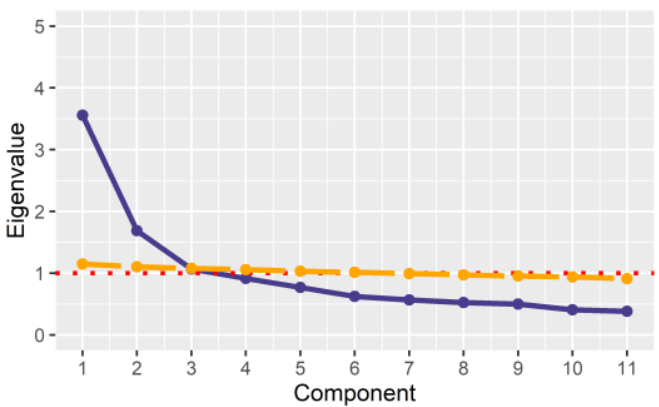

MAX Attitude Item Eigenvalues

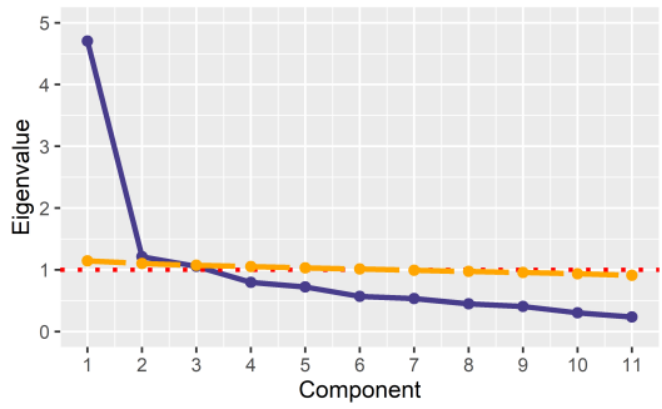

Figure 14: PCA Scree Plots (blue solid), Kaiser-Guttman Criterion (red dotted), and Parallel Analyses (orange dashed)

One further test, called Velicer's (1976) MAP test, can also be used as a more systematic way to determine how many factors to include in the EFA step. In this process, components are retained as long as they exhibit systematic variance, and are dropped when there is more unsystematic variance than systematic variance $\left(\mathrm{O}^{\prime}\right.$ Connor 2000). The results of Velicer's MAP test are shown in Table 8. 
Table 8 Results of Velicer's MAP test

\begin{tabular}{|l|l|}
\hline Scale & $\begin{array}{l}\text { Number of } \\
\text { Factors }\end{array}$ \\
\hline Mode Decision & \\
Factor & 2 \\
\hline Car & 1 \\
\hline Bike & 1 \\
\hline E-Scooter & 1 \\
\hline MAX & 1 \\
\hline
\end{tabular}

There are a number of known issues with some of these methods. The scree test is a visual inspection method, meaning that it could have different results depending on the researcher. The Kaiser-Guttman criterion has been suggested by numerous studies to lead to over factoring (Fabrigar and Wegener 2012, chap. 3). Parallel analysis has also been suggested to be an overly lenient method for determining the number of factors, as it only requires that factors perform slightly better than random chance in order to be included (Fabrigar and Wegener 2012, chap. 3). In order to achieve the goal of reducing each mode attitude scale to a single value and to retain a similar number of factors among each mode attitude scale, we decided to set the number of factors to align with the results of the MAP test. We chose to use 2 mode decision factors (constructs that influence the mode choice decision when travelling to PSU) and 1 attitude factor for each mode (a construct reflecting the overall perception of each mode).

Although PCA is a good place to start in order to get an idea of how many underlying constructs exist, the calculation of principal components does not take into account the unique random variance (error) that exists within each scale item, whereas the calculation of factors in exploratory factor analysis (EFA) does. Figure 15 
demonstrates this difference at a conceptual level - the $e$ indicates that random error is being controlled for in the survey items. As survey instruments are bound to have imperfect questions, EFA should be used to determine the final loading (correlation) of each item to each latent factor.
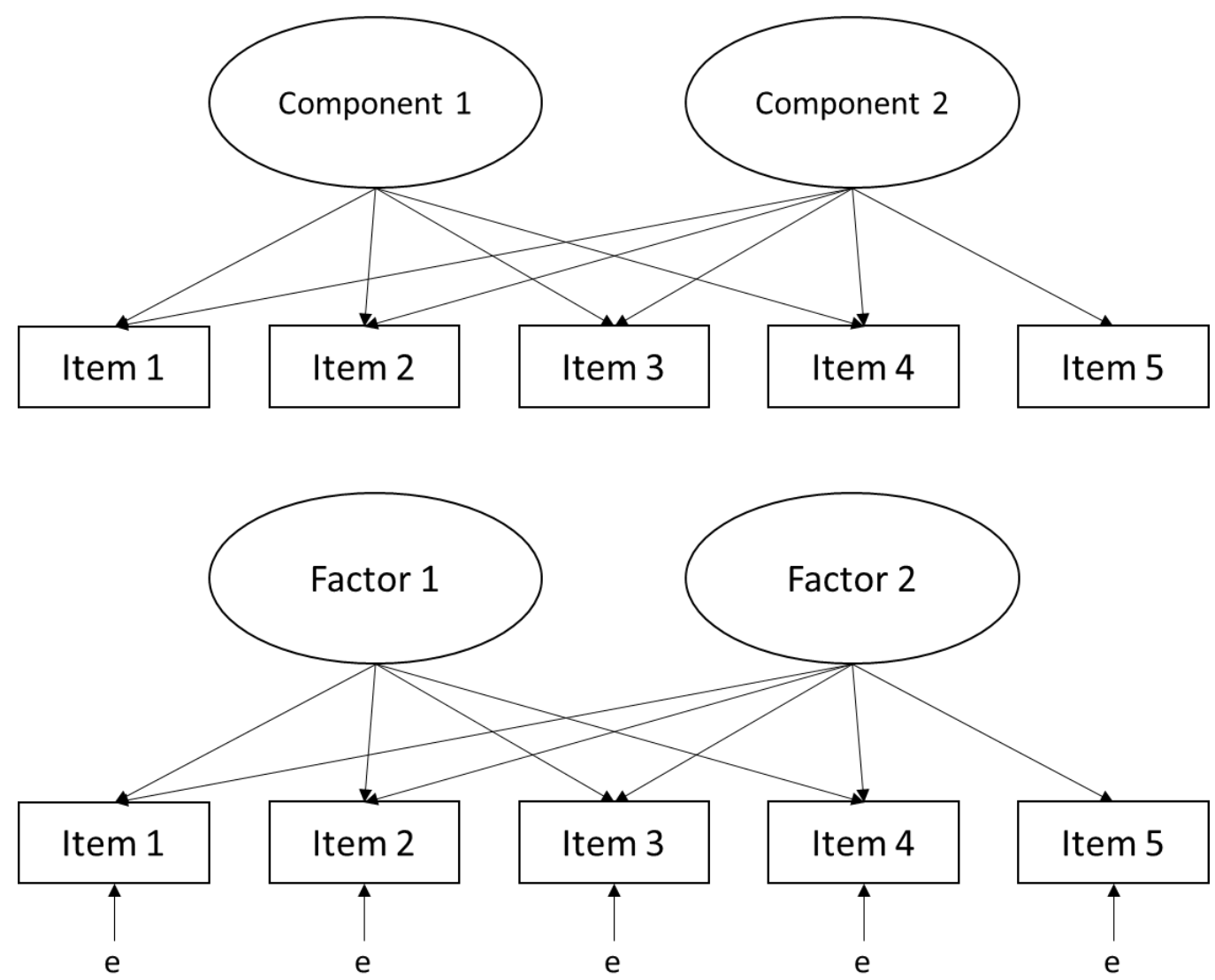

Figure 15: PCA (top) and EFA (bottom) path diagram framework

After selecting the number of factors to extract, it is necessary to perform a rotation if the scale is set to contain a number of factors greater than one. This is done to aid in the interpretation of the factor loadings by orienting them in a simple structure. The simple structure makes it more clear which items load the strongest onto which factors. We chose to perform a varimax rotation, which is the default option in 
SPSS. Varimax rotations are a type of orthogonal rotation, or those that assume factors are independent or uncorrelated with each other. They are called "Varimax" because they maximize the sum of the variances of the squared loadings for each factor. In effect, this maximizes high loadings and minimizes low loadings (UCLA: Statistical Consulting Group n.d.). We also chose to apply a Kaiser normalization, a default setting, which provides stability of solutions across samples.

The results of the factor rotation for the mode decision factors is shown in the rotated factor matrix in Table 9. The mode specific attitude factors did not require rotation, as we had chosen to extract a single factor, which already has a maximized sum of the variances of the squared loadings - the remaining (unrotated) factor matrices are shown in Table 10 through Table 13. Items with loadings (correlations to the rotated factors) below 0.30 have been omitted from the tables for clarity, however they are still included in the factor score calculation step. 
Table 9: Mode Decision Factor Item Loadings

\begin{tabular}{|c|c|c|}
\hline & $\begin{array}{l}\text { "Comfort } \\
\text { and Safety" }\end{array}$ & $\begin{array}{l}\text { "Exercise and the } \\
\text { Environment" }\end{array}$ \\
\hline $\begin{array}{l}\text { Q8_1 Obtaining exercise or physical } \\
\text { activity }\end{array}$ & & 0.80 \\
\hline Q8_2 My physical ability & & 0.61 \\
\hline $\begin{array}{l}\text { Q8_3 Opportunity to shower at } \\
\text { destination }\end{array}$ & & 0.53 \\
\hline $\begin{array}{l}\text { Q8_4 Arriving on time to } \\
\text { destination }\end{array}$ & 0.52 & \\
\hline $\begin{array}{l}\text { Q8_5 Frequency of transit } \\
\text { departures }\end{array}$ & 0.39 & \\
\hline Q8_6 Flexible time of departure & 0.49 & \\
\hline Q8_7 Travel cost/price & 0.46 & \\
\hline Q8_8 Travel time & 0.63 & \\
\hline Q8_9 Flexible travel route & 0.59 & \\
\hline Q8_10 Personal safety and security & 0.61 & \\
\hline Q8_11 Traffic safety & 0.63 & \\
\hline $\begin{array}{l}\text { Q8_12 The current weather } \\
\text { conditions }\end{array}$ & 0.45 & \\
\hline
\end{tabular}

Q8_13 My personal impact on the

0.46

environment (carbon footprint)

Q8_14 The opportunity to do other things while traveling

0.36

Q8_15 Physical comfort while traveling

0.52

The rotated factor matrix in Table 9 allows us to more simply interpret the possible underlying constructs that each factor could be representing. Factor one loads highly onto items such as personal safety and security, traffic safety, travel time, arriving on time to destination, physical comfort while traveling, and current weather conditions. For these reasons, we will refer to factor one as "comfort and safety." 
Additionally, factor two loads highly onto the obtaining exercise or physical activity, my physical ability, opportunity to shower at destination, and personal impact on the environment items. As such, we will call factor two "exercise and the environment." Table 10: Car Attitude Factor Item Loadings

\begin{tabular}{lc} 
& Car Attitude Factor \\
\hline Q15_1 I enjoy driving & 0.68 \\
\hline Q15_2 I feel safe in a car & 0.67 \\
\hline Q15_3 Driving is cool & 0.59 \\
\hline Q15_4 I feel comfortable riding in & \\
a car (Temperature, seat, space, \\
etc.) \\
$\begin{array}{l}\text { Q15_5 I don't mind searching for } \\
\text { a parking spot }\end{array}$ \\
$\begin{array}{l} \\
\text { Q15_6 Even if I get delayed by } \\
\text { traffic, I'd still prefer to take a car }\end{array}$ \\
\hline \\
$\begin{array}{l}\text { Q15_7r REVERSED I think that } \\
\text { cars are harmful to the } \\
\text { environment }\end{array}$ \\
\hline Q15_8 Cars are convenient
\end{tabular}


Table 11: Bike Attitude Factor Item Loadings

\begin{tabular}{lc} 
& Bike Attitude factor \\
\hline Q21_1 I enjoy riding a bike & 0.69 \\
\hline Q21_2 I feel safe riding a bike & 0.54 \\
\hline Q21_3 Riding a bike is cool & 0.75 \\
\hline Q21_4 I consider myself a bike & 0.45 \\
commuter & \\
Q21_5r REVERSED Most cyclists \\
ride recklessly \\
\hline $\begin{array}{l}\text { Q21_6r REVERSED I will not ride } \\
\text { somewhere if there are no bike } \\
\text { lanes }\end{array}$ \\
\hline $\begin{array}{l}\text { Q21_7r REVERSED Cyclists cause } \\
\text { unsafe situations for pedestrians }\end{array}$ \\
\hline $\begin{array}{l}\text { Q21_8 I think that riding a bike } \\
\text { helps the environment }\end{array}$ \\
\hline Q21_9 Bikes are convenient \\
\hline Q21_10 I am a bike advocate \\
\hline
\end{tabular}


Table 12: E-Scooter Attitude Factor Item Loadings

E-Scooter Attitude Factor

Q28_1 I enjoy riding an e-scooter

0.75

Q28_2 I feel safe riding an e-

scooter

0.61

Q28_3r REVERSED E-Scooters are

ugly

Q28_4 I am an e-scooter

commuter

0.41

Q28_5r REVERSED Most e-scooter

users ride recklessly

Q28_6r REVERSED I will not ride

somewhere if there are no

dedicated lanes

Q28_7r REVERSED E-Scooter

users cause unsafe situations for

pedestrians

Q28_8 I would use an e-scooter

more often if I knew there was

always one available close by

0.65

Q28_9 I think that riding an escooter helps the environment

0.51

Q28_10 Riding an e-scooter is

$\mathrm{cool}$

0.77

Q28_11 E-Scooters are

convenient

0.63 
Table 13: MAX Attitude Factor Item Loadings

\begin{tabular}{lc} 
& MAX Attitude Factor \\
\hline Q34_1 I enjoy riding MAX & 0.81 \\
\hline Q34_2 I feel safe riding MAX & 0.74 \\
Q34_3 I feel safe waiting at the & \\
MAX station & 0.69
\end{tabular}

\begin{tabular}{|c|c|}
\hline $\begin{array}{l}\text { Q34_4 I feel comfortable while } \\
\text { riding MAX (Temperature, seat, } \\
\text { space, etc.) }\end{array}$ & 0.74 \\
\hline Q34_5 I am a transit commuter & 0.44 \\
\hline $\begin{array}{l}\text { Q34_6 I am glad to have the time } \\
\text { to do other things while riding } \\
\text { MAX }\end{array}$ & 0.60 \\
\hline $\begin{array}{l}\text { Q34_7 MAX comes frequently } \\
\text { enough for me to use it } \\
\text { spontaneously }\end{array}$ & 0.51 \\
\hline $\begin{array}{l}\text { Q34_8 I think that riding MAX } \\
\text { helps the environment }\end{array}$ & 0.51 \\
\hline Q34_9 Riding MAX is cool & 0.65 \\
\hline $\begin{array}{l}\text { Q34_10r REVERSED Transit is } \\
\text { primarily for people with lower } \\
\text { incomes }\end{array}$ & \\
\hline Q34_11 MAX is convenient & 0.62 \\
\hline
\end{tabular}

\subsubsection{Calculated Latent Variable Scores}

Next, we used information about the factor loadings to compute factor score estimates for each respondent using the Thurstone (1935) regression approach. As summarized by DiStefano, Zhu, and Mîndrilă (2009), in this method, the factor scores are the dependent variables of a regression equation. The independent variables are the standardized individual item scores, and the regression parameters are the inverse of the product of the observed variable correlation matrix and the factor loadings matrix. 
The resulting scores are standardized to a mean of zero and a standard deviation of the squared multiple correlation between factors and variables. The resulting factor score estimates can then be used as independent variables in further regression analyses.

\subsubsection{Structural Equation Modelling (SEM)}

It is also possible to more directly incorporate latent factors in models through the use of structural equation modelling (SEM), which eliminates the need to create calculated score values (Fabrigar and Wegener 2012, chap. 2). However, it became quite complex when attempting to use SEM methods for ordinal logit and multinomial logit (MNL) regression models. Integrated Choice and Latent Variable (ICLV) SEM methods have recently been used to combine MNL models with latent variables, however these models are computationally expensive and were difficult for us to implement due to the need to obtain costly software to perform.

For these reasons, we elected to perform a set of SEM models using the $\mathrm{R}$ package lavaan (Rosseel 2012) to compare with the OLS models that made use of the unrefined and refined latent factor index estimates. As discussed in section 4.2.7, this comparison showed that the models using calculated latent variable scores performed similarly to the SEM models.

The SEM models were implemented according to the general framework shown in Figure 16. All measured elements are represented by squares, including the scale items, covariates, and the dependent variable. Each measured element displays some observed unexplained error (e), and SEM attempts to control for this. The latent factors 
are represented by circles. Since they are not directly measured, they do not possess unexplained error, however their true values can only be approximated. The arrows indicate that the scale items and independent variable are functions of the latent variables. The dependent variable is also a function of the other directly measured covariates. The SEM also controls for inter-item covariance; however, we have not reported this for simplicity's sake. The advantage of this type of model is that the intermediate step of factor score estimation is eliminated. Yet, the previous knowledge gained from the PCA is required in order to specify how many latent factors should be modelled. 


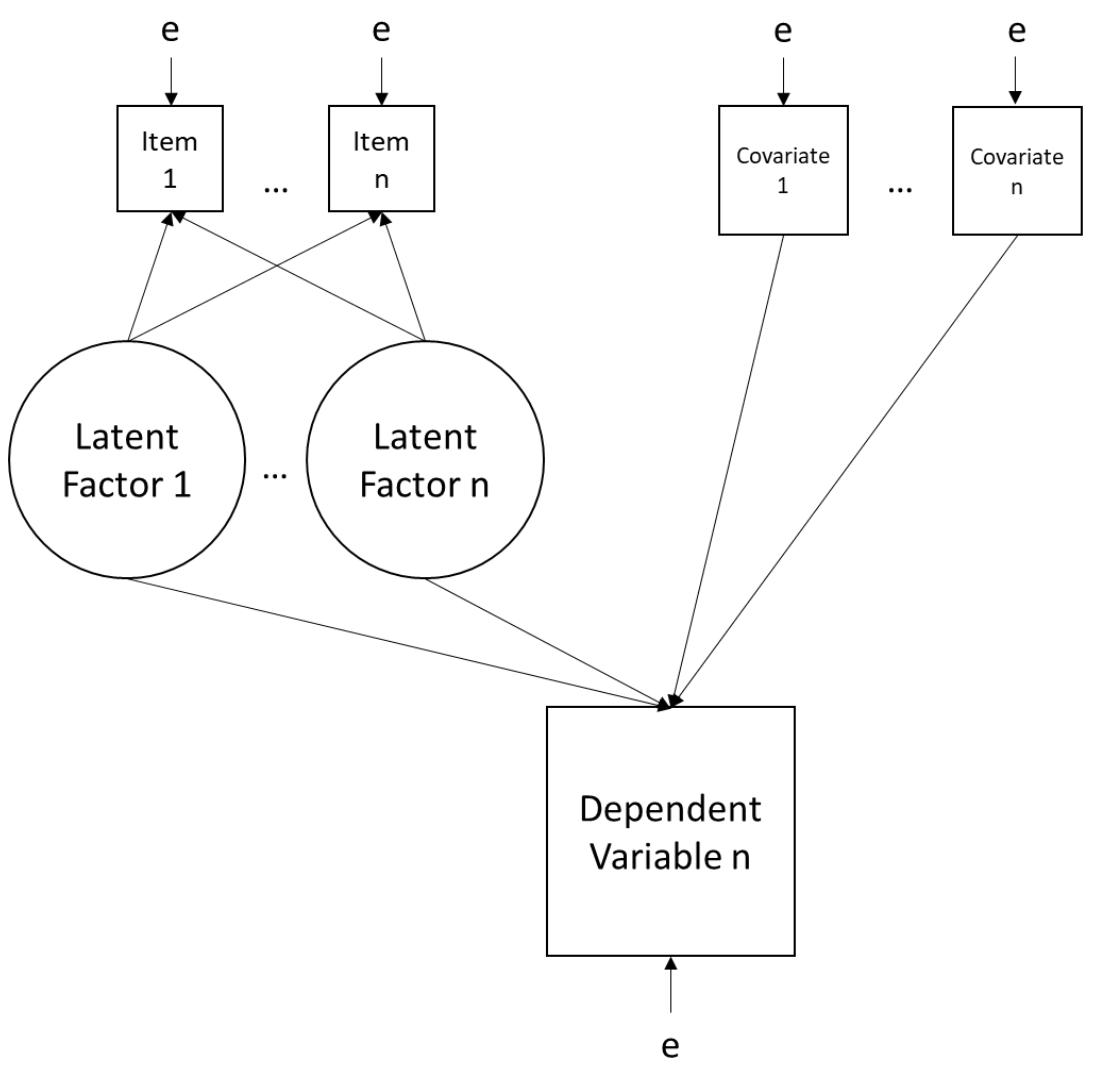

Figure 16: SEM path diagram framework

\subsubsection{Index method choice}

In order to select a latent variable estimation method for all model types, we performed a comparison of the propensity to switch score OLS models using the sum, mean, EFA factor score regression calculation, and SEM latent factor analysis methods.

These models are shown in Appendix B. We observed that parameters that were significant tended to stay significant and of the same order of magnitude (where standardized) across all estimation types, signaling that the calculation methods were comparable to each other. $\mathrm{R}^{2}$ values remained similar across all methods, although we did not have an $\mathrm{R}^{2}$ value from the SEM method to compare. For these reasons, we chose 
the EFA factor score regression calculation method to compute latent variable estimates. This method provides a less simplistic "weighted" technique for calculating the latent variable estimates, and it eliminates the need to generate more complex ICLV models for the stated choice experiment that would be necessary if using an SEM method.

\subsection{Number of Trips Ordinal Regression}

In order to understand how demographics, PSU-specific travel behavior, and latent attitudes are connected to total mode-specific trip frequency, we asked respondents to indicate how many one-way trips they took with a specific mode within the previous 7 days. Next, we generated ordinal logit regression models in order to describe the relationships of each independent variable to the independent variable of trip frequency. (Trip frequency was defined by categories of trip count ranges, which lends itself to ordinal regression.) In this section, we will describe the results by each primary mode: car, bike, e-scooter, and MAX. These modes were selected because they were used as alternatives in the stated choice experiment, and could be used to compare against the e-scooter mode. Each model was constructed hierarchically in four steps such that the contributions of each additional set of predictors could be seen. To save space, only significant parameters are reported in this section. The full models, including non-significant predictors, are reported in Appendix D. Each model was generated using the following predictors: demographics (income, race and ethnicity, gender, driver's license status, age, married status, number of children, general state of 
health, physical limitations status), PSU-specific travel behavior (number of days per week comes to PSU, home distance from campus, main mode of transportation to campus), latent attitudinal indicators (car, bike, e-scooter, MAX), and latent mode decision factors ("comfort and safety" and "exercise and environmental impact"). Odds ratios that are greater than one indicate a higher likelihood of a respondent answering one of the higher categories. Odds ratios that are less than one indicate a lower likelihood of a respondent answering one of the higher categories. The overall distribution of responses is shown in Figure 17.

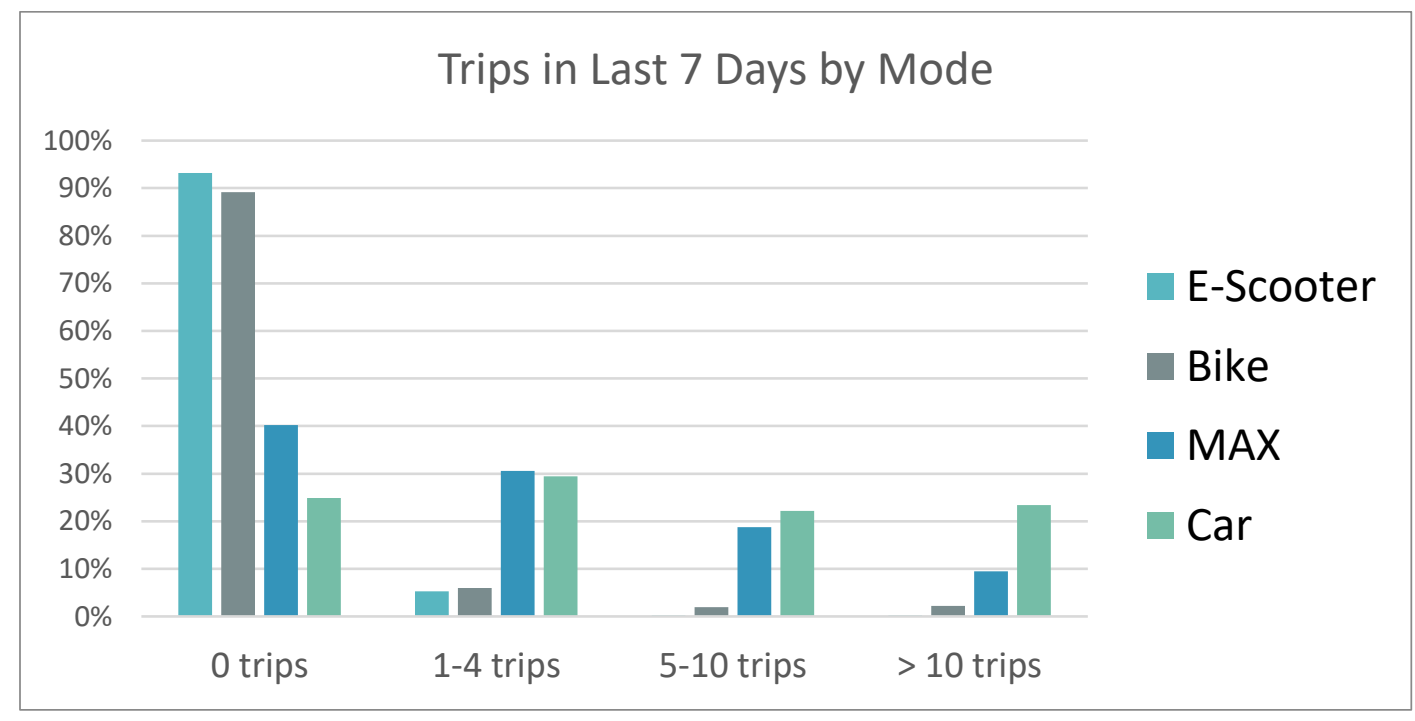

Figure 17: Distribution of responses for frequency of trips

Beginning with the car models, chi-squared tests of model fit revealed that each of the four models fit the data significantly better than a model with no predictors. The deviance reduced with each step, showing that the additional predictors contribute to an improved model. The model fit test results are shown in Table 14. 
Table 14: Car Model Fits

\begin{tabular}{|c|c|c|c|c|c|}
\hline Model & & Deviance (-2LL) & $\chi^{2}$ & df & $p$ \\
\hline \multicolumn{6}{|c|}{ Intercept } \\
\hline \multirow[t]{5}{*}{ Only } & & 5425.05 & & & \\
\hline & 1 & 4562.02 & 863.03 & 18 & 0.000 \\
\hline & 2 & 3595.84 & 1829.21 & 29 & 0.000 \\
\hline & 3 & 3367.92 & 2057.14 & 33 & 0.000 \\
\hline & 4 & 3271.30 & 2153.76 & 35 & 0.000 \\
\hline
\end{tabular}

The significant predictor odds ratios and their resulting standard errors are shown in Table 15. Items that predicted a significantly higher likelihood of taking more car trips included having a driver's license, home distance from campus, Car Attitude, and MAX Attitude. Respondents that were Asian only or Hispanic or Latinx/Latino/Latina only, came to campus more frequently during the week, took active transportation or public transit as their primary mode to get to PSU, or valued exercise and environmental impact when travelling to PSU had a lower likelihood of taking more car trips in the last 7 days. Native Hawaiian or Pacific Islander only respondents were substantially more likely than white respondents to take more car trips in the last 7 days, however this result is suspicious, considering only 13 such students responded to the survey out of 1968 useable responses. Overall, model 4 accounted for approximately $80 \%$ in the variance of the data, Nagelkerke pseudo- $R^{2}=0$. 
Table 15: Car Trips Ordinal Logit Regression Models (sig. predictors only)

\begin{tabular}{|c|c|c|c|c|c|c|c|c|}
\hline \multirow[b]{2}{*}{ Predictors } & \multicolumn{2}{|c|}{$\begin{array}{l}\text { 1. Frequency of } \\
\text { trips in last } 7 \\
\text { days, mode: } \\
\text { Car. Terms: } \\
\text { Demographics }\end{array}$} & \multicolumn{2}{|c|}{$\begin{array}{l}\text { 2. Frequency of } \\
\text { trips in last } 7 \\
\text { days, mode: } \\
\text { Car. Terms: } \\
\text { Demographics } \\
\text { + Current } \\
\text { travel behavior }\end{array}$} & \multicolumn{2}{|c|}{$\begin{array}{l}\text { 3. Frequency of } \\
\text { trips in last } 7 \\
\text { days, mode: } \\
\text { Car. Terms: } \\
\text { Demographics } \\
\text { + Current } \\
\text { travel behavior } \\
\text { + Mode } \\
\text { Attitudes }\end{array}$} & \multicolumn{2}{|c|}{$\begin{array}{l}\text { 4. Frequency of } \\
\text { trips in last } 7 \\
\text { days, mode: } \\
\text { Car. Terms: } \\
\text { Demographics } \\
\text { + Current } \\
\text { travel behavior } \\
\text { + Mode } \\
\text { Attitudes + } \\
\text { Decision } \\
\text { factors }\end{array}$} \\
\hline & $\begin{array}{c}\text { Odds } \\
\text { Ratios }\end{array}$ & $\begin{array}{l}\text { std. } \\
\text { Error }\end{array}$ & $\begin{array}{c}\text { Odds } \\
\text { Ratios }\end{array}$ & $\begin{array}{l}\text { std. } \\
\text { Error }\end{array}$ & $\begin{array}{l}\text { Odds } \\
\text { Ratios }\end{array}$ & $\begin{array}{l}\text { std. } \\
\text { Error }\end{array}$ & $\begin{array}{c}\text { Odds } \\
\text { Ratios }\end{array}$ & $\begin{array}{l}\text { std. } \\
\text { Error }\end{array}$ \\
\hline 0 trips $\mid 1-4$ trips & $0.38^{* * *}$ & 0.10 & $0.11^{* * *}$ & 0.39 & $0.11^{* * *}$ & 0.41 & $0.11^{* * *}$ & 0.42 \\
\hline 1-4 trips $\mid 5-10$ trips & $1.48^{* * *}$ & 0.10 & 0.62 & 0.39 & 0.66 & 0.40 & 0.65 & 0.42 \\
\hline $\begin{array}{l}5-10 \text { trips / More than } \\
10 \text { trips }\end{array}$ & $4.23^{* * *}$ & 0.11 & $2.31^{*}$ & 0.39 & $2.36^{*}$ & 0.40 & $2.36^{*}$ & 0.42 \\
\hline \multicolumn{9}{|l|}{ Demographics } \\
\hline \multicolumn{9}{|l|}{$\begin{array}{l}\text { Race and Ethnicity } \\
\text { (referent: White only) }\end{array}$} \\
\hline Asian only & $0.55^{* * *}$ & 0.13 & $0.54^{* * *}$ & 0.15 & $0.53^{* * *}$ & 0.16 & $0.57^{* * *}$ & 0.16 \\
\hline $\begin{array}{l}\text { Hispanic or } \\
\text { Latinx/Latino/Latina } \\
\text { only }\end{array}$ & 0.81 & 0.14 & $0.63^{* *}$ & 0.16 & $0.57^{* * *}$ & 0.16 & $0.59^{* *}$ & 0.17 \\
\hline $\begin{array}{l}\text { Native Hawaiian or } \\
\text { Pacific Islander only }\end{array}$ & 2.04 & 0.53 & $5.48^{*}$ & 0.69 & $5.19^{*}$ & 0.68 & $5.02^{*}$ & 0.68 \\
\hline \multicolumn{9}{|l|}{ Other Demographics } \\
\hline Has driver's license & & & $3.30^{* * *}$ & 0.15 & $2.86^{* * *}$ & 0.16 & $2.87^{* * *}$ & 0.16 \\
\hline \multicolumn{9}{|l|}{ Travel Behavior } \\
\hline \multicolumn{9}{|l|}{ Travel to PSU from home } \\
\hline $\begin{array}{l}\text { Number of days per } \\
\text { week comes to PSU }\end{array}$ & & & $0.81^{* * *}$ & 0.04 & $0.80^{* * *}$ & 0.04 & $0.80^{* * *}$ & 0.04 \\
\hline $\begin{array}{l}\text { Home distance from } \\
\text { campus }\end{array}$ & & & $1.03^{* * *}$ & 0.01 & $1.03^{* * *}$ & 0.01 & $1.03^{* * *}$ & 0.01 \\
\hline \multicolumn{9}{|l|}{$\begin{array}{l}\text { Main mode of } \\
\text { transportation to campus } \\
\text { (referent: Personal Car) }\end{array}$} \\
\hline Active Transportation & & & $0.11^{* * *}$ & 0.18 & $0.12^{* * *}$ & 0.19 & $0.12^{* * *}$ & 0.20 \\
\hline Public Transit & & & $0.30^{* * *}$ & 0.12 & $0.32^{* * *}$ & 0.13 & $0.31^{* * *}$ & 0.14 \\
\hline Other & & & $0.17^{* * *}$ & 0.36 & $0.22^{* * *}$ & 0.38 & $0.20^{* * *}$ & 0.38 \\
\hline
\end{tabular}




\begin{tabular}{|c|c|c|c|c|c|c|}
\hline \multicolumn{7}{|l|}{ Attitudinal Indicators } \\
\hline \multicolumn{7}{|l|}{$\begin{array}{l}\text { Latent Attitudes Factor } \\
\text { Score Estimates }\end{array}$} \\
\hline $\begin{array}{l}\text { Car (EFA factor score - } \\
\text { regression) }\end{array}$ & & & $1.36^{* * *}$ & 0.06 & $1.36^{* * *}$ & 0.07 \\
\hline $\begin{array}{l}\text { MAX (EFA factor score } \\
\text { - regression) }\end{array}$ & & & 1.13 & 0.07 & $1.15^{*}$ & 0.07 \\
\hline \multicolumn{7}{|l|}{$\begin{array}{l}\text { Latent Mode Decision } \\
\text { Factor Estimates }\end{array}$} \\
\hline $\begin{array}{l}\text { "Exercise and } \\
\text { environmental } \\
\text { impact" (EFA factor } \\
\text { score - regression) }\end{array}$ & & & & & $0.87^{*}$ & 0.06 \\
\hline $\begin{array}{l}\text { Observations } \\
\mathrm{R}^{2} \text { Nagelkerke }\end{array}$ & $\begin{array}{l}1690 \\
0.417\end{array}$ & $\begin{array}{l}1530 \\
0.718\end{array}$ & $\begin{array}{l}1446 \\
0.777\end{array}$ & & $\begin{array}{l}1411 \\
0.8\end{array}$ & \\
\hline
\end{tabular}


The chi-squared tests of fit for the bike models shown in Table 16 similarly tell us that each of the four models fit the data significantly better than a model with no predictors.

Table 16: Bike Model Fits

\begin{tabular}{lrllll}
\hline Model & & Deviance (-2LL) & $\chi^{2}$ & $\mathrm{df}$ & $\mathrm{p}$ \\
\hline Intercept & & & & & \\
Only & & 1674.72 & & & \\
& 1 & 1419.61 & 255.11 & 15 & 0.000 \\
& 2 & 1194.36 & 480.36 & 26 & 0.000 \\
& 3 & 962.87 & 711.85 & 30 & 0.000 \\
& 4 & 909.03 & 765.69 & 32 & 0.000 \\
\hline
\end{tabular}

The significant predictor odds ratios and their resulting standard errors are shown in Table 17. Items that predicted a significantly higher likelihood of taking more bike trips included Asian respondents, general state of health higher, taking active transportation to get to PSU regularly, and Bike Attitude. Respondents that are female, had more positive attitudes about cars, e-scooters, and MAX, and valued comfort and safety when choosing how to get to PSU had a lower likelihood of taking more bike trips in the last 7 days. Overall, model 4 accounted for approximately $55 \%$ in the variance of the data, Nagelkerke pseudo- $\mathrm{R}^{2}=0.553$. 
Table 17: Bike Trips Ordinal Logit Regression Models (sig. predictors only)

\begin{tabular}{|c|c|c|c|c|c|c|c|c|}
\hline \multirow[b]{2}{*}{ Predictors } & \multicolumn{2}{|c|}{$\begin{array}{c}\text { 1. Frequency of } \\
\text { trips in last } 7 \\
\text { days, mode: Bike. } \\
\text { Terms: } \\
\text { Demographics }\end{array}$} & \multicolumn{2}{|c|}{$\begin{array}{c}\text { 2. Frequency of } \\
\text { trips in last } 7 \\
\text { days, mode: Bike. } \\
\text { Terms: } \\
\text { Demographics + } \\
\text { Current travel } \\
\text { behavior }\end{array}$} & \multicolumn{2}{|c|}{$\begin{array}{l}\text { 3. Frequency of } \\
\text { trips in last } 7 \\
\text { days, mode: Bike. } \\
\text { Terms: } \\
\text { Demographics + } \\
\text { Current travel } \\
\text { behavior + Mode } \\
\text { Attitudes }\end{array}$} & \multicolumn{2}{|c|}{$\begin{array}{c}\text { 4. Frequency of } \\
\text { trips in last } 7 \\
\text { days, mode: Bike. } \\
\text { Terms: } \\
\text { Demographics + } \\
\text { Current travel } \\
\text { behavior + Mode } \\
\text { Attitudes + } \\
\text { Decision factors }\end{array}$} \\
\hline & $\begin{array}{c}\text { Odds } \\
\text { Ratios }\end{array}$ & $\begin{array}{l}\text { std. } \\
\text { Error }\end{array}$ & $\begin{array}{l}\text { Odds } \\
\text { Ratios }\end{array}$ & $\begin{array}{l}\text { std. } \\
\text { Error }\end{array}$ & $\begin{array}{l}\text { Odds } \\
\text { Ratios }\end{array}$ & $\begin{array}{l}\text { std. } \\
\text { Error }\end{array}$ & $\begin{array}{l}\text { Odds } \\
\text { Ratios }\end{array}$ & $\begin{array}{l}\text { std. } \\
\text { Error }\end{array}$ \\
\hline $\begin{array}{l}0 \text { trips|1-4 } \\
\text { trips }\end{array}$ & $4.96^{* * *}$ & 0.16 & $34.97^{* * *}$ & 0.7 & $43.29^{* * *}$ & 0.80 & $36.71^{* * *}$ & 0.85 \\
\hline $\begin{array}{l}1-4 \text { trips } \mid 5- \\
10 \text { trips }\end{array}$ & $12.73^{* * *}$ & 0.18 & $92.17^{* * *}$ & 0.7 & $139.41^{* * *}$ & 0.82 & $125.15^{* * *}$ & 0.86 \\
\hline $\begin{array}{l}5-10 \\
\text { trips |More } \\
\text { than } 10 \\
\text { trips }\end{array}$ & $24.84^{* * * *}$ & 0.21 & $188.68^{* * * *}$ & 0.71 & $343.38^{* * *}$ & 0.83 & $306.04^{* * *}$ & 0.88 \\
\hline \multicolumn{9}{|l|}{ Demographics } \\
\hline \multicolumn{9}{|l|}{$\begin{array}{l}\text { Race and } \\
\text { Ethnicity } \\
\text { (referent: } \\
\text { White only) }\end{array}$} \\
\hline Asian only & 0.98 & 0.23 & 1.19 & 0.27 & $2.23^{* *}$ & 0.30 & $2.03^{*}$ & 0.31 \\
\hline \multicolumn{9}{|l|}{$\begin{array}{l}\text { Gender } \\
\text { (referent: } \\
\text { Male) }\end{array}$} \\
\hline Female & $0.47^{* * *}$ & 0.17 & $0.46^{* * *}$ & 0.19 & $0.53^{* *}$ & 0.21 & $0.57^{* *}$ & 0.21 \\
\hline \multicolumn{9}{|l|}{$\begin{array}{l}\text { Other } \\
\text { Demographics }\end{array}$} \\
\hline $\begin{array}{l}\text { General } \\
\text { state of } \\
\text { health }\end{array}$ & & & $1.53^{* * *}$ & 0.1 & $1.47^{* * *}$ & 0.11 & $1.43^{* *}$ & 0.12 \\
\hline \multicolumn{9}{|l|}{ Travel Behavior } \\
\hline \multicolumn{9}{|l|}{$\begin{array}{l}\text { Main mode of } \\
\text { transportation } \\
\text { to campus } \\
\text { (referent: } \\
\text { Personal Car) }\end{array}$} \\
\hline $\begin{array}{l}\text { Active } \\
\text { Transportat } \\
\text { ion }\end{array}$ & & & $6.21^{* * *}$ & 0.32 & $3.74^{* * *}$ & 0.36 & $2.85^{* *}$ & 0.37 \\
\hline
\end{tabular}




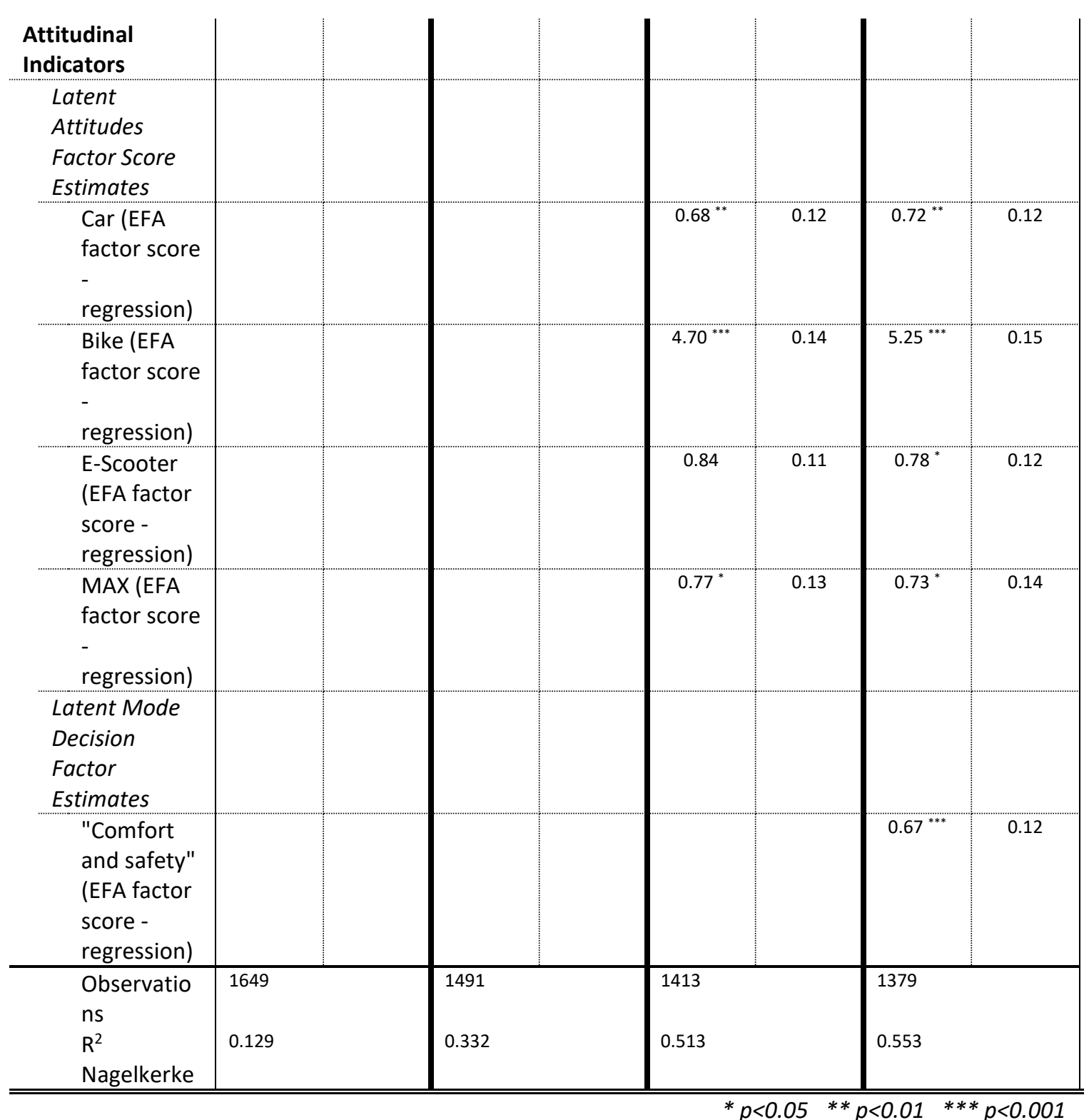


For the e-scooter models, we switched from using ordinal logit to a binary logit regression. We made this choice because there were only eight respondents that had taken between 5-10 or more than 10 e-scooter trips in the last 7 days. We transformed the data such that it belonged to two groups, 0 trips and at least 1 trip in the last seven days, a binary response. Odds ratios should be interpreted as a change in likelihood that a respondent would take at least one e-scooter trip in the last seven days. The chisquared tests of fit for the e-scooter models shown in Table 18 show that each of the four models fit the data significantly better than a model with no predictors.

Table 18: E-Scooter Model Fits

\begin{tabular}{lrrrrr}
\hline Model & \multicolumn{2}{c}{ Deviance (-2LL) } & \multicolumn{1}{c}{$\chi^{2}$} & $\mathrm{df}$ & $\mathrm{p}$ \\
\hline $\begin{array}{l}\text { Intercept } \\
\text { Only }\end{array}$ & & & & & \\
& 1 & 700.78 & & & \\
& 2 & 678.54 & 22.24 & 9 & 0.008 \\
& 3 & 590.86 & 109.92 & 20 & 0.000 \\
& 4 & 458.46 & 242.31 & 24 & 0.000 \\
& 442.06 & 258.72 & 26 & 0.000 \\
\hline
\end{tabular}

The significant predictor odds ratios and their resulting standard errors are shown in

Table 19. Items that predicted a significantly higher likelihood of taking more escooter trips included having physical limitations that make riding a bicycle or an escooter difficult and E-Scooter Attitude. Respondents that lived farther from campus and had smaller attitude scores towards bikes had a lower likelihood of taking more escooter trips in the last 7 days. Overall, model 4 accounted for approximately $20 \%$ in the 
variance of the data, Tjur pseudo- $R^{2}=0.198$. This pseudo- $R^{2}$ score was much lower than the other models.

Table 19: E-Scooter Trips Ordinal Logit Regression Models (sig. predictors only)

\begin{tabular}{|c|c|c|c|c|c|c|c|c|}
\hline \multirow[b]{2}{*}{ Predictors } & \multicolumn{2}{|c|}{$\begin{array}{l}\text { 1. Frequency of } \\
\text { trips in last } 7 \\
\text { days, mode: E- } \\
\text { Scooter. } \\
\text { Terms: } \\
\text { Demographics }\end{array}$} & \multicolumn{2}{|c|}{$\begin{array}{l}\text { 2. Frequency of } \\
\text { trips in last } 7 \\
\text { days, mode: E- } \\
\text { Scooter. } \\
\text { Terms: } \\
\text { Demographics } \\
\text { + Current } \\
\text { travel behavior }\end{array}$} & \multicolumn{2}{|c|}{$\begin{array}{l}\text { 3. Frequency of } \\
\text { trips in last } 7 \\
\text { days, mode: E- } \\
\text { Scooter. } \\
\text { Terms: } \\
\text { Demographics } \\
\text { + Current } \\
\text { travel behavior } \\
\text { + Mode } \\
\text { Attitudes }\end{array}$} & \multicolumn{2}{|c|}{$\begin{array}{l}\text { 4. Frequency of } \\
\text { trips in last } 7 \\
\text { days, mode: E- } \\
\text { Scooter. } \\
\text { Terms: } \\
\text { Demographics } \\
\text { + Current } \\
\text { travel behavior } \\
\text { + Mode } \\
\text { Attitudes + } \\
\text { Decision } \\
\text { factors }\end{array}$} \\
\hline & $\begin{array}{l}\text { Odds } \\
\text { Ratios }\end{array}$ & $\begin{array}{l}\text { std. } \\
\text { Error }\end{array}$ & $\begin{array}{l}\text { Odds } \\
\text { Ratios }\end{array}$ & $\begin{array}{l}\text { std. } \\
\text { Error }\end{array}$ & $\begin{array}{l}\text { Odds } \\
\text { Ratios }\end{array}$ & $\begin{array}{l}\text { std. } \\
\text { Error }\end{array}$ & $\begin{array}{l}\text { Odds } \\
\text { Ratios }\end{array}$ & $\begin{array}{l}\text { std. } \\
\text { Error }\end{array}$ \\
\hline (Intercept) & $0.09^{* * *}$ & 0.21 & $0.07^{* *}$ & 0.98 & $0.01^{* * *}$ & 1.07 & $0.01^{* * *}$ & 1.15 \\
\hline \multicolumn{9}{|l|}{ Demographics } \\
\hline \multicolumn{9}{|l|}{ Other Demographics } \\
\hline $\begin{array}{l}\text { Has physical } \\
\text { limitations that make } \\
\text { riding a bicycle or an } \\
\text { e-scooter difficult }\end{array}$ & & & 1.85 & 0.37 & $2.34^{*}$ & 0.41 & $2.60^{*}$ & 0.42 \\
\hline \multicolumn{9}{|l|}{ Travel Behavior } \\
\hline \multicolumn{9}{|l|}{ Travel to PSU from home } \\
\hline $\begin{array}{l}\text { Home distance from } \\
\text { campus }\end{array}$ & & & $0.95^{*}$ & 0.02 & $0.94^{* *}$ & 0.02 & $0.94^{* *}$ & 0.02 \\
\hline \multicolumn{9}{|l|}{ Attitudinal Indicators } \\
\hline \multicolumn{9}{|l|}{$\begin{array}{l}\text { Latent Attitudes Factor } \\
\text { Score Estimates }\end{array}$} \\
\hline $\begin{array}{l}\text { Bike (EFA factor score } \\
\text { - regression) }\end{array}$ & & & & & 0.64 ** & 0.17 & $0.67^{*}$ & 0.18 \\
\hline $\begin{array}{l}\text { E-Scooter (EFA factor } \\
\text { score - regression) }\end{array}$ & & & & & $5.35^{* * *}$ & 0.19 & $5.47^{\cdots *}$ & 0.2 \\
\hline $\begin{array}{l}\text { Observations } \\
R^{2} \text { Tjur }\end{array}$ & $\begin{array}{l}1485 \\
0.02\end{array}$ & & $\begin{array}{l}1347 \\
0.044\end{array}$ & & $\begin{array}{l}1283 \\
0.197\end{array}$ & & $\begin{array}{l}1253 \\
0.198\end{array}$ & \\
\hline
\end{tabular}


The chi-squared tests of fit for the MAX models shown in Table 20 similarly tell us that each of the four models fit the data significantly better than a model with no predictors.

Table 20: MAX Model Fits

\begin{tabular}{lrrrrr}
\hline Model & \multicolumn{2}{c}{ Deviance (-2LL) } & $\chi^{2}$ & $\mathrm{df}$ & $\mathrm{p}$ \\
\hline $\begin{array}{l}\text { Intercept } \\
\text { Only }\end{array}$ & & & & & \\
& 1 & 4948.74 & & & \\
& 2 & 3237.78 & 1710.96 & 29 & 0.000 \\
& 3 & 3005.85 & 1942.88 & 33 & 0.000 \\
& 4 & 2927.35 & 2021.39 & 35 & 0.000 \\
\hline
\end{tabular}

The significant predictor odds ratios and their resulting standard errors are shown in Table 21. Items that predicted a significantly higher likelihood of taking more MAX trips included Asian and Black race or ethnicities, frequency of travel to PSU, distance from PSU, using active transportation or transit as the primary mode to get to PSU, and positive MAX Attitude. Respondents that were married or living with a partner or had a more positive Bike Attitude had a lower likelihood of taking more MAX trips in the last 7 days. Overall, model 4 accounted for approximately $78 \%$ in the variance of the data, Nagelkerke pseudo- $\mathrm{R}^{2}=0.785$. 
Table 21: MAX Trips Ordinal Logit Regression Models (sig. predictors only)

\begin{tabular}{|c|c|c|c|c|c|c|c|c|}
\hline \multirow[b]{2}{*}{ Predictors } & \multicolumn{2}{|c|}{$\begin{array}{l}\text { 1. Frequency } \\
\text { of trips in last } \\
7 \text { days, mode: } \\
\text { MAX. Terms: } \\
\text { Demographics }\end{array}$} & \multicolumn{2}{|c|}{$\begin{array}{l}\text { 2. Frequency } \\
\text { of trips in last } \\
7 \text { days, mode: } \\
\text { MAX. Terms: } \\
\text { Demographics } \\
\text { + Current } \\
\text { travel behavior }\end{array}$} & \multicolumn{2}{|c|}{$\begin{array}{l}\text { 3. Frequency of } \\
\text { trips in last } 7 \\
\text { days, mode: } \\
\text { MAX. Terms: } \\
\text { Demographics } \\
\text { + Current } \\
\text { travel behavior } \\
\text { + Mode } \\
\text { Attitudes }\end{array}$} & \multicolumn{2}{|c|}{$\begin{array}{l}\text { 4. Frequency } \\
\text { of trips in last } \\
7 \text { days, mode: } \\
\text { MAX. Terms: } \\
\text { Demographics } \\
\text { + Current } \\
\text { travel behavior } \\
\text { + Mode } \\
\text { Attitudes + } \\
\text { Decision } \\
\text { factors }\end{array}$} \\
\hline & $\begin{array}{c}\text { Odds } \\
\text { Ratios }\end{array}$ & $\begin{array}{l}\text { std. } \\
\text { Error }\end{array}$ & $\begin{array}{c}\text { Odds } \\
\text { Ratios }\end{array}$ & $\begin{array}{l}\text { std. } \\
\text { Error }\end{array}$ & $\begin{array}{l}\text { Odds } \\
\text { Ratios }\end{array}$ & $\begin{array}{l}\text { std. } \\
\text { Error }\end{array}$ & $\begin{array}{l}\text { Odds } \\
\text { Ratios }\end{array}$ & $\begin{array}{l}\text { std. } \\
\text { Error }\end{array}$ \\
\hline 0 trips|1-4 trips & $0.64^{* * *}$ & 0.1 & 10.39 & 0.41 & $7.00^{* * *}$ & 0.43 & $8.00^{* * *}$ & 0.45 \\
\hline 1-4 trips $\mid 5-10$ trips & $2.49^{* * *}$ & 0.1 & $\underset{* * *}{66.02}$ & 0.42 & 47.92 & 0.44 & 54.30 & 0.45 \\
\hline $\begin{array}{l}5-10 \text { trips / More than } \\
10 \text { trips }\end{array}$ & 10.03 & 0.12 & $\underset{* * *}{348.39}$ & 0.43 & $\underset{* * *}{260.20}$ & 0.45 & $\underset{* * *}{294.89}$ & 0.47 \\
\hline \multicolumn{9}{|l|}{ Demographics } \\
\hline \multicolumn{9}{|l|}{$\begin{array}{l}\text { Race and Ethnicity } \\
\text { (referent: White only) }\end{array}$} \\
\hline Asian only & $1.94^{* * *}$ & 0.13 & 1.33 & 0.16 & $1.39^{*}$ & 0.16 & $1.39^{*}$ & 0.17 \\
\hline Black only & $3.06^{* * *}$ & 0.32 & $2.99^{* *}$ & 0.35 & $2.83^{* *}$ & 0.36 & $2.89^{* *}$ & 0.36 \\
\hline \multicolumn{9}{|l|}{ Other Demographics } \\
\hline $\begin{array}{l}\text { Is married or living } \\
\text { with partner }\end{array}$ & & & 0.77 & 0.14 & $0.72^{*}$ & 0.15 & $0.74^{*}$ & 0.15 \\
\hline \multicolumn{9}{|l|}{ Travel Behavior } \\
\hline \multicolumn{9}{|l|}{ Travel to PSU from home } \\
\hline $\begin{array}{l}\text { Number of days per } \\
\text { week comes to PSU }\end{array}$ & & & $1.23^{* * *}$ & 0.04 & $1.22^{* * *}$ & 0.04 & $1.24^{* * *}$ & 0.04 \\
\hline $\begin{array}{l}\text { Home distance from } \\
\text { campus }\end{array}$ & & & $1.05^{* * *}$ & 0.01 & $1.05^{* * *}$ & 0.01 & $1.05^{* * *}$ & 0.01 \\
\hline \multicolumn{9}{|l|}{$\begin{array}{l}\text { Main mode of } \\
\text { transportation to campus } \\
\text { (referent: Personal Car) }\end{array}$} \\
\hline Active Transportation & & & $5.70^{* * *}$ & 0.19 & $5.30^{* * *}$ & 0.21 & $5.21^{* * *}$ & 0.22 \\
\hline Public Transit & & & $\underset{* * *}{17.31}$ & 0.15 & 14.22 & 0.16 & 14.46 & 0.16 \\
\hline Other & & & $6.24^{* * *}$ & 0.36 & $5.98^{* * *}$ & 0.38 & $5.88^{* * *}$ & 0.38 \\
\hline
\end{tabular}




\begin{tabular}{|c|c|c|c|c|c|c|}
\hline \multicolumn{7}{|l|}{ Attitudinal Indicators } \\
\hline $\begin{array}{l}\text { Latent Attitudes Factor } \\
\text { Score Estimates }\end{array}$ & & & & & & \\
\hline $\begin{array}{l}\text { Bike (EFA factor score - } \\
\text { regression) }\end{array}$ & & & $0.83^{* *}$ & 0.07 & $0.86^{*}$ & 0.07 \\
\hline $\begin{array}{l}\text { MAX (EFA factor score } \\
\text { - regression) }\end{array}$ & & & $1.56^{* * *}$ & 0.07 & $1.57^{* * *}$ & 0.07 \\
\hline $\begin{array}{l}\text { Observations } \\
R^{2} \text { Nagelkerke }\end{array}$ & $\begin{array}{l}1684 \\
0.385\end{array}$ & $\begin{array}{l}1527 \\
0.701\end{array}$ & $\begin{array}{l}1446 \\
0.764\end{array}$ & & $\begin{array}{l}1411 \\
0.785\end{array}$ & \\
\hline
\end{tabular}


Overall, the results indicated that current travel behavior to PSU was strongly related to overall frequency of trips using certain modes outside of commuting to PSU. For example, those that took active transportation or public transit as their main mode of transportation to PSU were significantly less likely to take more car trips during a week. Those that took active transportation as their primary mode to PSU were much more likely to have taken a greater number of bike trips during the week. Those that took active transportation or public transit as their primary mode of transportation to PSU were substantially more likely to have taken more MAX trips in the last week.

Distance of respondent's home from PSU's campus also played a role in usage of specific modes. Respondents with homes that were farther from campus were slightly more likely to take more car trips and MAX trips in the last seven days. Respondents with homes that were farther from campus were less likely to take at least one escooter trip in the last seven days. This could be due to the distribution of e-scooters within the city, with the denser concentration of e-scooters usually found in the downtown core.

Looking at demographics, gender only played a significant role in predicting bike trips, with female respondents less likely to take more bike trips in the last seven days compared to males. Compared to White respondents, Asian respondents were less likely to take car trips and more likely to take more bike or MAX trips. Hispanic respondents were less likely to take car trips. Black respondents were more likely to take more MAX 
trips. Those respondents married or living with a partner were less likely to take more MAX trips. Respondents with a driver's license were more likely to take more car trips. Respondents with a better general state of health were more likely to have taken more bike trips. Interestingly, respondents that stated that they had physical limitations that make riding a bicycle or an e-scooter difficult were more likely to have ridden an escooter at least once in the previous seven days. Perhaps e-scooters offer users a less taxing method of getting around.

Latent attitudes and decision factors also played a strong role in explaining how frequently respondents made trips of specific modes. Users that felt more positively about cars were more likely to have taken more car trips and less likely to have taken more bike trips. Users that felt more positively about bikes were more likely to take more bike trips and less likely to have taken more MAX trips or at least one e-scooter trip. Users that felt more positively about e-scooters were less likely to have taken more bike trips and much more likely to have taken at least one e-scooter trip. Lastly, users that felt more positively about MAX were more likely to have taken more car and MAX trips and less likely to have taken more bike trips. It seems that attitudes tended to pit modes against each other except in the case of MAX, where positive MAX Attitude was linked to both more car trips and MAX trips. It follows that MAX champions tended to use both MAX and cars more, yet not all car champions used MAX more. Lastly, those that valued personal comfort and safety in choosing their mode when traveling to PSU 
took fewer bike trips. Those that valued exercise and environmental impact in choosing their mode when traveling to PSU took fewer car trips.

\subsection{Propensity to Switch Linear Regression}

In this section, we explore how demographics, travel behavior, and latent attitudes relate to respondent's stated "propensity to switch" to a different transportation mode in the event that their primary mode of transportation to PSU became unavailable. Propensity to switch was rated on a score of 1 to 10 and was selected directly by the respondent using a slider. Respondents were shown sliders for propensity to switch to modes only if they did not already take that mode as their primary mode of transportation to PSU. Grouped existing primary mode of transportation to PSU was used as one of the independent variables in the models. Recall that this variable was grouped into four more broad categories, including Personal Car, Active Transportation, Public Transit, or Other. Additionally, recall that the dependent variable in these models is Personal Car, Bike, E-Scooter, and MAX. Certain cases arose and are retained in the model where a person who took one mode were still shown a similar mode slider. For example, users that took public transit (bus), were still shown the MAX question. Another example is where a user selected "dropped off (Uber/Lyft/Taxi)". In this case, the respondent's primary mode was grouped in with "personal car," however they were still shown the propensity to switch to personal car question, given that a mode change would still take place in this situation. The complete display logic and remaining modes within the grouped variable are shown in Table 22 . 
Table 22: Display logic, propensity to switch questions

\begin{tabular}{|l|l|l|l|}
\hline $\begin{array}{c}\text { Propensity to } \\
\text { switch to this } \\
\text { mode }\end{array}$ & $\begin{array}{c}\text { Hide question if this } \\
\text { mode is already } \\
\text { primary mode to } \\
\text { PSU }\end{array}$ & $\begin{array}{c}\text { Grouped } \\
\text { Variable Name }\end{array}$ & $\begin{array}{c}\text { Remaining similar modes that are } \\
\text { included in grouped variable }\end{array}$ \\
\hline Bar & $\begin{array}{l}\text { Drive alone, Carpool } \\
\text { (two or more } \\
\text { persons) }\end{array}$ & Personal Car & $\begin{array}{l}\text { Dropped off (Uber/Lyft/Taxi), } \\
\text { Motorcycle/Moped }\end{array}$ \\
\hline E-Scooter & $\begin{array}{l}\text { Shared E-Scooter, } \\
\text { Private E-Scooter }\end{array}$ & $\begin{array}{l}\text { Active } \\
\text { Transportation }\end{array}$ & $\begin{array}{l}\text { Walk, Bike Share (BIKETOWN), Shared } \\
\text { E-Scooter (Lime, Bolt, Skip, Bird), } \\
\text { Private E-Scooter (e-Scooter I own), E- } \\
\text { Bike (that I own) }\end{array}$ \\
\hline MAX Light Rail & MAX Light Rail & Public Transit & Bus, Portland Street Car \\
\hline
\end{tabular}

We will describe the results by each primary mode: car, bike, e-scooter, and

MAX. These modes were selected because they were used as alternatives in the stated choice experiment. Each model was constructed hierarchically in four steps such that the contributions of each additional set of predictors could be seen. To save space, only significant parameters are reported in this section. The full models, including nonsignificant predictors, are reported in Appendix C. Each model was generated using the following predictors: demographics (income, race and ethnicity, gender, driver's license status, age, married status, number of children, general state of health, physical limitations status), travel behavior (number of days per week comes to PSU, home distance from campus, main mode of transportation to campus, and number of one-way trips by mode in the last 7 days), latent attitudinal indicators (car, bike, e-scooter, MAX), and latent mode decision factors ("comfort and safety" and "exercise and 
environmental impact"). The overall distribution of the results for each mode is shown in Figure 18.

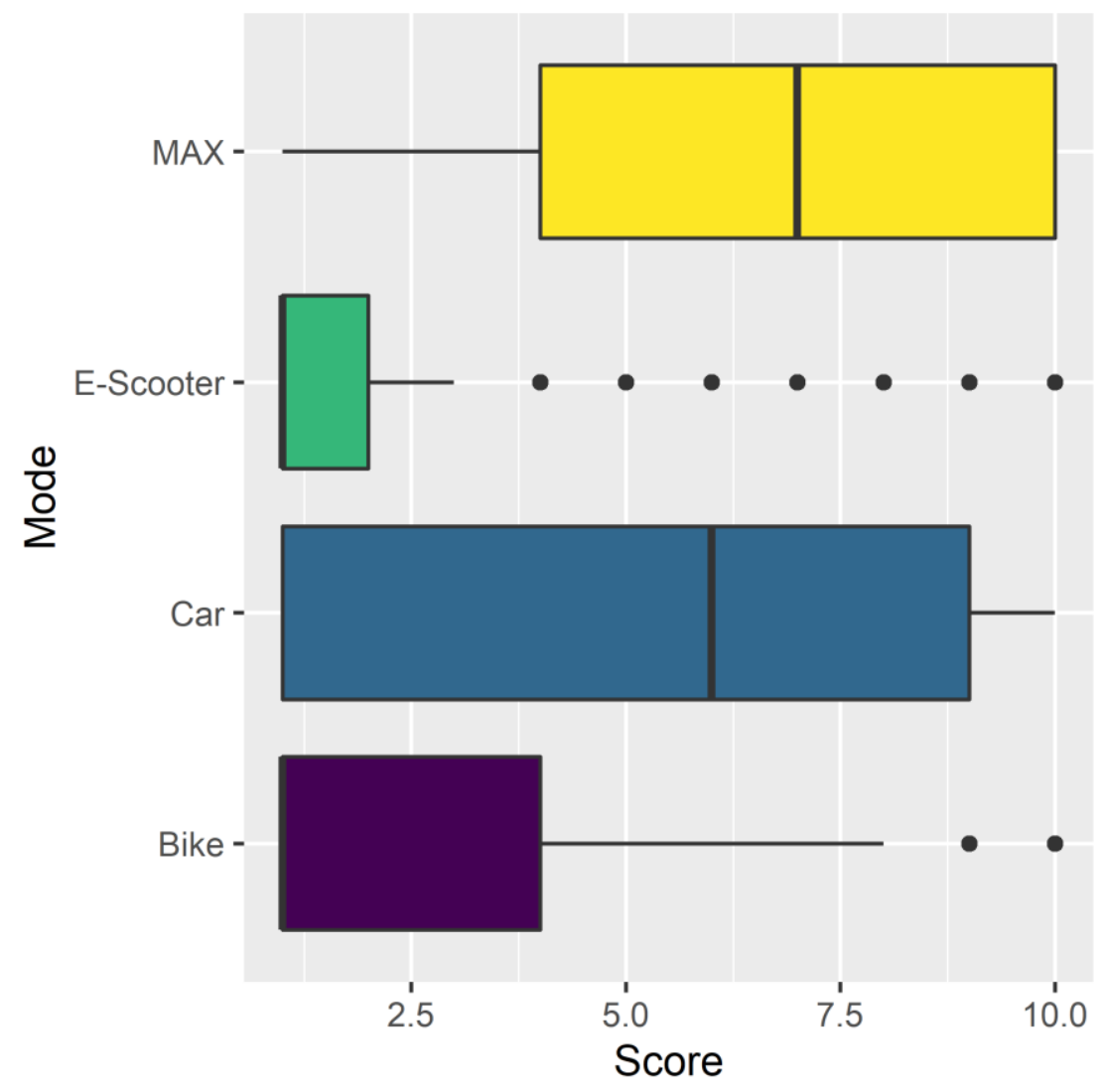

Figure 18: Propensity to Switch Scale Scores

Beginning again with the car models, the results are shown in Table 23. Overall, the full model explained $41 \%$ of the variance in the data, $R^{2}=0.407$. Asian respondents, driver's license status, physical limitations that make riding a bicycle or an e-scooter difficult, living farther from campus, number of total car trips in the previous 7 days, and attitude towards cars were positively and significantly related to propensity to switch to using a car. Number of bike trips in the previous 7 days and MAX Attitude was negatively and significantly related to propensity to switch to using a car. 
Table 23: Propensity to Switch to Car OLS Regression Models (sig. predictors only)

\begin{tabular}{|c|c|c|c|c|c|c|c|c|c|c|c|c|}
\hline \multirow[b]{2}{*}{ Predictors } & \multicolumn{3}{|c|}{$\begin{array}{l}\text { 1. Propensity to } \\
\text { switch to Car } \\
\text { Demographics }\end{array}$} & \multicolumn{3}{|c|}{$\begin{array}{l}\text { 2. Propensity to } \\
\text { switch to Car } \\
\text { Demographics + } \\
\text { Current travel } \\
\text { behavior }\end{array}$} & \multicolumn{3}{|c|}{$\begin{array}{l}\text { 3. Propensity to } \\
\text { switch to Car } \\
\text { Demographics + } \\
\text { Current travel } \\
\text { behavior + Mode } \\
\text { Attitudes }\end{array}$} & \multicolumn{3}{|c|}{$\begin{array}{l}\text { 4. Propensity to } \\
\text { switch to Car } \\
\text { Demographics + } \\
\text { Current travel } \\
\text { behavior + Mode } \\
\text { Attitudes + } \\
\text { Decision factors }\end{array}$} \\
\hline & $\begin{array}{l}\text { Esti } \\
\text { mat } \\
\text { es }\end{array}$ & $\begin{array}{l}\text { std. } \\
\text { Erro } \\
r\end{array}$ & $\begin{array}{c}\text { std. } \\
\text { Bet } \\
a\end{array}$ & $\begin{array}{c}\text { Esti } \\
\text { mat } \\
\text { es }\end{array}$ & $\begin{array}{l}\text { std. } \\
\text { Erro } \\
r\end{array}$ & $\begin{array}{c}\text { std. } \\
\text { Bet } \\
a\end{array}$ & $\begin{array}{c}\text { Esti } \\
\text { mat } \\
\text { es }\end{array}$ & $\begin{array}{l}\text { std. } \\
\text { Erro } \\
r\end{array}$ & $\begin{array}{c}\text { std. } \\
\text { Bet } \\
a\end{array}$ & $\begin{array}{l}\text { Esti } \\
\text { mat } \\
\text { es }\end{array}$ & $\begin{array}{l}\text { std. } \\
\text { Erro } \\
r\end{array}$ & $\begin{array}{c}\text { std. } \\
\text { Bet } \\
a\end{array}$ \\
\hline (Intercept) & 4.87 & 0.23 & 0 & $\begin{array}{c}2.69 \\
*\end{array}$ & 1.21 & 0.1 & $\begin{array}{c}2.43 \\
*\end{array}$ & 1.2 & 0.01 & 2.13 & 1.22 & 0.01 \\
\hline \multicolumn{13}{|l|}{ Demographics } \\
\hline \multicolumn{13}{|l|}{$\begin{array}{l}\text { Race and } \\
\text { Ethnicity } \\
\text { (referent: White } \\
\text { only) }\end{array}$} \\
\hline Asian only & 0.64 & 0.32 & 0.06 & 0.82 & 0.29 & 0.08 & 0.70 & 0.29 & 0.07 & 0.77 & 0.3 & 0.07 \\
\hline Other only & -0.46 & 1.23 & -0.01 & -1.74 & 1.02 & -0.04 & -2.32 & 1 & -0.06 & -2.44 & 1 & -0.06 \\
\hline \multicolumn{13}{|l|}{$\begin{array}{l}\text { Other } \\
\text { Demographics }\end{array}$} \\
\hline $\begin{array}{l}\text { Has driver's } \\
\text { license }\end{array}$ & & & & 1.34 & 0.25 & 0.14 & 0.94 & 0.26 & 0.1 & 1.00 & 0.26 & 0.11 \\
\hline $\begin{array}{l}\text { Has physical } \\
\text { limitations } \\
\text { that make } \\
\text { riding a } \\
\text { bicycle or an } \\
\text { e-scooter } \\
\text { difficult }\end{array}$ & & & & $\begin{array}{c}0.79 \\
*\end{array}$ & 0.32 & 0.07 & $\begin{array}{c}0.71 \\
*\end{array}$ & 0.32 & 0.06 & $\begin{array}{c}0.65 \\
*\end{array}$ & 0.33 & 0.05 \\
\hline
\end{tabular}




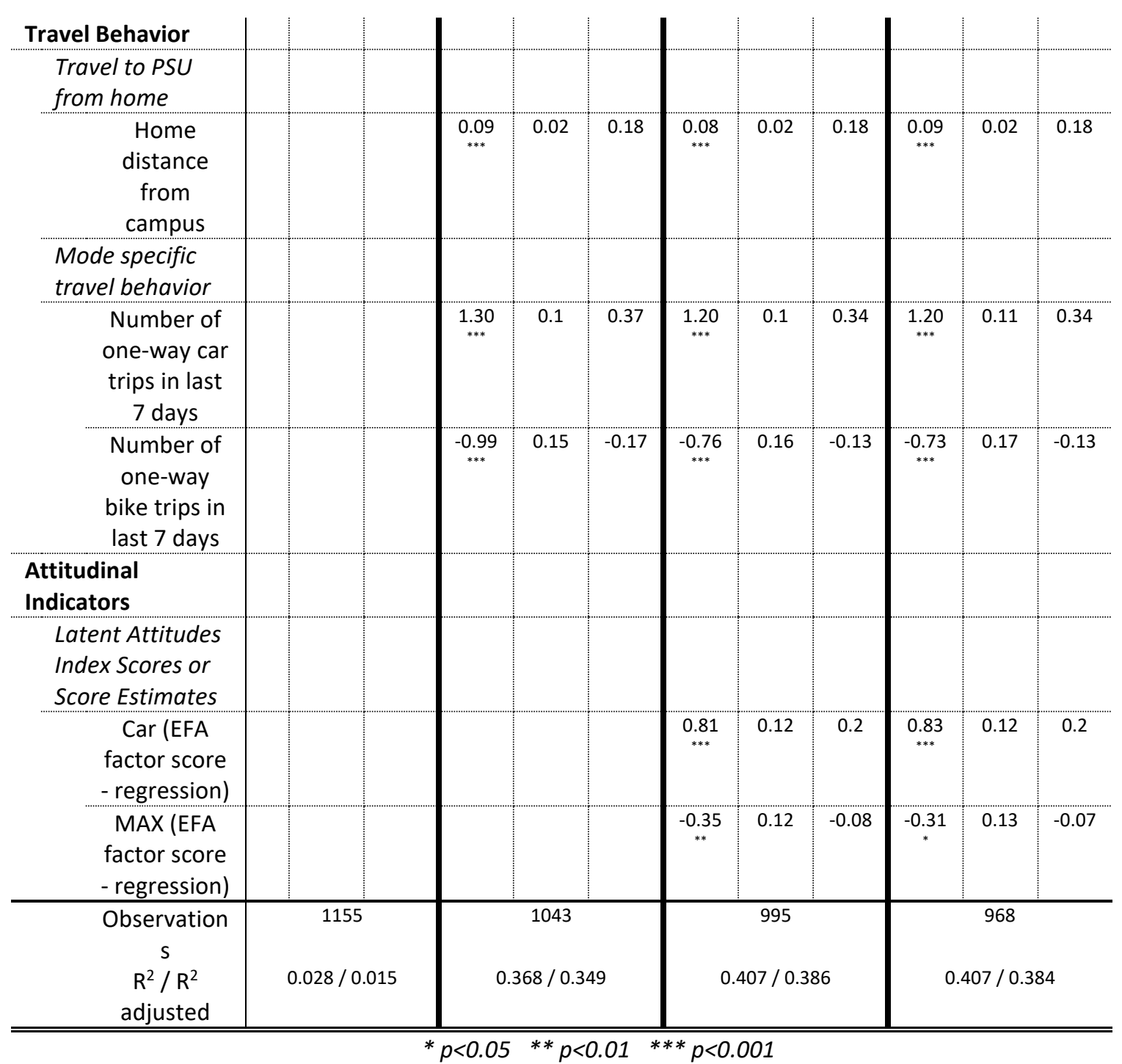


The results of the bike models are shown in Table 24. Overall, the full model explained $40 \%$ of the variance in the data, $R^{2}=0.400$. Respondents who rated their general state of health more highly, the number of days per week that respondents came to PSU, number of one-way bike trips in the last 8 days, Bike Attitude, and "exercise and environmental impact" latent mode decision factor score were all positively and significantly related to propensity to switch to using a bike. Female respondents, home distance from campus, number of one-way MAX trips in the last 7 days, Car Attitude, and "comfort and safety" latent mode decision factor score were all negatively and significantly related to propensity to switch to using a bike. 
Table 24: Propensity to Switch to Bike OLS Regression Models (sig. predictors only)

\begin{tabular}{|c|c|c|c|c|c|c|c|c|c|c|c|c|}
\hline \multirow[b]{2}{*}{ Predictors } & \multicolumn{3}{|c|}{$\begin{array}{l}\text { 1. Propensity to } \\
\text { switch to Bike } \\
\text { Demographics }\end{array}$} & \multicolumn{3}{|c|}{$\begin{array}{l}\text { 2. Propensity to } \\
\text { switch to Bike } \\
\text { Demographics + } \\
\text { Current travel } \\
\text { behavior }\end{array}$} & \multicolumn{3}{|c|}{$\begin{array}{l}\text { 3. Propensity to } \\
\text { switch to Bike } \\
\text { Demographics + } \\
\text { Current travel } \\
\text { behavior + Mode } \\
\text { Attitudes }\end{array}$} & \multicolumn{3}{|c|}{$\begin{array}{l}\text { 4. Propensity to } \\
\text { switch to Bike } \\
\text { Demographics + } \\
\text { Current travel } \\
\text { behavior + Mode } \\
\text { Attitudes + } \\
\text { Decision factors }\end{array}$} \\
\hline & $\begin{array}{l}\text { Esti } \\
\text { mat } \\
\text { es }\end{array}$ & $\begin{array}{l}\text { std. } \\
\text { Erro } \\
r\end{array}$ & $\begin{array}{c}\text { std. } \\
\text { Bet } \\
a\end{array}$ & $\begin{array}{l}\text { Esti } \\
\text { mat } \\
\text { es }\end{array}$ & $\begin{array}{l}\text { std. } \\
\text { Erro } \\
r\end{array}$ & $\begin{array}{c}\text { std. } \\
\text { Bet } \\
a\end{array}$ & $\begin{array}{l}\text { Esti } \\
\text { mat } \\
\text { es }\end{array}$ & $\begin{array}{l}\text { std. } \\
\text { Erro } \\
r\end{array}$ & $\begin{array}{c}\text { std. } \\
\text { Bet } \\
a\end{array}$ & $\begin{array}{l}\text { Esti } \\
\text { mat } \\
\text { es }\end{array}$ & $\begin{array}{l}\text { std. } \\
\text { Erro } \\
r\end{array}$ & $\begin{array}{c}\text { std. } \\
\text { Bet } \\
a\end{array}$ \\
\hline (Intercept) & 3.56 & 0.15 & 0 & 1.91 & 0.53 & -0.05 & 2.29 & 0.51 & 0.04 & 2.48 & 0.52 & 0.06 \\
\hline \multicolumn{13}{|l|}{ Demographics } \\
\hline \multicolumn{13}{|l|}{$\begin{array}{l}\text { Gender } \\
\text { (referent: } \\
\text { Male) }\end{array}$} \\
\hline Female & -0.96 & 0.15 & -0.17 & -0.68 & 0.14 & -0.12 & -0.57 & 0.14 & -0.1 & -0.52 & 0.14 & -0.09 \\
\hline \multicolumn{13}{|l|}{$\begin{array}{l}\text { Other } \\
\text { Demographics }\end{array}$} \\
\hline $\begin{array}{c}\text { General } \\
\text { state of } \\
\text { health }\end{array}$ & & & & 0.26 & 0.07 & 0.09 & 0.20 & 0.07 & 0.07 & 0.18 & 0.07 & 0.06 \\
\hline \multicolumn{13}{|l|}{ Travel Behavior } \\
\hline \multicolumn{13}{|l|}{$\begin{array}{l}\text { Travel to PSU } \\
\text { from home }\end{array}$} \\
\hline $\begin{array}{c}\text { Number of } \\
\text { days per } \\
\text { week } \\
\text { comes to } \\
\text { PSU }\end{array}$ & & & & 0.17 & 0.05 & 0.1 & 0.18 & 0.05 & 0.1 & 0.18 & 0.05 & 0.1 \\
\hline $\begin{array}{l}\text { Home } \\
\text { distance } \\
\text { from } \\
\text { campus }\end{array}$ & & & & -0.04 & 0.01 & -0.12 & -0.04 & 0.01 & -0.11 & -0.03 & 0.01 & -0.1 \\
\hline
\end{tabular}




\begin{tabular}{|c|c|c|c|c|c|c|c|c|c|}
\hline $\begin{array}{l}\text { Mode specific } \\
\text { travel } \\
\text { behavior }\end{array}$ & & & & & & & & & \\
\hline $\begin{array}{c}\text { Number } \\
\text { of one- } \\
\text { way bike } \\
\text { trips in } \\
\text { last } 7 \\
\text { days }\end{array}$ & 2.51 & 0.15 & 0.39 & 1.85 & 0.15 & 0.29 & 1.80 & 0.15 & 0.28 \\
\hline $\begin{array}{l}\text { Number } \\
\text { of one- } \\
\text { way MAX } \\
\text { trips in } \\
\text { last } 7 \\
\text { days } \\
\text { Attitudinal } \\
\text { Indicators }\end{array}$ & -0.16 & 0.08 & -0.06 & -0.16 & 0.08 & -0.05 & -0.16 & 0.08 & -0.06 \\
\hline $\begin{array}{l}\text { Latent } \\
\text { Attitudes } \\
\text { Index Scores } \\
\text { or Score } \\
\text { Estimates }\end{array}$ & & & & & & & & & \\
\hline $\begin{array}{c}\text { Car (EFA } \\
\text { factor } \\
\text { score - } \\
\text { regressio } \\
\mathrm{n} \text { ) }\end{array}$ & & & & -0.28 & 0.08 & -0.09 & -0.23 & 0.08 & -0.07 \\
\hline $\begin{array}{l}\text { Bike (EFA } \\
\text { factor } \\
\text { score - } \\
\text { regressio } \\
\text { n) }\end{array}$ & & & & 1.17 & 0.08 & 0.36 & 1.14 & 0.08 & 0.36 \\
\hline
\end{tabular}




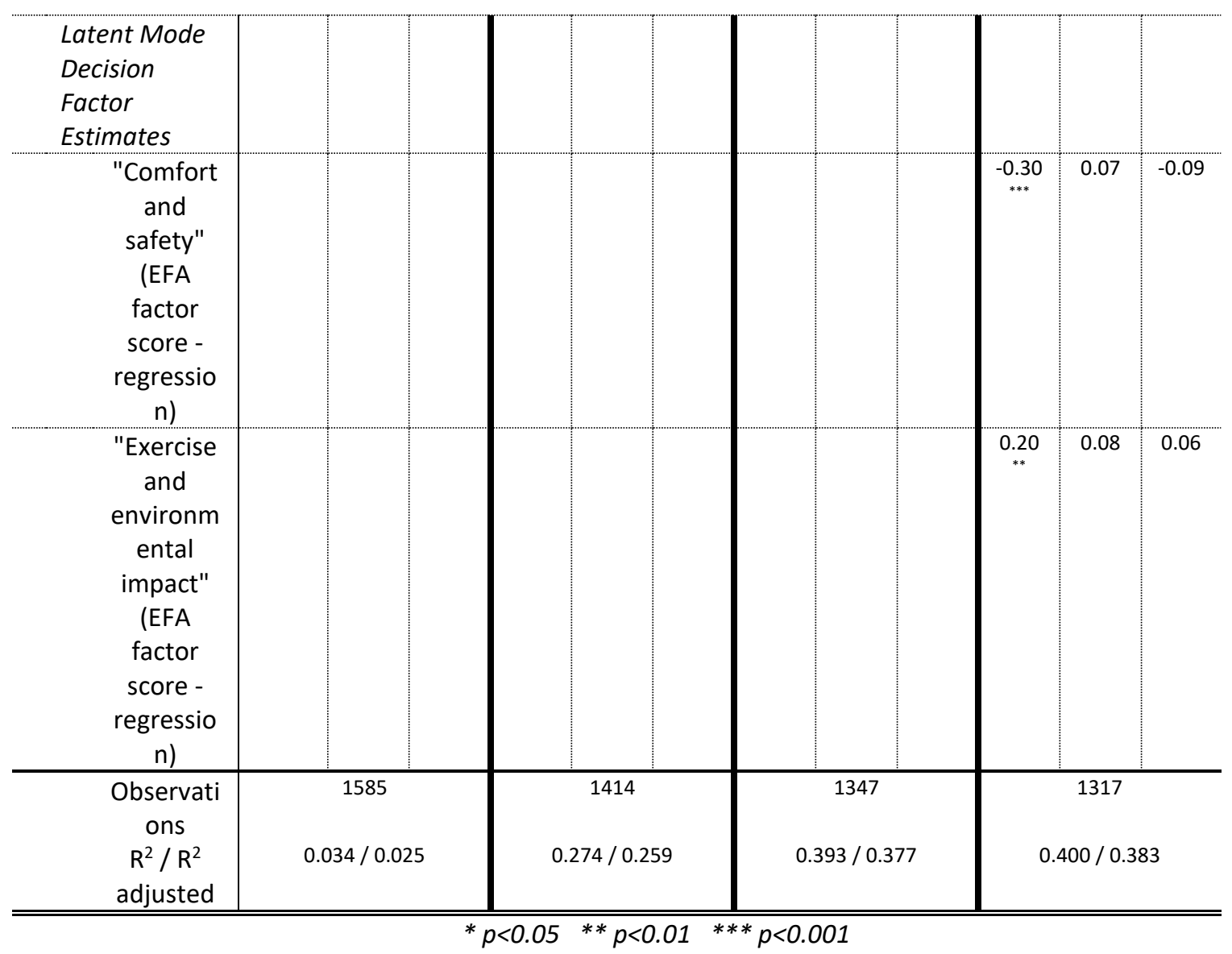


The results of the e-scooter models are shown in Table 25. Overall, the full model explained $32 \%$ of the variance in the data, $R^{2}=0.323$. Respondents with incomes between $\$ 25,000$ to $\$ 49,000$, respondents of gender "Other", number of e-scooter trips in the last 7 days, and E-Scooter Attitude were all positively and significantly related to propensity to switch to using an e-scooter. Home distance from campus was the only variable that was significantly and negatively related to switching to using an e-scooter. 
Table 25: Propensity to Switch to E-Scooter OLS Regression Models (sig. predictors only)

\begin{tabular}{|c|c|c|c|c|c|c|c|c|c|c|c|c|}
\hline \multirow[b]{2}{*}{ Predictors } & \multicolumn{3}{|c|}{$\begin{array}{l}\text { 1. Propensity to } \\
\text { switch to E- } \\
\text { Scooter } \\
\text { Demographics }\end{array}$} & \multicolumn{3}{|c|}{$\begin{array}{l}\text { 2. Propensity to } \\
\text { switch to E- } \\
\text { Scooter } \\
\text { Demographics + } \\
\text { Current travel } \\
\text { behavior }\end{array}$} & \multicolumn{3}{|c|}{$\begin{array}{l}\text { 3. Propensity to } \\
\text { switch to E- } \\
\text { Scooter } \\
\text { Demographics + } \\
\text { Current travel } \\
\text { behavior + Mode } \\
\text { Attitudes }\end{array}$} & \multicolumn{3}{|c|}{$\begin{array}{l}\text { 4. Propensity to } \\
\text { switch to E- } \\
\text { Scooter } \\
\text { Demographics + } \\
\text { Current travel } \\
\text { behavior + Mode } \\
\text { Attitudes + } \\
\text { Decision factors }\end{array}$} \\
\hline & $\begin{array}{l}\text { Esti } \\
\text { mat } \\
\text { es }\end{array}$ & $\begin{array}{l}\text { std. } \\
\text { Erro } \\
r\end{array}$ & $\begin{array}{c}\text { std. } \\
\text { Bet } \\
a\end{array}$ & $\begin{array}{c}\text { Esti } \\
\text { mat } \\
\text { es }\end{array}$ & $\begin{array}{l}\text { std. } \\
\text { Erro } \\
r\end{array}$ & $\begin{array}{c}\text { std. } \\
\text { Bet } \\
a\end{array}$ & $\begin{array}{c}\text { Esti } \\
\text { mat } \\
\text { es }\end{array}$ & $\begin{array}{c}\text { std. } \\
\text { Erro } \\
r\end{array}$ & $\begin{array}{c}\text { std. } \\
\text { Bet } \\
a\end{array}$ & $\begin{array}{l}\text { Esti } \\
\text { mat } \\
\text { es }\end{array}$ & $\begin{array}{l}\text { std. } \\
\text { Erro } \\
r\end{array}$ & $\begin{array}{c}\text { std. } \\
\text { Bet } \\
a\end{array}$ \\
\hline (Intercept) & 1.96 & 0.1 & 0 & 2.24 & 0.38 & -0.06 & 2.17 & 0.37 & -0.03 & 2.25 & 0.37 & -0.01 \\
\hline \multicolumn{13}{|l|}{ Demographics } \\
\hline \multicolumn{13}{|l|}{$\begin{array}{l}\text { Income } \\
\text { (referent: less } \\
\text { than } \$ 25,000 \text { ) }\end{array}$} \\
\hline $\begin{array}{r}\$ 25,000- \\
\$ 49,999\end{array}$ & 0.19 & 0.13 & 0.04 & 0.43 & 0.14 & 0.08 & 0.39 & 0.14 & 0.07 & 0.38 & 0.14 & 0.07 \\
\hline \multicolumn{13}{|l|}{$\begin{array}{l}\text { Gender } \\
\text { (referent: Male) }\end{array}$} \\
\hline Other & 0.69 & 0.64 & 0.03 & 0.87 & 0.59 & 0.04 & 1.13 & 0.56 & 0.05 & 1.37 & 0.59 & 0.06 \\
\hline \multicolumn{13}{|l|}{ Travel Behavior } \\
\hline \multicolumn{13}{|l|}{$\begin{array}{l}\text { Travel to PSU } \\
\text { from home }\end{array}$} \\
\hline $\begin{array}{l}\text { Home } \\
\text { distance } \\
\text { from } \\
\text { campus }\end{array}$ & & & & -0.03 & 0.01 & -0.14 & -0.03 & 0.01 & -0.14 & -0.03 & 0.01 & -0.14 \\
\hline \multicolumn{13}{|l|}{$\begin{array}{l}\text { Mode specific } \\
\text { travel behavior }\end{array}$} \\
\hline $\begin{array}{l}\text { Number of } \\
\text { one-way e- } \\
\text { scooter } \\
\text { trips in last } \\
7 \text { days }\end{array}$ & & & & 2.57 & 0.18 & 0.35 & 1.90 & 0.18 & 0.26 & 2.12 & 0.18 & 0.28 \\
\hline
\end{tabular}




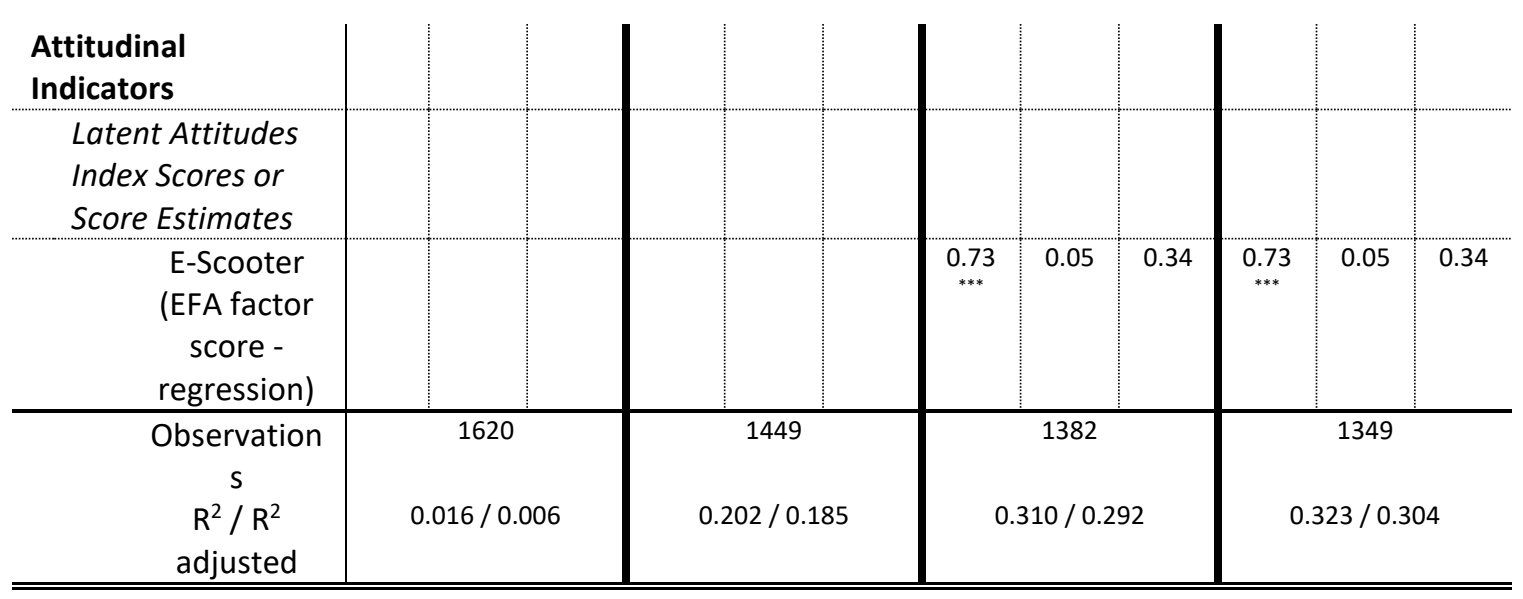

${ }^{*} p<0.05{ }^{* *} p<0.01 \quad * * * p<0.001$ 
Lastly, the results of the MAX models are shown in Table 26. Overall, the full model explained $18 \%$ of the variance in the data, $R^{2}=0.180$. Respondents of more than one race or ethnicity, number of one-way MAX trips in the last 7 days, MAX Attitude, and "comfort and safety" were all positively and significantly related to propensity to switch to using MAX. Older respondents and respondents that already use active transportation or a different mode of public transit to get to campus significantly and negatively related to switching to using MAX to get to campus. 
Table 26: Propensity to Switch to MAX OLS Regression Models (sig. predictors only)

\begin{tabular}{|c|c|c|c|c|c|c|c|c|c|c|c|c|}
\hline \multirow[b]{2}{*}{ Predictors } & \multicolumn{3}{|c|}{$\begin{array}{l}\text { 1. Propensity to } \\
\text { switch to MAX } \\
\text { Demographics }\end{array}$} & \multicolumn{3}{|c|}{$\begin{array}{l}\text { 2. Propensity to } \\
\text { switch to MAX } \\
\text { Demographics + } \\
\text { Current travel } \\
\text { behavior }\end{array}$} & \multicolumn{3}{|c|}{$\begin{array}{l}\text { 3. Propensity to } \\
\text { switch to MAX } \\
\text { Demographics + } \\
\text { Current travel } \\
\text { behavior + Mode } \\
\text { Attitudes }\end{array}$} & \multicolumn{3}{|c|}{$\begin{array}{l}\text { 4. Propensity to } \\
\text { switch to MAX } \\
\text { Demographics + } \\
\text { Current travel } \\
\text { behavior + Mode } \\
\text { Attitudes + } \\
\text { Decision factors }\end{array}$} \\
\hline & $\begin{array}{c}\text { Esti } \\
\text { mat } \\
\text { es }\end{array}$ & $\begin{array}{l}\text { std. } \\
\text { Erro } \\
r\end{array}$ & $\begin{array}{c}\text { std. } \\
\text { Bet } \\
a\end{array}$ & $\begin{array}{c}\text { Esti } \\
\text { mat } \\
\text { es }\end{array}$ & $\begin{array}{l}\text { std. } \\
\text { Erro } \\
r\end{array}$ & $\begin{array}{c}\text { std. } \\
\text { Bet } \\
a\end{array}$ & $\begin{array}{c}\text { Esti } \\
\text { mat } \\
\text { es }\end{array}$ & $\begin{array}{l}\text { std. } \\
\text { Erro } \\
r\end{array}$ & $\begin{array}{c}\text { std. } \\
\text { Bet } \\
a\end{array}$ & $\begin{array}{c}\text { Esti } \\
\text { mat } \\
\text { es }\end{array}$ & $\begin{array}{l}\text { std. } \\
\text { Erro } \\
r\end{array}$ & $\begin{array}{c}\text { std. } \\
\text { Bet } \\
a\end{array}$ \\
\hline (Intercept) & $\begin{array}{c}6.45 \\
* * *\end{array}$ & 0.21 & 0 & 7.18 & 0.85 & 0.23 & $\begin{array}{c}8.06 \\
* * *\end{array}$ & 0.86 & 0.32 & $\underbrace{8.59}_{* * *}$ & 0.88 & 0.31 \\
\hline $\begin{array}{l}\text { Demographics } \\
\text { Race and } \\
\text { Ethnicity } \\
\text { (referent: White } \\
\text { only) }\end{array}$ & & & & & & & & & & & & \\
\hline $\begin{array}{c}\text { More than } \\
\text { one race or } \\
\text { ethnicity }\end{array}$ & 0.51 & 0.3 & 0.05 & 0.49 & 0.3 & 0.05 & 0.61 & 0.31 & 0.06 & 0.63 & 0.3 & 0.06 \\
\hline $\begin{array}{l}\text { Other } \\
\text { Demographics }\end{array}$ & & & & & & & & & & & & \\
\hline Age & & & & -0.02 & 0.02 & -0.05 & -0.03 & 0.02 & -0.07 & -0.04 & 0.02 & -0.08 \\
\hline $\begin{array}{l}\text { Travel Behavior } \\
\text { Main mode of } \\
\text { transportation } \\
\text { to campus } \\
\text { (referent: } \\
\text { Personal Car) }\end{array}$ & & & & & & & & & & & & \\
\hline $\begin{array}{c}\text { Active } \\
\text { Transportat } \\
\text { ion }\end{array}$ & & & & -1.57 & 0.38 & -0.47 & -1.95 & 0.38 & -0.58 & -1.83 & 0.39 & -0.55 \\
\hline $\begin{array}{l}\text { Public } \\
\text { Transit }\end{array}$ & & & & -1.05 & 0.29 & -0.31 & -1.63 & 0.3 & -0.49 & -1.68 & 0.3 & -0.5 \\
\hline Other & & & & -0.98 & 0.65 & -0.29 & -1.44 & 0.67 & -0.43 & -1.45 & 0.67 & -0.43 \\
\hline $\begin{array}{l}\text { Mode specific } \\
\text { travel behavior }\end{array}$ & & & & & & & & & & & & \\
\hline $\begin{array}{c}\text { Number of } \\
\text { one-way } \\
\text { MAX trips in } \\
\text { last } 7 \text { days }\end{array}$ & & & & 1.49 & 0.15 & 0.33 & 1.26 & 0.15 & 0.28 & 1.28 & 0.15 & 0.28 \\
\hline
\end{tabular}




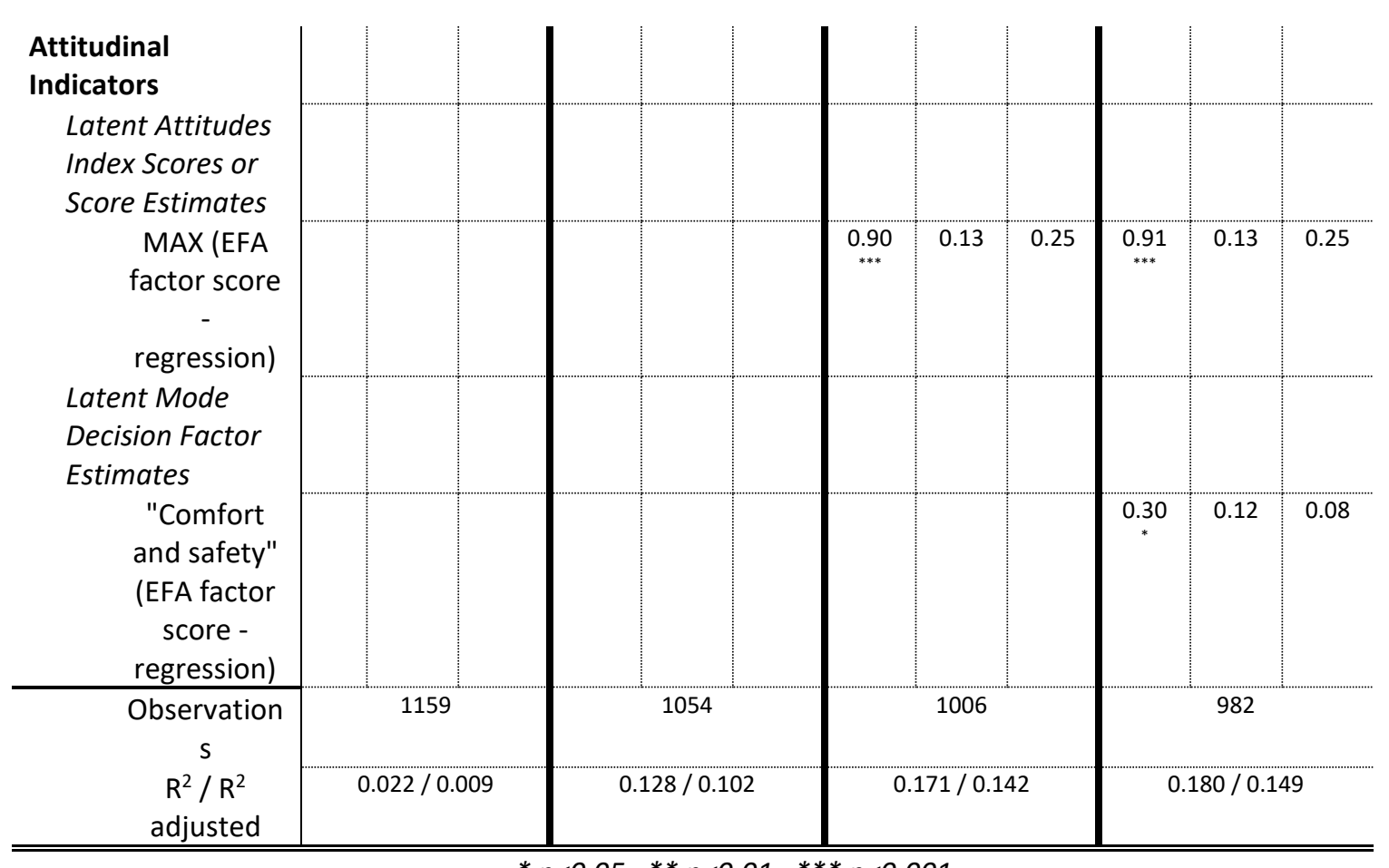


As seen previously in our results, existing travel behavior habits give us a large amount of information about what respondents say they would do if their current mode to PSU became unavailable. Having a driver's license predicted switching to car. The number of trips of a certain mode taken in the last 7 days was also significant, with those taking more bike trips more likely to switch to bike and less likely to switch to car. Those taking more car trips were more likely to switch to car. Those taking more MAX trips were less likely to switch to bike and more likely to switch to MAX. Those who took at least one e-scooter trip in the last 7 days were more likely to say that they would switch to e-scooter commuting. Respondents that lived farther away from campus were more likely to switch to car and less likely to switch to bike or e-scooter. Finally, those that already took an active mode of transportation to get to PSU said that they were less likely to switch to commuting on MAX.

A few demographic variables tell us information about what respondents said they would do. Asian respondents were more likely to say that they would switch to car, whereas respondents with more than one race or ethnicity said that they would more likely switch to MAX. Female respondents were less likely to switch to bike, and respondents who listed their gender as Other were more likely to switch to e-scooter commuting. Those with incomes between $\$ 25,000$ and $\$ 49,000$ were more likely than those with incomes under $\$ 25,000$ to switch to e-scooter commuting. Lastly, older respondents were less likely to switch to MAX. 
Perceived health also played a significant role in predicting some potential mode shift. Those with physical limitations that make riding an e-scooter or bicycle difficult were more likely to say that they would switch to commute by car. Those who rated their general state of health higher were more likely to switch to riding a bike to PSU. Lastly, latent attitudes also significantly predicted potential commute mode switches. Respondents with higher Car Attitude were less likely to switch to bike, respondents with higher MAX Attitude were less likely to switch to car and more likely to switch to MAX, respondents with higher Bike Attitude were more likely to switch to bike, and respondents with higher E-Scooter Attitude were more likely to switch to escooter. Respondents that valued exercise and environmental impact in their commute to PSU were more likely to switch to commuting by bike. Lastly, respondents that valued their physical comfort and safety in their commute mode choice were less likely to switch to bike and more likely to switch to MAX.

\subsection{Stated Choice Experiment MNL Regression}

The results of the stated choice experiment multinomial logistic regression are shown in Table 28. The model was constructed hierarchically in five steps such that the contributions of each additional set of predictors could be seen. To save space, only significant parameters and the final model build are reported in this section. The all models, including non-significant predictors, are reported in Appendix E. Each model was generated using the following predictors: manipulated mode choice attributes, demographics (income, race and ethnicity, gender, driver's license status, age, married 
status, number of children, general state of health, physical limitations status), travel behavior (number of days per week comes to PSU, home distance from campus, main mode of transportation to campus, number of one-way trips by mode in the last 7 days), latent attitudinal indicators (car, bike, e-scooter, MAX), and latent mode decision factors ("comfort and safety" and "exercise and environmental impact"). Odds ratios that are greater than one indicate a higher likelihood of a respondent choosing the corresponding choice. Resulting odds ratios that are less than one indicate a lower likelihood of a respondent choosing the corresponding choice. The car choice was used as the referent for the bike and e-scooter + MAX choices. This means that all odds ratios should be interpreted in relation to choosing the car choice.

The chi-squared tests of fit for the MAX models shown in Table 27 show that each of the five models fit the data significantly better than a model with no predictors.

Table 27: MNL Model Fits

\begin{tabular}{lrllll}
\hline \multicolumn{1}{l}{ Model } & Deviance (-2LL) & $\chi^{2}$ & $\mathrm{df}$ & $\mathrm{p}$ \\
\hline $\begin{array}{l}\text { Intercept } \\
\text { Only }\end{array}$ & 26814.23 & & & & \\
& 1 & 25639.64 & 52453.87 & 11 & 0 \\
& 2 & 19400.82 & 46215.05 & 53 & 0 \\
& 3 & 16598.88 & 43413.11 & 71 & 0 \\
& 4 & 14373.36 & 41187.59 & 79 & 0 \\
& 5 & 13969.83 & 40784.06 & 83 & 0 \\
\hline
\end{tabular}

Beginning with the bike choice, several items increased the likelihood of choosing bike over car. These included married or living with a partner status, number of days per week comes to PSU, home distance from campus, using Active Transportation or Public 
Transit as primary commute mode to PSU already, number of one-way bike trips in the last 7 days, Bike Attitude, MAX Attitude, and "exercise and environmental impact." On the other hand, experiment bike ride time, Black, Hispanic or Latinx/Latino/Latina, Native Hawaiian or Pacific Islander respondents, female or "other" gender respondents, having physical limitations that make riding a bicycle or an e-scooter difficult, number of one-way car trips in the last 7 days, Car Attitude, E-Scooter Attitude, and "comfort and safety" all significantly and negatively affected the likelihood that the respondent would choose the bike option.

Looking at the e-scooter + MAX choice, American Indian or Alaska Native respondents, number of days per week comes to PSU, already taking active transportation or public transit, number of one-way e-scooter trips in the last 7 days, number of one-way MAX trips in the last 7 days, Bike Attitude, E-Scooter Attitude, and MAX Attitude were significantly and positively related to an increased likelihood of choosing the e-scooter + MAX choice over car. Experiment walk time to e-scooter, experiment scoot time to MAX station, e-scooter cost, earning $\$ 50,000$ - $\$ 74,999$ per year, black respondents, female respondents, "other" gender respondents, driver's license status, general state of health, number of one-way car trips in last 7 days, and Car Attitude score were significantly and negatively related to choosing the e-scooter + MAX choice. 
Table 28: Stated Choice Experiment MNL Model (sig. predictors only)

\author{
5. Stated choice \\ experiment, Attributes + \\ Demographics + Current \\ travel behavior + Mode \\ Attitudes + Decision \\ factors \\ Log- \\ SE OR \\ Odds
}

\title{
Generic
}

\section{Attributes}

\begin{tabular}{|c|c|c|c|}
\hline Walk Time from Car Parking Location to Destination (mins) & $-0.035 * *$ & $(0.018)$ & $0.965 * *$ \\
\hline Car Drive Time (mins) & $-0.037 * * *$ & $(0.003)$ & $0.964 * * *$ \\
\hline Car Parking Cost (\$) & $-0.138 * * *$ & $(0.009)$ & $0.871 * * *$ \\
\hline Bike Ride Time (mins) & $-0.068 * * *$ & $(0.003)$ & $0.934 * * *$ \\
\hline Walk Time to E-Scooter (mins) & $-0.070 * * *$ & $(0.017)$ & $0.932 * * *$ \\
\hline E-Scooter Time to MAX Station (mins) & $-0.055 * * *$ & $(0.007)$ & $0.946 * * *$ \\
\hline E-scooter Cost (\$) & $-0.168 * * *$ & $(0.028)$ & $0.846 * * *$ \\
\hline MAX Ticket Cost (\$) & $-0.181 * * *$ & $(0.027)$ & $0.835 * * *$ \\
\hline MAX Ride Time (mins) & $-0.040 * * *$ & $(0.007)$ & $0.961 * * *$ \\
\hline
\end{tabular}




\section{Bike}

\section{Demographics}

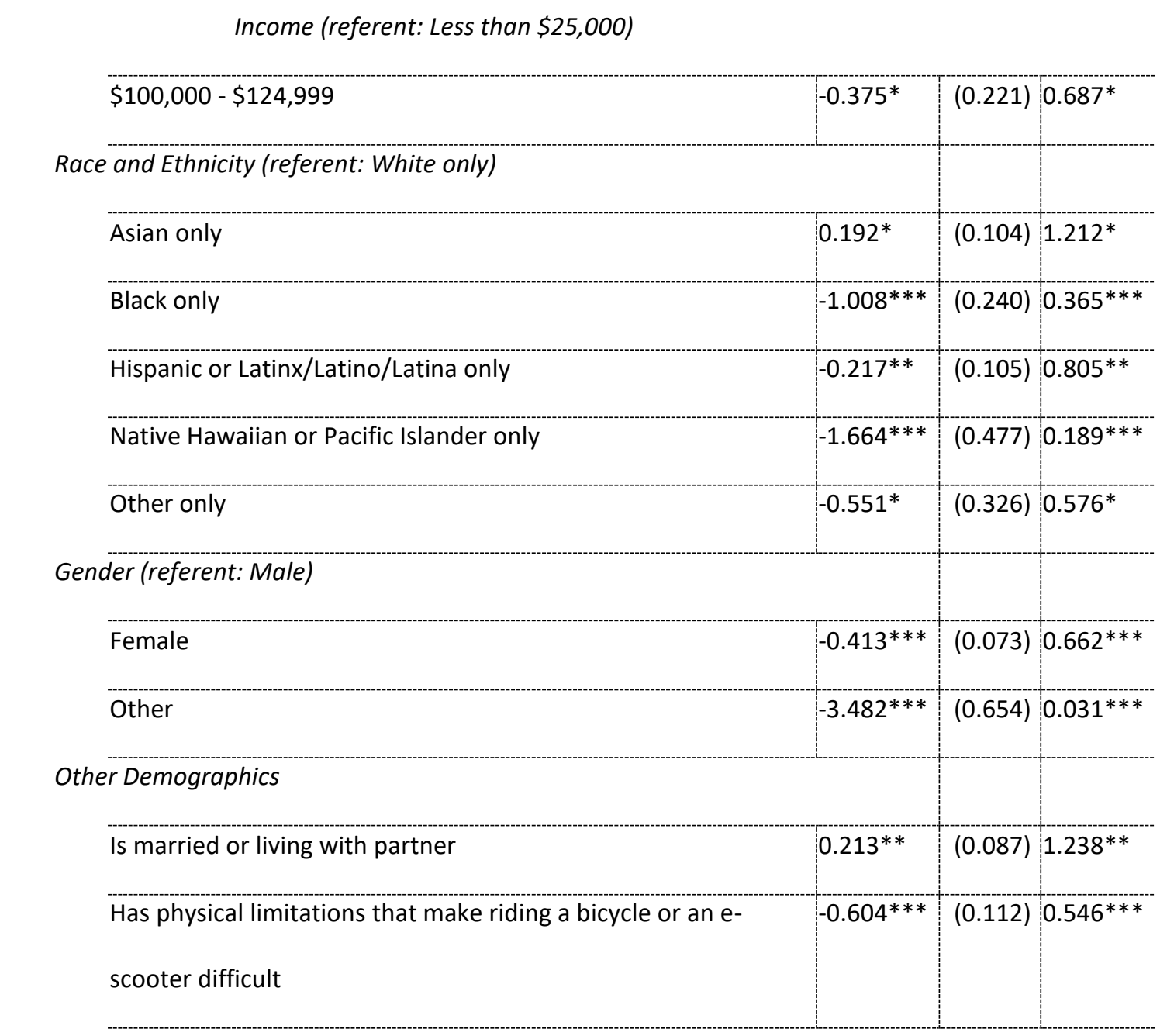

\section{Travel Behavior}

Main mode of transportation to campus (referent: Personal Car)

\begin{tabular}{l|l|l|l|}
\hline Primary Commute Mode to PSU is Active Transportation & $0.664^{* * *}$ & $(0.129)$ & $1.943^{* * *}$ \\
\hline Primary Commute Mode to PSU is Public Transit & $0.665^{* * *}$ & $(0.093)$ & $1.945^{* * *}$ \\
\hline Primary Commute Mode to PSU is Other & & & \\
\hline
\end{tabular}


Travel to PSU from home

\begin{tabular}{|l|l|l|l|l|}
\hline Number of days per week comes to PSU & $0.102 * * *$ & $(0.024)$ & $1.108^{* * *}$ \\
\hline Home distance from campus & $0.014 * * *$ & $(0.005)$ & $1.014 * * *$ \\
\hline
\end{tabular}

Mode specific travel behavior

\begin{tabular}{|l|l|l|l|}
\hline Number of one-way car trips in last 7 days & $0.124^{* * *}$ & $(0.035)$ & $0.883^{* * *}$ \\
\hline Number of one-way bike trips in last 7 days & $0.558^{* * *}$ & $(0.098)$ & $1.747^{* * *}$
\end{tabular}

\section{Attitudinal Indicators}

Latent Attitudes Index Score Estimates

\begin{tabular}{l|l|l|l|l}
\hline Car (EFA factor score - regression) & $-0.514^{* * *}$ & $(0.044)$ & $0.598^{* * *}$ \\
\hline Bike (EFA factor score - regression) & $1.097^{* * *}$ & $(0.048)$ & $2.995^{* * *}$ \\
\hline E-scooter (EFA factor score - regression) & $-0.114^{* * *}$ & $(0.040)$ & $0.892^{* * *}$ \\
\hline MAX (EFA factor score - regression) & & \\
\hline
\end{tabular}

Latent Mode Decision Factor Estimates

\begin{tabular}{l|l|l|l|l|l|l|l|}
\hline "Comfort and safety" (EFA factor score - regression) & $0.164^{* * *}$ & $(0.039)$ & $0.849^{* * *}$ \\
\hline "Exercise and environmental impact" (EFA factor score - & $0.102^{* * *}$ & $(0.039)$ & $1.107^{* * *}$ \\
regression) & & & \\
\hline
\end{tabular}




\section{E-Scooter + MAX}

\section{Demographics}

Income (referent: Less than $\$ 25,000)$

\begin{tabular}{|c|c|c|c|}
\hline$\$ 50,000-\$ 74,999$ & $-0.412 * * *$ & $(0.140)$ & $0.663^{* * *}$ \\
\hline \multicolumn{4}{|l|}{ and Ethnicity (referent: White only) } \\
\hline American Indian or Alaska Native only & $1.378^{* * *}$ & $(0.440)$ & $3.967 * * *$ \\
\hline Black only & $-0.603 * * *$ & $(0.211)$ & $0.547 * * *$ \\
\hline
\end{tabular}

Gender (referent: Male)

\begin{tabular}{l|l|l|l|l|l}
\hline Female & $-0.311 * * *$ & $(0.075)$ & $0.733^{* * *}$ \\
\hline Other & $-1.830 * * *$ & $(0.434)$ & $0.160 * * *$ \\
\hline
\end{tabular}

Other Demographics

\begin{tabular}{l|l|l|l|l|}
\hline Has driver's license & $-0.212 * *$ & $(0.103)$ & $0.809 * *$ \\
\hline General state of health & $-0.134 * * *$ & $(0.036)$ & $0.874 * * *$ \\
\hline
\end{tabular}

\section{Travel Behavior}

Main mode of transportation to campus (referent: Personal Car)

\begin{tabular}{|l|l|l|l|l|l|l|l|l}
\hline Primary Commute Mode to PSU is Active Transportation & $0.483^{* * *}$ & $(0.136)$ & $1.621^{* * *}$ \\
\hline Primary Commute Mode to PSU is Public Transit & $1.007^{* * *}$ & $(0.096)$ & $2.737^{* * *}$ \\
\hline Primary Commute Mode to PSU is Other & $1.190^{* * *}$ & $(0.258)$ & $3.286^{* * *}$ \\
\hline
\end{tabular}

Travel to PSU from home

\begin{tabular}{l|l|l|l|}
\hline Number of days per week comes to PSU & $0.062 * *$ & $(0.024)$ & $1.064 *$
\end{tabular}
Mode specific travel behavior

\begin{tabular}{l|l|l|l|}
\hline Number of one-way car trips in last 7 days & $0.114^{* * *}$ & $(0.035)$ & $0.892^{* * *}$ \\
\hline Number of one-way e-scooter trips in last 7 days & $0.431^{* * *}$ & $(0.131)$ & $1.539 * * *$ \\
& & & \\
\end{tabular}




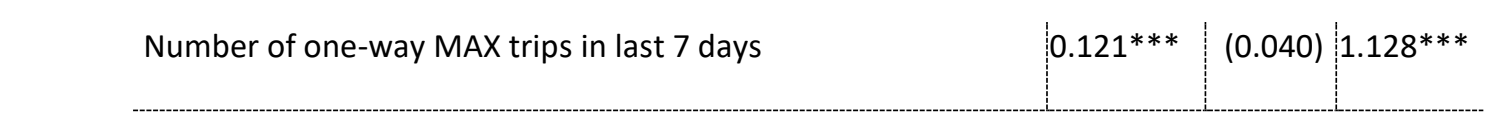

\section{Attitudinal Indicators}

Latent Attitudes Index Score Estimates

\begin{tabular}{l|l|l|l|}
\hline Car (EFA factor score - regression) & $-0.517^{* * *}$ & $(0.045)$ & $0.596^{* * *}$ \\
\hline Bike (EFA factor score - regression) & $0.167^{* * *}$ & $(0.046)$ & $1.182^{* * *}$ \\
\hline E-scooter (EFA factor score - regression) & $0.303^{* * *}$ & $(0.042)$ & $1.354^{* * *}$ \\
\hline MAX (EFA factor score - regression) & $0.521^{* * *}$ & $(0.043)$ & $1.683^{* * *}$ \\
\end{tabular}

Observations

Log Likelihood

Akaike Inf. Crit.
8,382

$-6,984.92$

$14,135.83$

Note: ${ }^{*} p<0.1 ;{ }^{* *} p<0.05 ;{ }^{* * *} p<0.01$ 


\subsection{Spatial Distribution of Mode Use Barriers}

We asked respondents to indicate if they experienced a variety of barriers preventing them from using bikes, e-scooters, or MAX more often than they already do. We mapped their responses using the method described in section 3.5.1 to determine areas of the metro area that may require infrastructure or policy improvements to encourage more students to take non-auto modes to PSU.

\subsubsection{Individual Mode Findings}

First, we explore certain barriers that are unique to only one mode in particular.

\subsubsection{Bike Barriers}

In Figure 19, we observe that a large proportion of respondents in the southeast are afraid that their bike will be stolen.

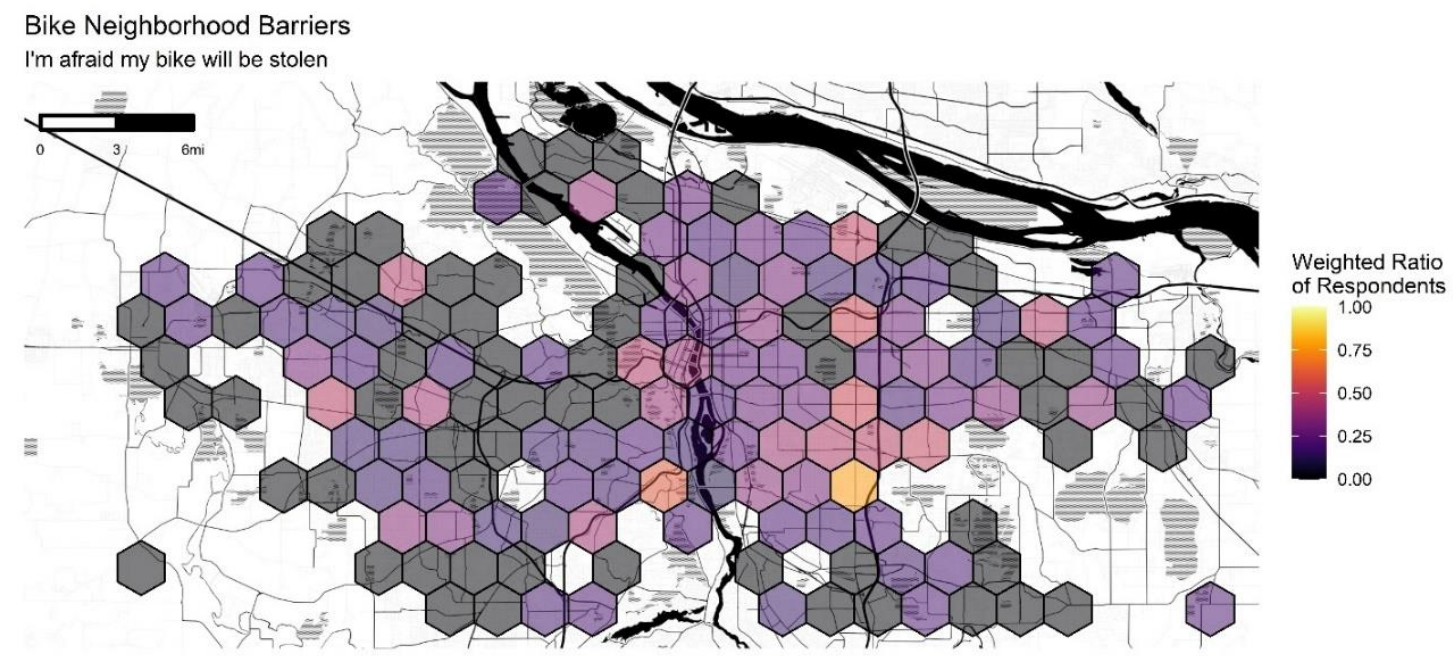

Figure 19: Bike Neighborhood Barriers: I'm afraid that my bike will be stolen 


\subsubsection{E-Scooter Barriers}

Although not pursued in this study, we hypothesize that the ability to use an escooter could be mediated by the availability of e-scooters nearby. Figure 20 shows that a large proportion of respondents throughout the metro area feel that they can't count on enough e-scooters being available for use when they need it.

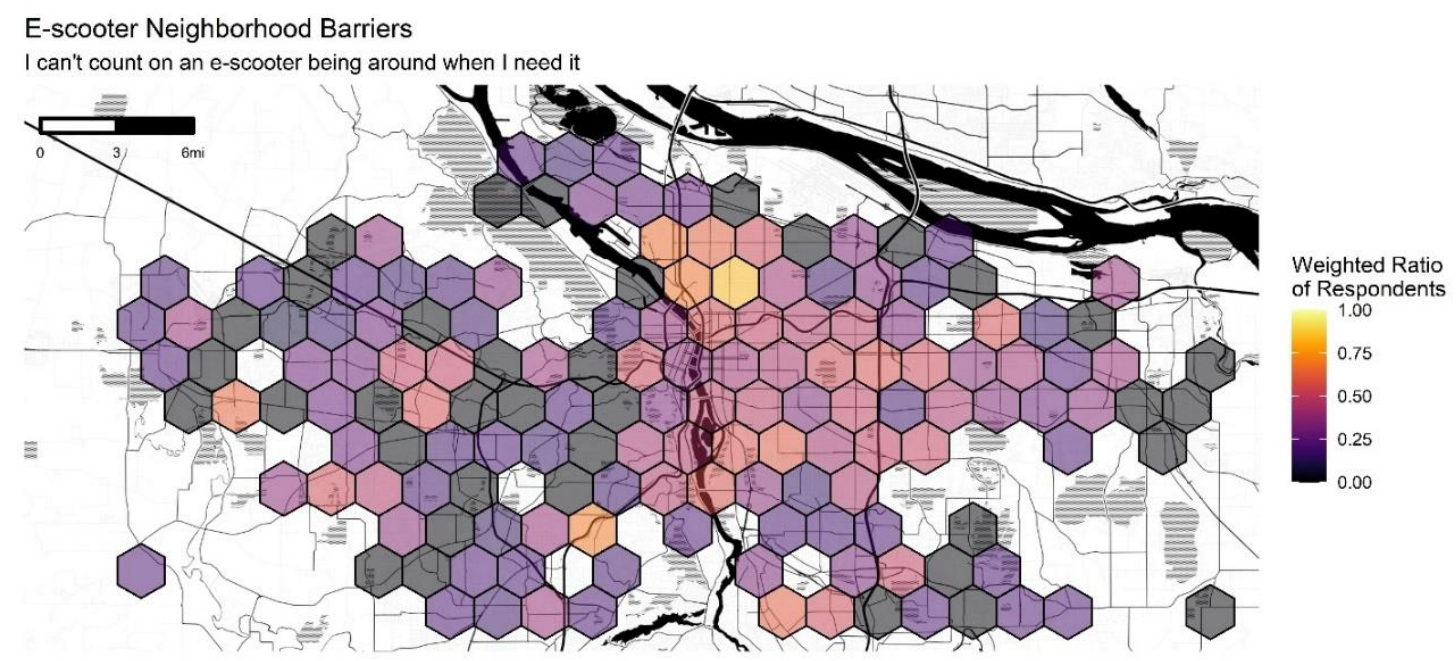

Figure 20: E-Scooter Neighborhood Barriers: I can't count on an e-scooter being around when I need it

The limits of e-scooter service areas could also serve as a major barrier for using an e-scooter. Figure 21 shows that a large share of respondents on the west side of the metro area are unable to use an e-scooter more often because they live outside of the service area. 
E-scooter Neighborhood Barriers

I live outside of an e-scooter service area

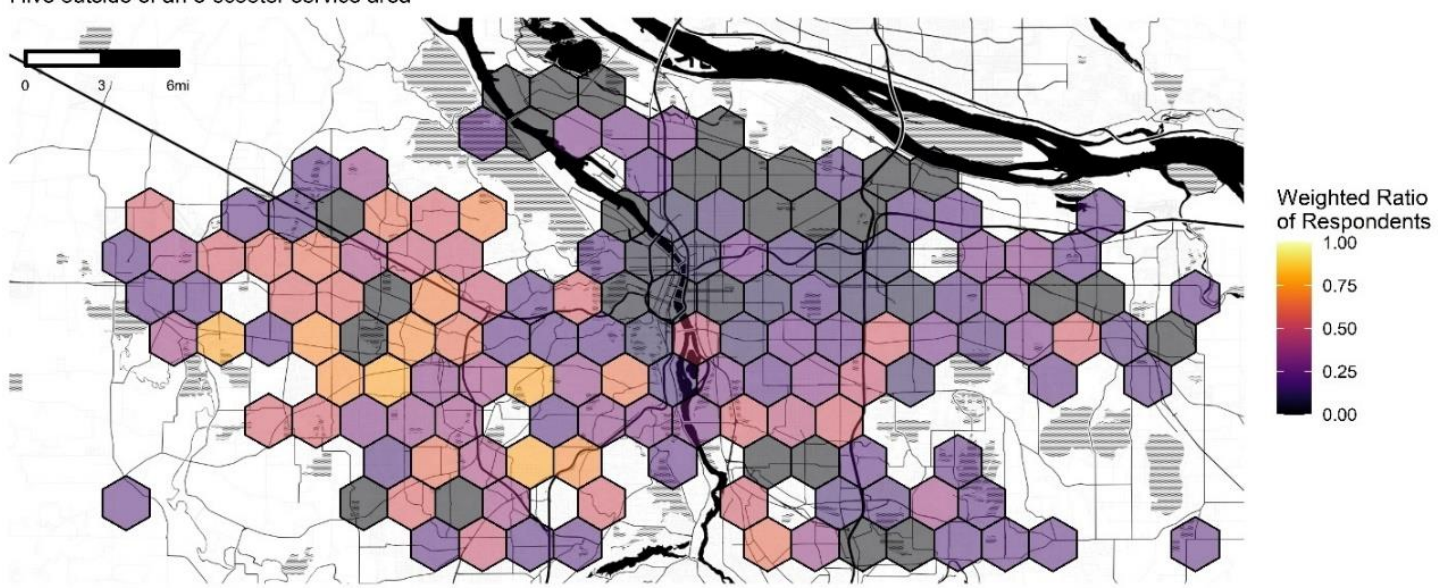

Figure 21: E-Scooter Neighborhood Barriers: I live outside of an e-scooter service area

Yet another barrier to using e-scooters more often could be lack of experience

using the mode. Figure 22 shows that respondents throughout the metro area feel that

they do not use e-scooters more often because they have actually never tried riding one before.

E-scooter Personal Barriers

I have never tried riding an e-scooter before

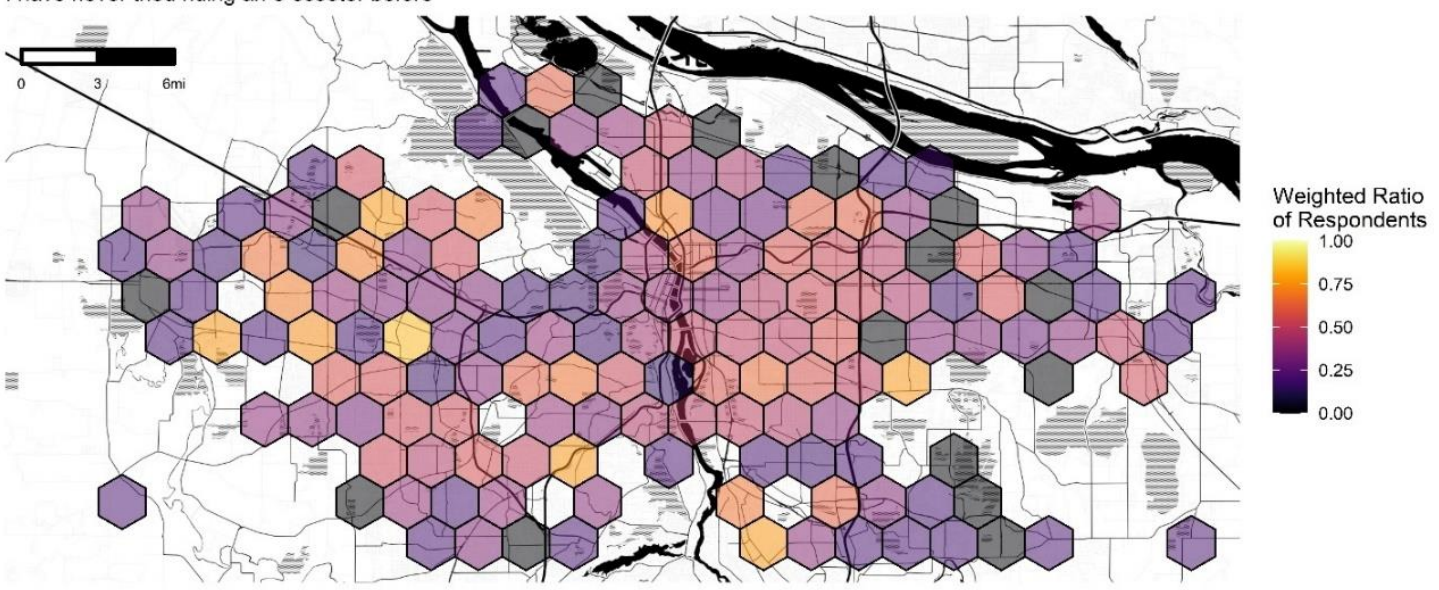

Figure 22: E-Scooter Personal Barriers: I have never tried riding an e-scooter before 


\subsubsection{MAX Barriers}

It comes as no surprise that respondents that feel they live too far from a MAX station experience it as a barrier to using MAX more frequently. The spatial distribution of this mode-specific barrier is clearly shown in Figure 23. Curiously, areas in the inner southeast feel that they live too far from the Orange Line, despite the fact that several orange line stops are located within the adjacent hexagon. This could be because these stops are located west of a large rail yard with limited crossings. Additionally, respondents in Southwest Portland also feel that they live too far from MAX. In theory, the planned MAX expansion in this area should help to rectify this issue.

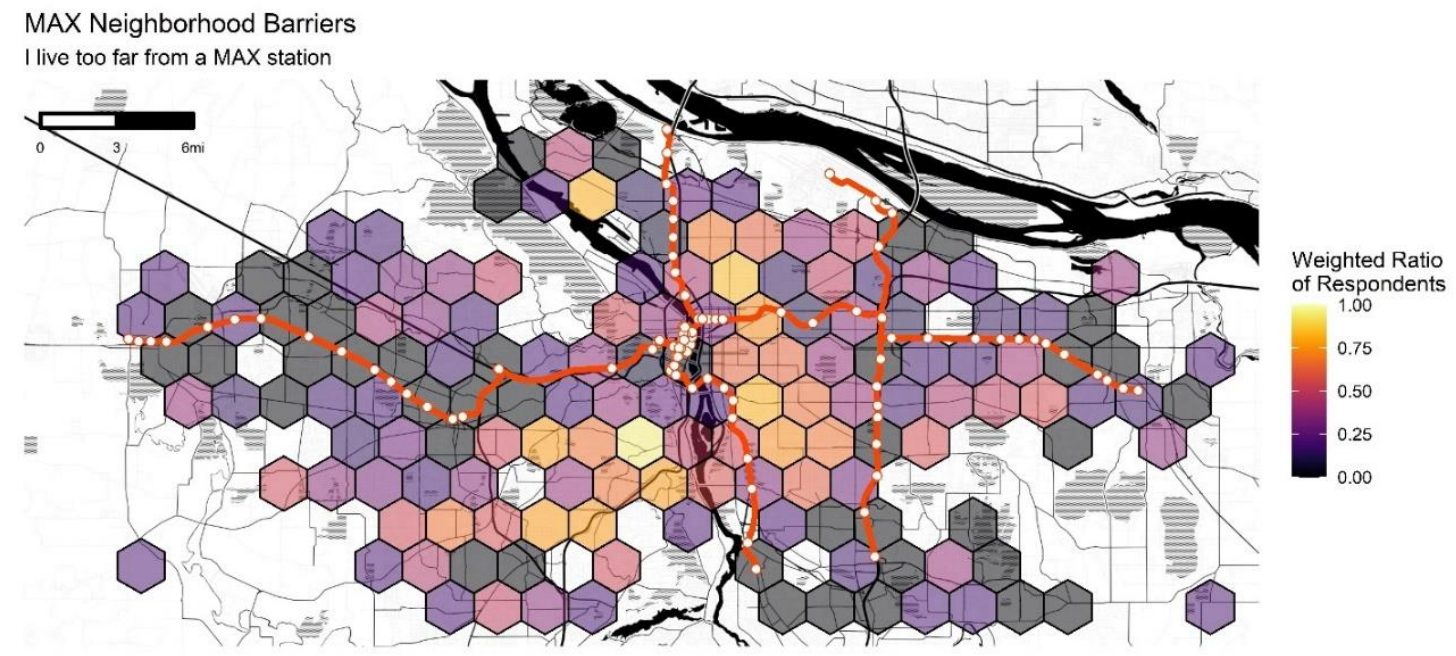

Figure 23: MAX Neighborhood Barriers: I live too far from a MAX station

It appears that safe pedestrian connections to MAX stations are not an issue for the most part. According to Figure 24, there could be one or two isolated areas, namely 
the Cully, Sumner, Madison South, and Montavilla neighborhoods that could use pedestrian infrastructure improvements.

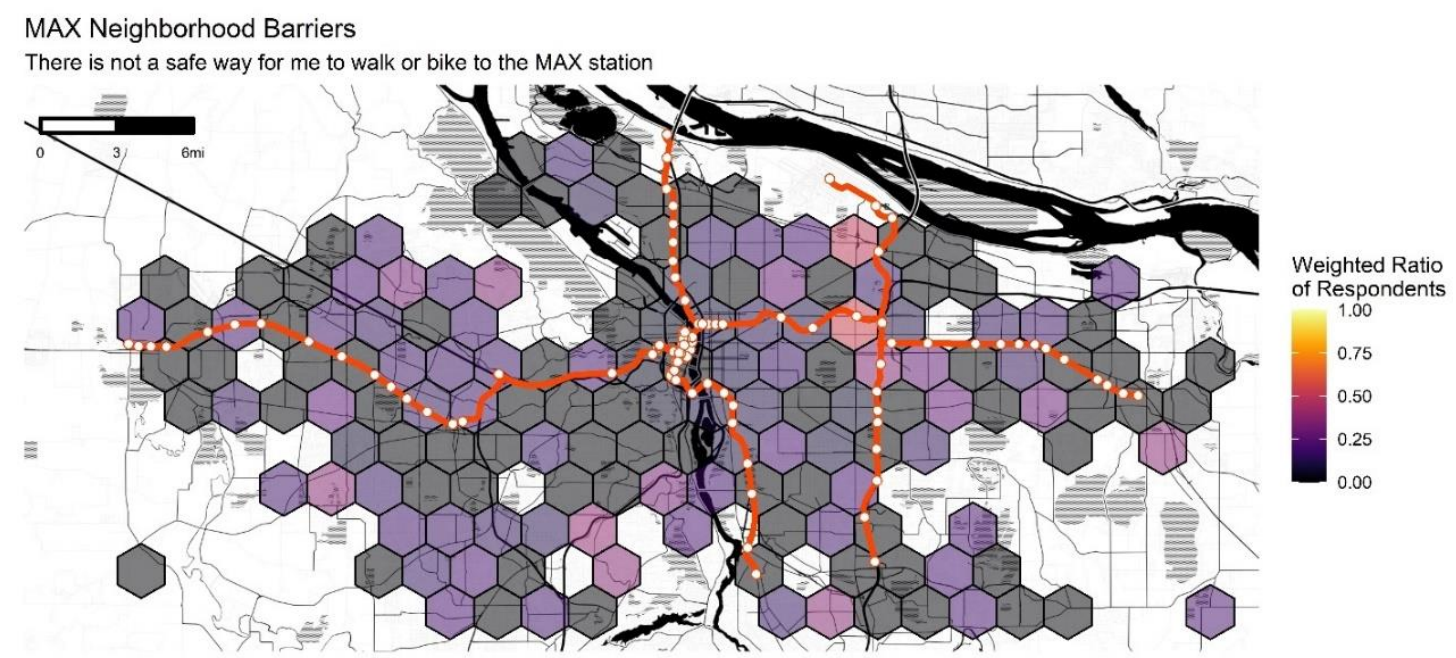

Figure 24: MAX Neighborhood Barriers: There is not a safe way for me to walk or bike to the MAX station As MAX is a limited fixed-route system, it comes as no surprise that some respondents felt that MAX does not go where they need it to. What is surprising, according to Figure 25, is that respondents in the Rose City Park and North Tabor neighborhoods seem to experience this the most severely, despite the fact that they may be among the most connected neighborhoods adjacent to the MAX system. 
MAX Personal Barriers

MAX does not go where I need to go

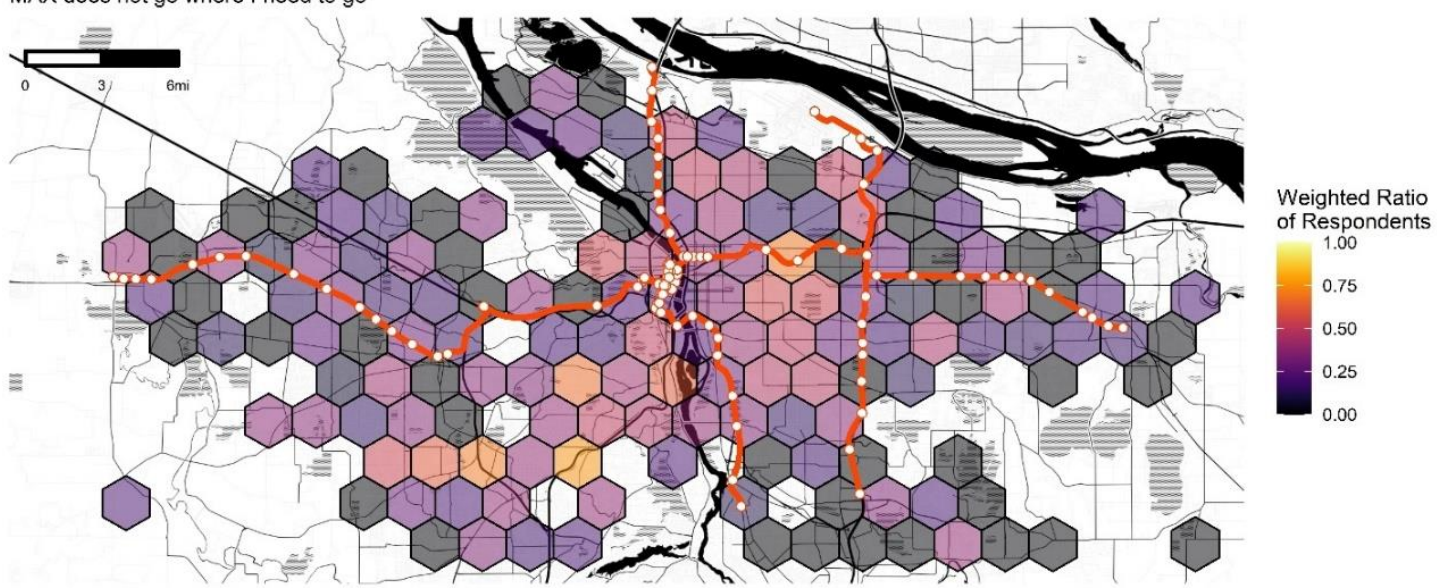

Figure 25: MAX Personal Barriers: MAX does not go where I need to go

\subsubsection{Comparison of Similar Barriers Across Modes}

We also asked about barriers that can impact more than one of the modes

uniquely. Beginning with traffic, we observe that both e-scooter and bike respondents appear similarly impacted by this barrier in Figure 26 and Figure 27.

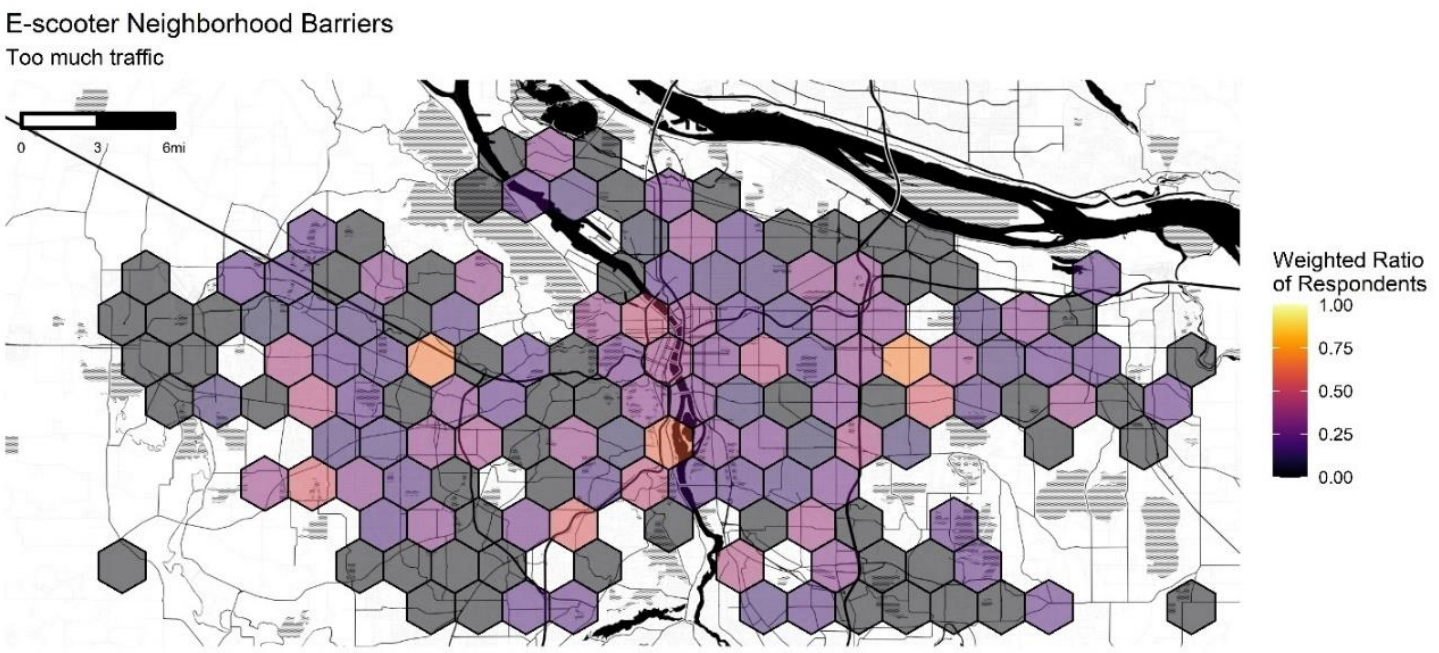

Figure 26: E-Scooter Neighborhood Barriers: Too much traffic 
Bike Neighborhood Barriers Too much traffic

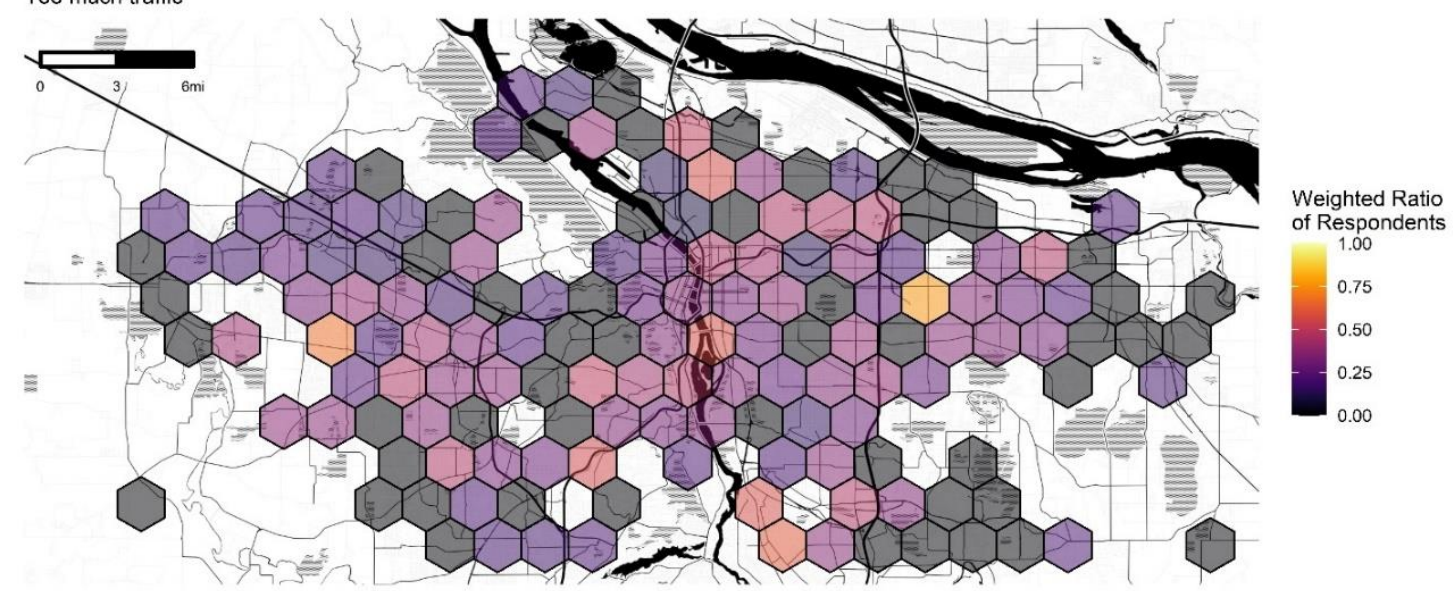

Figure 27: Bike Neighborhood Barriers: Too much traffic

In Portland, e-scooter riders are encouraged to use bike lanes where available.

We compared how respondents perceived the availability of this dedicated

infrastructure as barriers to both riding bikes and e-scooters in Figure 28 and Figure 29.

Despite one hot spot in Southwest Portland, it appears that both sets of users are

impacted equally by the availability of dedicated lanes. It should be noted that

Southwest Portland is generally not included in e-scooter service areas.

Bike Neighborhood Barriers

Not enough bike lanes or trails

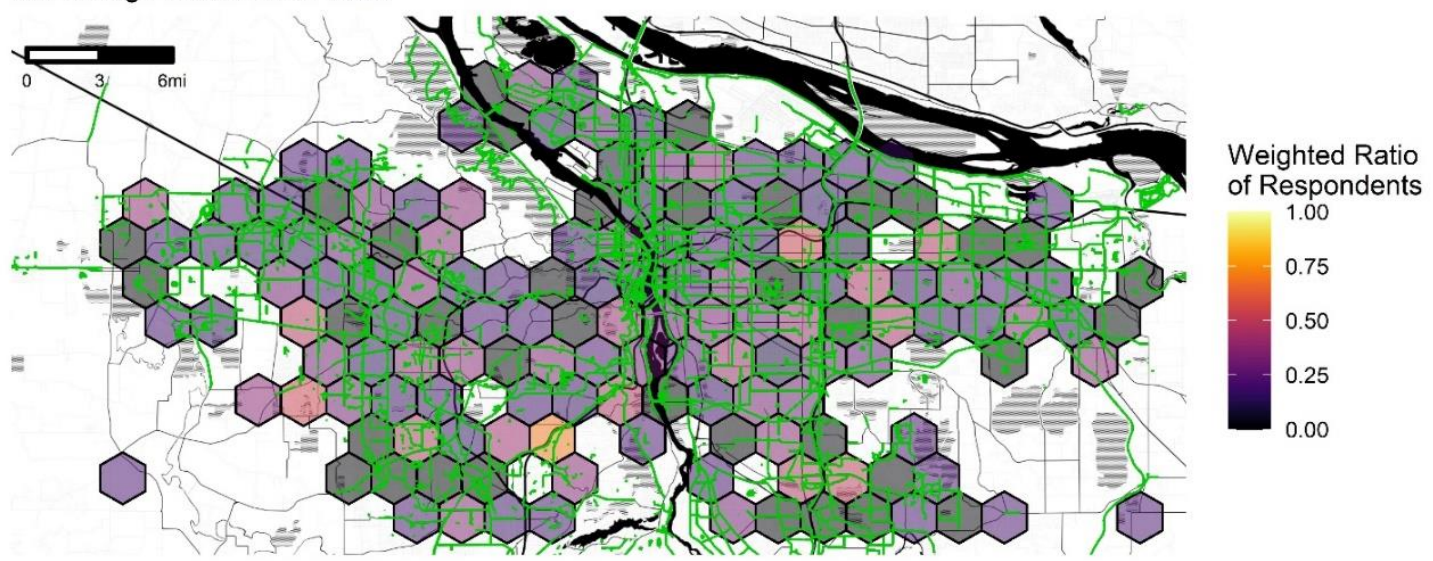


Figure 28: Bike Neighborhood Barriers: Not enough bike lanes or trails

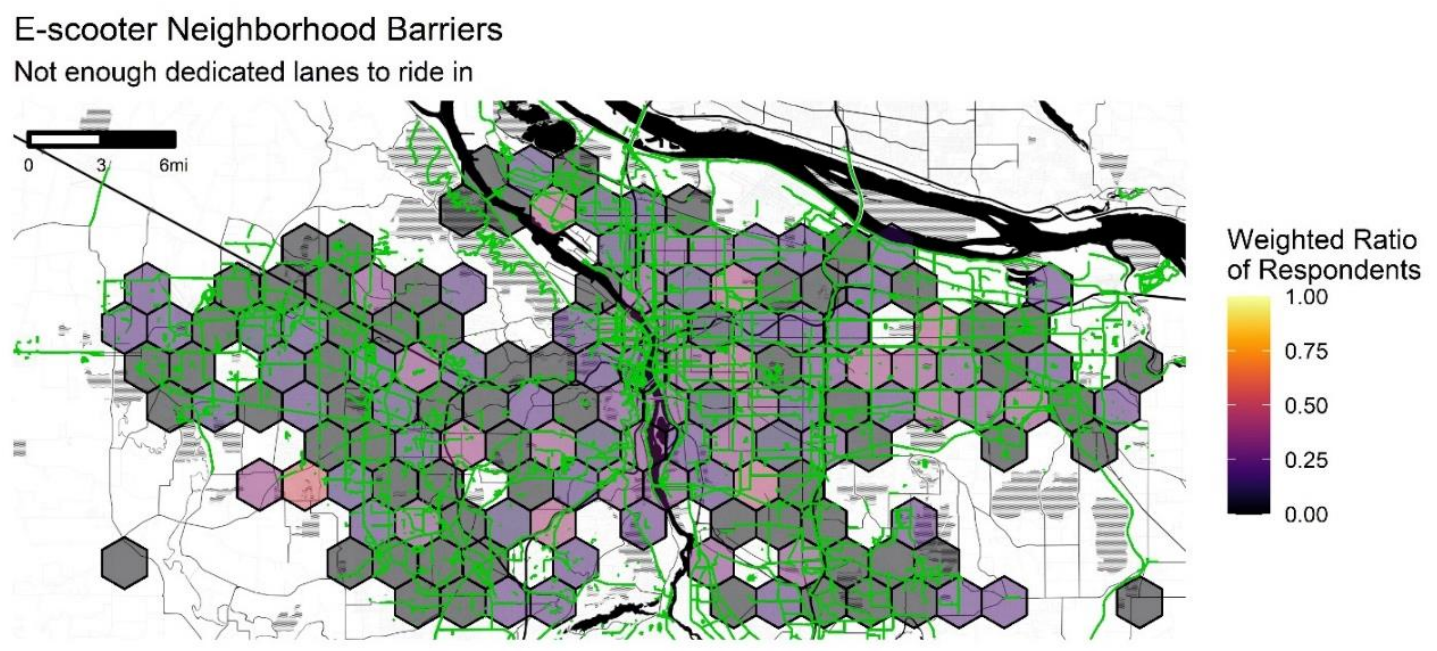

Figure 29: E-Scooter Neighborhood Barriers: Not enough dedicated lanes to ride in

We also asked if weather played a role in preventing users from riding bikes or escooters more frequently. According to Figure 30 and Figure 31, it appears that the weather affects both cyclists and e-scooter riders, and it may impact cyclists more.

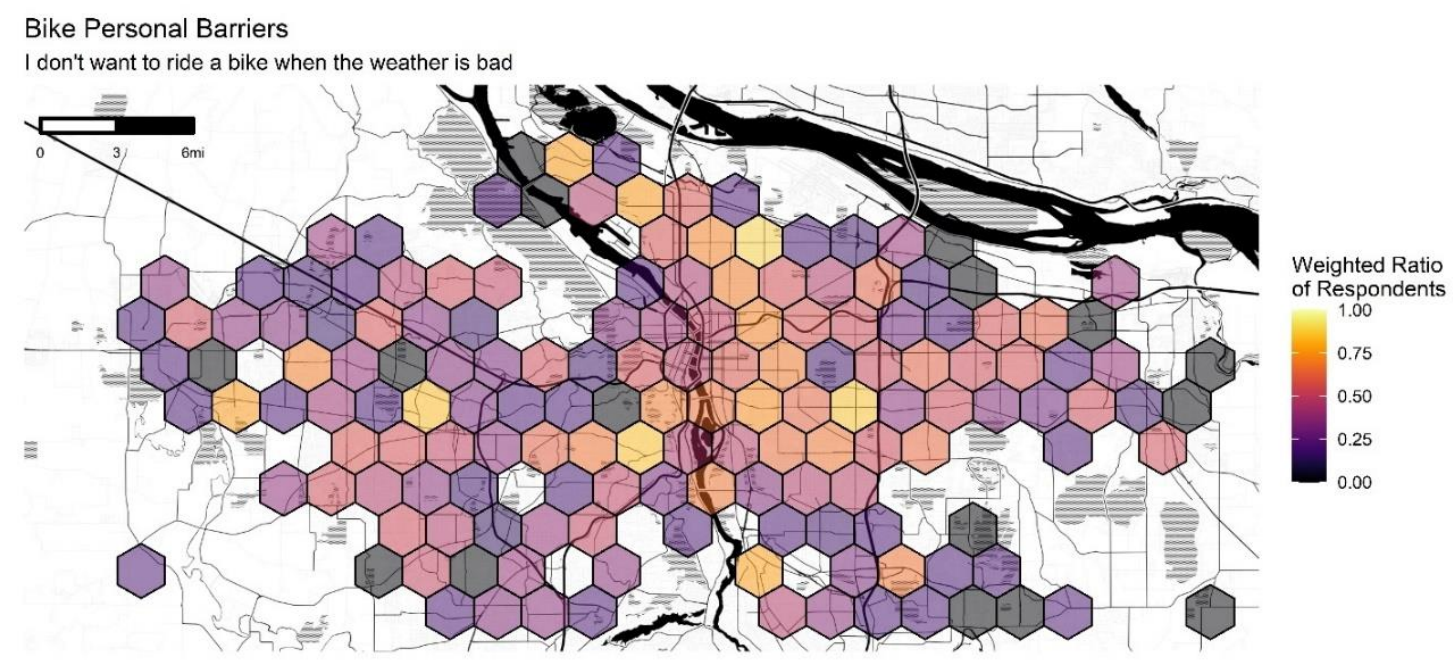

Figure 30: Bike Personal Barriers: I don't want to ride a bike when the weather is bad 
E-scooter Personal Barriers

I don't want to ride an e-scooter when the weather is bad

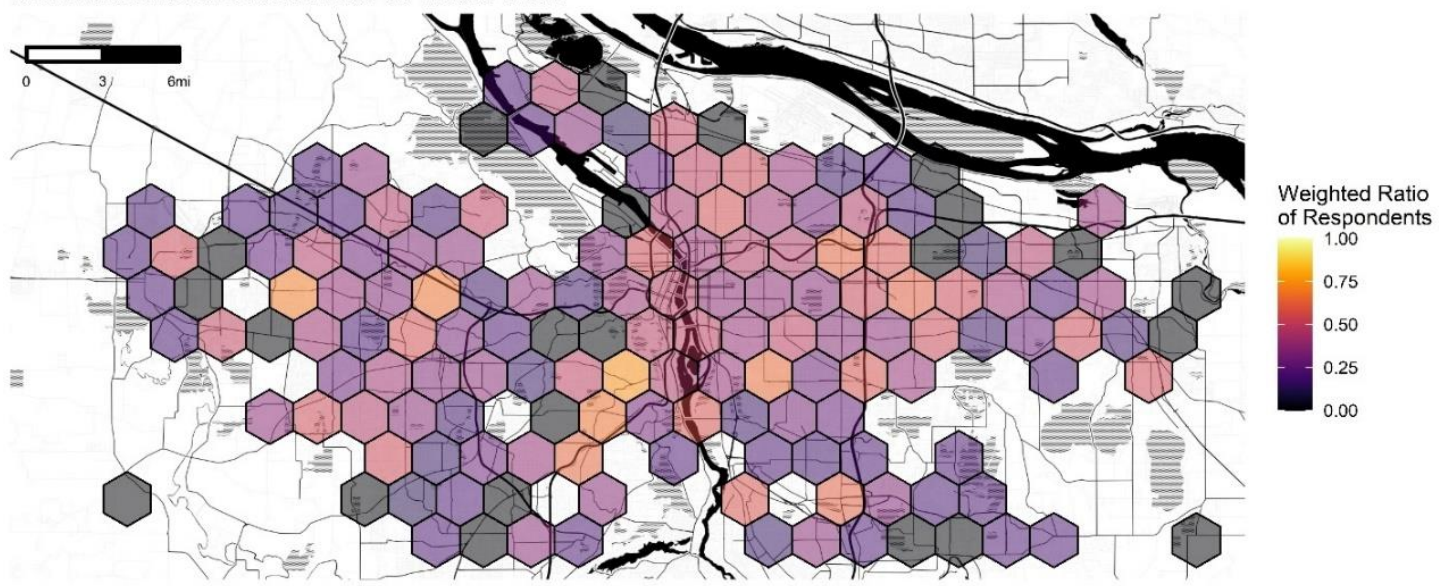

Figure 31: E-Scooter Personal Barriers: I don't want to ride an e-scooter when the weather is bad

Perceived speed could also play a role in preventing respondents from using all modes more frequently. We asked respondents to consider if bikes, e-scooters, and MAX were too slow. Observing the results in Figure 32, Figure 33, and Figure 34, it appears that respondents more frequently felt that bikes were too slow than they did escooters or MAX.

Bike Personal Barriers Bikes are too slow

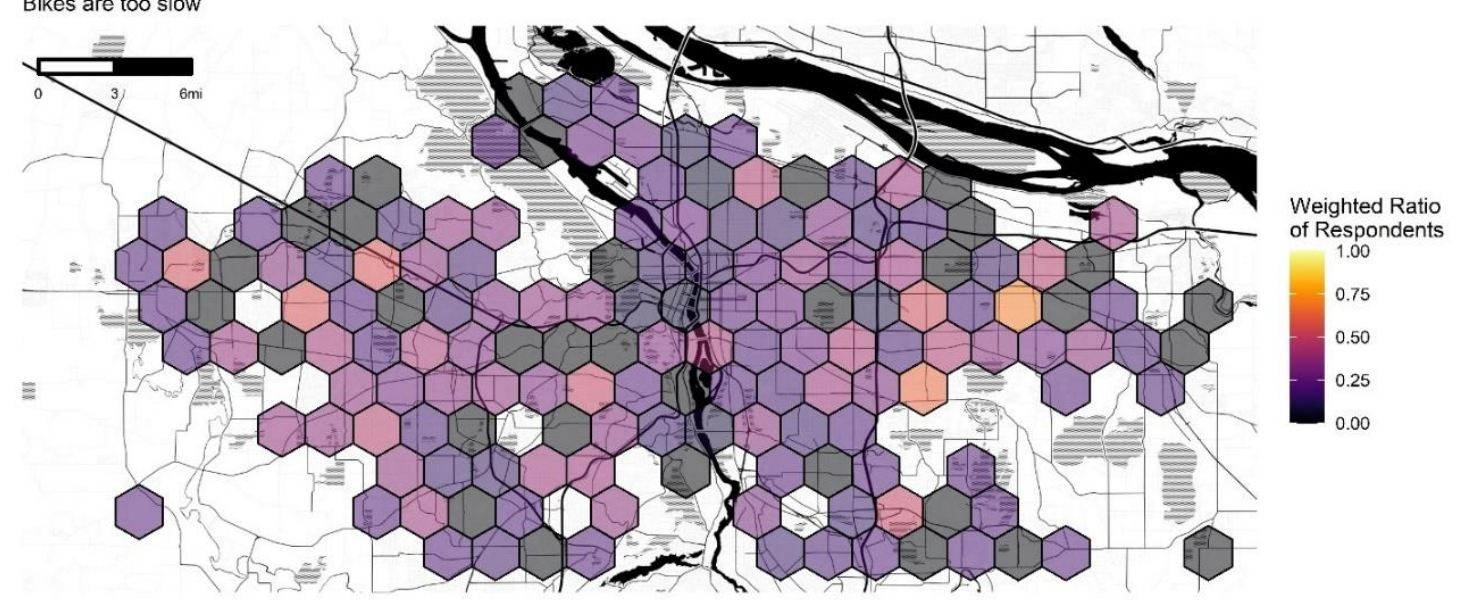


Figure 32: Bike Personal Barriers: Bikes are too slow

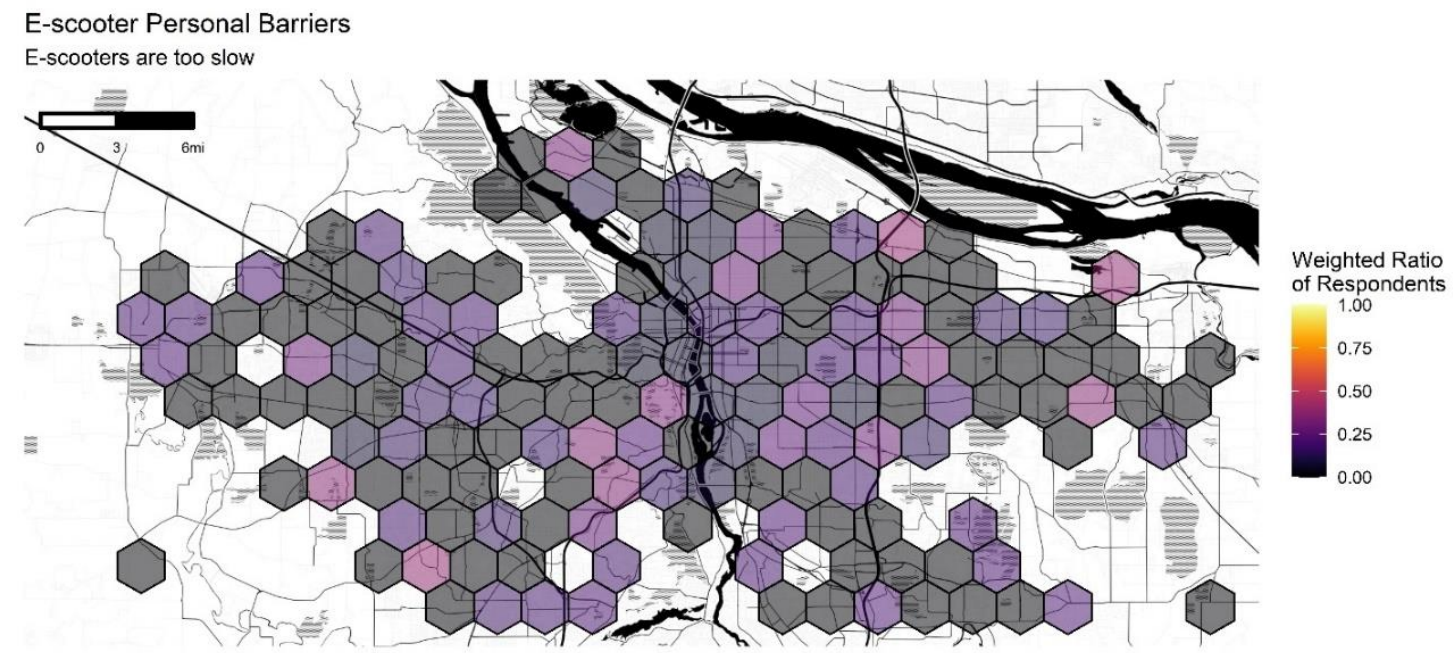

Figure 33: E-Scooter Personal Barriers: E-Scooters are too slow

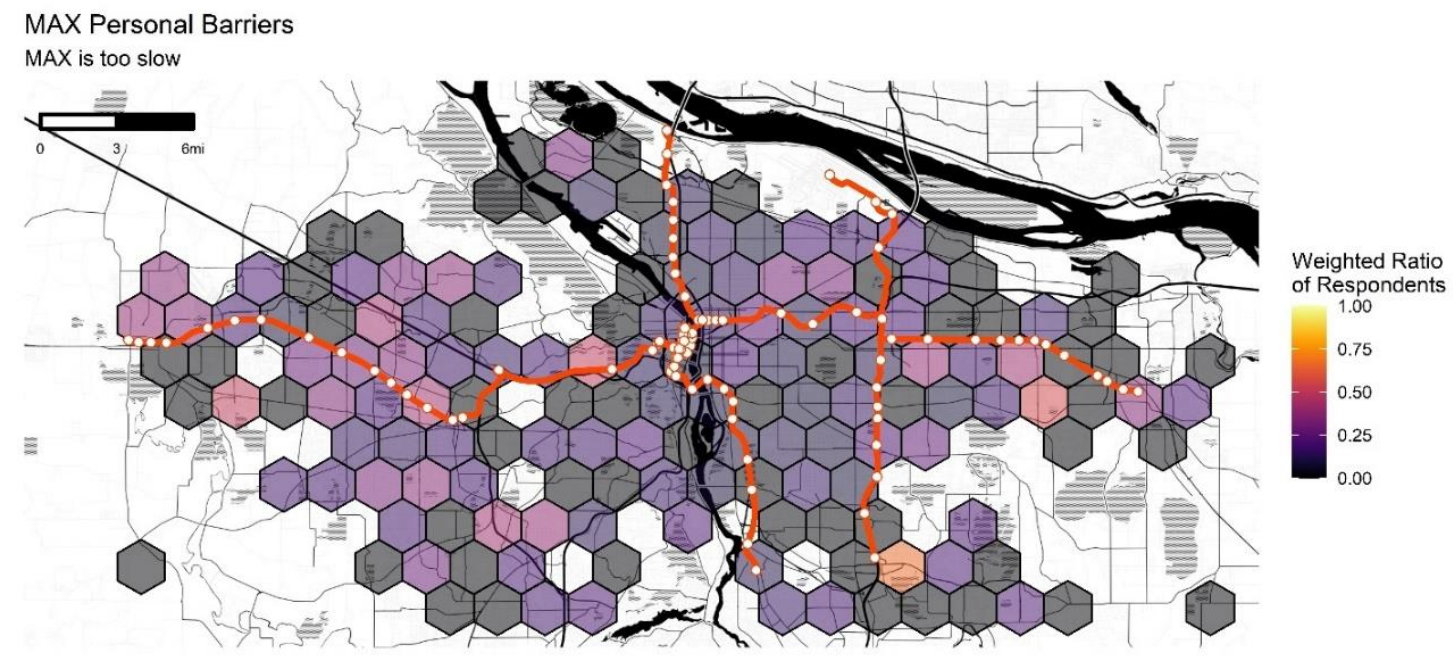

Figure 34: MAX Personal Barriers: MAX is too slow

Lastly, perceived affordability may play a role in preventing users from using any of these modes more frequently. Figure 35 through Figure 38 appear to show that 


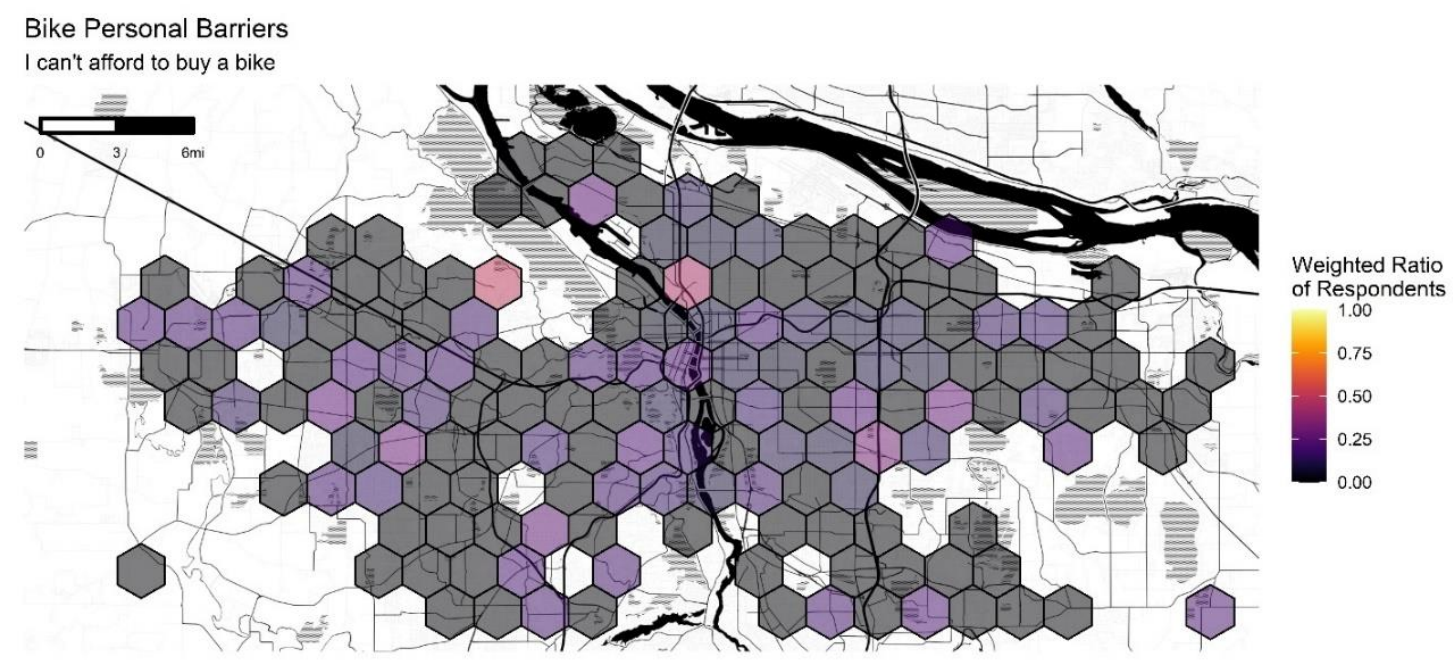

Figure 35: Bike Personal Barriers: I can't afford to buy a bike

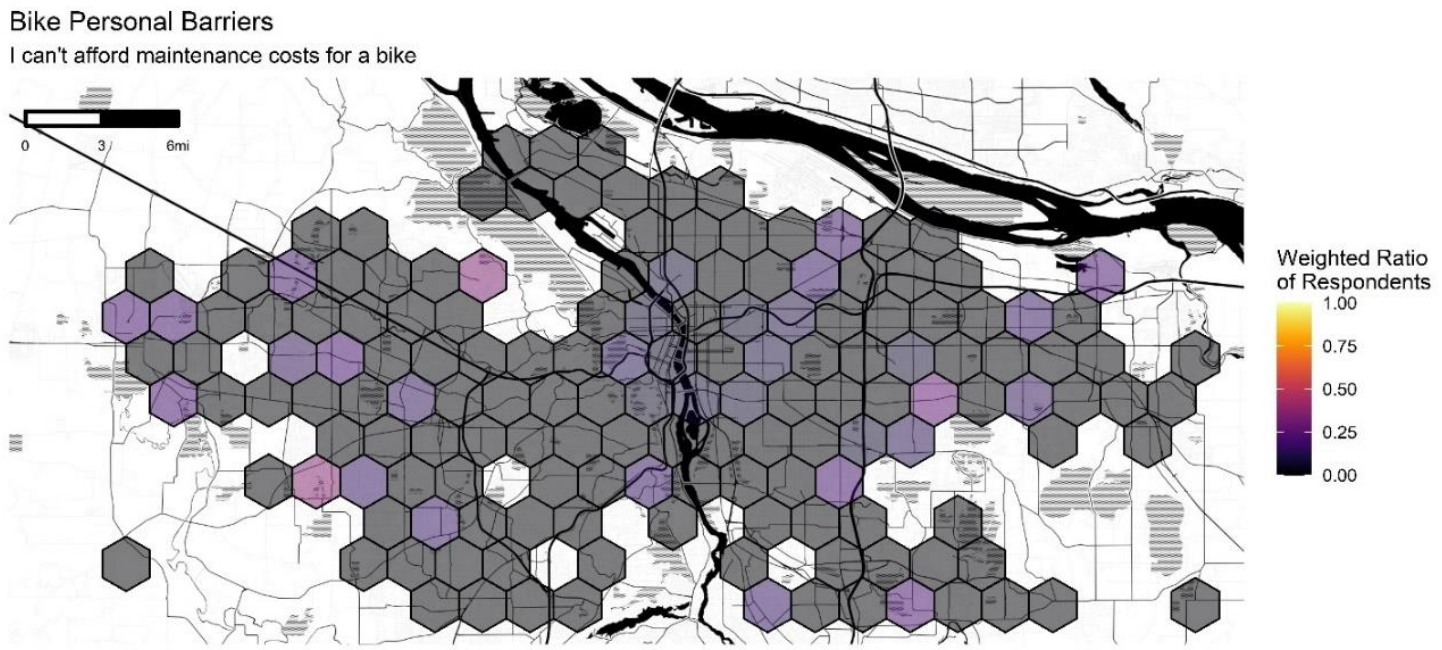

Figure 36: Bike Personal Barriers: I can't afford maintenance costs for a bike 


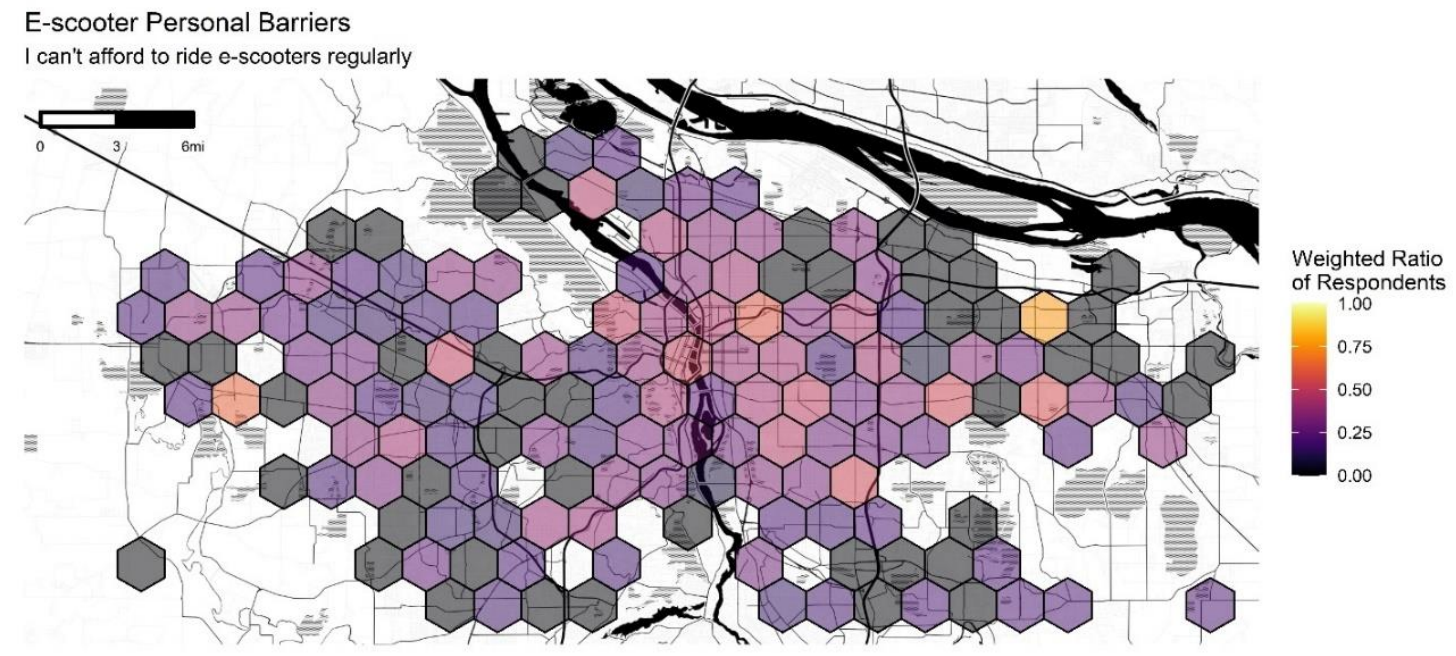

Figure 37: E-Scooter Personal Barriers: I can't afford to ride e-scooters regularly

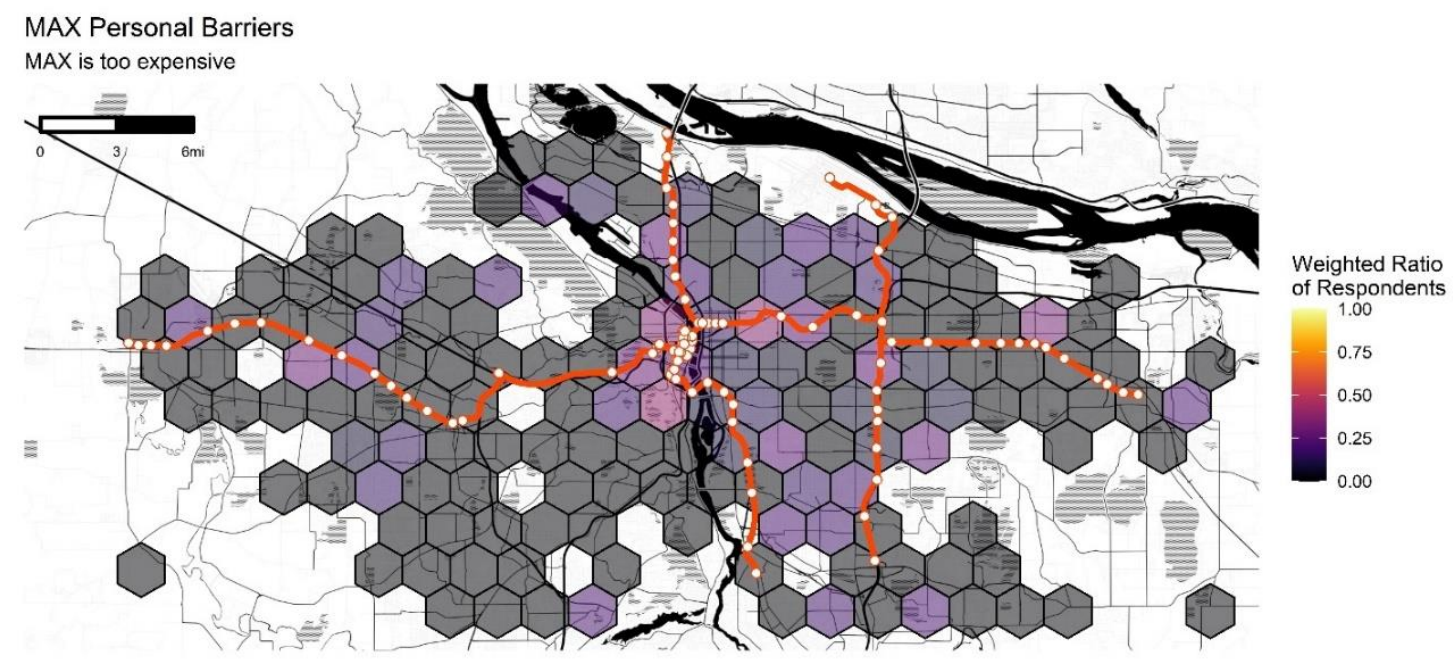

Figure 38: MAX Personal Barriers: MAX is too expensive

\subsection{MNL Sensitivity Analysis and Visualization}

We performed a suite of sensitivity analyses to better comprehend the effect size of several of the significant variables. The extent of each analysis is limited to the range of values provided in the results of the survey to avoid undue extrapolation. The 
impact on potential catchment area for bike, car, and e-scooter + MAX is then mapped using the output of the MNL model. All of the following maps consider estimated travel times obtained using the Google API for trips to PSU predicted for trips leaving at 8:00 AM on July 24, 2020. (It should be noted that Google's travel time algorithm had been updated at the time of testing to better reflect post-COVID travel times. That being said, we tested these travel times multiplied by both 1.25 and 1.50 with marginal differences in results, as previously stated.) Before beginning the sensitivity analyses, we first mapped the catchment areas of the three modes setting all variables to their mean and applying current travel costs, shown in Figure 39. This should be used as the baseline for comparing with other maps. The results indicate that the model does not predict that the e-scooter + MAX mode has a higher probability of being selected than bike or car anywhere within the Portland Metro area given today's travel times and prices. For reference, Figure 40 shows the limits of the Portland e-scooter service area limits for Lime as of $7 / 17 / 20$. 
Probability of Selecting a Mode to get to PSU

Test: Current Conditions

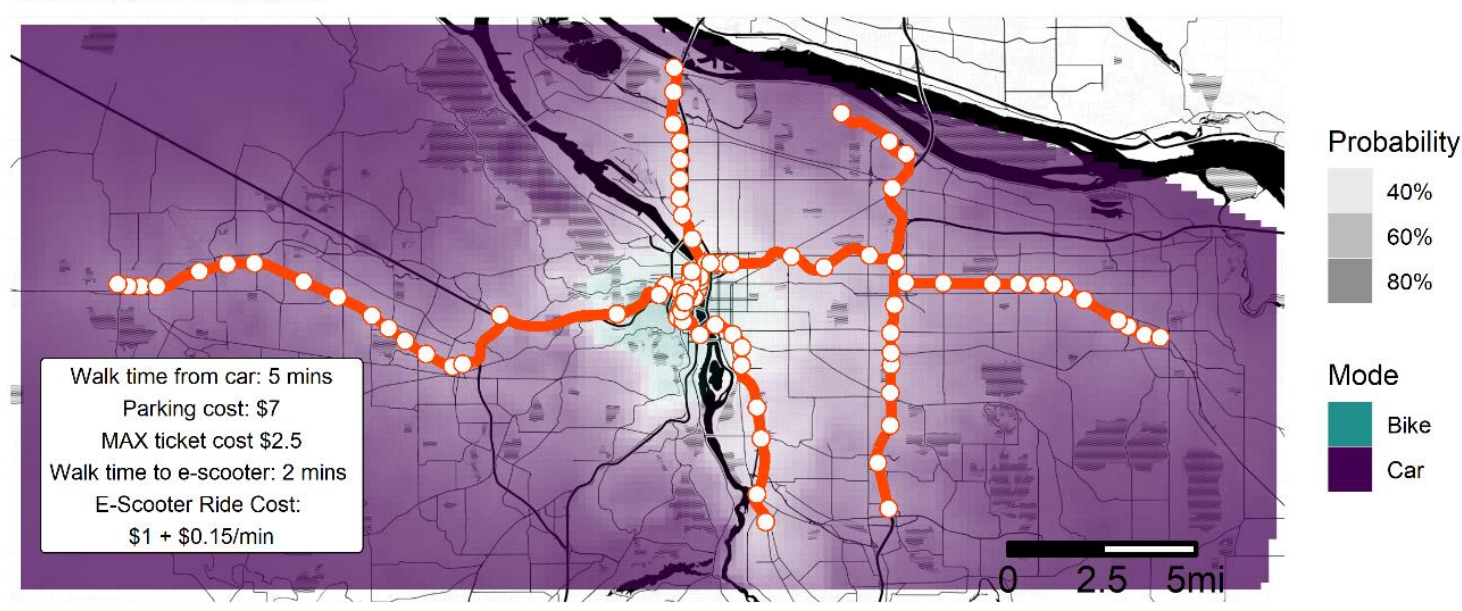

Figure 39: Mode Catchment Areas, Current Conditions

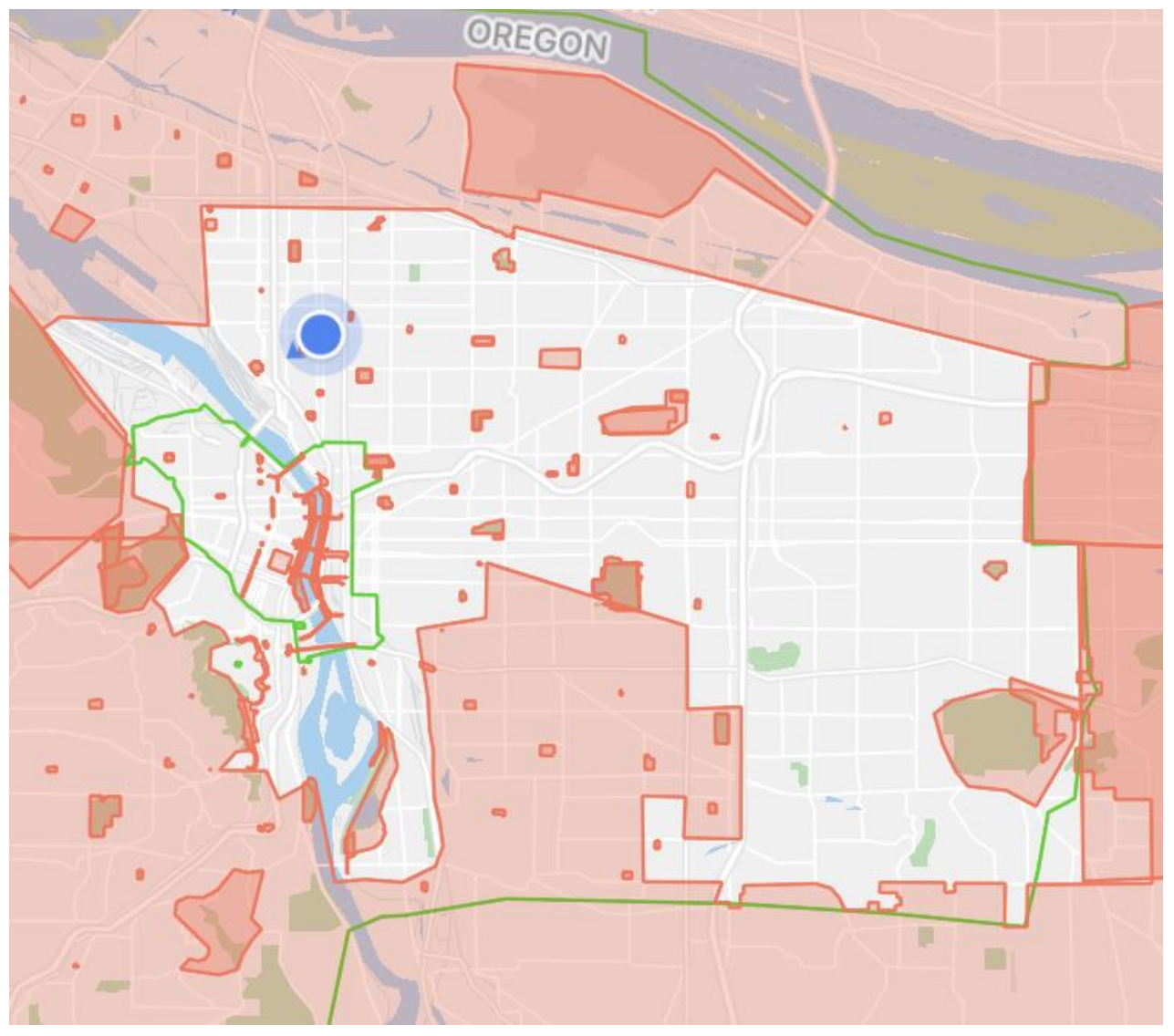

Figure 40: Lime Service Area, Portland, as of 7/17/20 


\subsubsection{Experiment Attributes}

In this subsection, we discuss the sensitivity of some of the attributes manipulated in the stated choice experiment.

\subsubsection{Travel Time}

The sensitivity analyses for travel for each mode are shown in Figure 41 through

Figure 44. It appears that car drive time and bike ride time were the only two travel time variables that could independently result in a mode shift within the range of the experiment values. All else held at average, travelers would be more likely to take a bike until the ride time reaches 32.5 minutes. Likewise, travelers would be more likely to take a car until the drive time reaches 42.5 minutes. The e-scooter + MAX option does not become more attractive than either of the other two modes in the ranges examined. 


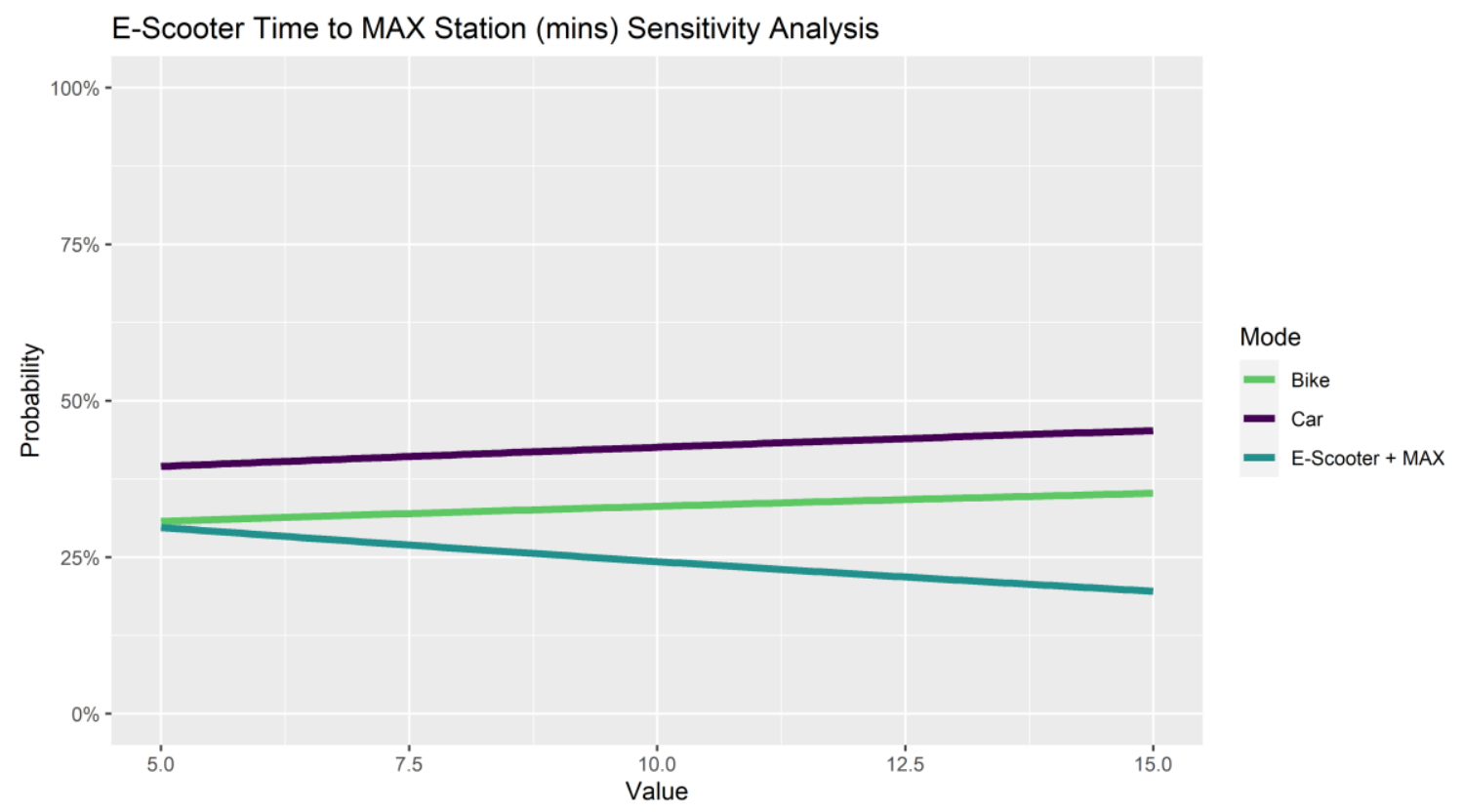

Figure 41: E-Scooter Travel Time Sensitivity Analysis

Bike Ride Time (mins) Sensitivity Analysis

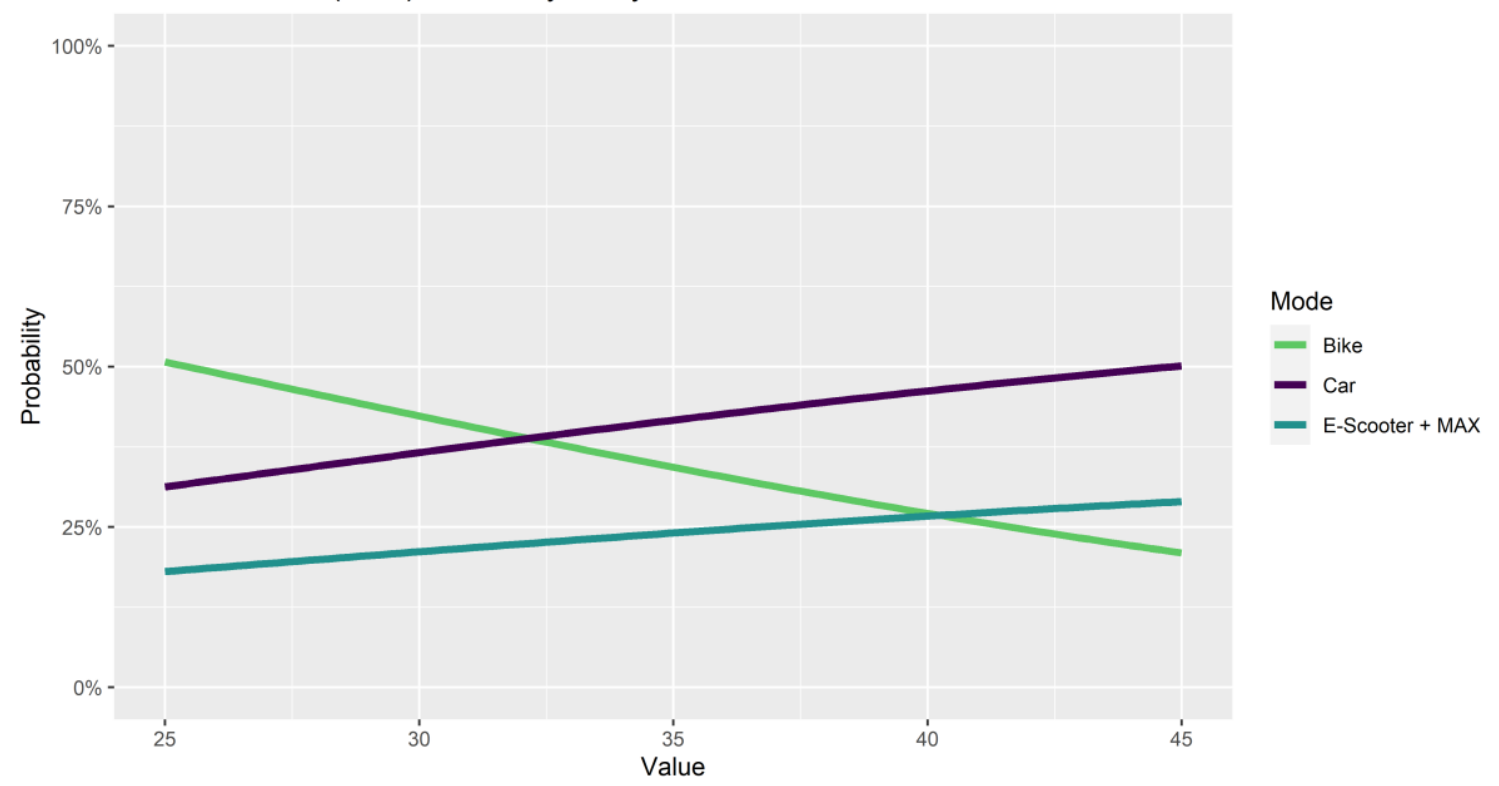

Figure 42: Bike Travel Time Sensitivity Analysis 


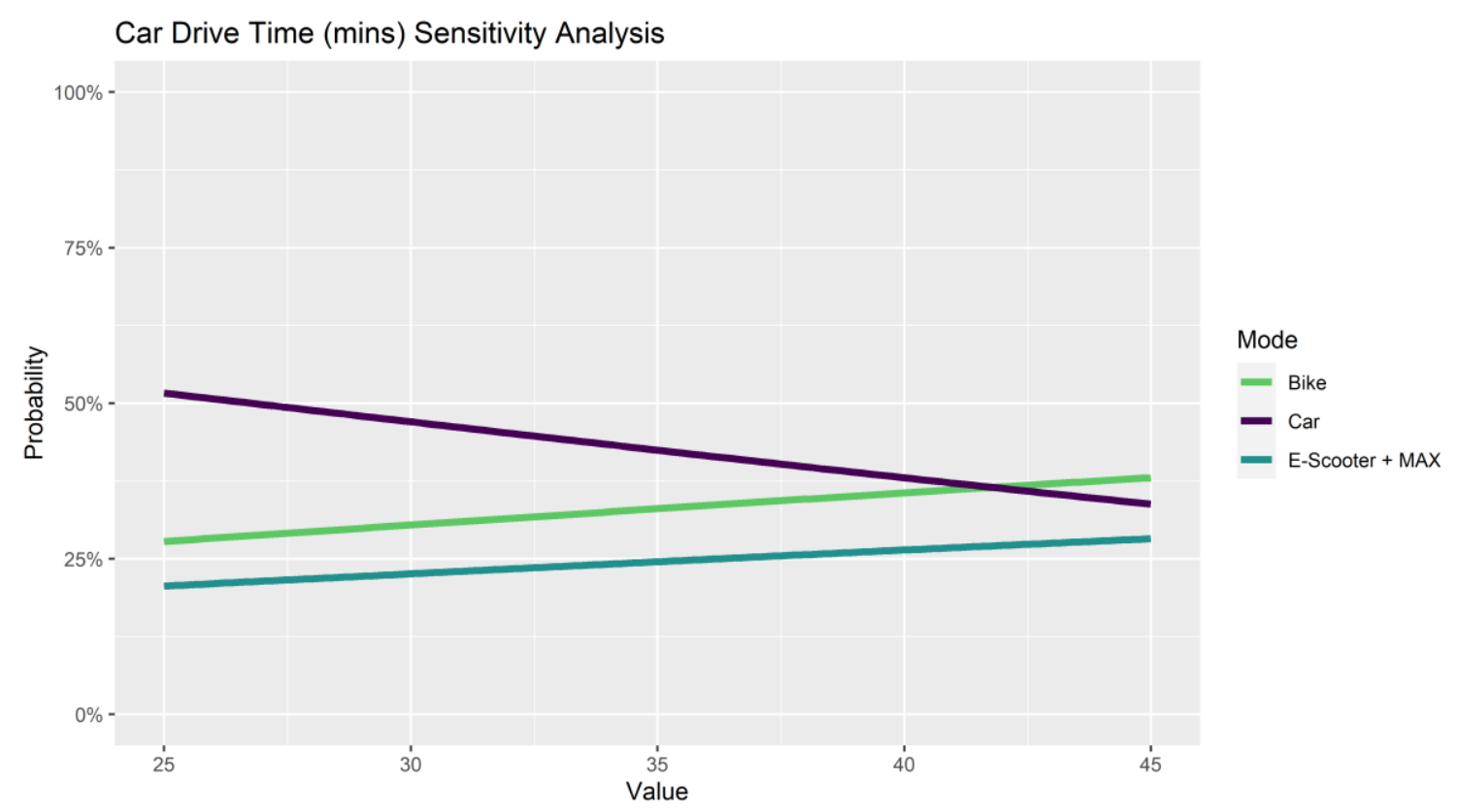

Figure 43: Car Travel Time Sensitivity Analysis

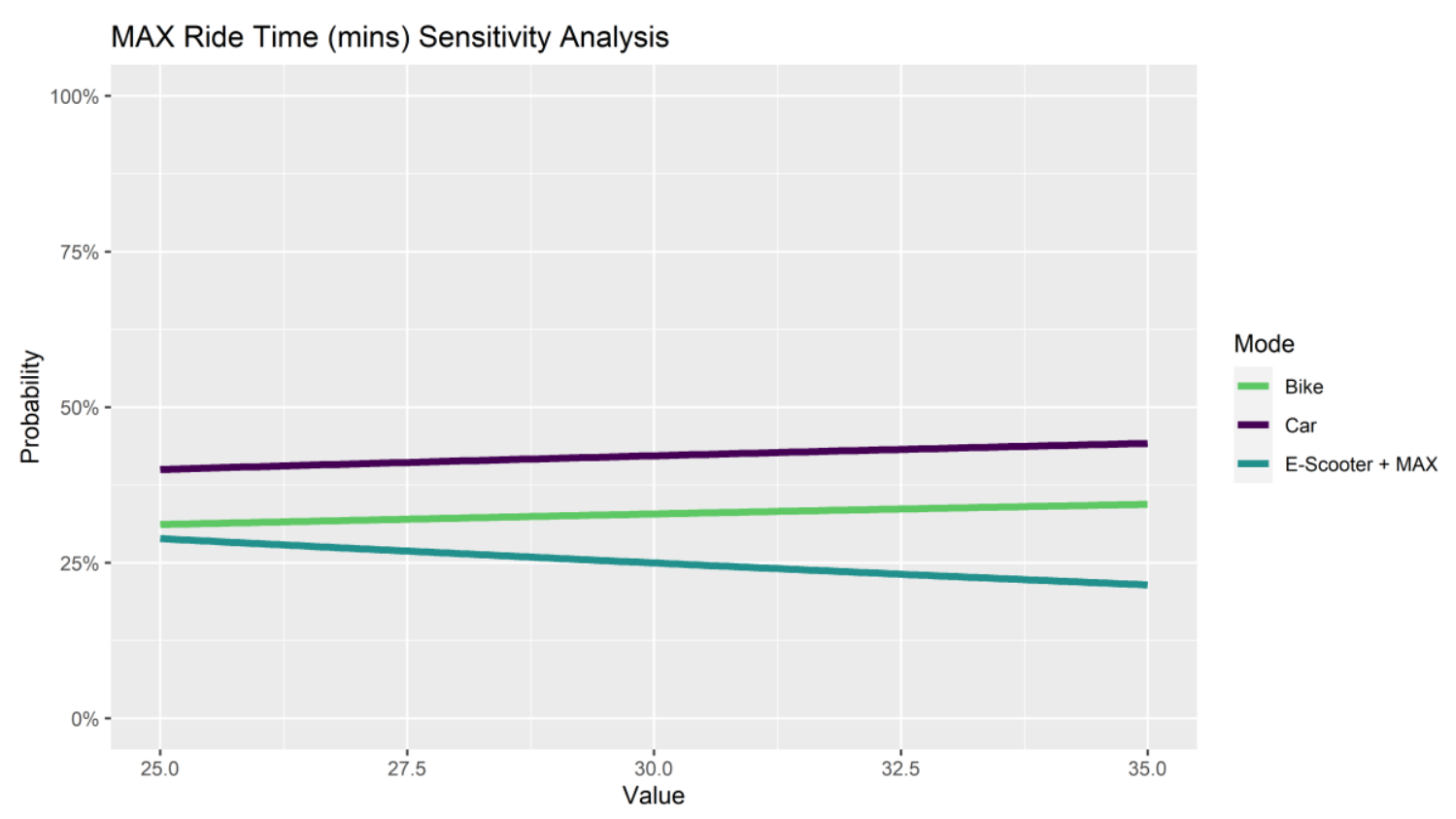

Figure 44: MAX Travel Time Sensitivity Analysis 


\subsubsection{Cost}

The sensitivity for car parking cost is displayed in Figure 45. As parking costs increase, the probability of a traveler selecting the car mode decreases. The traveler is more likely to select a bike starting at parking costs around $\$ 8.75$ per day. Additionally, the traveler would be more likely to select the e-scooter + MAX mode when parking costs exceed $\$ 11$ per day. Figure 46 displays the results of a parking cost increase from $\$ 7$ to $\$ 11$. In it, we observe an enlargement of the bike catchment area. Additionally, escooter + MAX has become the most attractive mode towards the southern end of the MAX Orange Line. A parking cost increase from $\$ 7$ to $\$ 15$, as shown in Figure 47 , would result in a larger enlargement of the bike and e-scooter catchment areas. Now, escooters are the most attractive mode near the stations of each MAX line, extending to the termini. 
Car Parking Cost (\$) Sensitivity Analysis

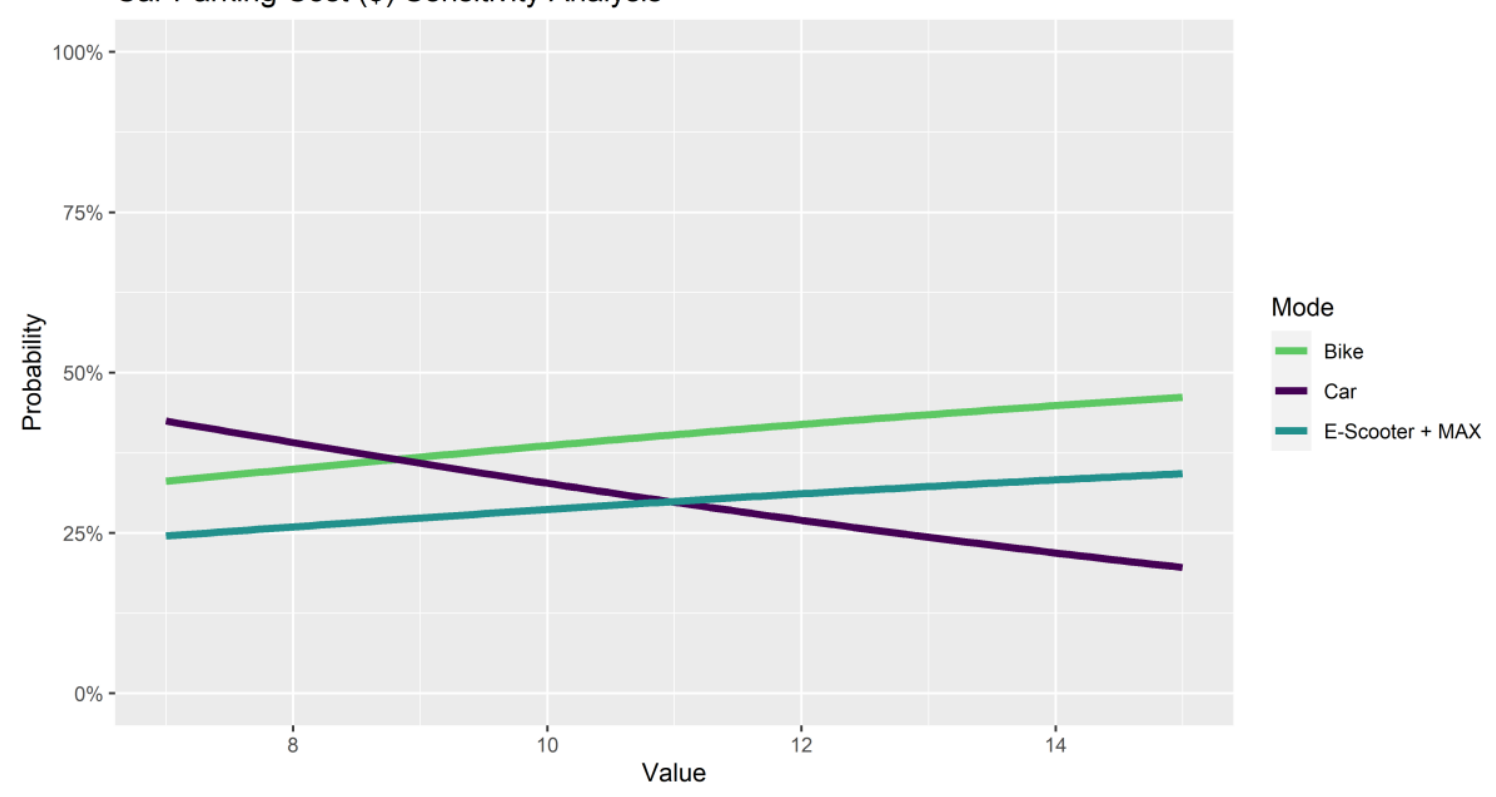

Figure 45: Car Parking Cost Sensitivity Analysis

Probability of Selecting a Mode to get to PSU

Test: Medium Parking Cost Increase

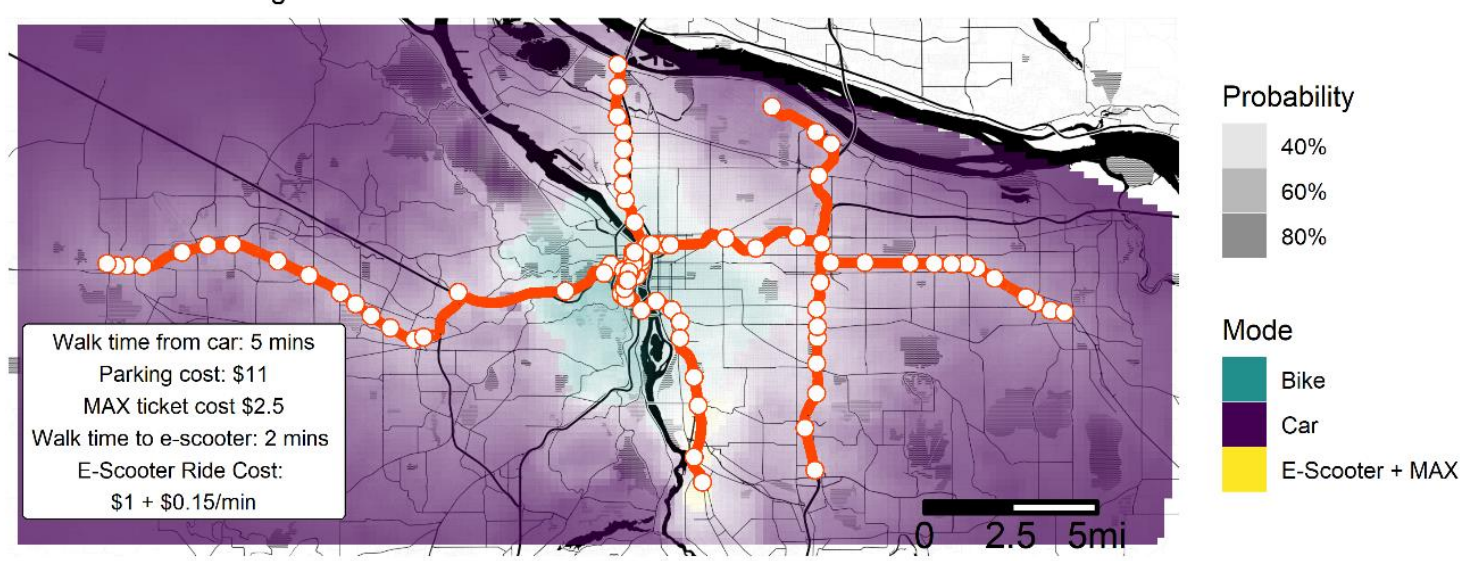

Figure 46: Mode Catchment Areas, Medium Parking Increase 
Probability of Selecting a Mode to get to PSU

Test: Large Parking Cost Increase

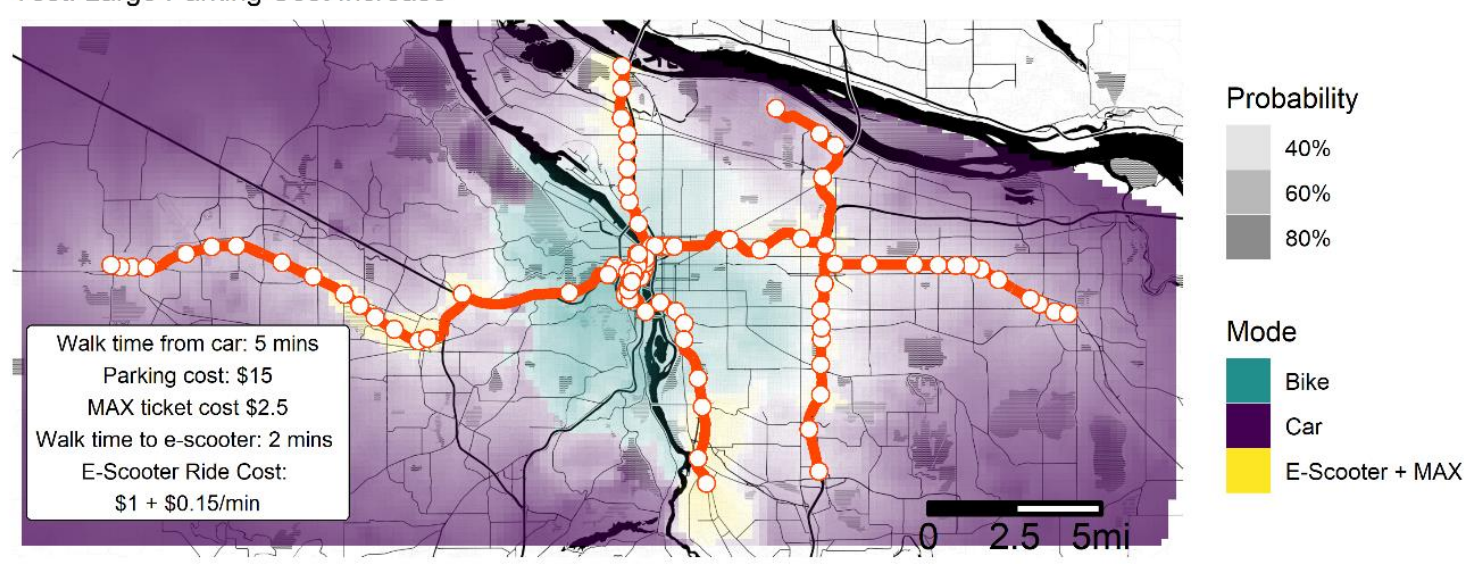

Figure 47: Mode Catchment Areas, Large Parking Increase

Next, we looked at the sensitivity of e-scooter cost. According to

Figure 48, all else held at the mean, there is no e-scooter price that would cause e-

scooter + MAX to have the highest probability of being selected. Along these lines, even setting e-scooter cost to free does not cause an e-scooter + MAX catchment area to appear in Figure 49. 


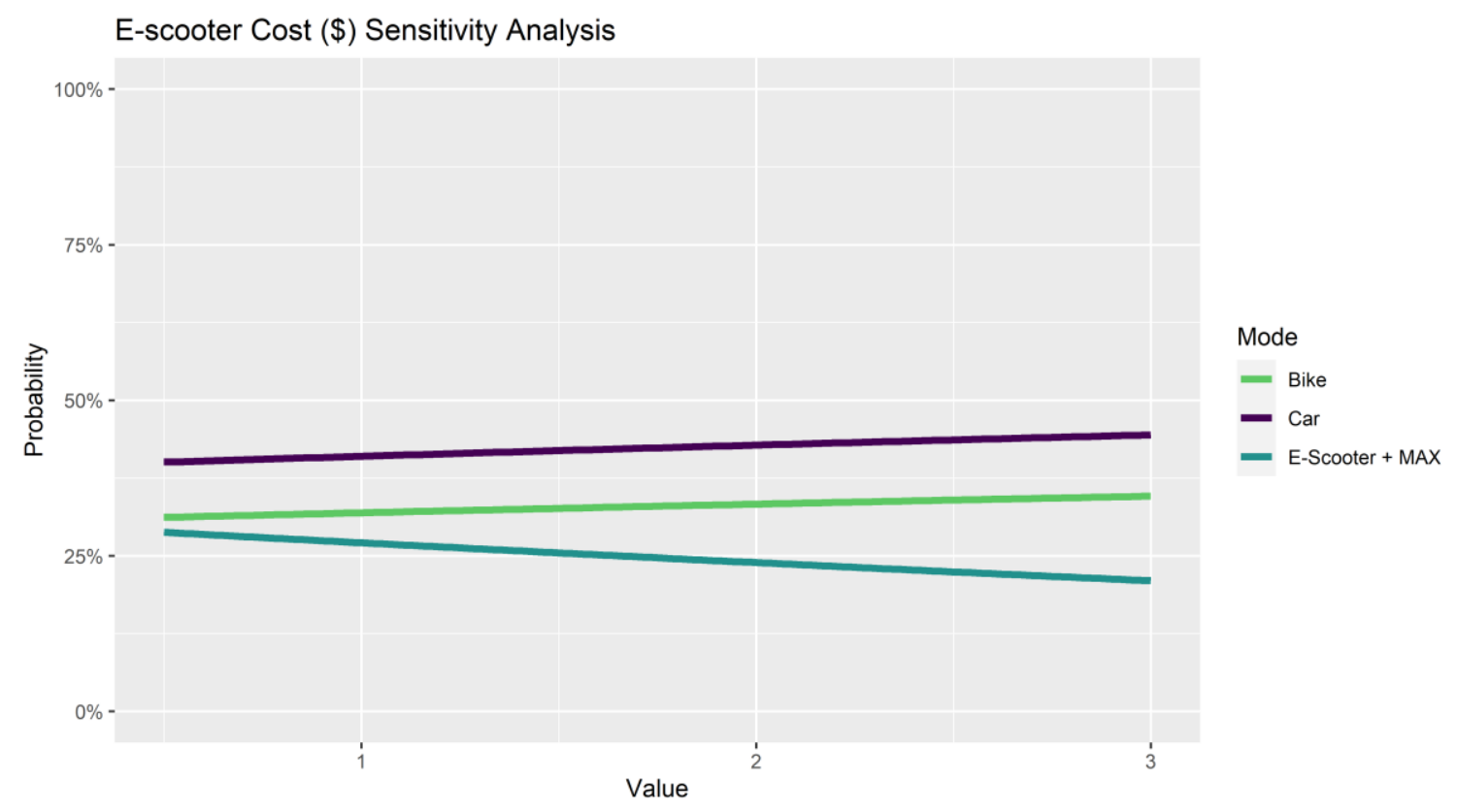

Figure 48: E-Scooter Cost Sensitivity Analysis

Probability of Selecting a Mode to get to PSU

Test: Free E-Scooters

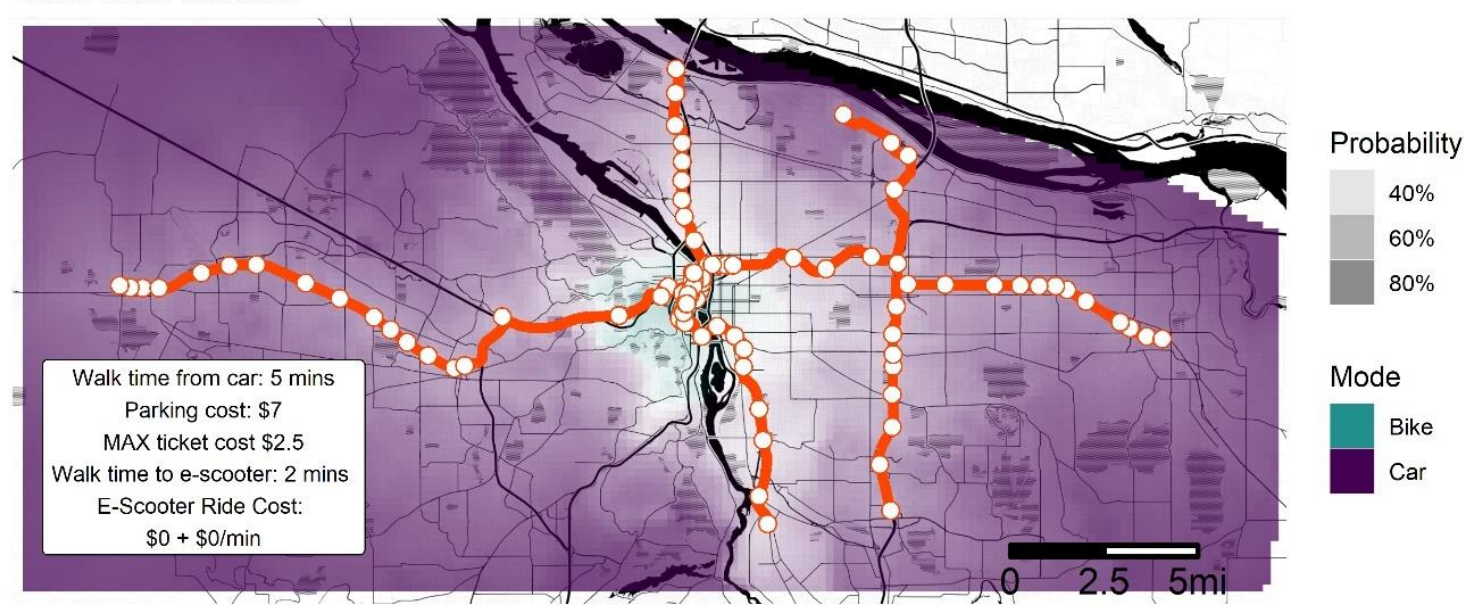

Figure 49: Mode Catchment Areas, Free E-Scooters 


\subsubsection{Demographics}

Next, we observe the effects of a few demographic variables, namely gender and race or ethnicity.

\subsubsection{Gender}

The sensitivity analysis for female respondents is shown in Figure 50. Females were most likely to choose car. Figure 51 shows a small bike catchment area for females. Setting the average respondent to male in Figure 52. shows the largest catchment area for bike, yet e-scooter + MAX would still not be likely to be selected anywhere in the metro area.

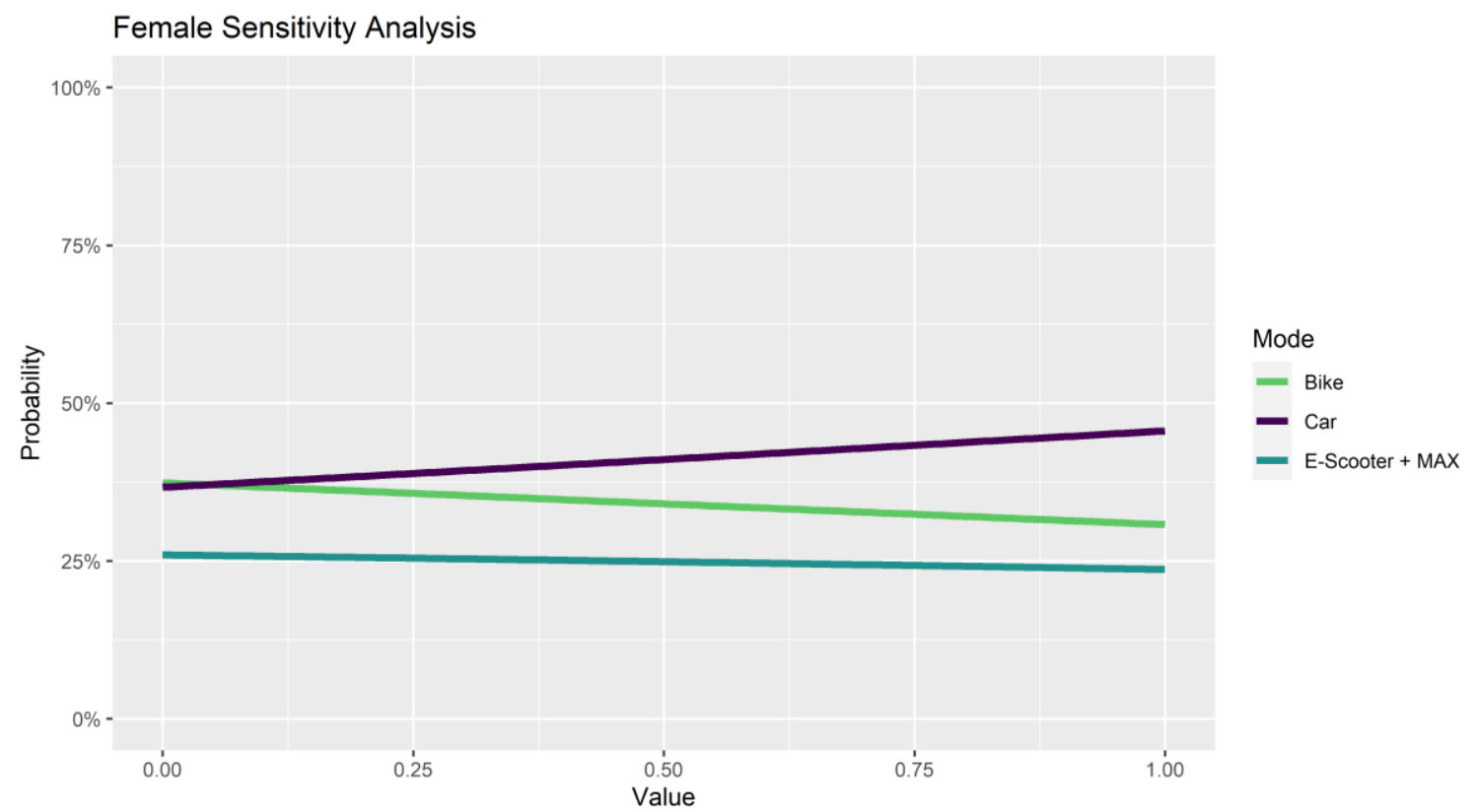

Figure 50: Gender sensitivity analysis: Female 
Probability of Selecting a Mode to get to PSU

Test: Female

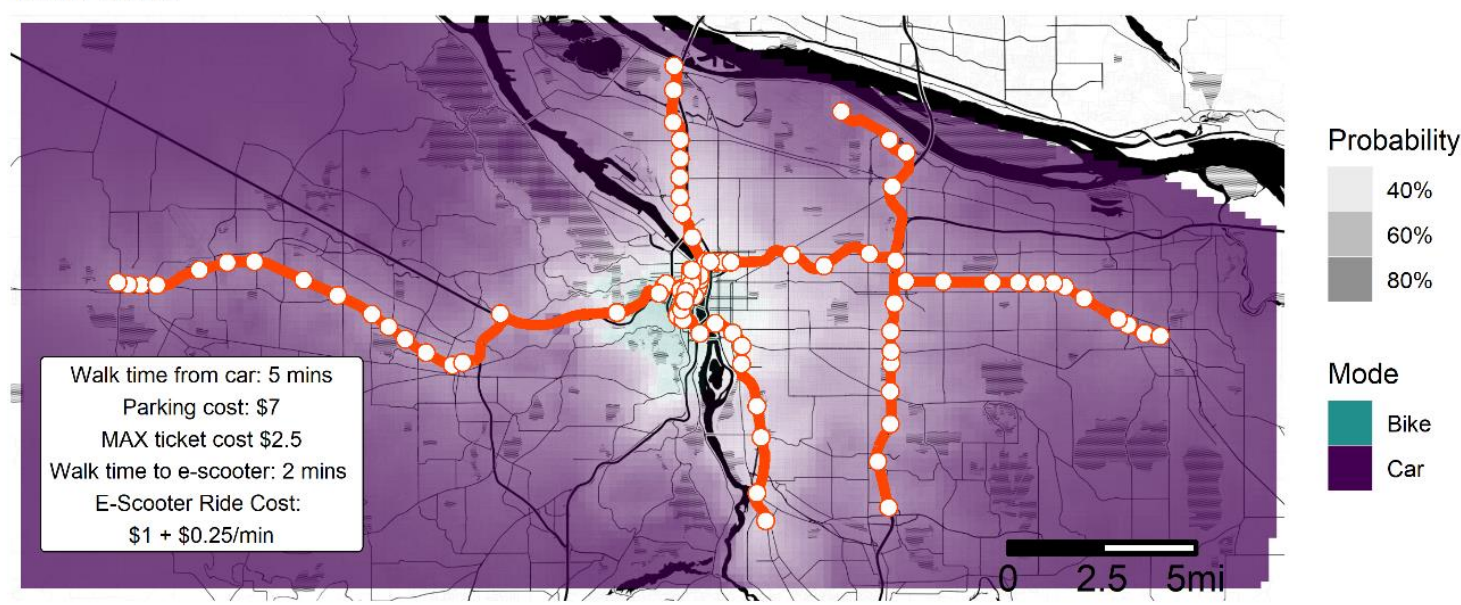

Figure 51: Mode Catchment Areas, Female Travelers

Probability of Selecting a Mode to get to PSU

Test: Male

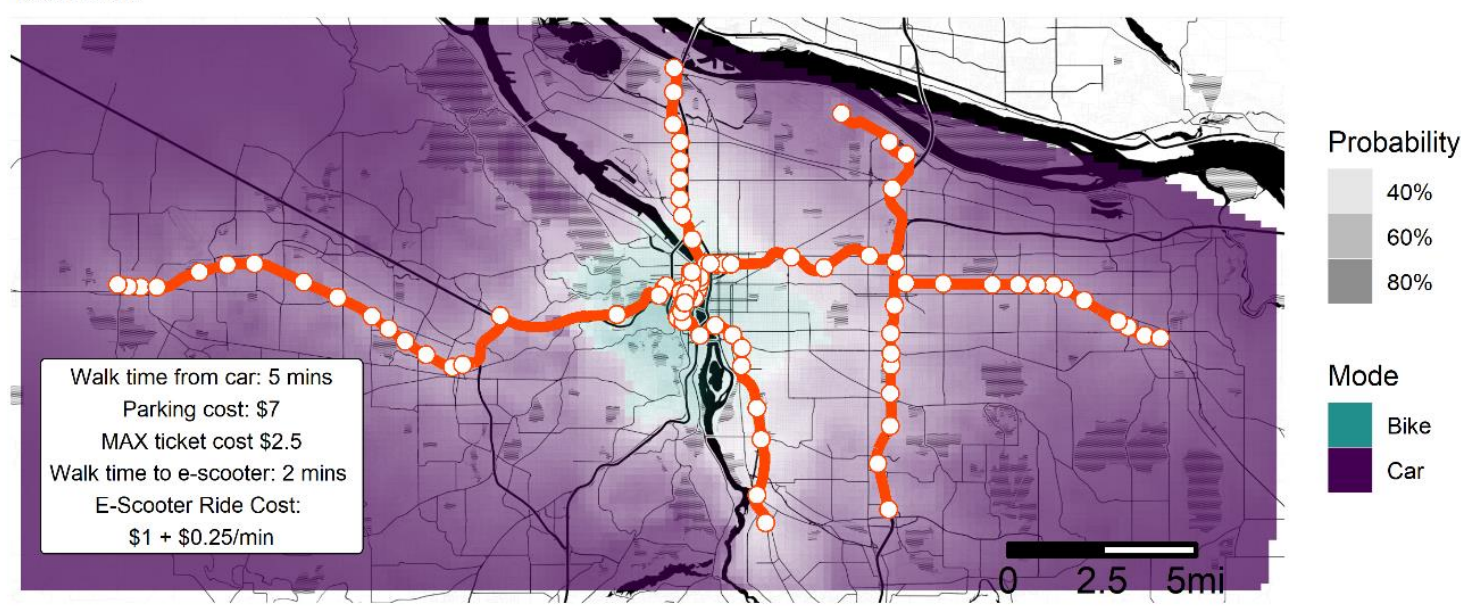

Figure 52: Mode Catchment Areas, Male Travelers 


\subsubsection{Race and Ethnicity}

The sensitivity analyses for the minority groups with the most respondents are shown in Figure 53 through Figure 55. Asian respondents displayed a very similar probability of selecting either car or bike. Black respondents showed the highest propensity to select car. Hispanic or Latinx/Latino/Latina respondents were not much different from the average respondents when it came to selecting a mode. As a result, Asian respondents had the largest bike catchment areas (Figure 56), followed by White respondents (Figure 59) and Hispanic or Latinx/Latino/Latina respondents (Figure 58). There was not any place in the metro area where Black respondents would be more likely to choose anything other than car (Figure 57).

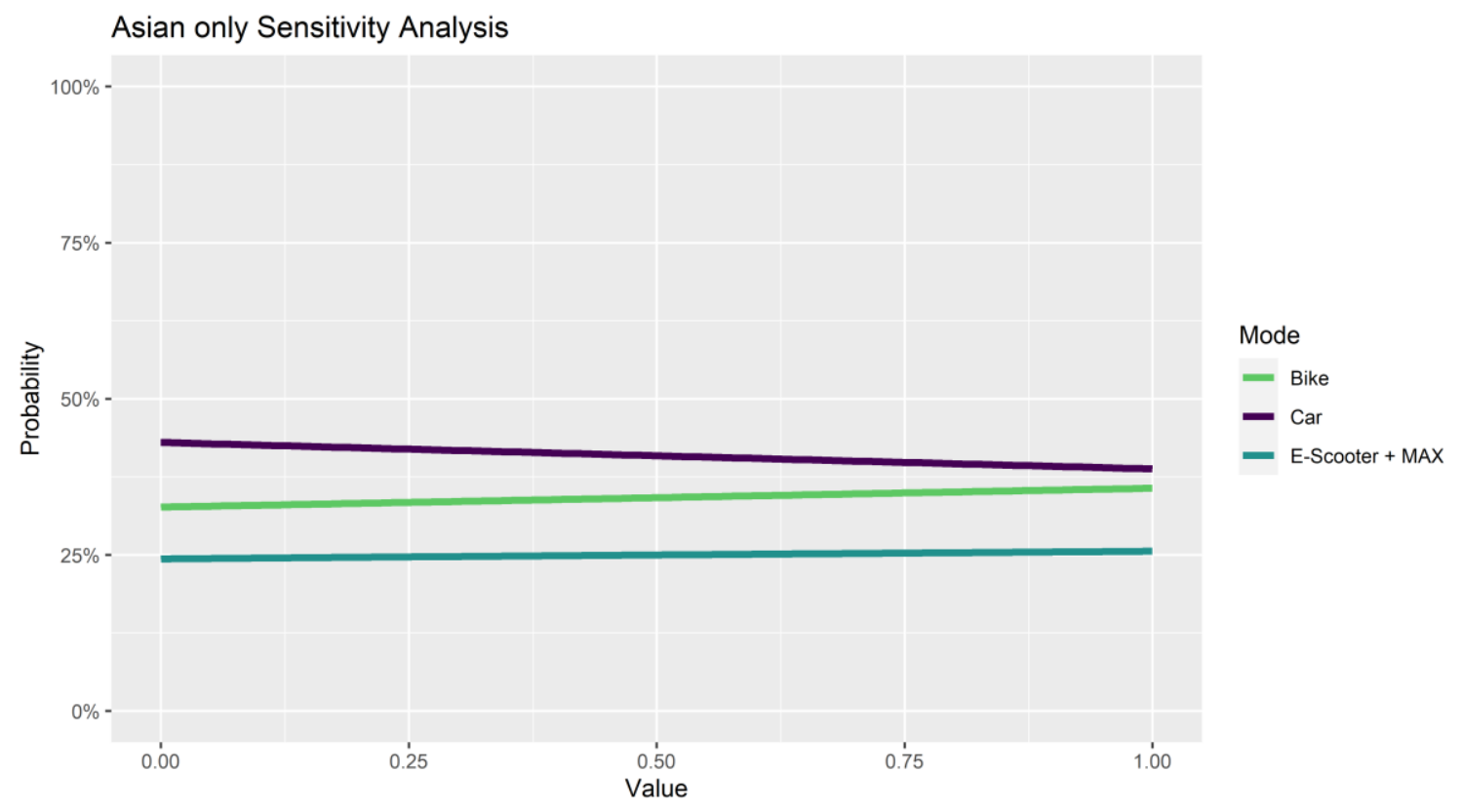

Figure 53: Race and Ethnicity Sensitivity Analysis: Asian 


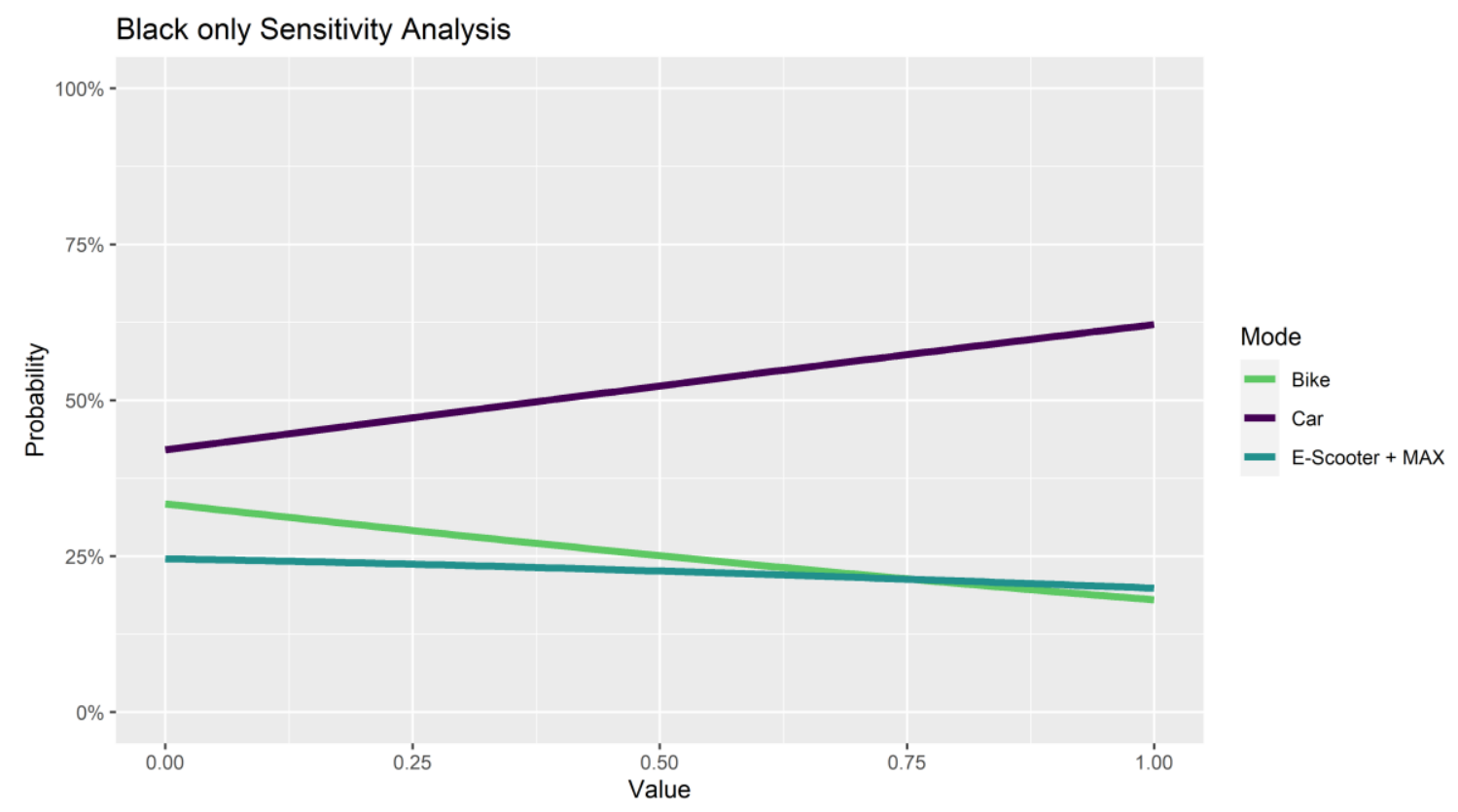

Figure 54: Race and Ethnicity Sensitivity Analysis: Black

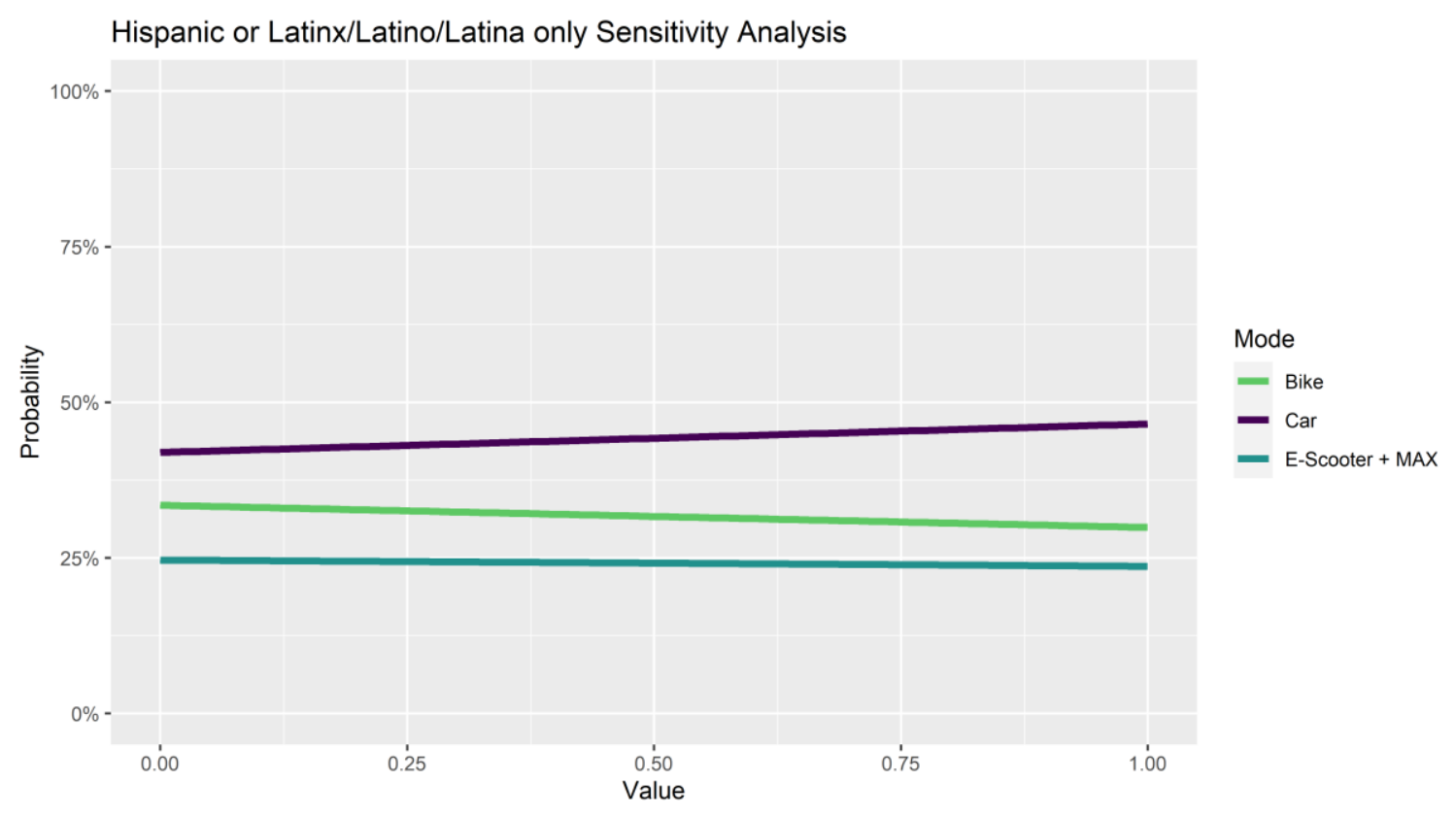

Figure 55: Race and Ethnicity Sensitivity Analysis: Hispanic or Latinx/Latino/Latina 
Probability of Selecting a Mode to get to PSU

Test: Race/Ethnicity: Asian

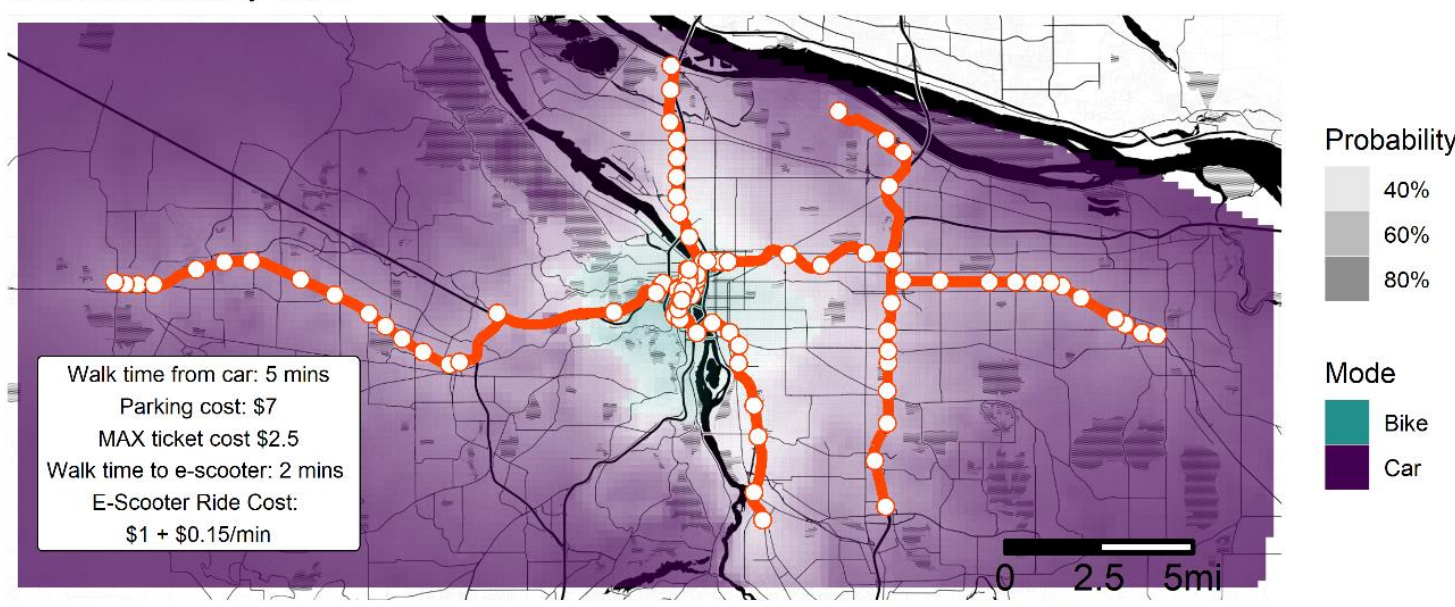

Figure 56: Mode Catchment Areas, Asian Travelers

Probability of Selecting a Mode to get to PSU

Test: Race/Ethnicity: Black

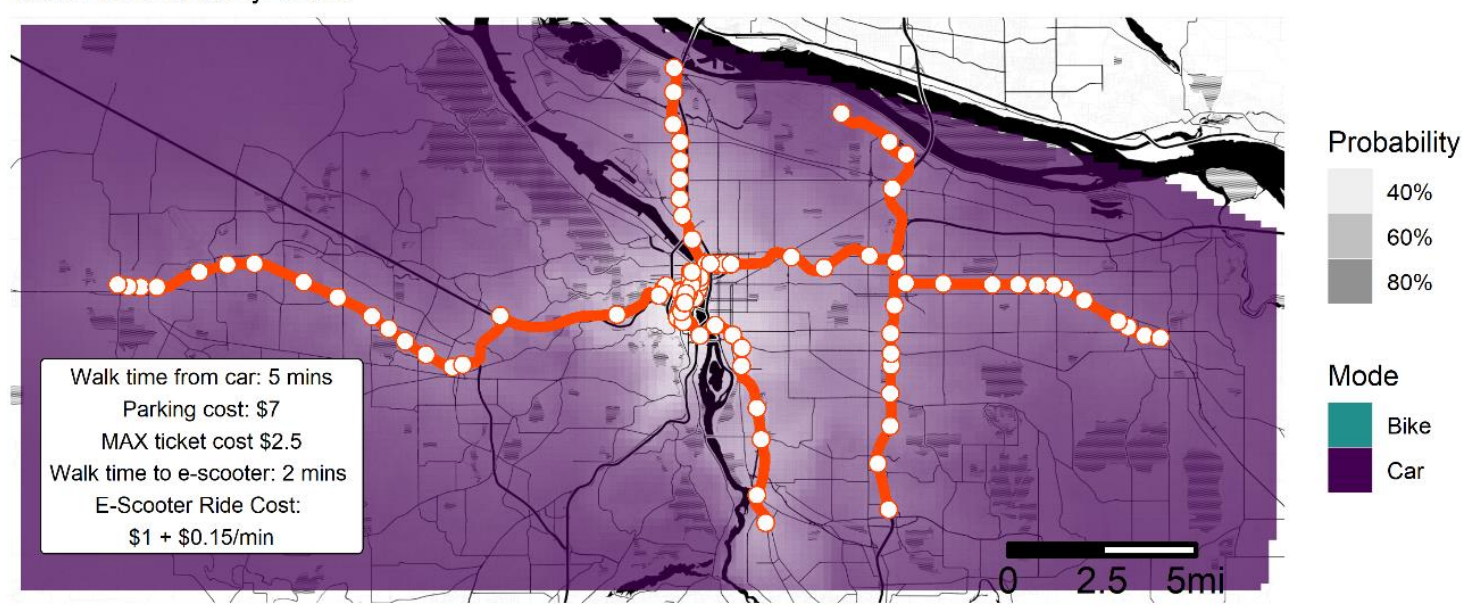

Figure 57: Mode Catchment Areas, Black Travelers 
Probability of Selecting a Mode to get to PSU

Test: Race/Ethnicity: Hispanic, Latinx

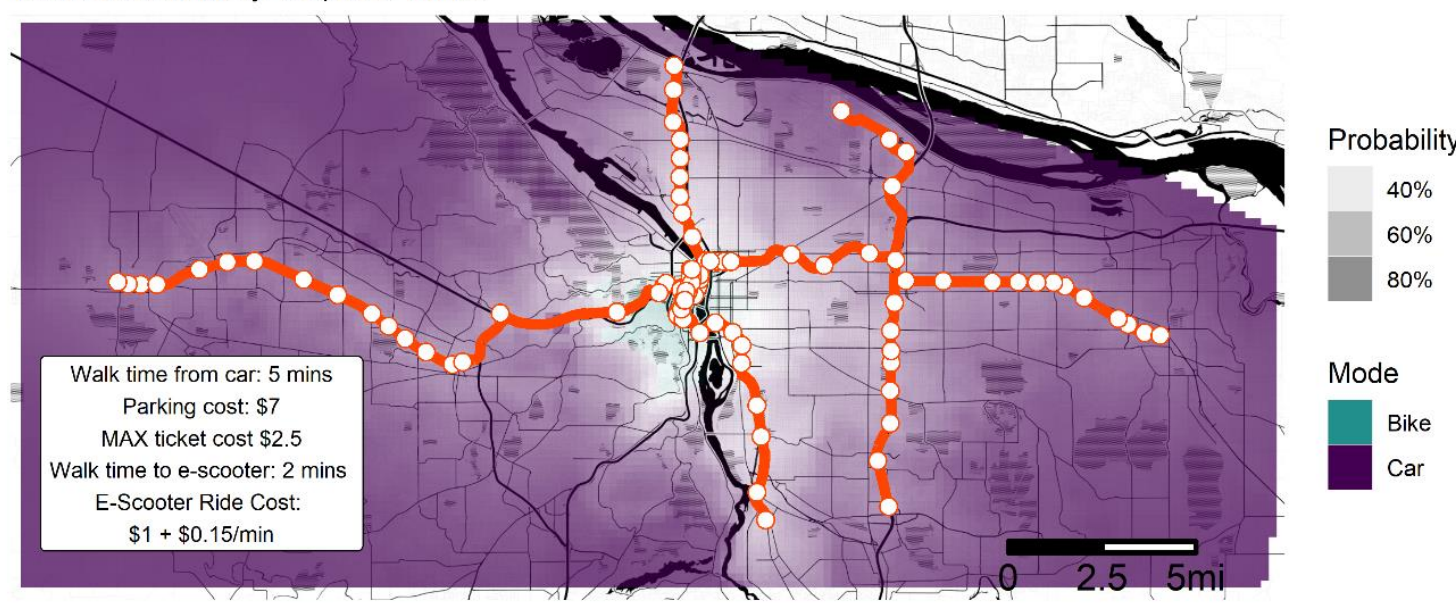

Figure 58: Mode Catchment Areas, Hispanic or Latinx Travelers

Probability of Selecting a Mode to get to PSU

Test: Race/Ethnicity: White

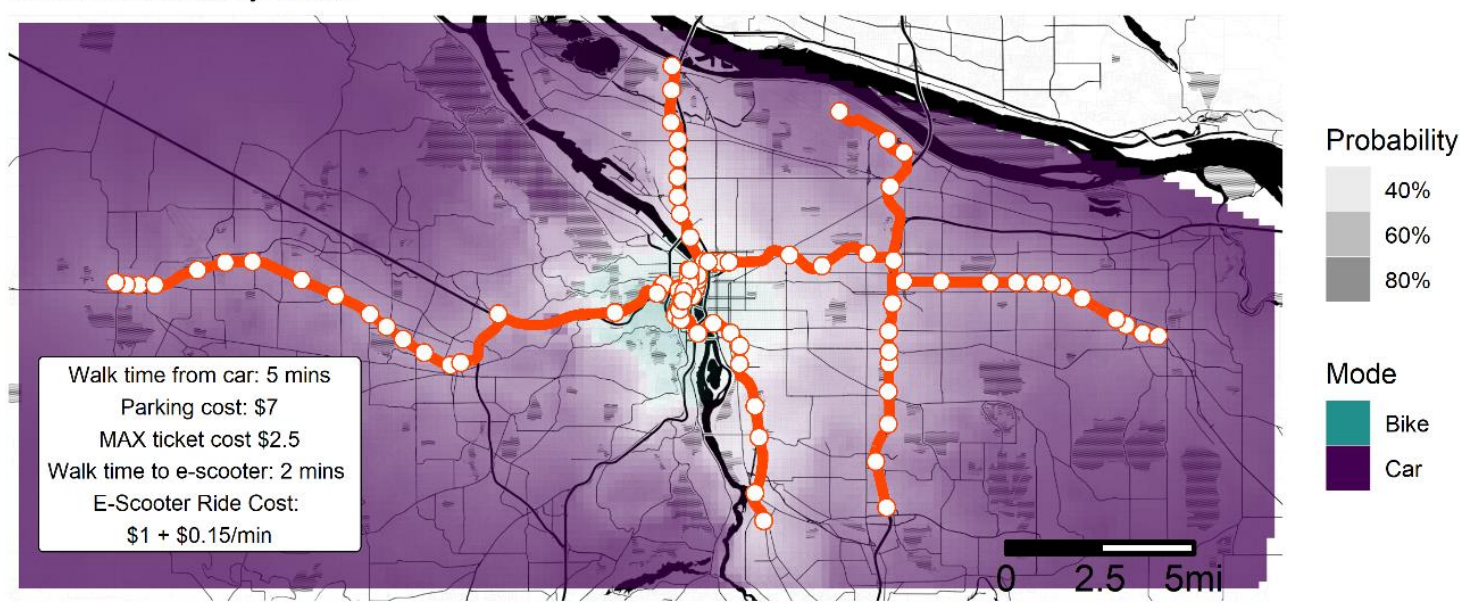

Figure 59: Mode Catchment Areas, White Travelers 


\subsubsection{Latent Attitudes}

Lastly, we performed sensitivity analyses on some of the estimated latent attitude indices. The Bike Attitude index had the most dramatic change in mode choice probability out of any other variable, as seen in Figure 60 . However, respondents with high Bike Attitude were never more likely to choose e-scooter + MAX over car, on average. The mode catchment areas, as a result, reflect this in that there is no place in the metro area where these respondents would choose e-scooter + MAX, all else held at average. Figure 61, or a simulation of a respondent with a very low Bike Attitude, also has no bike catchment area either. This is tempered by Figure 62 , which shows that those that view bikes favorably are willing to choose bike within the largest catchment area of all other variables.

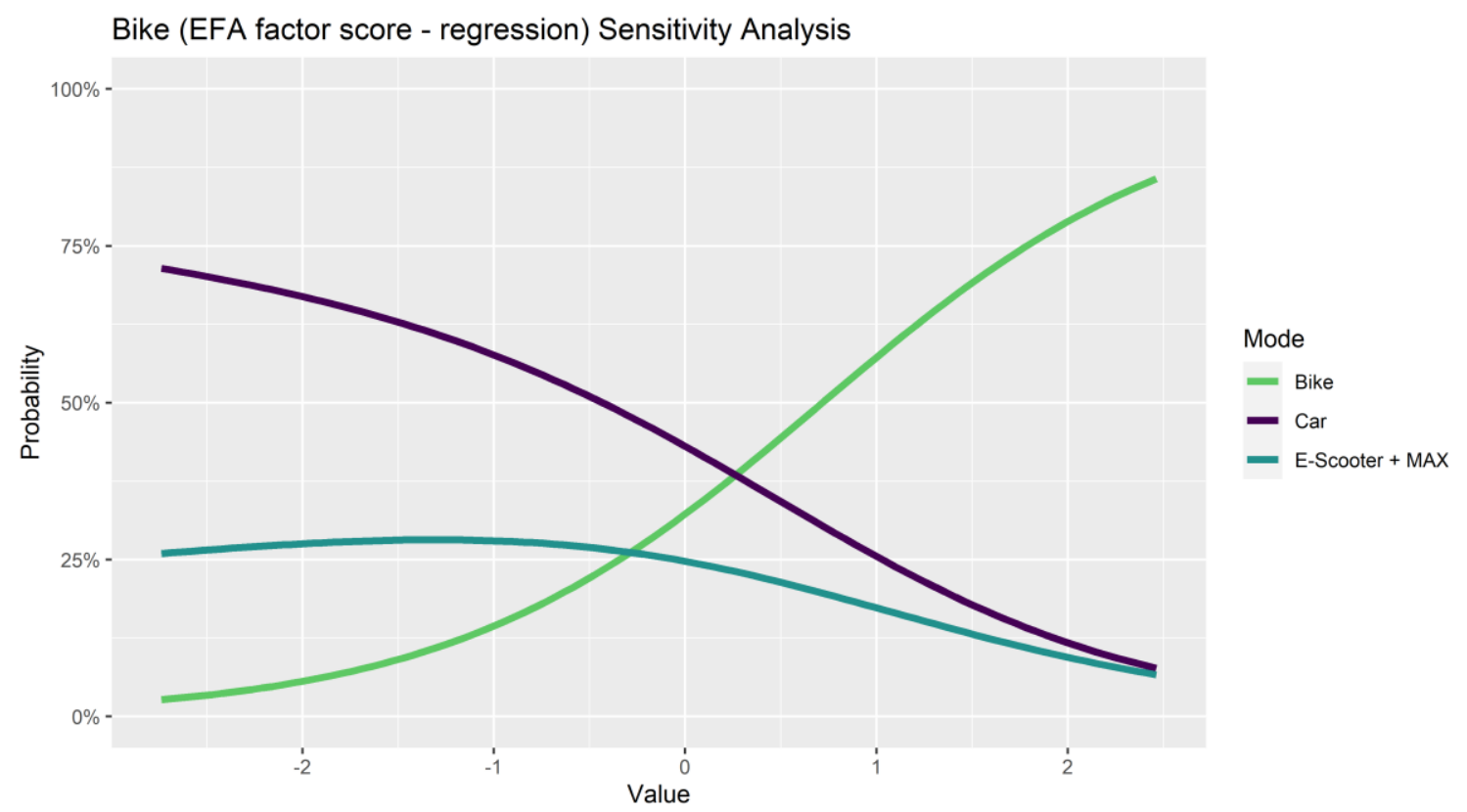

Figure 60: Latent Attitude Sensitivity Analysis: Bike 
Probability of Selecting a Mode to get to PSU

Test: Low Bike Attitude

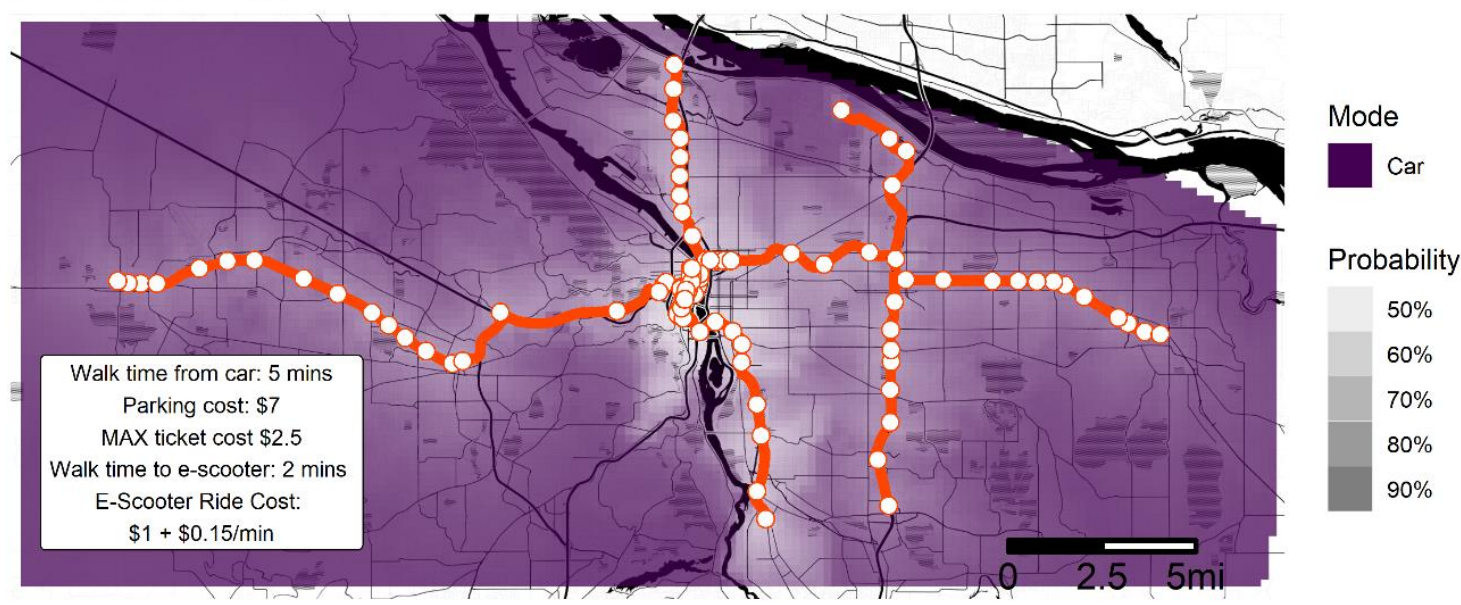

Figure 61: Mode Catchment Areas, Travelers with low Bike Attitude

Probability of Selecting a Mode to get to PSU

Test: High Bike Attitude

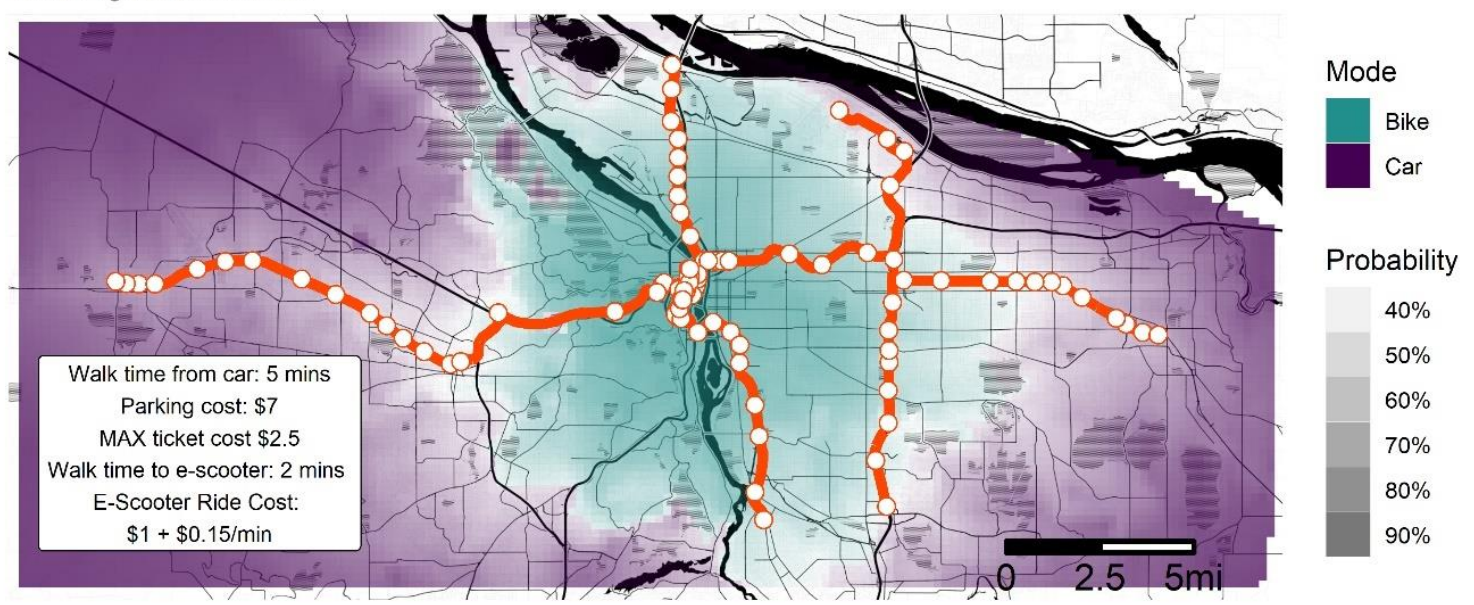

Figure 62: Mode Catchment Areas, Travelers with high Bike Attitude

Next, we find in Figure 63 that respondents with low Car Attitude scores are

more likely to choose bike, whereas respondents with high Car Attitude scores are most

likely to choose car. At no point does the e-scooter + MAX become the most attractive 
mode. As a result, we see in Figure 64 that respondents with low Car Attitude display a sizeable bike catchment area and a small e-scooter + MAX catchment area, mostly along the Orange Line towards Milwaukie. Respondents with high Car Attitude display no escooter + MAX catchment area and a miniscule biking catchment area in Figure 65.

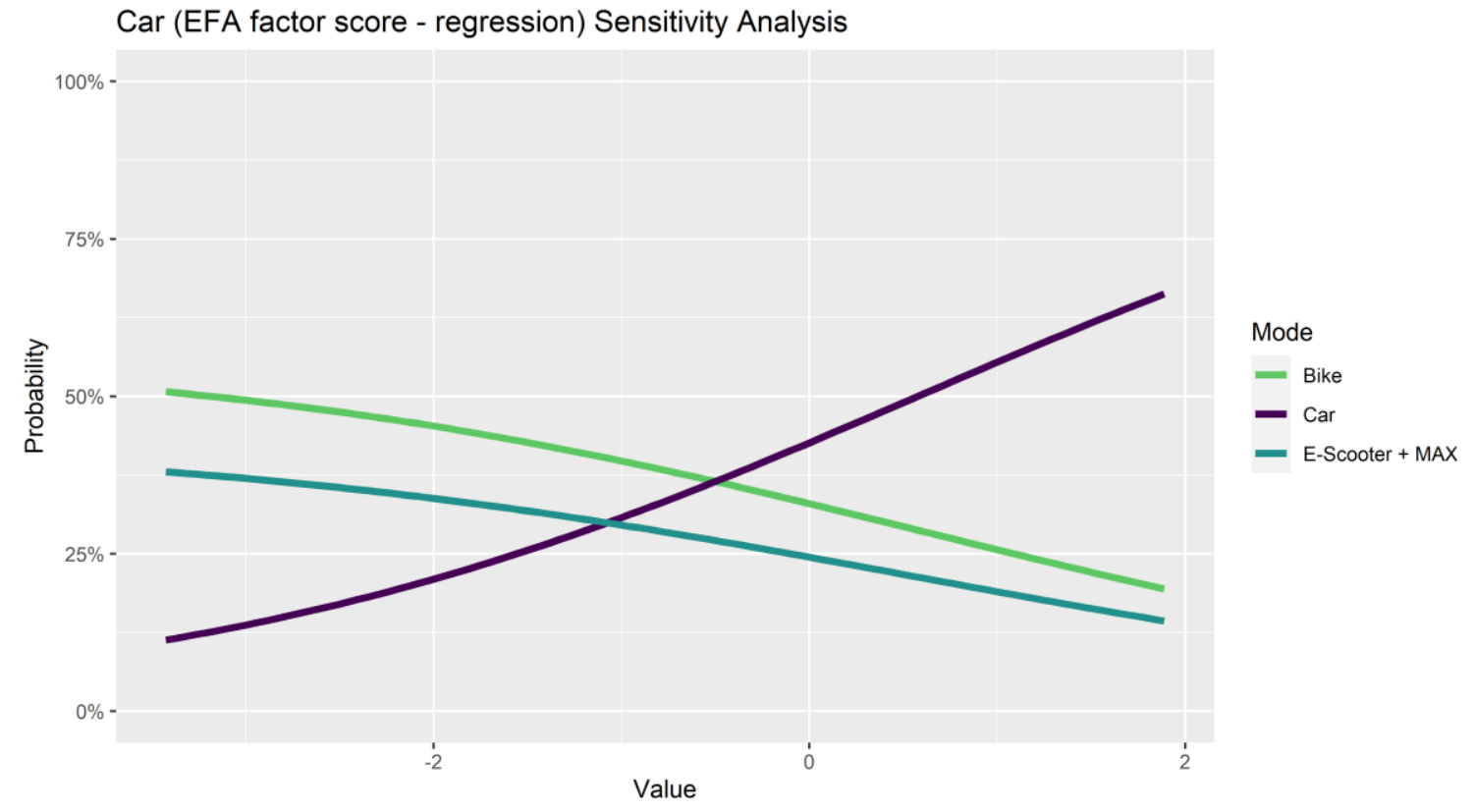

Figure 63: Latent Attitude Sensitivity Analysis: Car

Probability of Selecting a Mode to get to PSU

Test: Low Car Attitude

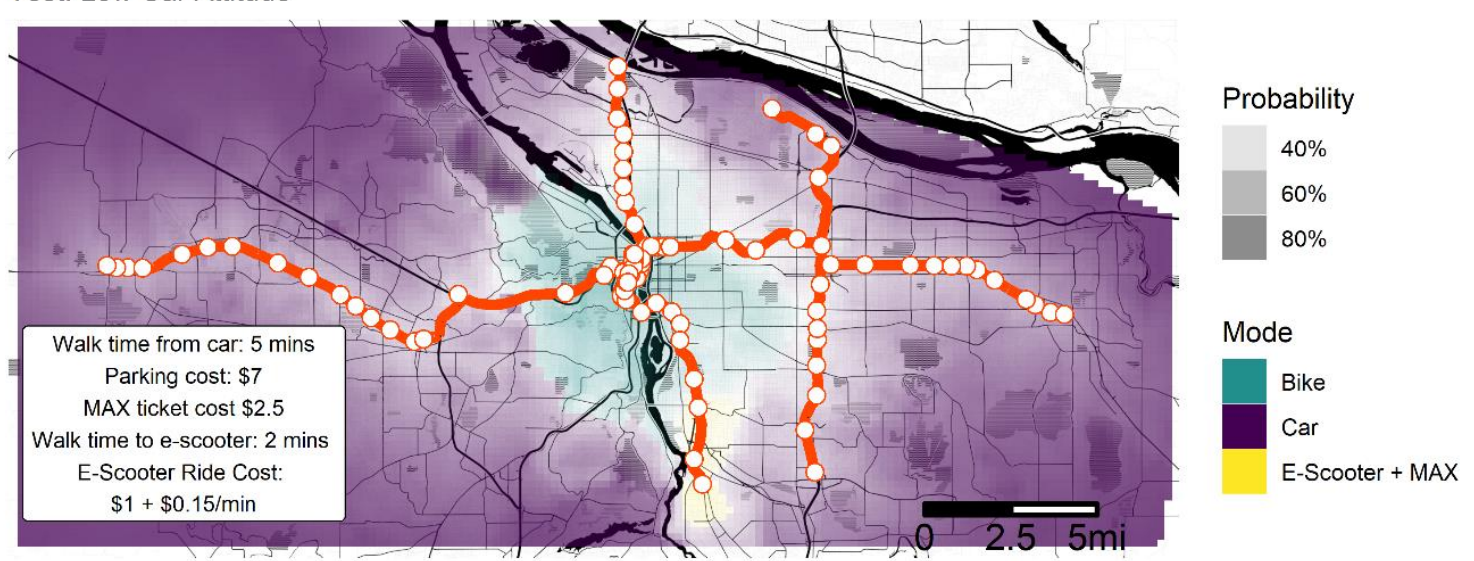

Figure 64: Mode Catchment Areas, Travelers with low Car Attitude 
Probability of Selecting a Mode to get to PSU

Test: High Car Attitude

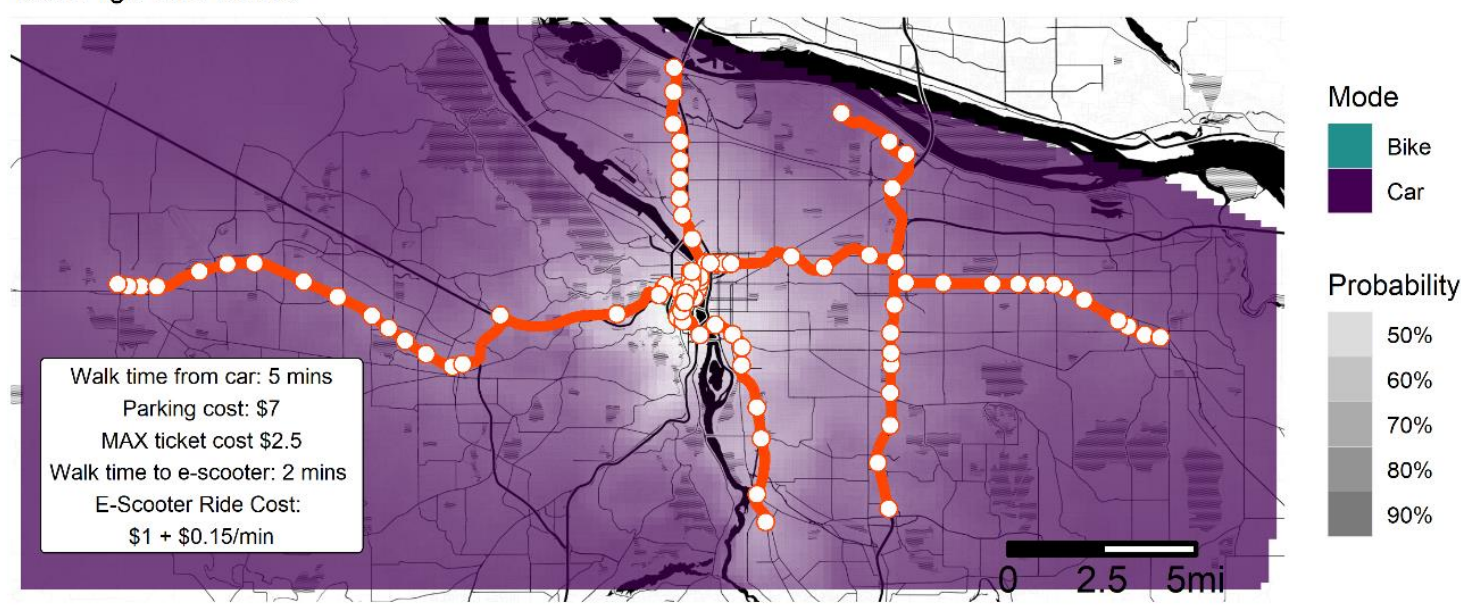

Figure 65: Mode Catchment Areas, Travelers with high Car Attitude

According to the e-scooter sensitivity analysis in Figure 66, only the most

enthusiastic e-scooter riders are more likely to choose the e-scooter + MAX option, all else held at average. Likewise, low E-Scooter Attitude respondents display a small bike catchment area in Figure 67. High E-Scooter Attitude respondents show a small set of escooter + MAX catchment areas along the Orange Line in Figure 68. 


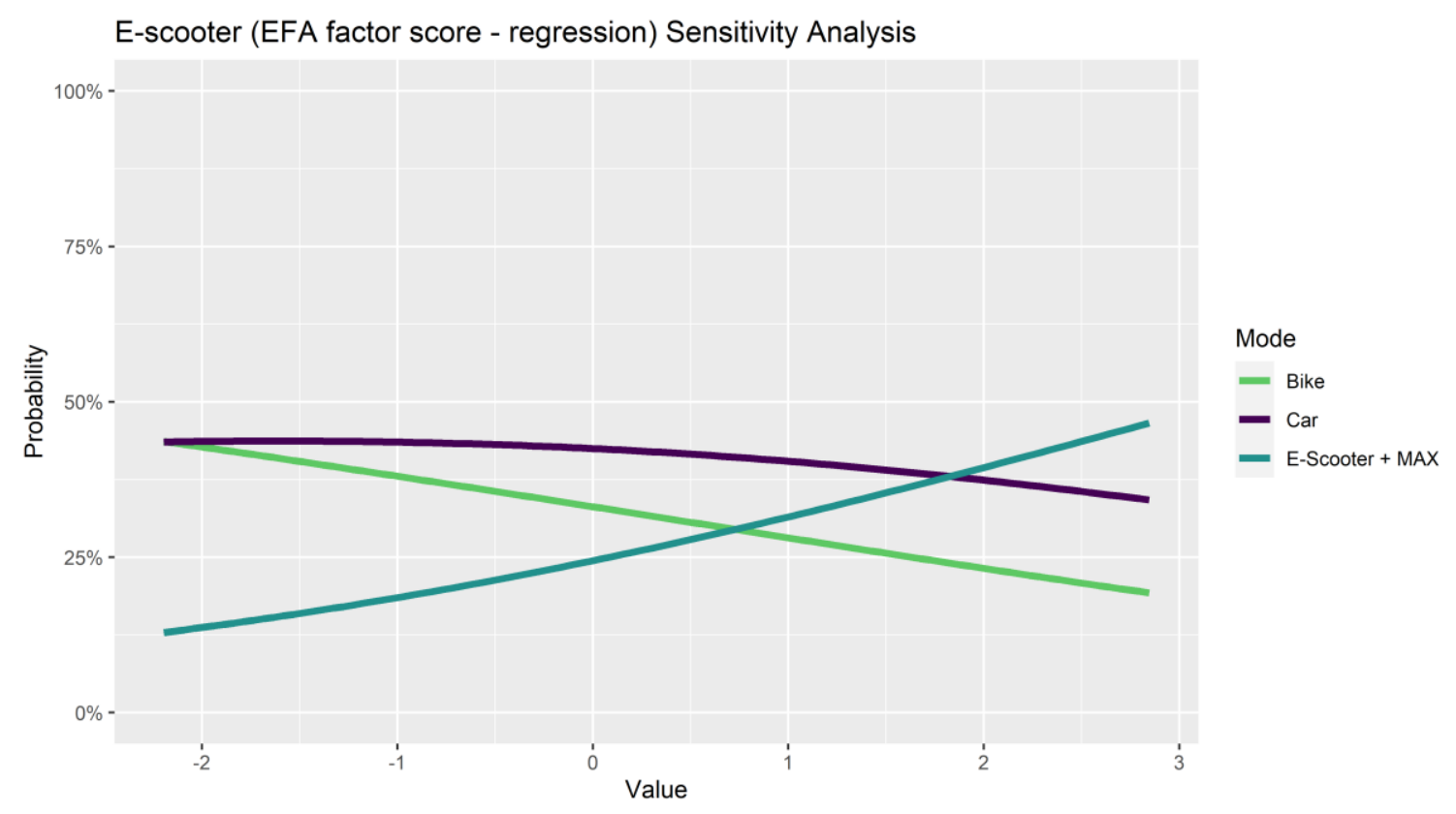

Figure 66: Latent Attitude Sensitivity Analysis: E-Scooter

Probability of Selecting a Mode to get to PSU

Test: Low E-Scooter Attitude

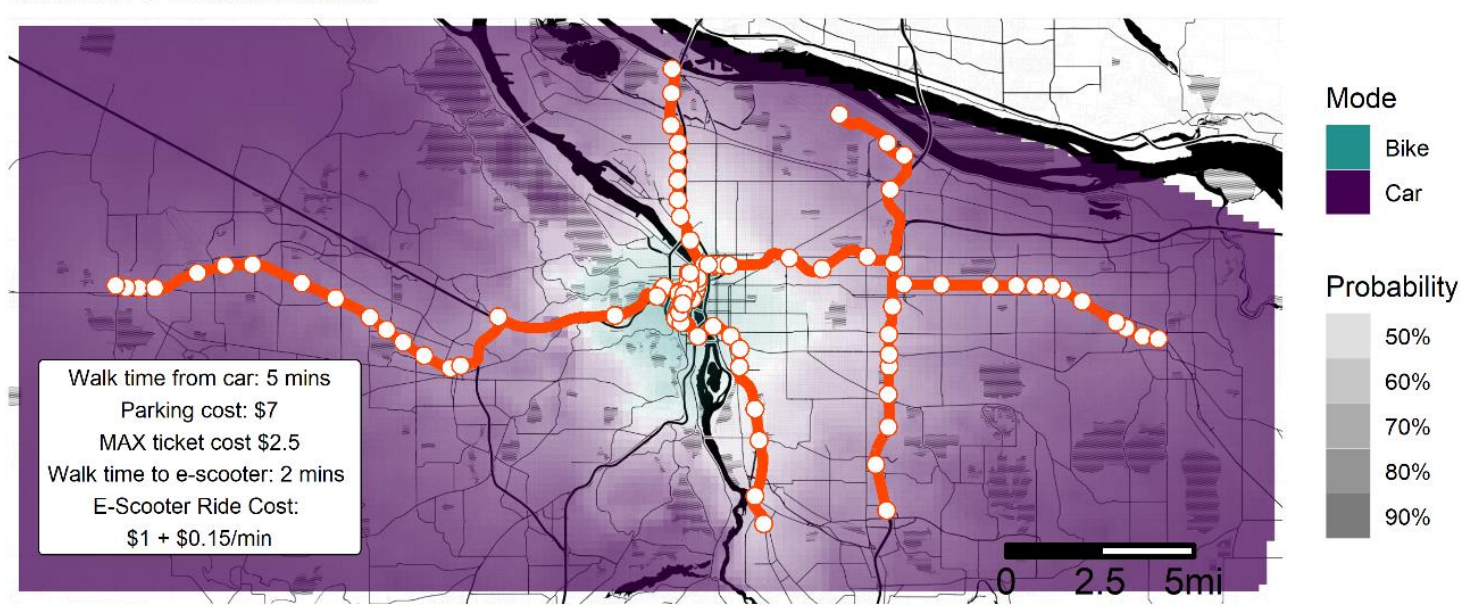

Figure 67: Mode Catchment Areas, Travelers with low E-Scooter Attitude 
Probability of Selecting a Mode to get to PSU

Test: High E-Scooter Attitude

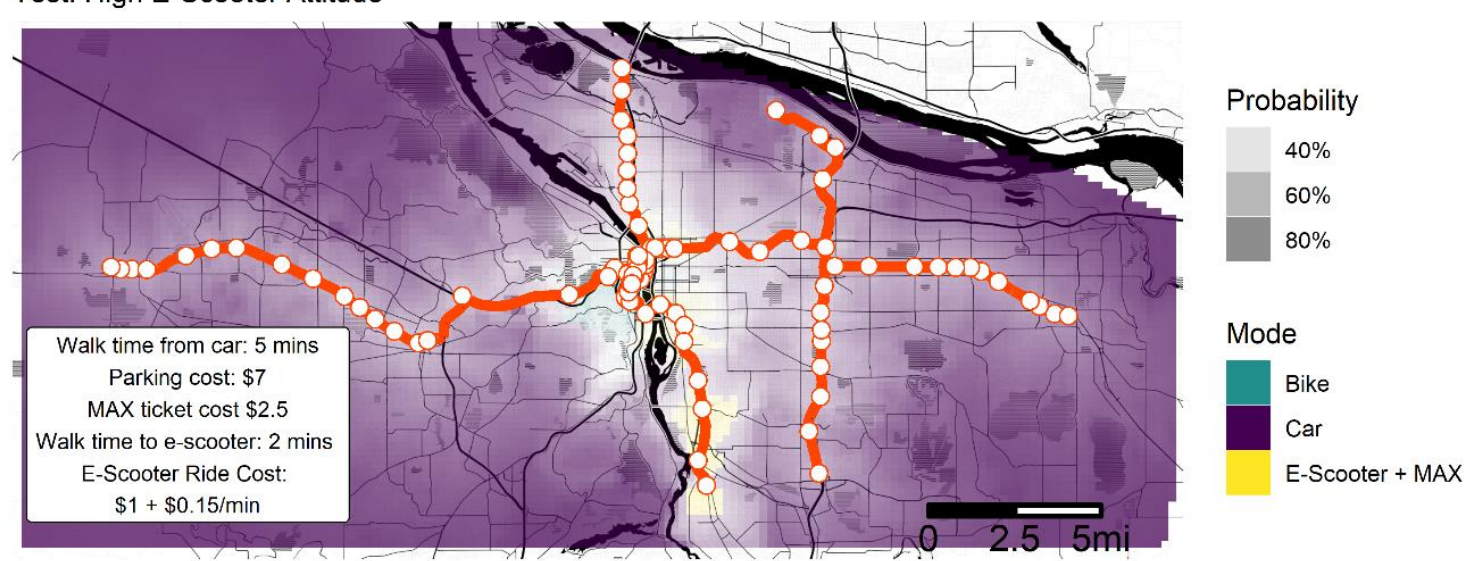

Figure 68: Mode Catchment Areas, Travelers with high E-Scooter Attitude

Lastly, respondents with high MAX Attitude seem to exhibit the most potential, all else held at the average, of selecting the e-scooter + MAX option, as seen in Figure 69. Consequently, respondents with low MAX Attitude exhibit a small bike catchment area in Figure 70. Respondents with high MAX Attitude exhibit the largest e-scooter + MAX catchment area of the latent attitudes in Figure 71, which extends along each line. 


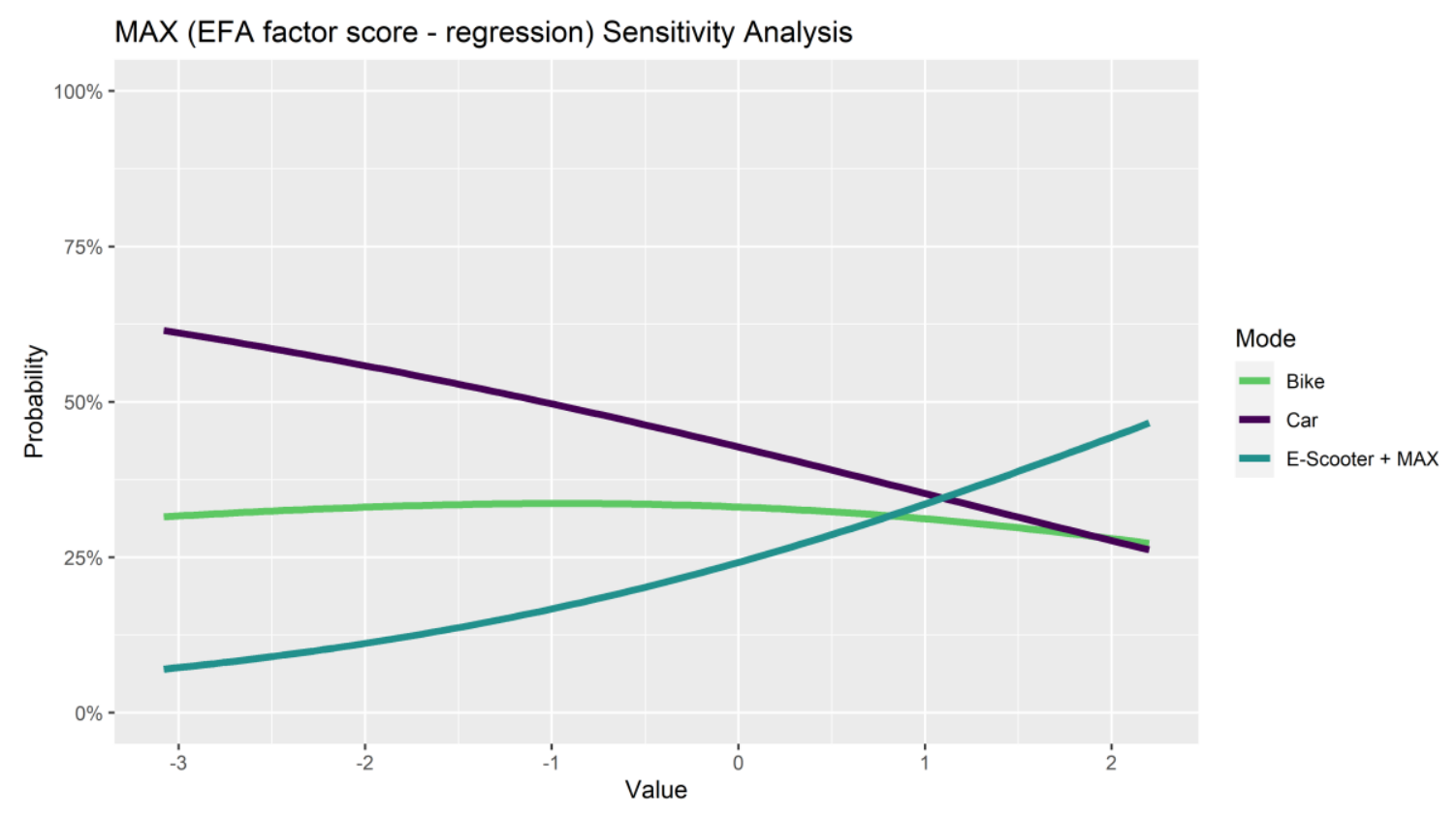

Figure 69: Latent Attitude Sensitivity Analysis: MAX

Probability of Selecting a Mode to get to PSU

Test: Low MAX Attitude

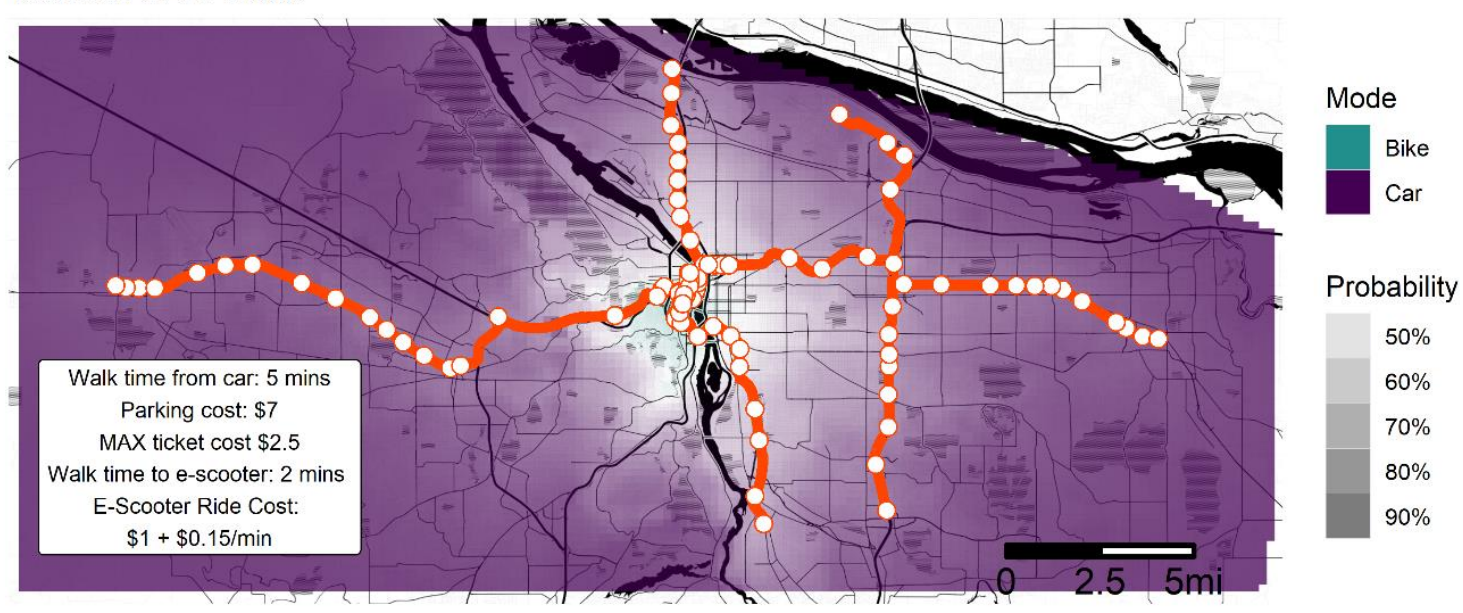

Figure 70: Mode Catchment Areas, Travelers with low MAX Attitude 
Probability of Selecting a Mode to get to PSU

Test: High MAX Attitude

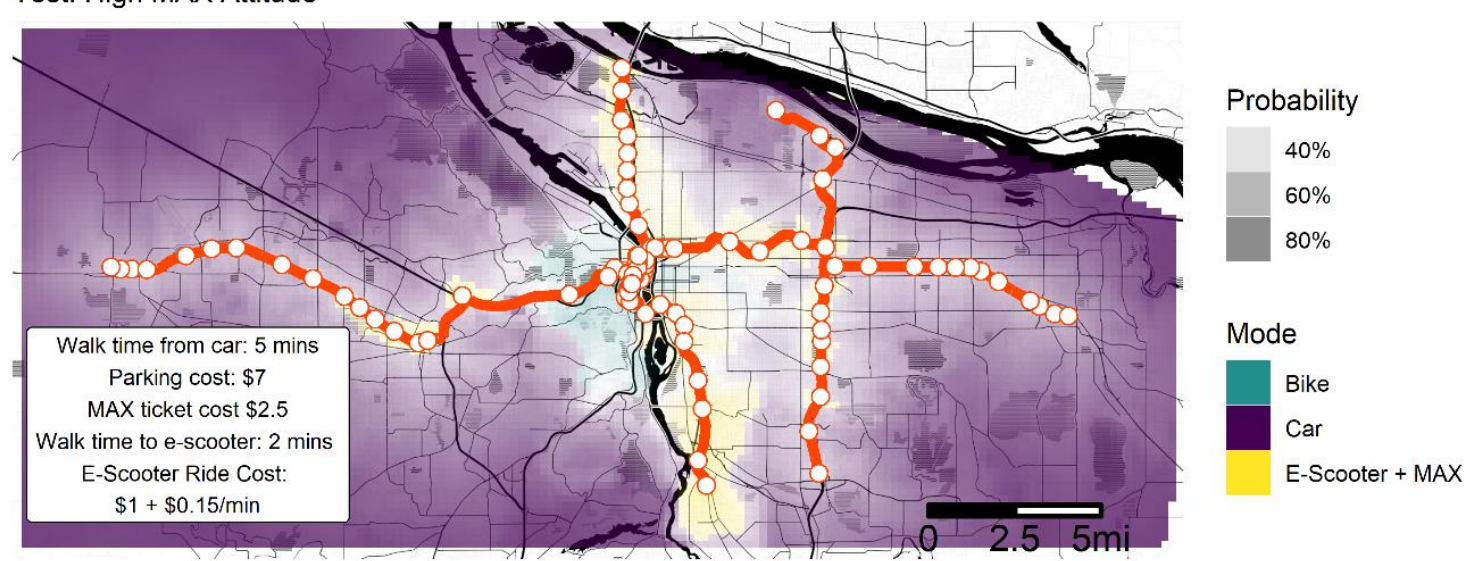

Figure 71: Mode Catchment Areas, Travelers with high MAX Attitude

\subsubsection{Example of obtaining "good" first-mile ridership}

The sensitivity analysis thus far does not reveal a single promising policy lever to substantially expand the e-scooter + MAX mode catchment area except for a large parking cost increase, which may be untenable for some students. We therefore tested the impact of a combination of policies including a free e-scooter trip while paying MAX fare and a medium increase in parking cost, from $\$ 7$ to $\$ 11$. The results are shown in

Figure 72. A detail of this map surrounding the Gateway neighborhood on the east side of the metro area is shown in Figure 73. 
Probability of Selecting a Mode to get to PSU

Test: Medium Parking Increase / Free E-Scooters

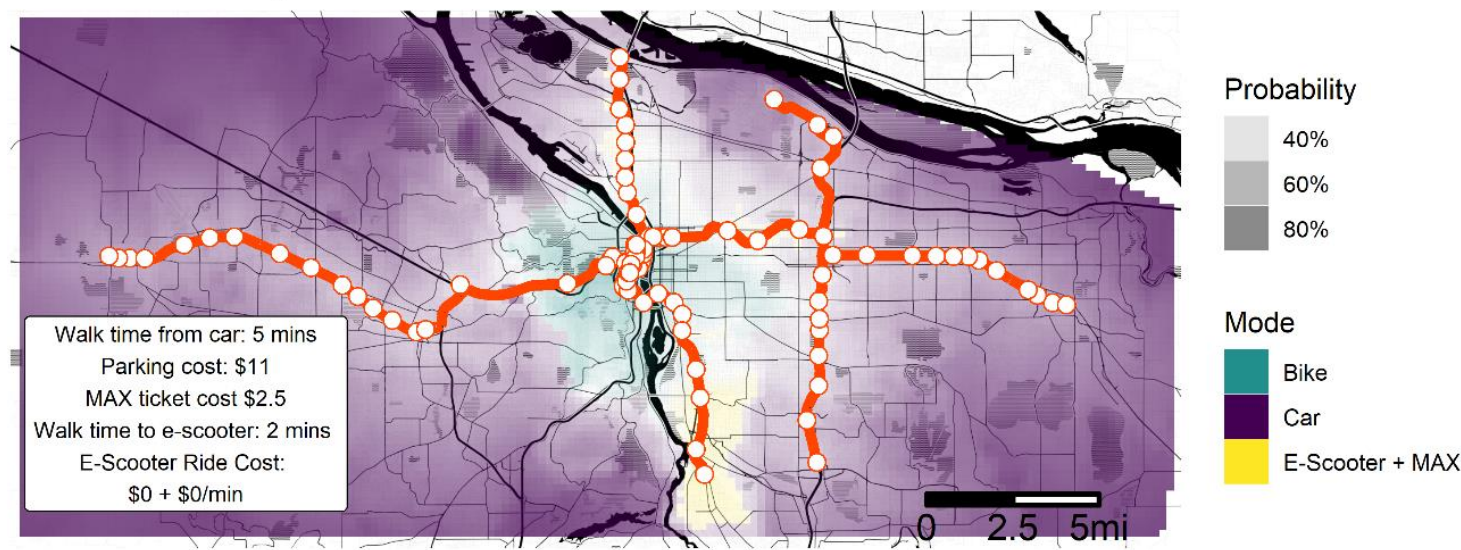

Figure 72: Mode Catchment Areas, Medium parking cost increase and free E-Scooters

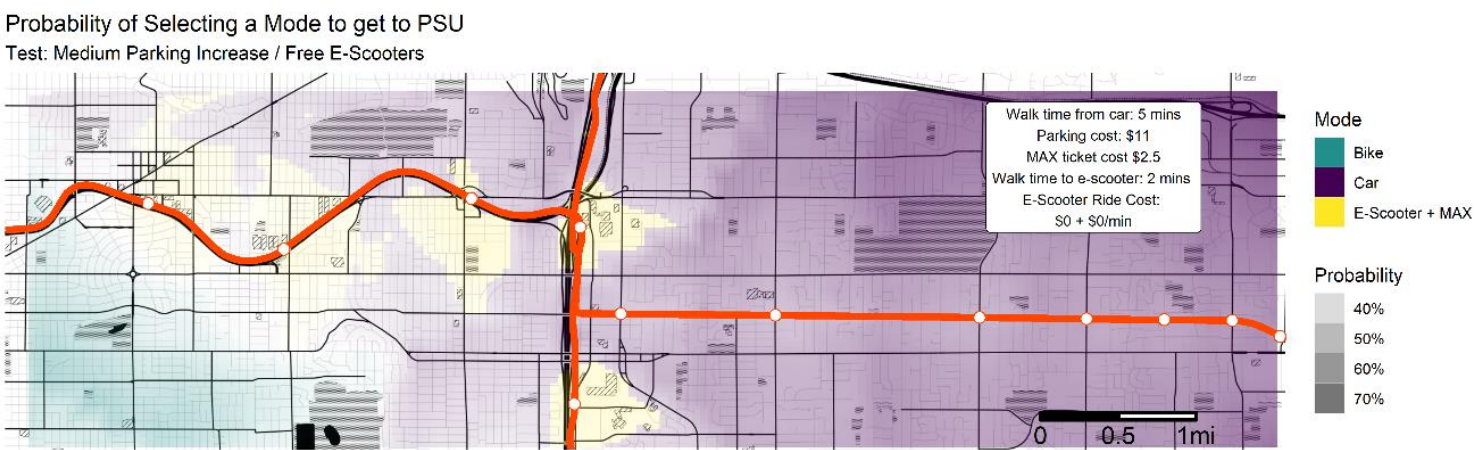

Figure 73: Mode Catchment Areas, Medium parking cost increase and free E-Scooters, detail

What would happen if, in addition to the free e-scooter fare and the increased parking cost, the university was able to implement a successful marketing campaign to increase students' attitudes towards e-scooters and MAX? Figure 74 and Figure 75 show the results of increasing both the MAX and e-scooter Attitude scores from the mean by one standard deviation. Clearly, taking these actions would lead to a substantial increase in the catchment area for the e-scooter + MAX mode. 
Probability of Selecting a Mode to get to PSU

Test: Medium Parking Increase / Free E-Scooters / MAX Publicity (mean + 1sd) / E-Scooter Publicity (mean + 1sd)

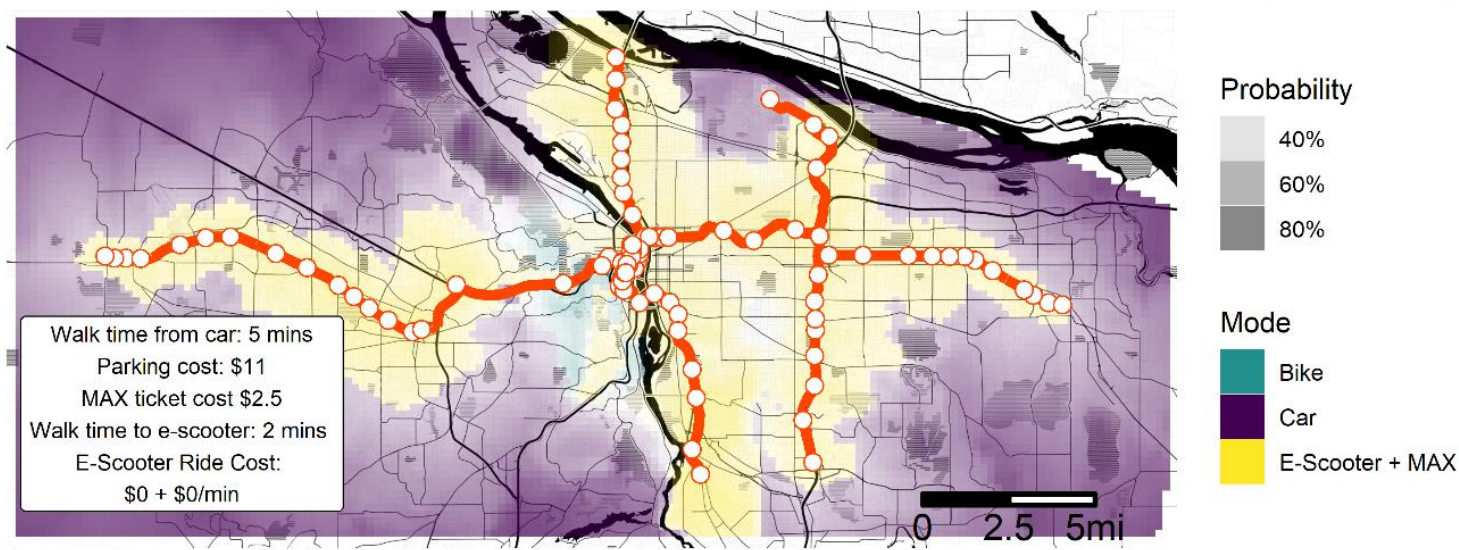

Figure 74: Mode Catchment Areas, Medium parking cost increase, free E-Scooters, MAX Publicity, EScooter Publicity

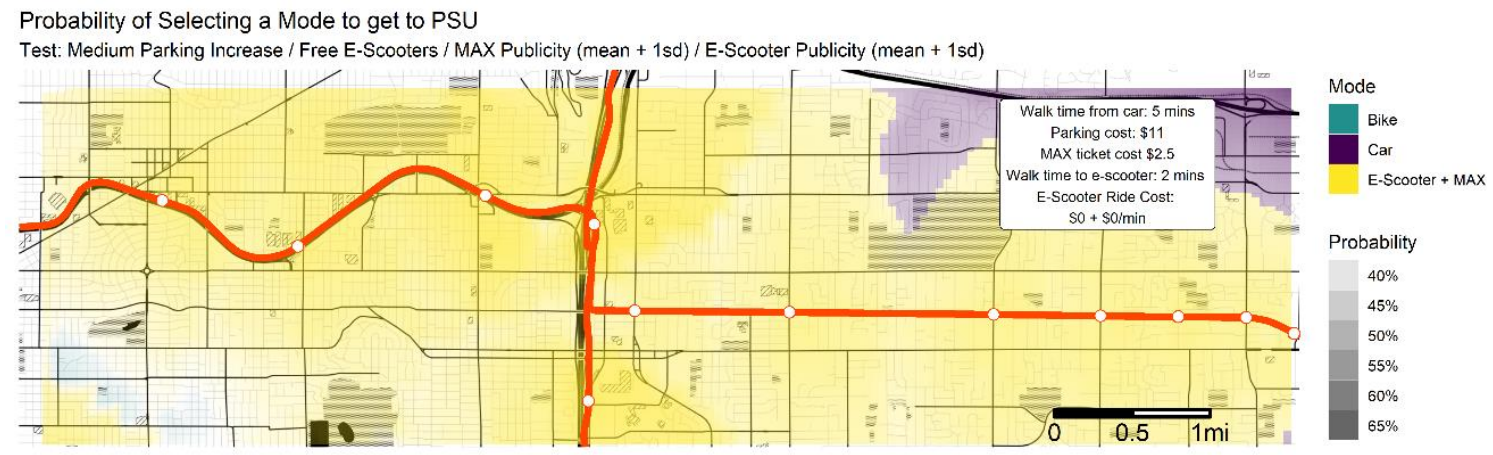

Figure 75: Mode Catchment Areas, Medium parking cost increase, free E-Scooters, MAX Publicity, EScooter Publicity, Gateway detail 


\section{Discussion and Conclusion}

In this study, we have considered the impact of mode attributes, sociodemographics, travel habits, and latent attitudes and priorities in models of mode use frequencies, propensity to switch to a new mode for commute purposes, and a stated choice experiment. We have investigated the spatial distribution of barriers to using non-auto modes. Additionally, we have also performed a spatial sensitivity analysis of the results of the stated choice experiment. This section provides a summary of the findings from these analyses, describes policy implications, discusses limitations with the methodology, and provides suggestions for future research.

\subsection{Barriers}

The maps presented in section 4.6 indicate that barriers to the usage of non-auto modes exist within the city. Bike theft, e-scooter availability, e-scooter know-how, and built environment access to MAX all serve as hurdles that may need to be addressed if transportation stakeholders expect residents to take up these modes more commonly that automobiles. Certain barriers also impacted multiple modes at once. For example, traffic impacted e-scooters and bike riders in a nearly uniform fashion. Yet, respondents seemed to agree that the lack of dedicated infrastructure was less of an issue throughout the close-in neighborhoods. Weather impacted both cyclists and e-scooter riders, and could have impacted cyclists more. In terms of speed, respondents perceived bikes to be too slow more frequently than MAX or e-scooters. Lastly, cost also 
presented a barrier to those wishing to use e-scooters, but it did not appear to affect cyclists or MAX riders to the same extent.

5.2 General Model Findings - Travel behavior, routine, built environment, and attitudes

We observed that current travel behavior and habits as they related to commuting to PSU were strong predictors of actual travel behavior outside of PSU and hypothetical behavioral changes in travel to PSU. The number of days that students came to PSU was negatively related to the number of total car trips in the past week and positively related to the total number of MAX trips in the past week. Those that came to PSU more days during the week said that they would be more likely to switch to taking a bike to PSU if their current mode became unavailable. Additionally, for each additional day during the week that they came to PSU, respondents were $11 \%$ more likely to select the bike choice and $6 \%$ more likely to select the e-scooter + MAX choice in the stated choice experiment compared to selecting car. It appears that students that come to PSU more frequently were more inclined to use modes other than car.

Next, the primary mode of transportation that students used to come to PSU was also a significant predictor in several models. Commuters whose primary mode was active transportation were less likely to take more car trips during the week, more likely to take more bike trips during the week, and more likely to take more MAX trips during the week compared to car commuters. Additionally, they said that they would be less likely to switch to using MAX if their primary mode of transportation became 
unavailable compared to car commuters. They were almost twice as likely to choose the bike choice and 1.63 times as likely to choose the e-scooter + MAX choice than car in the stated choice experiment compared to car commuters.

Commuters whose current primary mode was public transportation were also less likely to take more car trips during the week and more likely to take more MAX trips during the week compared to car commuters. They said that they would be less likely to switch to MAX than car commuters if their current commute mode became unavailable. Additionally, they said that they would be more likely to choose the bike choice or the escooter + MAX choice over the car choice in the stated choice experiment compared to car commuters. These findings suggest that active transportation and public transit commuters to PSU use cars less than car commuters.

Along these lines, stated trip frequency by mode in the last 7 days was also a strong predictor in several models. Students who took a larger number of car trips in the last week were more likely to switch to car if their current commute mode became unavailable and were less likely to pick bike or e-scooter + MAX in the stated choice experiment. Students who took larger numbers of bike trips in the last week were less likely to switch to car and more likely to switch to bike if their primary commute mode became unavailable, and more likely to pick bike in the stated choice experiment. Those who took more e-scooter trips in the previous week were more likely to switch to escooter commuting if their current commute mode became unavailable and were more likely to pick the e-scooter + MAX choice in the stated choice experiment. Lastly, 
students who took a larger number of MAX trips in the past week were less likely to switch to bike and more likely to switch to MAX if their current commute mode became unavailable and were more likely to select the e-scooter + MAX choice in the experiment. These findings suggest that respondents were rather siloed in their travel behavior, and they tended to predict that they would use the modes that they were most accustomed to using. This suggests that to bring about desired mode shift, conscious efforts may be needed to nudge people to try a mode that is outside of their comfort zone and habits.

Students' latent attitudes were also significant in the models. Students with positive Car Attitudes took more car trips and fewer bike trips in the previous seven days. They were likely to rate their propensity to switch to car as higher and were likely to rate their propensity to switch to bike as lower. In the stated choice experiment, they were less likely to choose either the bike or e-scooter + MAX option than car. Those with positive Bike Attitudes took more bike trips, no e-scooter trips, and fewer MAX trips in the previous 7 days. They rated their propensity to switch to bike as higher. They were more likely to choose the bike and e-scooter + MAX options than car in the stated choice experiment. Those with high E-Scooter Attitudes were less likely to have taken more bike trips in the previous 7 days yet were more likely to have taken at least one escooter trip in the previous 7 days. In the choice experiment, they were less likely to choose the bike than car and more likely to choose the e-scooter + MAX option than car. Those with a more positive MAX Attitude score were more likely to have taken more car 
trips, fewer bike trips, and more MAX trips in the previous 7 days. They were more likely to switch to MAX and less likely to switch to car if their current commute mode became unavailable. Lastly, they were more likely to choose bike than car and more likely to choose e-scooter + MAX than car in the choice experiment. These findings suggest that bike champions are a distinct group of travelers that tend to prefer cycling to other modes. MAX champions may also be car users, but would choose the multimodal options over car when given the opportunity. Car champions are simply not multimodal. E-Scooter champions prefer driving to cycling, but are interested in using the e-scooter by itself or with MAX.

The two latent factors uncovered using EFA that are important when choosing a mode of transportation for traveling to PSU, "Comfort and Safety" and "Exercise and Environmental Impact", were also significant predictors. Students that valued comfort and safety were less likely to take more bike trips in the past week, had lower propensities to switch to bike and higher propensities to switch to MAX if their current commute mode became unavailable, and less likely to choose bike over the car in the stated choice experiment. Those that valued exercise and environmental impact were less likely to have taken more car trips in the past 7 days, had higher propensity to switch to bike if their current commute mode became unavailable, and were more likely to choose the bike over the car in the stated choice experiment.

The built environment, in terms of home distance from campus, played a significant role in the models. For every additional mile away from campus, students were $3 \%$ 
more likely to have taken more car trips, $6 \%$ less likely to have taken at least one escooter trip, and $5 \%$ to have taken more MAX trips in the past week. Additionally, each mile away from campus positively contributed to the self-rated propensity to switch to car and negatively contributed to propensity to switch to bike or e-scooter for commuting to campus should their primary mode of commuting to campus become unavailable. Every additional mile caused respondents to be ever so slightly (1\%) more likely to choose bike over car in the hypothetical stated choice experiment, which is a possible indicator that these students had a slight preference to use something other than car if they could.

\subsection{E-Scooter Specific Findings}

What little e-scooter literature is available, though mostly not peer reviewed, has suggested that e-scooters may be successful at reducing racial (PBOT 2018) and gender (Clewlow 2019) disparities, at least in perception. Indeed, this could also translate to usage, as the ordinal logit models of this study showed no significant difference in the likelihood of taking at least one e-scooter trip in the last 7 days among of Black, Hispanic, and Asian respondents from White respondents. Similarly, respondents that were Black, Hispanic, or Asian did not rate themselves significantly different from White respondents when it came to their stated propensity to switch to e-scooter commuting should their present mode become unavailable. However, in the stated choice experiment, Black respondents were $45 \%$ less likely than white respondents to choose 
e-scooter + MAX over the car choice. The results of the present study are therefore mixed in terms of reducing racial disparities.

Gender also presented mixed results. The literature has often suggested that females are less likely to choose to bike than males (Broach and Dill 2016). Our results support this conclusion. Females were $43 \%$ less likely than males to have taken more bike trips in the past week. Females also rated themselves as less likely to switch to commuting by bike if their current commute mode became unavailable compared to males. They were $34 \%$ less likely to choose bike in the choice experiment over car compared to males. Looking at e-scooter use, females were not significantly different from males in taking at least one e-scooter trip in the previous week or in rating their propensity to switch to e-scooter commuting, however they were $27 \%$ less likely to choose the e-scooter + MAX option than males in the stated choice experiment. It is impossible to confirm the null hypothesis that females do not exhibit different behavior in terms of e-scooter use compared to males in these models, however it could be said that any differences that exist are small in magnitude. The significant result of females being less likely to choose e-scooter + MAX than males could be confounded by the fact that this mode choice actually incorporates two modes of which females may hold two differing perceptions. We are therefore unable to prove that e-scooters offer greater gender parity in terms of perception and usage, however we cannot disprove it either.

The nascent literature has suggested that e-scooters offer a great potential providing a means of completing first mile and last mile trips to transit, enabling more 
people to reduce their car usage (Smith and Schwieterman 2018; ITDP 2018; Zarif, Pankratz, and Kelman 2019). Our findings tend to refute this claim.

Referring back to the findings regarding respondents' primary mode of transportation to PSU, if car commuters lost the ability to commute by car, they would be more likely to switch to MAX than active transportation commuters and public transit users would be. In contrast, however, car commuters in the hypothetical stated choice experiment would more often choose to travel to PSU by car instead of selecting bike or e-scooter + MAX, suggesting that they are less inclined to switch to multimodal travel behavior. This finding does not support the idea that e-scooters as a last mile solution could be successful at causing mode shift away from cars; instead, they more successfully attract mode shift from active transportation and public transportation commuters, as shown above. This is supported by recent e-scooter surveys that ask about mode shift (PBOT 2018; 6t 2019). These studies also found that e-scooters more frequently replaced trips that otherwise would have been taken by transit and walking.

Furthermore, the sensitivity analysis suggests that there currently is no location in the Portland metro area where using an e-scooter as a first-mile mode to travel to MAX for trips to PSU is more utilitarian for the average PSU student than riding a bike or taking a car directly, given today's travel times and parking, transit, and e-scooter prices, and controlling for socio-demographics and latent attitudes. These findings refute the suggestion that e-scooters are currently increasing access to transit when these additional covariates are considered. 


\subsection{Policy Implications}

Naturally, the question about what policy changes would be necessary to make taking an e-scooter + MAX more utilitarian than the other modes arises. In and of itself, reducing the price of e-scooters, even making them free, would not, on average, cause any change in the probable catchment area of e-scooter + MAX, as evidenced by Figure 49. Similarly, a conscious effort to improve students' latent attitude toward e-scooters would only increase the mode catchment area a small amount, as seen in Figure 68. Really, the policy change that would have the biggest impact is an increase in parking price at PSU, as seen in Figure 46 and Figure 47. This is a similar finding to that of Asgari and Jin (2020) from their work on transportation habits and emerging modes. Increasing parking price with the expectation of increasing e-scooter + MAX usage should be done with care, however, as our models assume that the e-scooter service area encompasses all areas surrounding the MAX system and that e-scooters are always available within a two-minute walk. This is not currently the case in Portland. In fact, the medium parking increase combined with $100 \%$ subsidized e-scooter trips, a scenario shown in Figure 72 , would result in some of the utilitarian catchment areas that are outside the bounds of the current e-scooter service area, namely on the west side and in Milwaukie.

Considering the impacts of these policy actions, we suggest a few key takeaways. First, cities should not solely depend on e-scooters as a first-mile/last-mile solution to solve transportation inequities without implementing concurrent policy to encourage transit use and access. One potential solution is to effectively limit e-scooter service 
areas exclusively to suburbs in order to encourage combining e-scooters with transit. However, this could be a tough sell to the e-scooter companies themselves, as the majority of trips (and revenue) tend to occur closer to the city center.

Cities also need to rethink how they encourage equity in transportation outcomes. Our results did not indicate any significant differences among races and ethnicities in answering questions about barriers preventing more frequent e-scooter usage. This reveals that we did not design our survey inclusively enough to capture the reasons that communities of color were significantly less likely to choose e-scooter + MAX in the stated choice experiment. Perhaps fears of harassment by other residents or the police could be one facet of a more complicated construct that systematically excluded people of color from this form of micromobility.

Along these lines, perhaps e-scooters themselves are not the solution to solving gender disparities in active transportation use in general, as evidenced by our results and those of previous cycling literature. It is possible that improving the availability of safer infrastructure is necessary to encourage uptake of active transportation and micromobility by female travelers.

Lastly, cities should consider that some policy measures that we have suggested could also improve cycling levels, including increasing the availability of safer infrastructure and increasing parking prices. Perhaps it could be more cost effective for cities to focus on improving cycling mode share instead of e-scooter mode share. 


\subsection{Limitations}

The findings of this study should be considered with some caveats. The sample consisted of Portland State University students. The values, opinions, and habits of this sample could differ from a randomly selected sample of residents of Portland or the rest of the country. The respondent age was skewed, with most respondents indicating that they were younger. Additionally, the income distribution was also biased toward the lower income portion of the spectrum.

The Google Maps API was used to perform geocoding of text responses naming the closest intersection to each respondent's home. Although we did our best to clean out geocoding matches that did not make sense, it is possible that some of the matched locations could be inaccurate due to the variability of manually typed text.

There are inherent limitations with stated behavior data compared to observed behavior. Respondents may be unconsciously biased towards reporting quantities that are different than ground truth quantities due to personal values or memory limitations. These limitations are further compounded with regards to statements that indicate the intentions for future actions.

Although questions regarding current travel behavior were asked before the 2020 COVID-19 pandemic drastically changed travel behavior in Portland, the survey was distributed in early March. It is possible that the results indicate a different level of mode share compared to months with better weather. 
The weighting function for the barrier maps was arbitrarily selected in order to lessen the apparent impact of cells with fewer respondents. Differences in the transformation of the hyperbolic tangent function would lead to different results.

The propensity to switch scores for e-scooter were much lower than those for any of the other modes, as seen in Figure 18. Additionally, the sample size of respondents that had taken at least one e-scooter trip in the previous seven days was also low $(n=111)$ as shown in Figure 17. E-scooter findings should be taken together with the understanding that e-scooters received low switch scores and were not used by many students recently.

The MNL model in particular has several limitations. MNL models assume independence of irrelevant alternatives (IIA), meaning that the ratio of the choice probabilities is independent of the presence or absence of any other alternative in a choice set (Hensher, Rose, and Greene 2005). The exclusion of additional modes of transportation to PSU, such as walking, bus, WES, streetcar, skateboard, etc. could have biased the model. There is, however, a trade off in the survey's cognitive burden on the respondent and the accuracy of the resulting model that was considered during the design. Additionally, the predictions of MNL models best represent situations where the factors are within the range of the inputs that were used to construct the model. This means that it would not be the best statistical practice to use the model to predict results for car travel times that are longer than $\mathbf{4 5}$ minutes or shorter than 25 minutes. This is because extrapolation could yield results that are less accurate than 
interpolation, especially if the relationship between travel time and choice probability are more closely modeled by a different curve outside of the tested range.

We make conclusions considering significant demographic predictors for the escooter + MAX mode. As stated previously, our mixed results when compared to other models could be due to the fact that we treated this choice as a single mode when it actually incorporates two modes. Respondents could have different opinions for each of these modes individually. Our intention was to note the effects of factors on the experience of a multimodal trip. These effects may not be the same for trips that make use of e-scooters or MAX exclusively.

\subsection{Future Research}

More research similar to the present study is needed in order to grow the body of work describing the societal impacts, both positive and negative, of e-scooters and micromobility. Similar efforts in different cities with various levels of transit quality would be useful in order to distill the independent contributions of e-scooters from transit of various levels of service.

Additionally, research surrounding the impacts of various policy measures to effect increased first-mile/last-mile e-scooter usage should be undertaken. The success of such measures should be judged based not only on total uptake, but also the mobility gained by underrepresented demographic groups and the proportion of mode shift away from private automobiles. 
More effort is needed to find ways that encourage travelers to leave their cars behind in exchange for other modes that have a lower environmental impact. Transportation currently lacks effective "carrots" that can encourage the use of greener modes. Practitioners need behavior-change tools that are more palatable than corresponding "sticks," such as parking costs and congestion. E-Scooters hold some promise, in that they are fun and relatively effortless, however the environmental assessment of Hollingsworth et al. (2019) suggests that we may need to look elsewhere for more climate-friendly solutions. Additionally, it is important that we understand how to use e-scooters to shift travelers away from cars and towards other modes instead of just subdividing the non-auto piece of the mode share pie.

\subsection{Conclusion}

Overall, the findings from this study suggest that the potential of e-scooters to provide a competitive first-mile/last-mile solution is overstated, at least without substantial policy changes. The fact that the "stick" initiatives, such as increased parking price, outperform the "carrot" initiatives, such as free e-scooters and publicity campaigns, should give cities pause when it comes to determining the best method of increasing multimodal mobility for their residents. If care is not taken, vulnerable populations could be handed an undue financial burden.

The findings are overall mixed in suggesting that e-scooters bring about improved racial and gender equity in transportation. African American respondents were significantly less likely than white respondents to choose the e-scooter + MAX mode in 
the stated choice experiment, however they were not significantly different from white respondents when it came to their propensity to switch to e-scooter commuting or their likelihood to have taken at least one e-scooter trip in the previous week. Similarly, women were significantly less likely than men to choose the e-scooter + MAX mode in the stated choice experiment, however they were not significantly different from men when it came to their propensity to switch to e-scooters for commuting to PSU or to have taken an e-scooter trip in the previous week. As stated above, it is possible that the MAX in the e-scooter + MAX mode could be confounding the results.

E-Scooters are an exciting transportation development for a society that values disruption and quick solutions. However, in their current form, shared e-scooter systems are not independently solving the larger inequities that decades of transportation planning and land development biased towards automobiles have caused. It is possible that e-scooter companies may also be acting as policy entrepreneurs (Kingdon 1984) by touting their product as an effective solution to these societal problems, even if the science does not support their claims.

It is true that e-scooters are an extremely nimble and adaptable mode, and thus it may be possible that a change in management and deployment strategy coupled with other pro-multimodal policies could bring about the desired impacts. However, these necessary changes are unlikely to come about organically, so long as e-scooter companies remain dependent on venture capital and profit maximization. Therefore, cities need to quickly claim responsibility for shaping the micromobility environment 
through targeted policy and oversight if they hope to use it to repair existing transportation inequities. 
References

6t. 2019. "Usages et Usagers Des Trottinettes Électriques En Free-Floating En France." 6t-bureau de recherche. https://6-t.co/trottinettes-freefloating/.

Akima, Hiroshi, and Albrecht Gebhardt. 2020. Akima: Interpolation of Irregularly and Regularly Spaced Data. https://CRAN.R-project.org/package=akima.

Aloulou, Foued. 2018. "The Application of Discrete Choice Models in Transport." In Statistics - Growing Data Sets and Growing Demand for Statistics, edited by Türkmen Göksel. InTech. https://doi.org/10.5772/intechopen.74955.

Asgari, Hamidreza, and Xia Jin. 2020. "Incorporating Habitual Behavior into Mode Choice Modeling in Light of Emerging Mobility Services." Sustainable Cities and Society 52 (January): 101735. https://doi.org/10.1016/j.scs.2019.101735.

Baquero, Oswaldo Santos. 2019. Ggsn: North Symbols and Scale Bars for Maps Created with "ggplot2" or "Ggmap." https://CRAN.R-project.org/package=ggsn.

Bivand, Roger, and Nicholas Lewin-Koh. 2020. Maptools: Tools for Handling Spatial Objects. https://CRAN.R-project.org/package=maptools.

Broach, Joseph, and Jennifer Dill. 2016. "Using Predicted Bicyclist and Pedestrian Route Choice to Enhance Mode Choice Models." Transportation Research Record 2564 (1): 52-59. https://doi.org/10.3141/2564-06.

Cattell, Raymond B. 1966. "The Scree Test For The Number Of Factors." Multivariate Behavioral Research 1 (2): 245-76. https://doi.org/10.1207/s15327906mbr0102_10.

Clewlow, Regina R. 2019. "The Micro-Mobility Revolution: The Introduction and Adoption of Electric Scooters in the United States." In Proceedings of the 98th Annual Meeting of the Transportation Research Board, 13. Washington, DC, January 13-17, 2019: Transportation Research Board. https://trid.trb.org/view/1572549.

Cronbach, Lee J. 1951. "Coefficient Alpha and the Internal Structure of Tests." Psychometrika 16 (3): 38.

Dill, Jennifer. 2019. “The E-Scooter Gender Gap." Jennifer Dill, Ph.D. (blog). February 1, 2019. https://jenniferdill.net/2019/02/01/the-e-scooter-gender-gap/.

DiStefano, Christine, Min Zhu, and Diana Mîndrilă. 2009. “Understanding and Using Factor Scores: Considerations for the Applied Researcher" 14 (20): 12.

Dorman, Michael. 2020. Nngeo: K-Nearest Neighbor Join for Spatial Data. https://CRAN.R-project.org/package=nngeo.

Eccarius, Timo, and Chung-Cheng Lu. 2020. "Adoption Intentions for Micro-MobilityInsights from Electric Scooter Sharing in Taiwan." Transportation Research Part D: Transport and Environment 84 (July): 102327. https://doi.org/10.1016/j.trd.2020.102327.

Egset, Kaja Solland, and Trond Nordfjærn. 2019. "The Role of Transport Priorities, Transport Attitudes and Situational Factors for Sustainable Transport Mode Use 
in Wintertime." Transportation Research Part F: Traffic Psychology and Behaviour 62 (April): 473-82. https://doi.org/10.1016/j.trf.2019.02.003.

Fabrigar, Leandre R., and Duane T. Wegener. 2012. Exploratory Factor Analysis. Oxford: Oxford University Press.

Fedorov, V. V. (Valerii Vadimovich). 1972. Theory of Optimal Experiments. Probability and Mathematical Statistics. New York: Academic Press.

Fleming, Kelly L. 2018. "Social Equity Considerations in the New Age of Transportation: Electric, Automated, and Shared Mobility" 13 (1): 20.

Goodman, Dan, Adrian Witte, Rae-Leigh Stark, and Alexandra Frackelton. 2019. "EScooter Management in Midsized Cities in the United States." Chapel Hill, NC: Pedestrian and Bicycle Information Center. www.pedbikeinfo.org.

Hasan, Asad, Zhiyu Wang, and Alireza S. Mahani. 2016. "Fast Estimation of Multinomial Logit Models: R Package Mnlogit." Journal of Statistical Software 75 (3): 1-24. https://doi.org/doi:10.18637/jss.v075.i03.

Hensher, David A., John M. Rose, and William H. Greene. 2005. Applied Choice Analysis: A Primer. Cambridge, UK: Cambridge University Press.

Hollingsworth, Joseph, Brenna Copeland, and Jeremiah X Johnson. 2019. "Are E-Scooters Polluters? The Environmental Impacts of Shared Dockless Electric Scooters." Environmental Research Letters 14 (8): 084031. https://doi.org/10.1088/17489326/ab2da8.

Horne, Jack. 2018. ChoiceDes: Design Functions for Choice Studies. https://CRAN.Rproject.org/package $=$ choiceDes.

ITDP. 2018. "E-Scooters Could Be a Last-Mile Solution for Everyone." December 14, 2018. https://www.itdp.org/2018/12/14/e-scooters-last-mile-solution/.

Kahle, David, and Hadley Wickham. 2013. "Ggmap: Spatial Visualization with Ggplot2." The R Journal 5 (1): 144-161.

Kingdon, John W. 1984. Agendas, Alternatives, and Public Policies. Boston: Little, Brown. Levinson, David M., Wes Marshall, and Kay Axhausen. 2017. Elements of Access: Transport Planning for Engineers, Transport Engineering for Planners. Network Design Lab.

Louviere, Jordan J, David A Hensher, and Joffre D Swait. 2000. Stated Choice Methods Analysis and Applications. Cambridge, UK ; New York, NY, USA: Cambridge University Press.

NIST/SEMATECH. 2013. "E-Handbook of Statistical Methods." 2013. http://www.itl.nist.gov/div898/handbook/.

Nunnally, Jum C. 1978. Psychometric Theory. 2d ed. McGraw-Hill Series in Psychology. New York: McGraw-Hill.

O'Connor, Brian P. 2000. "SPSS and SAS Programs for Determining the Number of Components Using Parallel Analysis and Velicer's MAP Test." Behavior Research Methods, Instruments, \& Computers, 7. 
PBOT. 2018. “2018 E-Scooter Findings Report." Portland, OR: Portland Bureau of Transportation.

https://www.portlandoregon.gov/transportation/article/709719.

- - - n.d. "Portland E-Scooter Pilot FAQ." Accessed March 30, 2020. https://www.portlandoregon.gov/transportation/article/692208.

Pebesma, Edzer. 2018. "Simple Features for R: Standardized Support for Spatial Vector Data." The R Journal 10 (1): 439-446. https://doi.org/10.32614/RJ-2018-009.

Populus. 2018. "The Micro-Mobility Revolution: The Introduction and Adoption of Electric Scooters in the United States." Populus.

R Core Team. 2020. R: A Language and Environment for Statistical Computing. Vienna, Austria: R Foundation for Statistical Computing. https://www.R-project.org/.

ReliaSoft Corporation. 2017. "Optimal Custom Designs." In Experiment Design \& Analysis Reference. http://reliawiki.org/index.php/Optimal_Custom_Designs.

Rosseel, Yves. 2012. "Lavaan: An R Package for Structural Equation Modeling." Journal of Statistical Software 48 (2): 1-36.

Schuller, Aurélien, and Maxime Aboukrat. 2019. "White Paper: The Role of e-Scooters and Light Electric Vehicles in Decarbonizing Cities." Carbone4.

Smith, C. Scott. 2020. "E-Scooter Mobility: Estimates of the Time-Savings and Accessibility Benefits Achieved via Chicago's 2019 E-Scooter Pilot Program." Chicago: Chaddick Institute for Metropolitan Development at Depaul University.

Smith, C. Scott, and Joseph P. Schwieterman. 2018. "E-Scooter Scenarios: Evaluating the Potential Mobility Benefits of Shared Dockless Scooters in Chicago." Chaddick Institute Policy Series. Chicago, IL: Chaddick Institute for Metropolitan Development at DePaul University.

Thurstone, L.L. 1935. The Vectors of Mind. The Vectors of Mind. University of Chicago Press: Chicago.

Transportation Research Board. 2013. Transit Capacity and Quality of Service Manual, Third Edition. National Academy of Sciences.

UCLA: Statistical Consulting Group. n.d. "Principal Components (PCA) and Exploratory Factor Analysis (EFA) with SPSS." Accessed May 27, 2020. https://stats.idre.ucla.edu/spss/seminars/efa-spss/\#s4.

Velicer, Wayne F. 1976. "Determining the Number of Components from the Matrix of Partial Correlations." Psychometrika 41 (3): 321-27. https://doi.org/10.1007/BF02293557.

Venables, W. N., and B. D. Ripley. 2002. Modern Applied Statistics with S. Fourth. New York: Springer. http://www.stats.ox.ac.uk/pub/MASS4.

Wheeler, Bob. 2019. AlgDesign: Algorithmic Experimental Design. https://CRAN.Rproject.org/package=AlgDesign .

Yap, Menno D., Gonçalo Correia, and Bart van Arem. 2016. "Preferences of Travellers for Using Automated Vehicles as Last Mile Public Transport of Multimodal Train Trips." Transportation Research Part A: Policy and Practice 94 (December): 1-16. https://doi.org/10.1016/j.tra.2016.09.003. 
Zarif, Rasheq, Derek M. Pankratz, and Ben Kelman. 2019. "Small Is Beautiful: Making Micromobility Work for Citizens, Cities, and Service Providers." Deloitte Insights (blog). 2019. https://www2.deloitte.com/us/en/insights/focus/future-ofmobility/micro-mobility-is-the-future-of-urban-transportation.html.

Zou, Zhenpeng, Hannah Younes, Sevgi Erdoğan, and Jiahui Wu. 2020. "Exploratory Analysis of Real-Time E-Scooter Trip Data in Washington, D.C." Transportation Research Record: Journal of the Transportation Research Board, May, 036119812091976. https://doi.org/10.1177/0361198120919760.

Zuo, Ting, Heng Wei, Na Chen, and Chun Zhang. 2020. "First-and-Last Mile Solution via Bicycling to Improving Transit Accessibility and Advancing Transportation Equity." Cities 99 (April): 102614. https://doi.org/10.1016/j.cities.2020.102614. 


\section{Appendices}

(This page was intentionally left blank) 


\section{A. Pearson Correlations of Scale Items}

Personal Car Attitude Items, Pearson Correlations

Q15_1 Q15_2 Q15_3 Q15_4 Q15_5 Q15_6 Q15_7r Q15_8

\begin{tabular}{|c|c|c|c|c|c|c|c|c|}
\hline Q15_1 I enjoy driving & 1 & & & & & & & \\
\hline Q15_2 I feel safe in a car & $.439 * *$ & 1 & & & & & & \\
\hline Q15_3 Driving is cool & $.551^{* *}$ & $.379 * *$ & 1 & & & & & \\
\hline $\begin{array}{l}\text { Q15_4 I feel comfortable } \\
\text { riding in a car } \\
\text { (Temperature, seat, space, } \\
\text { etc.) }\end{array}$ & $.398 * *$ & $.478^{* *}$ & $.300^{* *}$ & 1 & & & & \\
\hline $\begin{array}{l}\text { Q15_5 I don't mind } \\
\text { searching for a parking spot }\end{array}$ & $.258^{* *}$ & $.196^{* *}$ & $.201^{* *}$ & $.147 * *$ & 1 & & & \\
\hline $\begin{array}{l}\text { Q15_6 Even if I get delayed } \\
\text { by traffic, I'd still prefer to } \\
\text { take a car }\end{array}$ & $.372^{* *}$ & $.390^{* *}$ & $.359 * *$ & $.367^{* *}$ & $.298^{* *}$ & 1 & & \\
\hline $\begin{array}{l}\text { Q15_7r REVERSED I think } \\
\text { that cars are harmful to the } \\
\text { environment }\end{array}$ & $.131^{* *}$ & $.191 * *$ & $.259 * *$ & 0.011 & $.110^{* *}$ & $.224 * *$ & 1 & \\
\hline Q15_8 Cars are convenient & $.291 * *$ & $.380 * *$ & $.254 * *$ & $.443^{* *}$ & $.166^{* *}$ & $.397 * *$ & $.047^{*}$ & 1 \\
\hline
\end{tabular}

**. Correlation is significant at the 0.01 level (2-tailed).

*. Correlation is significant at the 0.05 level (2-tailed). 
Bike Attitude Items, Pearson Correlations

\begin{tabular}{|c|c|c|c|c|c|c|c|c|c|c|}
\hline & $\begin{array}{l}\mathrm{Q} 21_{-} \\
1\end{array}$ & $\begin{array}{l}\mathrm{Q} 21_{-} \\
2\end{array}$ & $\begin{array}{l}\mathrm{Q} 21_{-} \\
3\end{array}$ & $\begin{array}{l}Q 21_{-} \\
4\end{array}$ & $\begin{array}{l}Q 21_{-} \\
5 r\end{array}$ & $\begin{array}{l}\text { Q21_- } \\
6 r\end{array}$ & $\begin{array}{l}\mathrm{Q} 21_{-} \\
7 \mathrm{r}\end{array}$ & $\begin{array}{l}Q 21_{-} \\
8\end{array}$ & $\begin{array}{l}\mathrm{Q} 21_{-} \\
9\end{array}$ & $\begin{array}{l}\text { Q21_- } \\
10\end{array}$ \\
\hline $\begin{array}{l}\text { Q21_1 I enjoy riding a } \\
\text { bike }\end{array}$ & 1 & & & & & & & & & \\
\hline $\begin{array}{l}\text { Q21_2 I feel safe } \\
\text { riding a bike }\end{array}$ & $\begin{array}{l}.462^{*} \\
*\end{array}$ & 1 & & & & & & & & \\
\hline $\begin{array}{l}\text { Q21_3 Riding a bike is } \\
\text { cool }\end{array}$ & $\begin{array}{l}.542 * \\
*\end{array}$ & $\begin{array}{l}.353^{*} \\
*\end{array}$ & 1 & & & & & & & \\
\hline $\begin{array}{l}\text { Q21_4 I consider } \\
\text { myself a bike } \\
\text { commuter }\end{array}$ & $\begin{array}{l}.353^{*} \\
*\end{array}$ & $\begin{array}{l}.350^{*} \\
*\end{array}$ & $\begin{array}{l}.262^{*} \\
*\end{array}$ & 1 & & & & & & \\
\hline $\begin{array}{l}\text { Q21_5r REVERSED } \\
\text { Most cyclists ride } \\
\text { recklessly }\end{array}$ & $\begin{array}{l}.129 * \\
*\end{array}$ & $\begin{array}{l}.145^{*} \\
*\end{array}$ & $\begin{array}{l}.267 * \\
*\end{array}$ & $\begin{array}{l}.077^{*} \\
*\end{array}$ & 1 & & & & & \\
\hline $\begin{array}{l}\text { Q21_6r REVERSED I } \\
\text { will not ride } \\
\text { somewhere if there } \\
\text { are no bike lanes }\end{array}$ & $\begin{array}{l}.139 * \\
*\end{array}$ & $\begin{array}{l}.259 * \\
*\end{array}$ & 0.037 & $\begin{array}{l}.183^{*} \\
*\end{array}$ & $\begin{array}{l}.141^{*} \\
*\end{array}$ & 1 & & & & \\
\hline $\begin{array}{l}\text { Q21_7r REVERSED } \\
\text { Cyclists cause unsafe } \\
\text { situations for } \\
\text { pedestrians }\end{array}$ & $\begin{array}{l}.193 * \\
*\end{array}$ & $\begin{array}{l}.172 * \\
*\end{array}$ & $\begin{array}{l}.267^{*} \\
*\end{array}$ & $\begin{array}{l}.104^{*} \\
*\end{array}$ & $\begin{array}{l}.558^{*} \\
*\end{array}$ & $\begin{array}{l}.140^{*} \\
*\end{array}$ & 1 & & & \\
\hline $\begin{array}{l}\text { Q21_8 I think that } \\
\text { riding a bike helps the } \\
\text { environment }\end{array}$ & $\begin{array}{l}.275^{*} \\
*\end{array}$ & $\begin{array}{l}.131^{*} \\
*\end{array}$ & $\begin{array}{l}.409 * \\
*\end{array}$ & 0.027 & $\begin{array}{l}.181 * \\
*\end{array}$ & $\begin{array}{l}- \\
.107^{*} \\
*\end{array}$ & $\begin{array}{l}.212 * \\
*\end{array}$ & 1 & & \\
\hline $\begin{array}{l}\text { Q21_9 Bikes are } \\
\text { convenient }\end{array}$ & $\begin{array}{l}.419 * \\
*\end{array}$ & $\begin{array}{l}.375^{*} \\
*\end{array}$ & $\begin{array}{l}.465 * \\
*\end{array}$ & $\begin{array}{l}.351^{*} \\
*\end{array}$ & $\begin{array}{l}.155^{*} \\
*\end{array}$ & $\begin{array}{l}.089 * \\
*\end{array}$ & $\begin{array}{l}.183^{*} \\
*\end{array}$ & $\begin{array}{l}.285^{*} \\
*\end{array}$ & 1 & \\
\hline $\begin{array}{l}\text { Q21_10 I am a bike } \\
\text { advocate }\end{array}$ & $\begin{array}{l}.435^{*} \\
*\end{array}$ & $\begin{array}{l}.313^{*} \\
*\end{array}$ & $\begin{array}{l}.535^{*} \\
*\end{array}$ & $\begin{array}{l}.338^{*} \\
*\end{array}$ & $\begin{array}{l}.227^{*} \\
*\end{array}$ & $\begin{array}{l}.067^{*} \\
*\end{array}$ & $\begin{array}{l}.252^{*} \\
*\end{array}$ & $\begin{array}{l}.363^{*} \\
*\end{array}$ & $\begin{array}{l}.430 * \\
*\end{array}$ & 1 \\
\hline
\end{tabular}


E-Scooter Attitude Items, Pearson Correlations

\begin{tabular}{|c|c|c|c|c|c|c|c|c|c|c|c|}
\hline & $\begin{array}{l}\text { Q28_ } \\
1\end{array}$ & $\begin{array}{l}\mathrm{Q} 28 \_ \\
2\end{array}$ & $\begin{array}{l}\text { Q28_ } \\
3 r\end{array}$ & $\begin{array}{l}\text { Q28_- } \\
4\end{array}$ & $\begin{array}{l}Q 28 \\
5 r\end{array}$ & $\begin{array}{l}\text { Q28_ } \\
6 r\end{array}$ & $\begin{array}{l}\text { Q28_- } \\
7 \mathrm{r}\end{array}$ & $\begin{array}{l}\text { Q28_ } \\
8\end{array}$ & $\begin{array}{l}\text { Q28_ } \\
9 \\
\end{array}$ & $\begin{array}{l}\text { Q28_ } \\
10\end{array}$ & $\begin{array}{l}\text { Q28_ } \\
11\end{array}$ \\
\hline $\begin{array}{l}\text { Q28_1 I enjoy } \\
\text { riding an e- } \\
\text { scooter }\end{array}$ & 1 & & & & & & & & & & \\
\hline $\begin{array}{l}\text { Q28_2 I feel } \\
\text { safe riding an } \\
\text { e-scooter }\end{array}$ & $\begin{array}{l}.534^{*} \\
*\end{array}$ & 1 & & & & & & & & & \\
\hline $\begin{array}{l}\text { Q28_3r } \\
\text { REVERSED E- } \\
\text { Scooters are } \\
\text { ugly }\end{array}$ & $\begin{array}{l}.367^{*} \\
*\end{array}$ & $\begin{array}{l}.239 * \\
*\end{array}$ & 1 & & & & & & & & \\
\hline $\begin{array}{l}\text { Q28_4 I am an } \\
\text { e-scooter } \\
\text { commuter }\end{array}$ & $\begin{array}{l}.333^{*} \\
*\end{array}$ & $\begin{array}{l}.333^{*} \\
*\end{array}$ & $\begin{array}{l}.139 * \\
*\end{array}$ & 1 & & & & & & & \\
\hline $\begin{array}{l}\text { Q28_5r } \\
\text { REVERSED } \\
\text { Most e- } \\
\text { scooter users } \\
\text { ride recklessly }\end{array}$ & $\begin{array}{l}.185 * \\
*\end{array}$ & $\begin{array}{l}.279 * \\
*\end{array}$ & $\begin{array}{l}.389 * \\
*\end{array}$ & $\begin{array}{l}.101 * \\
*\end{array}$ & 1 & & & & & & \\
\hline $\begin{array}{l}\text { Q28_6r } \\
\text { REVERSED I } \\
\text { will not ride } \\
\text { somewhere if } \\
\text { there are no } \\
\text { dedicated } \\
\text { lanes }\end{array}$ & $\begin{array}{l}.147^{*} \\
*\end{array}$ & $\begin{array}{l}.198^{*} \\
*\end{array}$ & $\begin{array}{l}.100 * \\
*\end{array}$ & $\begin{array}{l}.071 * \\
*\end{array}$ & $\begin{array}{l}.158^{*} \\
*\end{array}$ & 1 & & & & & \\
\hline $\begin{array}{l}\text { Q28_7r } \\
\text { REVERSED E- } \\
\text { Scooter users } \\
\text { cause unsafe } \\
\text { situations for } \\
\text { pedestrians }\end{array}$ & $\begin{array}{l}.222^{*} \\
*\end{array}$ & $\begin{array}{l}.286^{*} \\
*\end{array}$ & $\begin{array}{l}.404^{*} \\
*\end{array}$ & $\begin{array}{l}.174^{*} \\
*\end{array}$ & $\begin{array}{l}.627^{*} \\
*\end{array}$ & $\begin{array}{l}.177^{*} \\
*\end{array}$ & 1 & & & & \\
\hline $\begin{array}{l}\text { Q28_8 I would } \\
\text { use an e- } \\
\text { scooter more } \\
\text { often if I knew } \\
\text { there was } \\
\text { always one } \\
\text { available close } \\
\text { by }\end{array}$ & $\begin{array}{l}.515 * \\
*\end{array}$ & $\begin{array}{l}.389 * \\
*\end{array}$ & $\begin{array}{l}.298^{*} \\
*\end{array}$ & $\begin{array}{l}.346 * \\
*\end{array}$ & $\begin{array}{l}.149 * \\
*\end{array}$ & 0.019 & $\begin{array}{l}.172^{*} \\
*\end{array}$ & 1 & & & \\
\hline $\begin{array}{l}\text { Q28_9 I think } \\
\text { that riding an } \\
\text { e-scooter } \\
\text { helps the } \\
\text { environment }\end{array}$ & $\begin{array}{l}.320^{*} \\
*\end{array}$ & $\begin{array}{l}.264^{*} \\
*\end{array}$ & $\begin{array}{l}.273^{*} \\
*\end{array}$ & $\begin{array}{l}.129 * \\
*\end{array}$ & $\begin{array}{l}.156 * \\
*\end{array}$ & $\begin{array}{l}- \\
.125 * \\
*\end{array}$ & $\begin{array}{l}.173^{*} \\
*\end{array}$ & $\begin{array}{l}.341 * \\
*\end{array}$ & 1 & & \\
\hline
\end{tabular}




\begin{tabular}{|c|c|c|c|c|c|c|c|c|c|c|c|}
\hline $\begin{array}{l}\text { Q28_10 Riding } \\
\text { an e-scooter is } \\
\text { cool }\end{array}$ & $\begin{array}{l}.555^{*} \\
*\end{array}$ & $\begin{array}{l}.416^{*} \\
*\end{array}$ & $\begin{array}{l}.539 * \\
*\end{array}$ & $\begin{array}{l}.283^{*} \\
*\end{array}$ & $\begin{array}{l}.299 * \\
*\end{array}$ & $.045^{*}$ & $\begin{array}{l}.303^{*} \\
*\end{array}$ & $\begin{array}{l}.499 * \\
*\end{array}$ & $\begin{array}{l}.430 * \\
*\end{array}$ & 1 & \\
\hline $\begin{array}{l}\text { Q28_11 E- } \\
\text { Scooters are } \\
\text { convenient }\end{array}$ & $\begin{array}{l}.476^{*} \\
*\end{array}$ & $\begin{array}{l}.389 * \\
*\end{array}$ & $\begin{array}{l}.289 * \\
*\end{array}$ & $\begin{array}{l}.212^{*} \\
*\end{array}$ & $\begin{array}{l}.158^{*} \\
*\end{array}$ & -0.002 & $\begin{array}{l}.131 * \\
*\end{array}$ & $\begin{array}{l}.389 * \\
*\end{array}$ & $\begin{array}{l}.459 * \\
*\end{array}$ & $\begin{array}{l}.476^{*} \\
*\end{array}$ & 1 \\
\hline
\end{tabular}

**. Correlation is significant at the 0.01 level (2-tailed).

*. Correlation is significant at the 0.05

level (2-tailed). 
Mode Decision Factors, Pearson Correlations

\begin{tabular}{|c|c|c|c|c|c|c|c|c|c|c|c|c|c|c|c|}
\hline & $\begin{array}{c}\text { Q8 } \\
\_1\end{array}$ & $\begin{array}{c}\text { Q8 } \\
2\end{array}$ & $\begin{array}{c}\text { Q8 } \\
-3\end{array}$ & $\begin{array}{c}\text { Q8 } \\
-4\end{array}$ & $\begin{array}{c}\text { Q8 } \\
\_5\end{array}$ & $\begin{array}{c}Q 8 \\
6\end{array}$ & $\begin{array}{c}\text { Q8 } \\
-7\end{array}$ & $\begin{array}{c}\text { Q8 } \\
-8\end{array}$ & $\begin{array}{c}\text { Q8 } \\
-9\end{array}$ & $\begin{array}{c}\text { Q8 } \\
\_10\end{array}$ & $\begin{array}{l}\text { Q8 } \\
-11\end{array}$ & $\begin{array}{c}\mathrm{Q} 8 \\
\_12\end{array}$ & $\begin{array}{l}\text { Q8 } \\
-13\end{array}$ & $\begin{array}{c}\text { Q8 } \\
\_14\end{array}$ & $\begin{array}{l}\text { Q8 } \\
\_15\end{array}$ \\
\hline $\begin{array}{l}\text { Q8_1 } \\
\text { Obtaining } \\
\text { exercise } \\
\text { or physical } \\
\text { activity }\end{array}$ & 1 & & & & & & & & & & & & & & \\
\hline $\begin{array}{l}\text { Q8_2 My } \\
\text { physical } \\
\text { ability }\end{array}$ & $\begin{array}{l}.549 \\
* *\end{array}$ & 1 & & & & & & & & & & & & & \\
\hline $\begin{array}{l}\text { Q8_3 } \\
\text { Opportuni } \\
\text { ty to } \\
\text { shower at } \\
\text { destinatio } \\
\text { n }\end{array}$ & $\begin{array}{l}.432 \\
* *\end{array}$ & $\begin{array}{l}.335 \\
* *\end{array}$ & 1 & & & & & & & & & & & & \\
\hline $\begin{array}{l}\text { Q8_4 } \\
\text { Arriving } \\
\text { on time to } \\
\text { destinatio } \\
n\end{array}$ & .010 & $\begin{array}{l}.112 \\
* *\end{array}$ & $\begin{array}{l}- \\
0.02 \\
26\end{array}$ & 1 & & & & & & & & & & & \\
\hline $\begin{array}{l}\text { Q8_5 } \\
\text { Frequency } \\
\text { of transit } \\
\text { departure } \\
\text { s }\end{array}$ & $\begin{array}{l}.167 \\
* *\end{array}$ & $\begin{array}{l}.199 \\
* *\end{array}$ & $\begin{array}{l}.122 \\
* *\end{array}$ & $\begin{array}{l}.297 \\
* *\end{array}$ & 1 & & & & & & & & & & \\
\hline $\begin{array}{l}\text { Q8_6 } \\
\text { Flexible } \\
\text { time of } \\
\text { departure }\end{array}$ & $\begin{array}{l}.084 \\
* *\end{array}$ & $\begin{array}{l}.154 \\
* *\end{array}$ & $\begin{array}{l}.112 \\
* *\end{array}$ & $\begin{array}{l}.281 \\
* *\end{array}$ & $\begin{array}{l}.533 \\
* *\end{array}$ & 1 & & & & & & & & & \\
\hline $\begin{array}{l}\text { Q8_7 } \\
\text { Travel } \\
\text { cost/price }\end{array}$ & $\begin{array}{l}.133 \\
* *\end{array}$ & $\begin{array}{l}.228 \\
* *\end{array}$ & $\begin{array}{l}.079 \\
* *\end{array}$ & $\begin{array}{l}.297 \\
* *\end{array}$ & $\begin{array}{l}.380 \\
* *\end{array}$ & $\begin{array}{l}.291 \\
* *\end{array}$ & 1 & & & & & & & & \\
\hline $\begin{array}{l}\text { Q8_8 } \\
\text { Travel } \\
\text { time }\end{array}$ & .037 & $\begin{array}{l}.121 \\
* *\end{array}$ & $\begin{array}{l}.058 \\
* *\end{array}$ & $\begin{array}{l}.388 \\
* *\end{array}$ & $\begin{array}{l}.206 \\
* *\end{array}$ & $\begin{array}{l}.315 \\
* *\end{array}$ & $\begin{array}{l}.366 \\
* *\end{array}$ & 1 & & & & & & & \\
\hline $\begin{array}{l}\text { Q8_9 } \\
\text { Flexible } \\
\text { travel } \\
\text { route }\end{array}$ & $\begin{array}{l}.165 \\
* *\end{array}$ & $\begin{array}{l}.225 \\
* *\end{array}$ & $\begin{array}{l}.186 \\
* *\end{array}$ & $\begin{array}{l}.228 \\
* *\end{array}$ & $\begin{array}{l}.177 \\
* *\end{array}$ & $\begin{array}{l}.421 \\
* *\end{array}$ & $\begin{array}{l}.223 \\
* *\end{array}$ & $\begin{array}{l}.435 \\
* *\end{array}$ & 1 & & & & & & \\
\hline $\begin{array}{l}\text { Q8_10 } \\
\text { Personal } \\
\text { safety and } \\
\text { security }\end{array}$ & $\begin{array}{l}.154 \\
* *\end{array}$ & $\begin{array}{l}.243 \\
* *\end{array}$ & $\begin{array}{l}.058 \\
* *\end{array}$ & $\begin{array}{l}.303 \\
* *\end{array}$ & $\begin{array}{l}.171 \\
* *\end{array}$ & $\begin{array}{l}.180 \\
* *\end{array}$ & $\begin{array}{l}.260 \\
* *\end{array}$ & $\begin{array}{l}.339 \\
* *\end{array}$ & $\begin{array}{l}.372 \\
* *\end{array}$ & 1 & & & & & \\
\hline $\begin{array}{l}\text { Q8_11 } \\
\text { Traffic } \\
\text { safety }\end{array}$ & $\begin{array}{l}.179 \\
* *\end{array}$ & $\begin{array}{l}.259 \\
* *\end{array}$ & $\begin{array}{l}.166 \\
* *\end{array}$ & $\begin{array}{l}.258 \\
* *\end{array}$ & $\begin{array}{l}.201 \\
* *\end{array}$ & $\begin{array}{l}.239 \\
* *\end{array}$ & $\begin{array}{l}.292 \\
* *\end{array}$ & $\begin{array}{l}.340 \\
* *\end{array}$ & $\begin{array}{l}.419 \\
* *\end{array}$ & $\begin{array}{l}.651 \\
* *\end{array}$ & 1 & & & & \\
\hline $\begin{array}{l}\text { Q8_12 } \\
\text { The } \\
\text { current } \\
\text { weather } \\
\text { conditions }\end{array}$ & $\begin{array}{l}.155 \\
* *\end{array}$ & $\begin{array}{l}.233 \\
* *\end{array}$ & $\begin{array}{l}.143 \\
* *\end{array}$ & $\begin{array}{l}.165 \\
* *\end{array}$ & $\begin{array}{l}.081 \\
* *\end{array}$ & $\begin{array}{l}.143 \\
* *\end{array}$ & $\begin{array}{l}.191 \\
* *\end{array}$ & $\begin{array}{l}.293 \\
* *\end{array}$ & $\begin{array}{l}.348 \\
* *\end{array}$ & $\begin{array}{l}.355 \\
* *\end{array}$ & $\begin{array}{l}.428 \\
* *\end{array}$ & 1 & & & \\
\hline
\end{tabular}




\begin{tabular}{|c|c|c|c|c|c|c|c|c|c|c|c|c|c|c|c|}
\hline $\begin{array}{l}\text { Q8_13 My } \\
\text { personal } \\
\text { impact on } \\
\text { the } \\
\text { environm } \\
\text { ent } \\
\text { (carbon } \\
\text { footprint) }\end{array}$ & $\begin{array}{l}.354 \\
* *\end{array}$ & $\begin{array}{l}.277 \\
* *\end{array}$ & $\begin{array}{l}.210 \\
* *\end{array}$ & $\begin{array}{l}.109 \\
* *\end{array}$ & $\begin{array}{l}.234 \\
* *\end{array}$ & $\begin{array}{l}.120 \\
* *\end{array}$ & $\begin{array}{l}.212 \\
* *\end{array}$ & $\begin{array}{l}.078 \\
* *\end{array}$ & $\begin{array}{l}.177 \\
* *\end{array}$ & $\begin{array}{l}.218 \\
* *\end{array}$ & $\begin{array}{l}.300 \\
* *\end{array}$ & $\begin{array}{l}.242 \\
* *\end{array}$ & 1 & & \\
\hline $\begin{array}{l}\text { Q8_14 } \\
\text { The } \\
\text { opportuni } \\
\text { ty to do } \\
\text { other } \\
\text { things } \\
\text { while } \\
\text { traveling }\end{array}$ & $\begin{array}{l}.253 \\
* *\end{array}$ & $\begin{array}{l}.181 \\
* *\end{array}$ & $\begin{array}{l}.231 \\
* *\end{array}$ & $\begin{array}{l}.106 \\
* *\end{array}$ & $\begin{array}{l}.253 \\
* *\end{array}$ & $\begin{array}{l}.220 \\
* *\end{array}$ & $\begin{array}{l}.172 \\
* *\end{array}$ & $\begin{array}{l}.137 \\
* *\end{array}$ & $\begin{array}{l}.274 \\
* *\end{array}$ & $\begin{array}{l}.134 \\
* *\end{array}$ & $\begin{array}{l}.198 \\
* *\end{array}$ & $\begin{array}{l}.214 \\
* *\end{array}$ & $\begin{array}{l}.367 \\
* *\end{array}$ & 1 & \\
\hline $\begin{array}{l}\text { Q8_15 } \\
\text { Physical } \\
\text { comfort } \\
\text { while } \\
\text { traveling }\end{array}$ & $\begin{array}{l}.105 \\
* *\end{array}$ & $\begin{array}{l}.206 \\
* *\end{array}$ & $\begin{array}{l}.133 \\
* *\end{array}$ & $\begin{array}{l}.247 \\
* *\end{array}$ & $\begin{array}{l}.138 \\
* *\end{array}$ & $\begin{array}{l}.230 \\
* *\end{array}$ & $\begin{array}{l}.168 \\
* *\end{array}$ & $\begin{array}{l}.295 \\
* * \\
\end{array}$ & $\begin{array}{l}.368 \\
* *\end{array}$ & $\begin{array}{l}.424 \\
* *\end{array}$ & $\begin{array}{l}.385 \\
* * \\
\end{array}$ & $\begin{array}{l}.346 \\
* *\end{array}$ & $\begin{array}{l}.194 \\
* *\end{array}$ & $\begin{array}{l}.349 \\
* *\end{array}$ & 1 \\
\hline
\end{tabular}

$* *$. Correlation is

significant at the 0.01

level (2-tailed).

*. Correlation is

significant at the 0.05

level (2-tailed). 


\section{B. Full Latent Variable Estimation Method Comparisons}

\begin{tabular}{|c|c|c|c|c|c|c|c|c|c|c|c|c|}
\hline \multirow[b]{2}{*}{ Predictors } & \multicolumn{3}{|c|}{$\begin{array}{l}\text { 1. Propensity to } \\
\text { switch to Car OLS } \\
\text { with summed mode } \\
\text { attitude items }\end{array}$} & \multicolumn{3}{|c|}{$\begin{array}{l}\text { 2. Propensity to } \\
\text { switch to Car OLS with } \\
\text { averaged mode } \\
\text { attitude items }\end{array}$} & \multicolumn{3}{|c|}{$\begin{array}{l}\text { 3. Propensity to } \\
\text { switch to Car OLS } \\
\text { with EFA factor } \\
\text { scores calculated } \\
\text { using regression } \\
\text { method }\end{array}$} & \multicolumn{3}{|c|}{$\begin{array}{l}\text { 4. Propensity to } \\
\text { switch to car } \\
\text { SEM including latent } \\
\text { variable analysis }\end{array}$} \\
\hline & $\begin{array}{c}\text { Esti } \\
\text { mate } \\
s\end{array}$ & $\begin{array}{l}\text { std. } \\
\text { Error }\end{array}$ & $\begin{array}{l}\text { std. } \\
\text { Beta }\end{array}$ & $\begin{array}{l}\text { Estim } \\
\text { ates }\end{array}$ & $\begin{array}{l}\text { std. } \\
\text { Error }\end{array}$ & $\begin{array}{l}\text { std. } \\
\text { Beta }\end{array}$ & $\begin{array}{c}\text { Esti } \\
\text { mat } \\
\text { es }\end{array}$ & $\begin{array}{l}\text { std. } \\
\text { Error }\end{array}$ & $\begin{array}{l}\text { std. } \\
\text { Beta }\end{array}$ & $\begin{array}{c}\text { Esti } \\
\text { mate } \\
s\end{array}$ & $\begin{array}{l}\text { std. } \\
\text { Error }\end{array}$ & $\begin{array}{l}\text { std. } \\
\text { Beta }\end{array}$ \\
\hline (Intercept) & -0.03 & 1.49 & 0.00 & -0.10 & 1.49 & 0.00 & 2.13 & 1.22 & 0.01 & 2.33 & 1.18 & 0.65 \\
\hline \multicolumn{13}{|l|}{ Demographics } \\
\hline \multicolumn{13}{|l|}{$\begin{array}{l}\text { Income (referent: } \\
\text { Less than } \$ 25,000 \text { ) }\end{array}$} \\
\hline $\begin{array}{l}\$ 25,000- \\
\$ 49,999\end{array}$ & 0.14 & 0.31 & 0.01 & 0.15 & 0.31 & 0.01 & 0.20 & 0.31 & 0.02 & 0.21 & 0.30 & 0.02 \\
\hline $\begin{array}{l}\$ 50,000- \\
\$ 74,999\end{array}$ & 0.36 & 0.42 & 0.03 & 0.37 & 0.42 & 0.03 & 0.36 & 0.42 & 0.03 & 0.33 & 0.41 & 0.02 \\
\hline $\begin{array}{l}\$ 75,000- \\
\$ 99,999\end{array}$ & 1.02 & 0.54 & 0.05 & 0.94 & 0.54 & 0.05 & 0.95 & 0.54 & 0.05 & 1.04 & 0.53 & 0.06 \\
\hline $\begin{array}{l}\$ 100,000- \\
\$ 124,999\end{array}$ & 0.18 & 0.67 & 0.01 & 0.09 & 0.69 & 0.00 & 0.06 & 0.69 & 0.00 & 0.04 & 0.68 & 0.00 \\
\hline $\begin{array}{l}\text { Greater than } \\
\$ 125,000\end{array}$ & -0.23 & 0.71 & 0.01 & -0.20 & 0.71 & -0.01 & 0.32 & 0.77 & -0.01 & -0.66 & 0.74 & -0.03 \\
\hline \multicolumn{13}{|l|}{$\begin{array}{l}\text { Race and Ethnicity } \\
\text { (referent: White } \\
\text { only) }\end{array}$} \\
\hline $\begin{array}{l}\text { American } \\
\text { Indian or } \\
\text { Alaska Native } \\
\text { only }\end{array}$ & 0.68 & 1.48 & 0.01 & 0.63 & 1.48 & 0.01 & 0.21 & 1.70 & 0.00 & -0.08 & 1.67 & 0.00 \\
\hline Asian only & $\begin{array}{c}0.75 \\
*\end{array}$ & 0.29 & 0.07 & $\begin{array}{c}0.74 \\
*\end{array}$ & 0.30 & 0.07 & $\begin{array}{c}0.77 \\
*\end{array}$ & 0.30 & 0.07 & 0.79 & 0.29 & 0.08 \\
\hline Black only & 0.04 & 0.64 & 0.00 & 0.04 & 0.64 & 0.00 & 0.21 & 0.66 & 0.01 & 0.24 & 0.64 & 0.01 \\
\hline $\begin{array}{l}\text { Hispanic or } \\
\text { Latinx/Latino/L } \\
\text { atina only }\end{array}$ & 0.19 & 0.32 & 0.02 & 0.18 & 0.32 & 0.01 & 0.22 & 0.33 & 0.02 & 0.26 & 0.32 & 0.02 \\
\hline $\begin{array}{l}\text { More than one } \\
\text { race or } \\
\text { ethnicity }\end{array}$ & 0.47 & 0.29 & 0.04 & 0.45 & 0.29 & 0.04 & 0.35 & 0.30 & 0.03 & 0.38 & 0.29 & 0.04 \\
\hline $\begin{array}{l}\text { Native } \\
\text { Hawaiian or } \\
\text { Pacific Islander } \\
\text { only }\end{array}$ & -2.36 & 1.49 & 0.04 & -2.38 & 1.49 & -0.04 & 2.35 & 1.49 & -0.04 & -2.31 & 1.46 & -0.04 \\
\hline Other only & $\begin{array}{l}-2.45 \\
*\end{array}$ & 1.00 & 0.06 & $\begin{array}{l}-2.45 \\
*\end{array}$ & 1.00 & -0.06 & $\begin{array}{l}- \\
2.44 \\
*\end{array}$ & 1.00 & -0.06 & -2.23 & 0.98 & -0.06 \\
\hline \multicolumn{13}{|l|}{$\begin{array}{l}\text { Gender (referent: } \\
\text { Male) }\end{array}$} \\
\hline Female & -0.05 & 0.21 & 0.01 & -0.06 & 0.21 & -0.01 & 0.01 & 0.21 & 0.00 & -0.07 & 0.20 & -0.01 \\
\hline Non-Binary & 0.58 & 0.50 & 0.03 & 0.57 & 0.50 & 0.03 & 0.61 & 0.50 & 0.03 & 0.55 & 0.49 & 0.03 \\
\hline Other & 1.84 & 1.16 & 0.04 & 1.82 & 1.16 & 0.04 & 1.98 & 1.17 & 0.05 & 2.01 & 1.14 & 0.05 \\
\hline
\end{tabular}




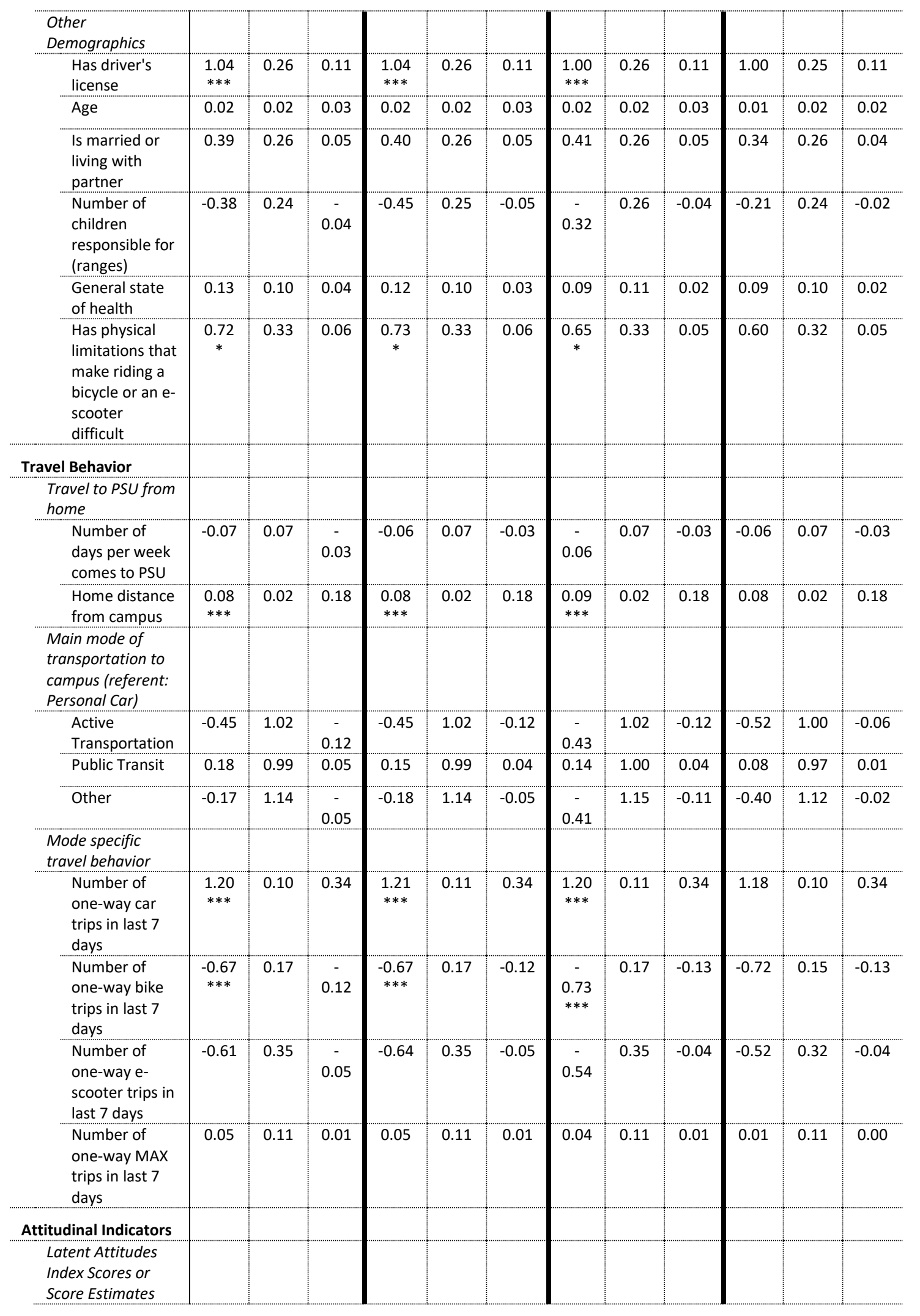




\begin{tabular}{|c|c|c|c|c|c|c|c|c|c|c|c|c|}
\hline Car (item sum) & $\begin{array}{l}0.15 \\
* * *\end{array}$ & 0.02 & 0.19 & & & & & & & & & \\
\hline $\begin{array}{l}\text { Bike (item } \\
\text { sum) }\end{array}$ & -0.03 & 0.02 & 0. & & & & & & & & & \\
\hline $\begin{array}{l}\text { E-Scooter } \\
\text { (item sum) }\end{array}$ & 0.02 & 0.02 & 0.03 & & & & & & & & & \\
\hline $\begin{array}{l}\text { MAX (item } \\
\text { sum) }\end{array}$ & $\begin{array}{c}-0.04 \\
*\end{array}$ & 0.02 & $\begin{array}{c}- \\
0.06\end{array}$ & & & & & & & & & \\
\hline $\begin{array}{l}\text { Car (item } \\
\text { mean) }\end{array}$ & & & & $\begin{array}{l}1.05 \\
* * *\end{array}$ & 0.16 & 0.19 & & & & & & \\
\hline $\begin{array}{l}\text { Bike (item } \\
\text { mean) }\end{array}$ & & & & -0.26 & 0.20 & -0.04 & & & & & & \\
\hline $\begin{array}{l}\text { E-Scooter } \\
\text { (item mean) }\end{array}$ & & & & 0.23 & 0.19 & 0.03 & & & & & & \\
\hline $\begin{array}{l}\text { MAX (item } \\
\text { mean) }\end{array}$ & & & & $\begin{array}{c}-0.38 \\
*\end{array}$ & 0.18 & -0.06 & & & & & & \\
\hline $\begin{array}{l}\text { Car (EFA factor } \\
\text { score - } \\
\text { regression) }\end{array}$ & & & & & & & $\begin{array}{l}0.83 \\
* * *\end{array}$ & 0.12 & 0.20 & & & \\
\hline $\begin{array}{l}\text { Bike (EFA } \\
\text { factor score - } \\
\text { regression) }\end{array}$ & & & & & & & 0.07 & 0.13 & -0.02 & & & \\
\hline $\begin{array}{l}\text { E-Scooter (EFA } \\
\text { factor score - } \\
\text { regression) }\end{array}$ & & & & & & & 0.08 & 0.12 & 0.02 & & & \\
\hline $\begin{array}{l}\text { MAX (EFA } \\
\text { factor score - } \\
\text { regression) }\end{array}$ & & & & & & & $\begin{array}{c}- \\
0.31 \\
*\end{array}$ & 0.13 & -0.07 & & & \\
\hline $\begin{array}{l}\text { Car (SEM } \\
\text { latent variable } \\
\text { estimate) }\end{array}$ & & & & & & & & & & 1.16 & 0.17 & 0.24 \\
\hline $\begin{array}{l}\text { Bike (SEM } \\
\text { latent variable } \\
\text { estimate) }\end{array}$ & & & & & & & & & & -0.10 & 0.18 & -0.02 \\
\hline $\begin{array}{l}\text { E-Scooter (SEM } \\
\text { latent variable } \\
\text { estimate) }\end{array}$ & & & & & & & & & & 0.01 & 0.15 & 0.00 \\
\hline $\begin{array}{l}\text { MAX (SEM } \\
\text { latent variable } \\
\text { estimate) }\end{array}$ & & & & & & & & & & -0.32 & 0.16 & -0.06 \\
\hline
\end{tabular}




\begin{tabular}{|c|c|c|c|c|c|c|c|c|c|c|c|c|}
\hline \multicolumn{13}{|l|}{$\begin{array}{l}\text { Latent Mode Decision } \\
\text { Factor Estimates }\end{array}$} \\
\hline $\begin{array}{l}\text { "Comfort and } \\
\text { safety" (EFA } \\
\text { factor score - } \\
\text { regression) }\end{array}$ & 0.05 & 0.11 & 0.01 & 0.05 & 0.11 & 0.01 & 0.04 & 0.12 & 0.01 & & & \\
\hline $\begin{array}{l}\text { "Exercise and } \\
\text { environmental } \\
\text { impact" (EFA } \\
\text { factor score - } \\
\text { regression) }\end{array}$ & -0.08 & 0.13 & $\begin{array}{c}- \\
0.02\end{array}$ & -0.09 & 0.13 & -0.02 & $\begin{array}{c}- \\
0.05\end{array}$ & 0.13 & -0.01 & & & \\
\hline $\begin{array}{l}\text { "Comfort and } \\
\text { safety" (SEM } \\
\text { latent variable } \\
\text { estimate) }\end{array}$ & & & & & & & & & & 0.07 & 0.34 & 0.01 \\
\hline $\begin{array}{l}\text { "Exercise and } \\
\text { environmental } \\
\text { impact" (SEM } \\
\text { latent variable } \\
\text { estimate) }\end{array}$ & & & & & & & & & & -0.02 & 0.20 & -0.01 \\
\hline Observations & \multicolumn{3}{|l|}{1000} & \multicolumn{3}{|c|}{995} & \multirow{2}{*}{\multicolumn{3}{|c|}{$\begin{array}{c}968 \\
0.407 / 0.384\end{array}$}} & \multirow{2}{*}{\multicolumn{3}{|c|}{982}} \\
\hline $\begin{array}{l}\mathrm{R}^{2} / \mathrm{R}^{2} \\
\text { adjusted }\end{array}$ & \multicolumn{3}{|c|}{$0.403 / 0.380$} & \multicolumn{3}{|c|}{0.404 / 0.381} & & & & & & \\
\hline
\end{tabular}




\begin{tabular}{|c|c|c|c|c|c|c|c|c|c|c|c|c|}
\hline \multirow[b]{2}{*}{ Predictors } & \multicolumn{3}{|c|}{$\begin{array}{l}\text { 1. Propensity to } \\
\text { switch to Bike OLS } \\
\text { with summed mode } \\
\text { attitude items }\end{array}$} & \multicolumn{3}{|c|}{$\begin{array}{l}\text { 2. Propensity to } \\
\text { switch to Bike OLS } \\
\text { with averaged mode } \\
\text { attitude items }\end{array}$} & \multicolumn{3}{|c|}{$\begin{array}{l}\text { 3. Propensity to } \\
\text { switch to Bike OLS } \\
\text { with EFA factor } \\
\text { scores calculated } \\
\text { using regression } \\
\text { method }\end{array}$} & \multicolumn{3}{|c|}{$\begin{array}{l}\text { 4. Propensity to } \\
\text { switch to bike } \\
\text { SEM including latent } \\
\text { variable analysis }\end{array}$} \\
\hline & $\begin{array}{l}\text { Esti } \\
\text { mat } \\
\text { es }\end{array}$ & $\begin{array}{l}\text { std. } \\
\text { Error }\end{array}$ & $\begin{array}{l}\text { std. } \\
\text { Beta }\end{array}$ & $\begin{array}{c}\text { Esti } \\
\text { mat } \\
\text { es }\end{array}$ & $\begin{array}{l}\text { std. } \\
\text { Error }\end{array}$ & $\begin{array}{l}\text { std. } \\
\text { Beta }\end{array}$ & $\begin{array}{c}\text { Esti } \\
\text { mat } \\
\text { es }\end{array}$ & $\begin{array}{l}\text { std. } \\
\text { Error }\end{array}$ & $\begin{array}{l}\text { std. } \\
\text { Beta }\end{array}$ & $\begin{array}{c}\text { Esti } \\
\text { mat } \\
\text { es }\end{array}$ & $\begin{array}{l}\text { std. } \\
\text { Error }\end{array}$ & $\begin{array}{l}\text { std. } \\
\text { Beta }\end{array}$ \\
\hline (Intercept) & $\begin{array}{c}- \\
1.83 \\
*\end{array}$ & 0.78 & 0.04 & $\begin{array}{c}- \\
1.85 \\
*\end{array}$ & 0.78 & 0.05 & $\begin{array}{l}2.48 \\
* * *\end{array}$ & 0.52 & 0.06 & 2.41 & 0.50 & 0.91 \\
\hline \multicolumn{13}{|l|}{ Demographics } \\
\hline \multicolumn{13}{|l|}{$\begin{array}{l}\text { Income (referent: } \\
\text { Less than } \$ 25,000 \text { ) }\end{array}$} \\
\hline $\begin{array}{l}\$ 25,000- \\
\$ 49,999\end{array}$ & 0.27 & 0.19 & 0.03 & 0.26 & 0.19 & 0.03 & 0.24 & 0.19 & 0.03 & 0.25 & 0.19 & 0.03 \\
\hline $\begin{array}{l}\$ 50,000- \\
\$ 74,999\end{array}$ & 0.22 & 0.25 & 0.02 & 0.22 & 0.25 & 0.02 & 0.25 & 0.25 & 0.02 & 0.20 & 0.25 & 0.02 \\
\hline $\begin{array}{l}\$ 75,000- \\
\$ 99,999\end{array}$ & 0.00 & 0.32 & 0.00 & 0.02 & 0.32 & 0.00 & 0.04 & 0.32 & 0.00 & 0.06 & 0.32 & 0.00 \\
\hline $\begin{array}{l}\$ 100,000- \\
\$ 124,999\end{array}$ & 0.21 & 0.41 & 0.01 & 0.25 & 0.42 & 0.01 & 0.28 & 0.42 & 0.02 & 0.28 & 0.41 & 0.02 \\
\hline $\begin{array}{l}\text { Greater than } \\
\$ 125,000\end{array}$ & $\overline{-}$ & 0.40 & $\begin{array}{c}- \\
0.03\end{array}$ & $\begin{array}{c}- \\
0.50\end{array}$ & 0.40 & $\begin{array}{c}- \\
0.03\end{array}$ & 0.44 & 0.42 & 0.03 & $\begin{array}{c}- \\
0.47\end{array}$ & 0.41 & $\begin{array}{c}- \\
0.03\end{array}$ \\
\hline \multicolumn{13}{|l|}{$\begin{array}{l}\text { Race and Ethnicity } \\
\text { (referent: White } \\
\text { only) }\end{array}$} \\
\hline $\begin{array}{l}\text { American } \\
\text { Indian or } \\
\text { Alaska Native } \\
\text { only }\end{array}$ & 0.17 & 0.85 & 0.00 & 0.16 & 0.85 & 0.00 & 0.10 & 0.92 & 0.00 & 0.20 & 0.90 & 0.01 \\
\hline Asian only & 0.00 & 0.19 & 0.00 & 0.01 & 0.19 & 0.00 & 0.06 & 0.20 & 0.01 & 0.07 & 0.19 & 0.01 \\
\hline Black only & 0.02 & 0.44 & 0.00 & 0.03 & 0.44 & 0.00 & $\begin{array}{c}- \\
0.09\end{array}$ & 0.45 & 0.00 & $\begin{array}{c}- \\
0.03\end{array}$ & 0.44 & 0.00 \\
\hline $\begin{array}{l}\text { Hispanic or } \\
\text { Latinx/Latino/L } \\
\text { atina only }\end{array}$ & $\overline{-}-\overline{25}$ & 0.20 & $\begin{array}{c}- \\
0.03\end{array}$ & $\begin{array}{c}- \\
0.24\end{array}$ & 0.20 & $\begin{array}{c}- \\
0.03\end{array}$ & $\overline{-}$ & 0.20 & 0.02 & $\begin{array}{c}- \\
0.21\end{array}$ & 0.20 & $\begin{array}{c}- \\
0.03\end{array}$ \\
\hline $\begin{array}{l}\text { More than one } \\
\text { race or } \\
\text { ethnicity }\end{array}$ & 0.31 & 0.18 & 0.04 & 0.30 & 0.18 & 0.04 & 0.32 & 0.19 & 0.04 & 0.29 & 0.18 & 0.04 \\
\hline $\begin{array}{l}\text { Native } \\
\text { Hawaiian or } \\
\text { Pacific Islander } \\
\text { only }\end{array}$ & $\overline{-}$ & 0.78 & $\overline{-}$ & $\overline{-}-$ & 0.78 & $\begin{array}{c}- \\
0.03\end{array}$ & $\overline{-}$ & 0.79 & $\begin{array}{c}- \\
0.03\end{array}$ & $\begin{array}{c}- \\
1.24\end{array}$ & 0.77 & 0.04 \\
\hline Other only & $\begin{array}{c}- \\
0.14\end{array}$ & 0.56 & $\begin{array}{c}- \\
0.01\end{array}$ & $\begin{array}{l}- \\
0.14\end{array}$ & 0.55 & $\begin{array}{c}- \\
0.01\end{array}$ & $\begin{array}{l}- \\
0.22\end{array}$ & 0.58 & $\begin{array}{c}- \\
0.01\end{array}$ & $\overline{-}$ & 0.57 & $\begin{array}{c}- \\
0.01\end{array}$ \\
\hline \multicolumn{13}{|l|}{$\begin{array}{l}\text { Gender (referent: } \\
\text { Male) }\end{array}$} \\
\hline Female & $\begin{array}{l}- \\
0.52 \\
* * *\end{array}$ & 0.13 & 0.09 & $\begin{array}{c}- \\
0.52 \\
* * *\end{array}$ & 0.13 & 0.09 & $\begin{array}{l}- \\
0.52 \\
* * *\end{array}$ & 0.14 & 0.09 & 0.48 & 0.13 & 0.09 \\
\hline Non-Binary & 0.25 & 0.34 & $\begin{array}{c}- \\
0.02\end{array}$ & $\begin{array}{c}- \\
0.27\end{array}$ & 0.34 & $\begin{array}{c}- \\
0.02\end{array}$ & $\begin{array}{c}- \\
0.32\end{array}$ & 0.35 & $\begin{array}{c}- \\
0.02\end{array}$ & $\begin{array}{c}- \\
0.30\end{array}$ & 0.34 & $\begin{array}{c}- \\
0.02 \\
0.02\end{array}$ \\
\hline Other & $\begin{array}{c}- \\
0.05\end{array}$ & 0.80 & 0.00 & $\begin{array}{c}- \\
0.06\end{array}$ & 0.80 & 0.00 & $\begin{array}{c}- \\
0.16\end{array}$ & 0.81 & 0.00 & $\begin{array}{c}- \\
0.13\end{array}$ & 0.80 & 0.00 \\
\hline \multicolumn{13}{|l|}{$\begin{array}{l}\text { Other } \\
\text { Demographics }\end{array}$} \\
\hline $\begin{array}{l}\text { Has driver's } \\
\text { license }\end{array}$ & $\begin{array}{c}- \\
0.21\end{array}$ & 0.18 & $\begin{array}{c}- \\
0.03\end{array}$ & $\begin{array}{c}- \\
0.23\end{array}$ & 0.18 & $\begin{array}{c}- \\
0.03\end{array}$ & $\begin{array}{c}- \\
0.22\end{array}$ & 0.19 & $\begin{array}{c}- \\
0.03\end{array}$ & $\begin{array}{c}- \\
0.18\end{array}$ & 0.18 & $\begin{array}{c}- \\
0.02\end{array}$ \\
\hline
\end{tabular}




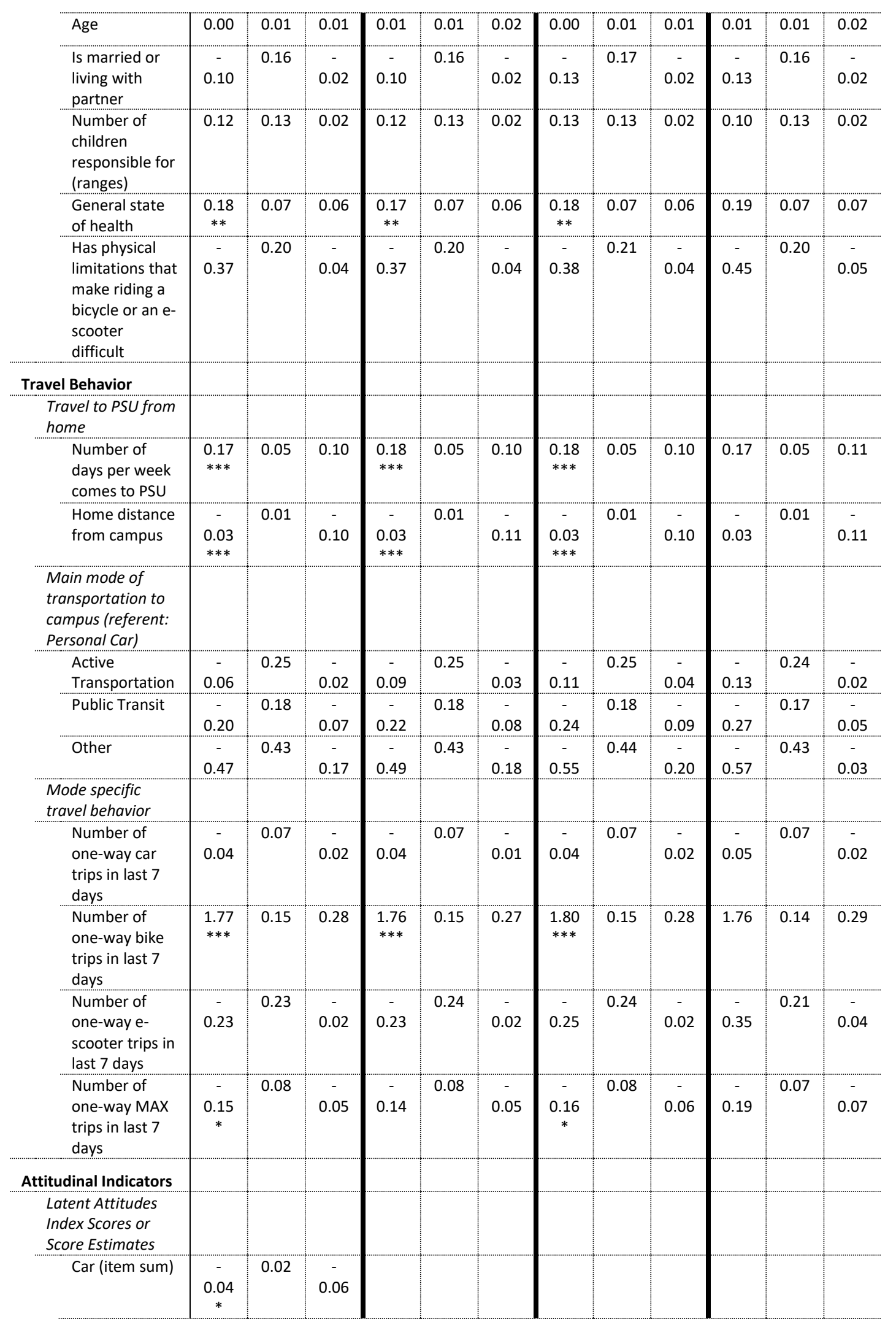




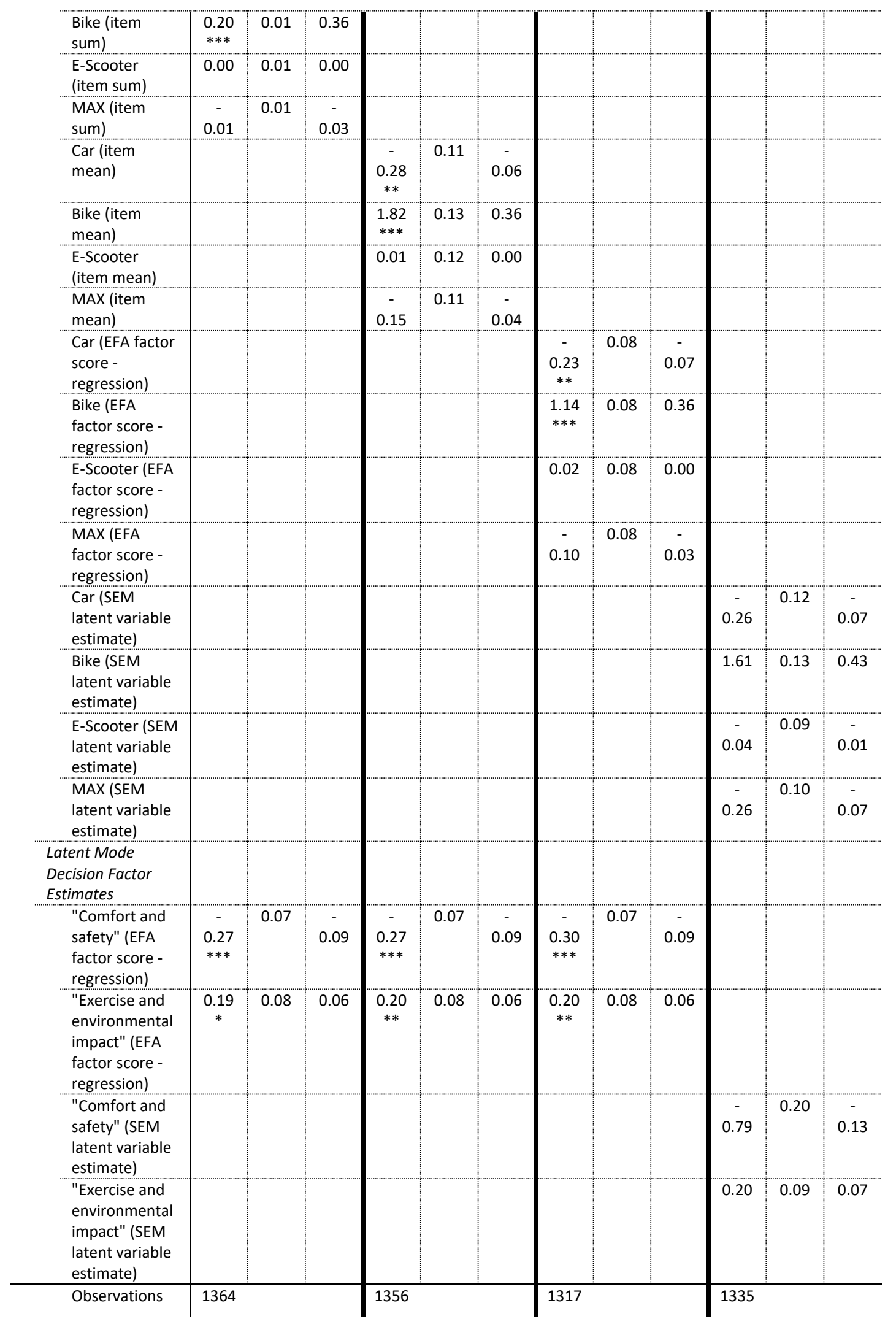




\begin{tabular}{l|l|l|l|l}
$\begin{array}{l}R^{2} / R^{2} \\
\text { adjusted }\end{array}$ & $0.401 / 0.384$ & $0.404 / 0.387$ & $0.400 / 0.383$ & \\
\hline \hline
\end{tabular}

${ }^{*} p<0.05 \quad * * p<0.01 \quad * * * p<0.001$ 


\begin{tabular}{|c|c|c|c|c|c|c|c|c|c|c|c|c|}
\hline \multirow[b]{2}{*}{ Predictors } & \multicolumn{3}{|c|}{$\begin{array}{l}\text { 1. Propensity to } \\
\text { switch to E-Scooter } \\
\text { OLS with summed } \\
\text { mode attitude items }\end{array}$} & \multicolumn{3}{|c|}{$\begin{array}{l}\text { 2. Propensity to } \\
\text { switch to E-Scooter } \\
\text { OLS with averaged } \\
\text { mode attitude items }\end{array}$} & \multicolumn{3}{|c|}{$\begin{array}{l}\text { 3. Propensity to } \\
\text { switch to E-Scooter } \\
\text { OLS with EFA factor } \\
\text { scores calculated } \\
\text { using regression } \\
\text { method }\end{array}$} & \multicolumn{3}{|c|}{$\begin{array}{l}\text { 4. Propensity to } \\
\text { switch to E-Scooter } \\
\text { SEM including latent } \\
\text { variable analysis }\end{array}$} \\
\hline & $\begin{array}{l}\text { Esti } \\
\text { mate } \\
s\end{array}$ & $\begin{array}{l}\text { std. } \\
\text { Error }\end{array}$ & $\begin{array}{l}\text { std. } \\
\text { Beta }\end{array}$ & $\begin{array}{c}\text { Esti } \\
\text { mate } \\
s\end{array}$ & $\begin{array}{l}\text { std. } \\
\text { Error }\end{array}$ & $\begin{array}{l}\text { std. } \\
\text { Beta }\end{array}$ & $\begin{array}{l}\text { Esti } \\
\text { mate } \\
s\end{array}$ & $\begin{array}{l}\text { std. } \\
\text { Error }\end{array}$ & $\begin{array}{l}\text { std. } \\
\text { Beta }\end{array}$ & $\begin{array}{c}\text { Esti } \\
\text { mate } \\
s\end{array}$ & $\begin{array}{l}\text { std. } \\
\text { Error }\end{array}$ & $\begin{array}{l}\text { std. } \\
\text { Beta }\end{array}$ \\
\hline (Intercept) & $\begin{array}{c}-1.54 \\
* *\end{array}$ & 0.56 & -0.01 & $\begin{array}{l}-1.54 \\
* *\end{array}$ & 0.56 & -0.01 & $\begin{array}{l}2.25 \\
* * *\end{array}$ & 0.37 & -0.01 & 2.99 & 0.03 & 2.91 \\
\hline \multicolumn{13}{|l|}{ Demographics } \\
\hline \multicolumn{13}{|l|}{$\begin{array}{l}\text { Income (referent: } \\
\text { Less than } \$ 25,000 \text { ) }\end{array}$} \\
\hline $\begin{array}{l}\$ 25,000- \\
\$ 49,999\end{array}$ & $\begin{array}{c}0.40 \\
* *\end{array}$ & 0.13 & 0.08 & $\begin{array}{c}0.40 \\
* *\end{array}$ & 0.13 & 0.08 & $\begin{array}{c}0.38 \\
* *\end{array}$ & 0.14 & 0.07 & 0.39 & 0.13 & 0.08 \\
\hline $\begin{array}{l}\$ 50,000- \\
\$ 74,999\end{array}$ & 0.29 & 0.18 & 0.04 & 0.30 & 0.18 & 0.04 & 0.27 & 0.18 & 0.04 & 0.30 & 0.18 & 0.05 \\
\hline $\begin{array}{l}\$ 75,000- \\
\$ 99,999\end{array}$ & 0.23 & 0.23 & 0.03 & 0.25 & 0.23 & 0.03 & 0.23 & 0.23 & 0.03 & 0.24 & 0.23 & 0.03 \\
\hline $\begin{array}{l}\$ 100,000- \\
\$ 124,999\end{array}$ & 0.05 & 0.29 & 0.00 & 0.13 & 0.29 & 0.01 & 0.08 & 0.29 & 0.01 & 0.08 & 0.29 & 0.01 \\
\hline $\begin{array}{l}\text { Greater than } \\
\$ 125,000\end{array}$ & 0.37 & 0.28 & 0.03 & 0.31 & 0.28 & 0.03 & 0.26 & 0.29 & 0.02 & 0.24 & 0.29 & 0.02 \\
\hline \multicolumn{13}{|l|}{$\begin{array}{l}\text { Race and Ethnicity } \\
\text { (referent: White } \\
\text { only) }\end{array}$} \\
\hline $\begin{array}{l}\text { American } \\
\text { Indian or } \\
\text { Alaska Native } \\
\text { only }\end{array}$ & 0.12 & 0.57 & 0.00 & 0.04 & 0.57 & 0.00 & 0.03 & 0.62 & 0.00 & 0.06 & 0.61 & 0.00 \\
\hline Asian only & 0.01 & 0.14 & 0.00 & 0.02 & 0.14 & 0.00 & 0.09 & 0.14 & 0.02 & 0.07 & 0.14 & 0.01 \\
\hline Black only & -0.02 & 0.31 & 0.00 & -0.05 & 0.31 & 0.00 & 0.00 & 0.32 & 0.00 & 0.01 & 0.32 & 0.00 \\
\hline $\begin{array}{l}\text { Hispanic or } \\
\text { Latinx/Latino/ } \\
\text { Latina only }\end{array}$ & -0.12 & 0.14 & -0.02 & -0.13 & 0.14 & -0.02 & -0.06 & 0.15 & -0.01 & -0.04 & 0.14 & -0.01 \\
\hline $\begin{array}{l}\text { More than } \\
\text { one race or } \\
\text { ethnicity }\end{array}$ & 0.15 & 0.13 & 0.03 & 0.14 & 0.13 & 0.02 & 0.16 & 0.14 & 0.03 & 0.17 & 0.13 & 0.03 \\
\hline $\begin{array}{l}\text { Native } \\
\text { Hawaiian or } \\
\text { Pacific } \\
\text { Islander only }\end{array}$ & -0.72 & 0.57 & -0.03 & -0.71 & 0.57 & -0.03 & -0.75 & 0.57 & -0.03 & -0.72 & 0.56 & -0.03 \\
\hline Other only & 0.03 & 0.40 & 0.00 & 0.01 & 0.40 & 0.00 & -0.01 & 0.42 & 0.00 & -0.01 & 0.41 & 0.00 \\
\hline \multicolumn{13}{|l|}{$\begin{array}{l}\text { Gender (referent: } \\
\text { Male) }\end{array}$} \\
\hline Female & -0.08 & 0.10 & -0.02 & -0.06 & 0.10 & -0.01 & -0.07 & 0.10 & -0.02 & -0.03 & 0.10 & -0.01 \\
\hline Non-Binary & -0.43 & 0.24 & -0.04 & -0.39 & 0.24 & -0.04 & -0.47 & 0.25 & -0.05 & -0.50 & 0.24 & -0.05 \\
\hline Other & $\begin{array}{c}1.34 \\
*\end{array}$ & 0.58 & 0.05 & $\begin{array}{c}1.37 \\
*\end{array}$ & 0.58 & 0.06 & $\begin{array}{c}1.37 \\
*\end{array}$ & 0.59 & 0.06 & 1.42 & 0.58 & 0.06 \\
\hline \multicolumn{13}{|l|}{$\begin{array}{l}\text { Other } \\
\text { Demographics }\end{array}$} \\
\hline $\begin{array}{l}\text { Has driver's } \\
\text { license }\end{array}$ & 0.1 & 0.13 & 0.02 & 0.09 & 0.13 & 0.02 & 0.08 & 0.14 & 0.01 & 0.07 & 0.13 & 0.01 \\
\hline Age & 0 & 0.01 & -0.01 & 0.00 & 0.01 & -0.01 & 0.00 & 0.01 & -0.01 & 0.00 & 0.01 & -0.01 \\
\hline
\end{tabular}




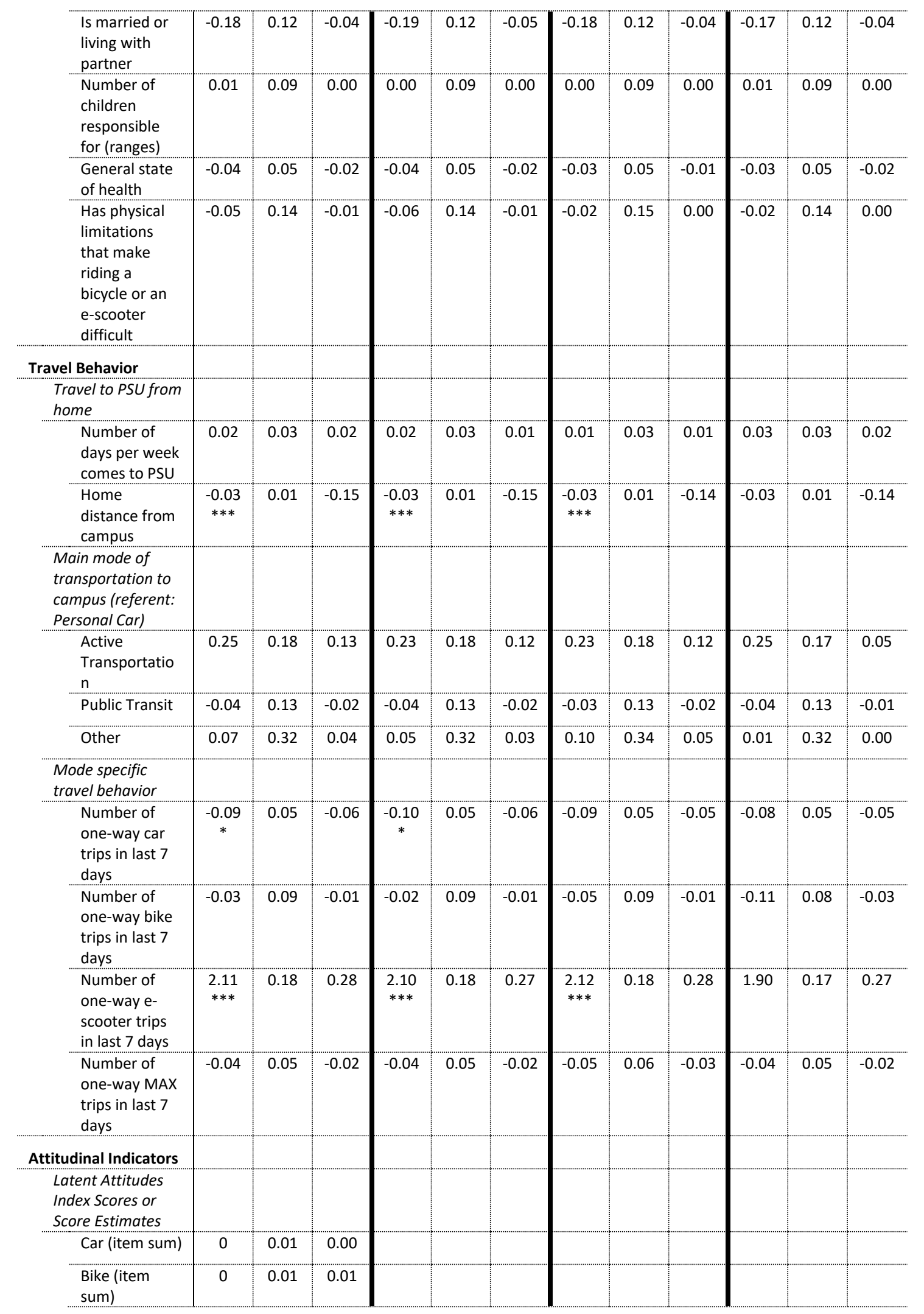




\begin{tabular}{|c|c|c|c|c|c|c|c|c|c|c|c|c|}
\hline $\begin{array}{l}\text { E-Scooter } \\
\text { (item sum) }\end{array}$ & $\begin{array}{l}0.12 \\
* * *\end{array}$ & 0.01 & 0.35 & & & & & & & & & \\
\hline $\begin{array}{l}\text { MAX (item } \\
\text { sum) }\end{array}$ & 0.01 & 0.01 & 0.03 & & & & & & & & & \\
\hline $\begin{array}{l}\text { Car (item } \\
\text { mean) }\end{array}$ & & & & -0.01 & 0.07 & 0.00 & & & & & & \\
\hline $\begin{array}{l}\text { Bike (item } \\
\text { mean) }\end{array}$ & & & & 0.04 & 0.09 & 0.01 & & & & & & \\
\hline $\begin{array}{l}\text { E-Scooter } \\
\text { (item mean) }\end{array}$ & & & & $\begin{array}{l}1.26 \\
* * *\end{array}$ & 0.09 & 0.35 & & & & & & \\
\hline $\begin{array}{l}\text { MAX (item } \\
\text { mean) }\end{array}$ & & & & 0.08 & 0.08 & 0.03 & & & & & & \\
\hline $\begin{array}{l}\text { Car (EFA } \\
\text { factor score - } \\
\text { regression) }\end{array}$ & & & & & & & -0.04 & 0.06 & -0.02 & & & \\
\hline $\begin{array}{l}\text { Bike (EFA } \\
\text { factor score - } \\
\text { regression) }\end{array}$ & & & & & & & 0.04 & 0.06 & 0.02 & & & \\
\hline $\begin{array}{l}\text { E-Scooter (EFA } \\
\text { factor score - } \\
\text { regression) }\end{array}$ & & & & & & & $\begin{array}{l}0.73 \\
* * *\end{array}$ & 0.05 & 0.34 & & & \\
\hline $\begin{array}{l}\text { MAX (EFA } \\
\text { factor score - } \\
\text { regression) }\end{array}$ & & & & & & & 0.07 & 0.06 & 0.03 & & & \\
\hline $\begin{array}{l}\text { Car (SEM } \\
\text { latent variable } \\
\text { estimate) }\end{array}$ & & & & & & & & & & -0.14 & 0.08 & -0.05 \\
\hline $\begin{array}{l}\text { Bike (SEM } \\
\text { latent variable } \\
\text { estimate) }\end{array}$ & & & & & & & & & & 0.03 & 0.08 & 0.01 \\
\hline $\begin{array}{l}\text { E-Scooter } \\
\text { (SEM latent } \\
\text { variable } \\
\text { estimate) }\end{array}$ & & & & & & & & & & 0.93 & 0.07 & 0.40 \\
\hline $\begin{array}{l}\text { MAX (SEM } \\
\text { latent variable } \\
\text { estimate) }\end{array}$ & & & & & & & & & & 0.06 & 0.07 & 0.02 \\
\hline $\begin{array}{l}\text { ent Mode } \\
\text { ision Factor } \\
\text { imates }\end{array}$ & & & & & & & & & & & & \\
\hline $\begin{array}{l}\text { "Comfort and } \\
\text { safety" (EFA } \\
\text { factor score - } \\
\text { regression) }\end{array}$ & -0.02 & 0.05 & -0.01 & -0.02 & 0.05 & -0.01 & -0.03 & 0.05 & -0.02 & & & \\
\hline $\begin{array}{l}\text { "Exercise and } \\
\text { environmental } \\
\text { impact" (EFA } \\
\text { factor score - } \\
\text { regression) }\end{array}$ & -0.03 & 0.05 & -0.01 & -0.02 & 0.05 & -0.01 & 0.00 & 0.06 & 0.00 & & & \\
\hline $\begin{array}{l}\text { "Comfort and } \\
\text { safety" (SEM } \\
\text { latent variable } \\
\text { estimate) }\end{array}$ & & & & & & & & & & -0.18 & 0.14 & -0.04 \\
\hline $\begin{array}{l}\text { "Exercise and } \\
\text { environmental } \\
\text { impact" (SEM } \\
\text { latent variable } \\
\text { estimate) }\end{array}$ & & & & & & & & & & 0.02 & 0.07 & 0.01 \\
\hline
\end{tabular}




\begin{tabular}{|c|c|c|c|c|}
\hline Observations & 1397 & 1388 & 1349 & 1370 \\
\hline $\begin{array}{l}\mathrm{R}^{2} / \mathrm{R}^{2} \\
\text { adjusted }\end{array}$ & $0.332 / 0.314$ & $0.328 / 0.310$ & $0.323 / 0.304$ & \\
\hline
\end{tabular}




\begin{tabular}{|c|c|c|c|c|c|c|c|c|c|c|c|c|}
\hline \multirow[b]{2}{*}{ Predictors } & \multicolumn{3}{|c|}{$\begin{array}{l}\text { 1. Propensity to switch } \\
\text { to MAX OLS with } \\
\text { summed mode } \\
\text { attitude items }\end{array}$} & \multicolumn{3}{|c|}{$\begin{array}{l}\text { 2. Propensity to switch } \\
\text { to MAX OLS with } \\
\text { averaged mode } \\
\text { attitude items }\end{array}$} & \multicolumn{3}{|c|}{$\begin{array}{l}\text { 3. Propensity to switch } \\
\text { to MAX OLS with EFA } \\
\text { factor scores } \\
\text { calculated using } \\
\text { regression method }\end{array}$} & \multicolumn{3}{|c|}{$\begin{array}{l}\text { 4. Propensity to } \\
\text { switch to MAX } \\
\text { SEM including latent } \\
\text { variable analysis }\end{array}$} \\
\hline & $\begin{array}{l}\text { Estim } \\
\text { ates }\end{array}$ & $\begin{array}{l}\text { std. } \\
\text { Error }\end{array}$ & $\begin{array}{l}\text { std. } \\
\text { Beta }\end{array}$ & $\begin{array}{l}\text { Estim } \\
\text { ates }\end{array}$ & $\begin{array}{l}\text { std. } \\
\text { Error }\end{array}$ & $\begin{array}{l}\text { std. } \\
\text { Beta }\end{array}$ & $\begin{array}{l}\text { Estim } \\
\text { ates }\end{array}$ & $\begin{array}{l}\text { std. } \\
\text { Error }\end{array}$ & $\begin{array}{l}\text { std. } \\
\text { Beta }\end{array}$ & $\begin{array}{l}\text { Estim } \\
\text { ates }\end{array}$ & $\begin{array}{l}\text { std. } \\
\text { Error }\end{array}$ & $\begin{array}{l}\text { std. } \\
\text { Beta }\end{array}$ \\
\hline (Intercept) & $\begin{array}{l}5.40 \\
* * *\end{array}$ & 1.29 & 0.32 & $\begin{array}{l}5.09 \\
* * *\end{array}$ & 1.3 & 0.33 & $\begin{array}{l}8.59 \\
* * *\end{array}$ & 0.88 & 0.31 & 7.95 & 0.84 & 2.35 \\
\hline \multicolumn{13}{|l|}{ Demographics } \\
\hline \multicolumn{13}{|l|}{$\begin{array}{l}\text { Income (referent: } \\
\text { Less than } \$ 25,000)\end{array}$} \\
\hline $\begin{array}{l}\$ 25,000- \\
\$ 49,999\end{array}$ & -0.34 & 0.3 & -0.04 & -0.35 & 0.3 & -0.04 & -0.34 & 0.31 & -0.04 & -0.38 & 0.31 & -0.04 \\
\hline $\begin{array}{l}\$ 50,000- \\
\$ 74,999\end{array}$ & -0.05 & 0.39 & 0 & -0.09 & 0.39 & -0.01 & -0.07 & 0.4 & -0.01 & -0.10 & 0.39 & -0.01 \\
\hline $\begin{array}{l}\$ 75,000- \\
\$ 99,999\end{array}$ & -0.45 & 0.49 & -0.03 & -0.41 & 0.49 & -0.03 & -0.42 & 0.5 & -0.03 & -0.62 & 0.49 & -0.04 \\
\hline $\begin{array}{l}\$ 100,000- \\
\$ 124,999\end{array}$ & -0.12 & 0.65 & -0.01 & -0.14 & 0.65 & -0.01 & -0.12 & 0.66 & -0.01 & -0.17 & 0.65 & -0.01 \\
\hline $\begin{array}{l}\text { Greater than } \\
\$ 125,000\end{array}$ & -0.04 & 0.65 & 0 & 0.03 & 0.65 & 0 & 0.14 & 0.67 & 0.01 & 0.13 & 0.66 & 0.01 \\
\hline \multicolumn{13}{|l|}{$\begin{array}{l}\text { Race and Ethnicity } \\
\text { (referent: White } \\
\text { only) }\end{array}$} \\
\hline $\begin{array}{l}\text { American } \\
\text { Indian or } \\
\text { Alaska Native } \\
\text { only }\end{array}$ & -0.2 & 1.31 & 0 & -0.17 & 1.31 & 0 & -0.55 & 1.45 & -0.01 & -0.59 & 1.42 & -0.01 \\
\hline Asian only & 0.22 & 0.35 & 0.02 & 0.23 & 0.35 & 0.02 & 0.19 & 0.36 & 0.02 & 0.07 & 0.34 & 0.01 \\
\hline Black only & 1.23 & 0.76 & 0.05 & 1.23 & 0.76 & 0.05 & 1.21 & 0.79 & 0.05 & 1.05 & 0.78 & 0.04 \\
\hline $\begin{array}{l}\text { Hispanic or } \\
\text { Latinx/Latino/L } \\
\text { atina only }\end{array}$ & 0.41 & 0.33 & 0.04 & 0.39 & 0.33 & 0.04 & 0.37 & 0.34 & 0.04 & 0.42 & 0.33 & 0.04 \\
\hline $\begin{array}{l}\text { More than one } \\
\text { race or } \\
\text { ethnicity }\end{array}$ & $\begin{array}{c}0.61 \\
*\end{array}$ & 0.3 & 0.06 & 0.55 & 0.3 & 0.06 & $\begin{array}{c}0.63 \\
*\end{array}$ & 0.3 & 0.06 & 0.66 & 0.30 & 0.07 \\
\hline $\begin{array}{l}\text { Native } \\
\text { Hawaiian or } \\
\text { Pacific Islander } \\
\text { only }\end{array}$ & 1.26 & 1.28 & 0.03 & 1.3 & 1.28 & 0.03 & 1.28 & 1.29 & 0.03 & 1.02 & 1.28 & 0.02 \\
\hline Other only & 1.03 & 0.95 & 0.03 & 1 & 0.95 & 0.03 & 1.21 & 1.01 & 0.04 & 1.12 & 0.99 & 0.03 \\
\hline \multicolumn{13}{|l|}{$\begin{array}{l}\text { Gender (referent: } \\
\text { Male) }\end{array}$} \\
\hline Female & 0.16 & 0.22 & 0.02 & 0.14 & 0.22 & 0.02 & 0.13 & 0.22 & 0.02 & 0.21 & 0.22 & 0.03 \\
\hline Non-Binary & -0.6 & 0.57 & -0.03 & -0.72 & 0.57 & -0.04 & -0.85 & 0.6 & -0.05 & -0.68 & 0.58 & -0.04 \\
\hline Other & -0.48 & 1.33 & -0.01 & -0.51 & 1.33 & -0.01 & -0.55 & 1.34 & -0.01 & -1.00 & 1.32 & -0.02 \\
\hline \multicolumn{13}{|l|}{$\begin{array}{l}\text { Other } \\
\text { Demographics }\end{array}$} \\
\hline $\begin{array}{l}\text { Has driver's } \\
\text { license }\end{array}$ & -0.39 & 0.32 & -0.04 & -0.36 & 0.32 & -0.04 & -0.35 & 0.32 & -0.04 & -0.35 & 0.31 & -0.04 \\
\hline Age & $\begin{array}{c}-0.04 \\
*\end{array}$ & 0.02 & -0.09 & $\begin{array}{c}-0.04 \\
*\end{array}$ & 0.02 & -0.08 & $\begin{array}{c}-0.04 \\
*\end{array}$ & 0.02 & -0.08 & -0.03 & 0.02 & -0.07 \\
\hline
\end{tabular}




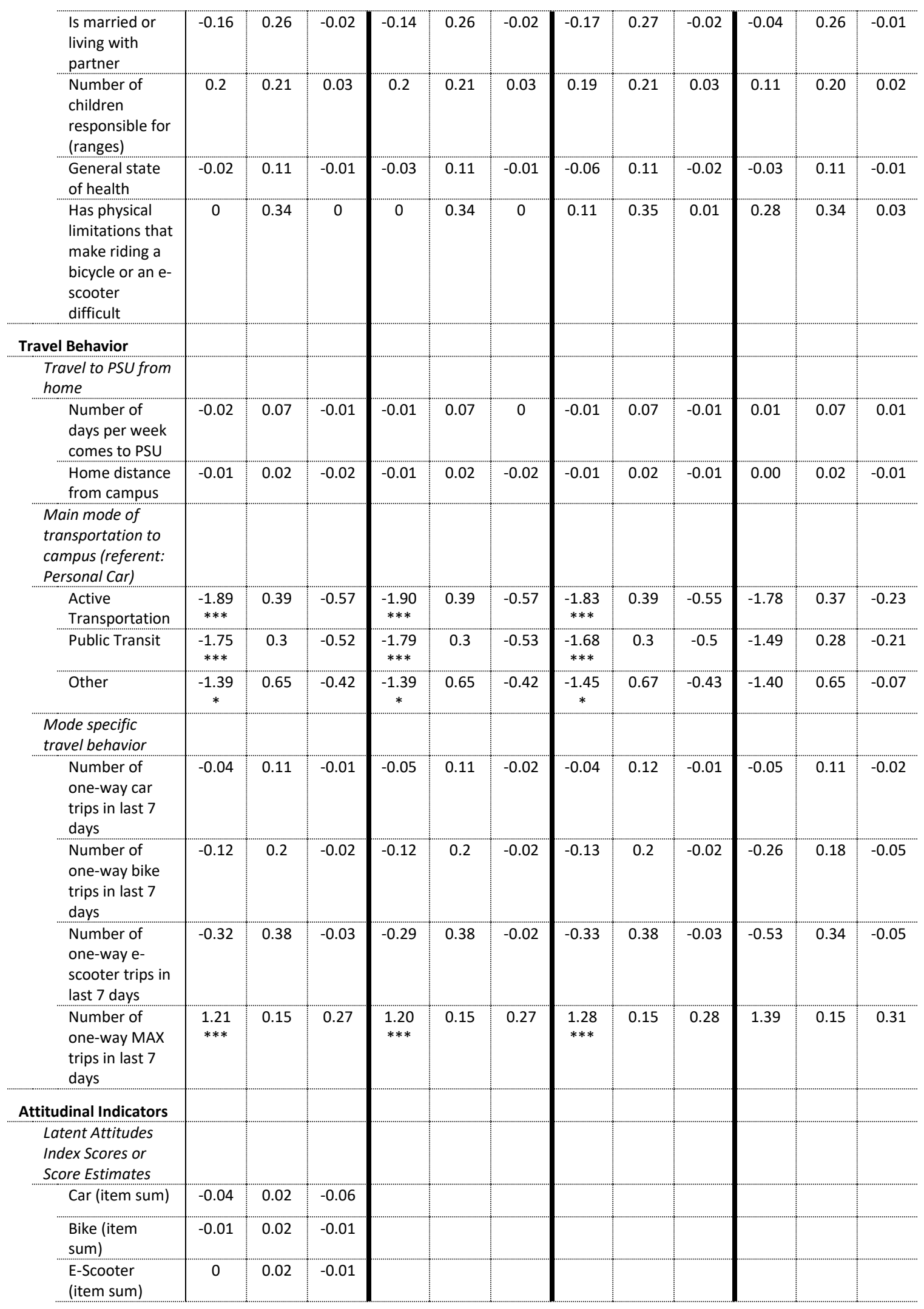




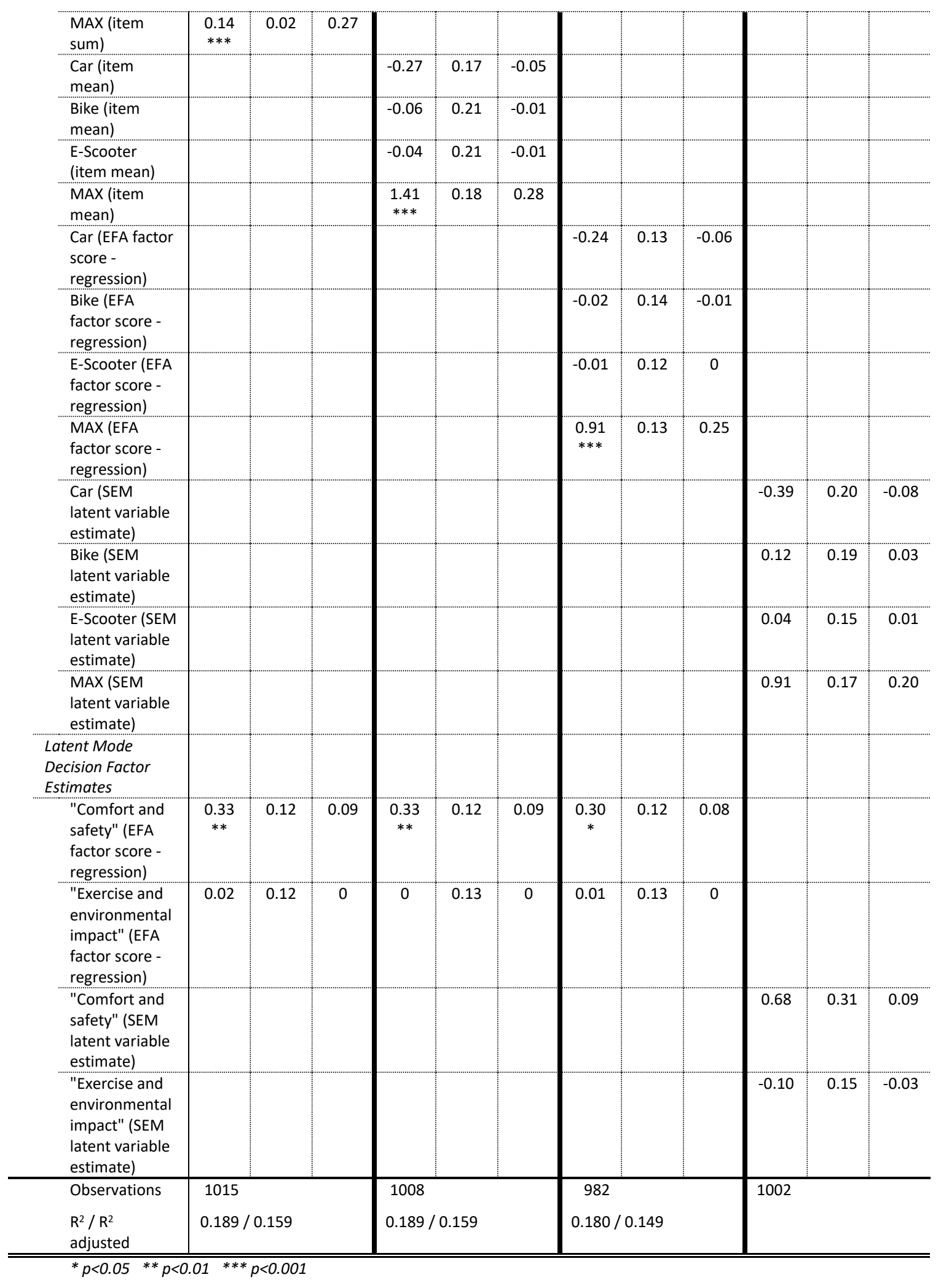




\section{Full OLS Models}

\begin{tabular}{|c|c|c|c|c|c|c|c|c|c|c|c|c|}
\hline \multirow[b]{2}{*}{ Predictors } & \multicolumn{3}{|c|}{$\begin{array}{l}\text { 1. Propensity to switch } \\
\text { to Car Demographics }\end{array}$} & \multicolumn{3}{|c|}{$\begin{array}{l}\text { 2. Propensity to switch } \\
\text { to Car Demographics + } \\
\text { Current travel } \\
\text { behavior }\end{array}$} & \multicolumn{3}{|c|}{$\begin{array}{l}\text { 3. Propensity to switch } \\
\text { to Car Demographics + } \\
\text { Current travel } \\
\text { behavior + Mode } \\
\text { Attitudes }\end{array}$} & \multicolumn{3}{|c|}{$\begin{array}{c}\text { 4. Propensity to } \\
\text { switch to Car } \\
\text { Demographics + } \\
\text { Current travel } \\
\text { behavior + Mode } \\
\text { Attitudes + Decision } \\
\text { factors }\end{array}$} \\
\hline & $\begin{array}{l}\text { Estim } \\
\text { ates }\end{array}$ & $\begin{array}{l}\text { std. } \\
\text { Error }\end{array}$ & $\begin{array}{l}\text { std. } \\
\text { Beta }\end{array}$ & $\begin{array}{l}\text { Estim } \\
\text { ates }\end{array}$ & $\begin{array}{l}\text { std. } \\
\text { Error }\end{array}$ & $\begin{array}{l}\text { std. } \\
\text { Beta }\end{array}$ & $\begin{array}{l}\text { Estim } \\
\text { ates }\end{array}$ & $\begin{array}{l}\text { std. } \\
\text { Error }\end{array}$ & $\begin{array}{l}\text { std. } \\
\text { Beta }\end{array}$ & $\begin{array}{l}\text { Estim } \\
\text { ates }\end{array}$ & $\begin{array}{l}\text { std. } \\
\text { Error }\end{array}$ & $\begin{array}{l}\text { std. } \\
\text { Beta }\end{array}$ \\
\hline (Intercept) & $\begin{array}{c}4.87 \\
* * *\end{array}$ & 0.23 & 0 & $\begin{array}{c}2.69 \\
*\end{array}$ & 1.21 & 0.1 & $\begin{array}{c}2.43 \\
*\end{array}$ & 1.2 & 0.01 & 2.13 & 1.22 & 0.01 \\
\hline \multicolumn{13}{|l|}{ Demographics } \\
\hline \multicolumn{13}{|l|}{$\begin{array}{l}\text { Income (referent: } \\
\text { less than } \$ 25,000)\end{array}$} \\
\hline $\begin{array}{c}\$ 25,000- \\
\$ 49,999\end{array}$ & $\begin{array}{c}0.80 \\
*\end{array}$ & 0.31 & 0.08 & 0.25 & 0.31 & 0.02 & 0.23 & 0.31 & 0.02 & 0.2 & 0.31 & 0.02 \\
\hline $\begin{array}{l}\$ 50,000- \\
\$ 74,999\end{array}$ & 0.64 & 0.42 & 0.05 & 0.21 & 0.41 & 0.01 & 0.32 & 0.41 & 0.02 & 0.36 & 0.42 & 0.03 \\
\hline $\begin{array}{l}\$ 75,000- \\
\$ 99,999\end{array}$ & $\underset{* *}{1.90}$ & 0.59 & 0.09 & 0.98 & 0.54 & 0.05 & 0.97 & 0.54 & 0.05 & 0.95 & 0.54 & 0.05 \\
\hline $\begin{array}{l}\$ 100,000- \\
\$ 124,999\end{array}$ & 1.32 & 0.74 & 0.05 & 0.22 & 0.65 & 0.01 & 0.37 & 0.67 & 0.01 & 0.06 & 0.69 & 0 \\
\hline $\begin{array}{l}\text { Greater than } \\
\$ 125,000\end{array}$ & 0.73 & 0.76 & 0.03 & -0.36 & 0.7 & -0.01 & -0.55 & 0.75 & -0.02 & -0.32 & 0.77 & -0.01 \\
\hline \multicolumn{13}{|l|}{$\begin{array}{l}\text { Race and Ethnicity } \\
\text { (referent: White } \\
\text { only) }\end{array}$} \\
\hline $\begin{array}{c}\text { American } \\
\text { Indian or } \\
\text { Alaska Native } \\
\text { only }\end{array}$ & 2.81 & 1.63 & 0.05 & 1.28 & 1.5 & 0.02 & -0.2 & 1.69 & 0 & -0.21 & 1.7 & 0 \\
\hline Asian only & $\underset{*}{0.64}$ & 0.32 & 0.06 & $\underset{* *}{0.82}$ & 0.29 & 0.08 & 0.70 & 0.29 & 0.07 & $\begin{array}{c}0.77 \\
*\end{array}$ & 0.3 & 0.07 \\
\hline Black only & -0.24 & 0.74 & -0.01 & 0.12 & 0.65 & 0 & 0.17 & 0.65 & 0.01 & 0.21 & 0.66 & 0.01 \\
\hline $\begin{array}{l}\text { Hispanic or } \\
\text { Latinx/Latino/L } \\
\text { atina only }\end{array}$ & 0.64 & 0.35 & 0.05 & 0.35 & 0.32 & 0.03 & 0.25 & 0.32 & 0.02 & 0.22 & 0.33 & 0.02 \\
\hline $\begin{array}{l}\text { More than one } \\
\text { race or } \\
\text { ethnicity }\end{array}$ & 0.52 & 0.33 & 0.05 & $\underset{*}{0.66}$ & 0.29 & 0.06 & 0.34 & 0.29 & 0.03 & 0.35 & 0.3 & 0.03 \\
\hline $\begin{array}{c}\text { Native } \\
\text { Hawaiian or } \\
\text { Pacific Islander } \\
\text { only }\end{array}$ & -2.22 & 1.83 & -0.04 & -2.1 & 1.52 & -0.04 & -2.35 & 1.48 & -0.04 & -2.35 & 1.49 & -0.04 \\
\hline Other only & -0.46 & 1.23 & -0.01 & -1.74 & 1.02 & -0.04 & $\underset{*}{-2.32}$ & 1 & -0.06 & $\begin{array}{c}-2.44 \\
*\end{array}$ & 1 & -0.06 \\
\hline \multicolumn{13}{|l|}{$\begin{array}{l}\text { Gender (referent: } \\
\text { Male) }\end{array}$} \\
\hline Female & 0.27 & 0.23 & 0.04 & -0.21 & 0.21 & -0.03 & 0 & 0.21 & 0 & -0.01 & 0.21 & 0 \\
\hline Non-Binary & -0.33 & 0.55 & -0.02 & -0.01 & 0.49 & 0 & 0.49 & 0.49 & 0.03 & 0.61 & 0.5 & 0.03 \\
\hline Other & 1.84 & 1.31 & 0.04 & 1.63 & 1.1 & 0.04 & 1.72 & 1.08 & 0.04 & 1.98 & 1.17 & 0.05 \\
\hline $\begin{array}{l}\text { Other } \\
\text { Demographics }\end{array}$ & & & & & & & & & & & & \\
\hline
\end{tabular}




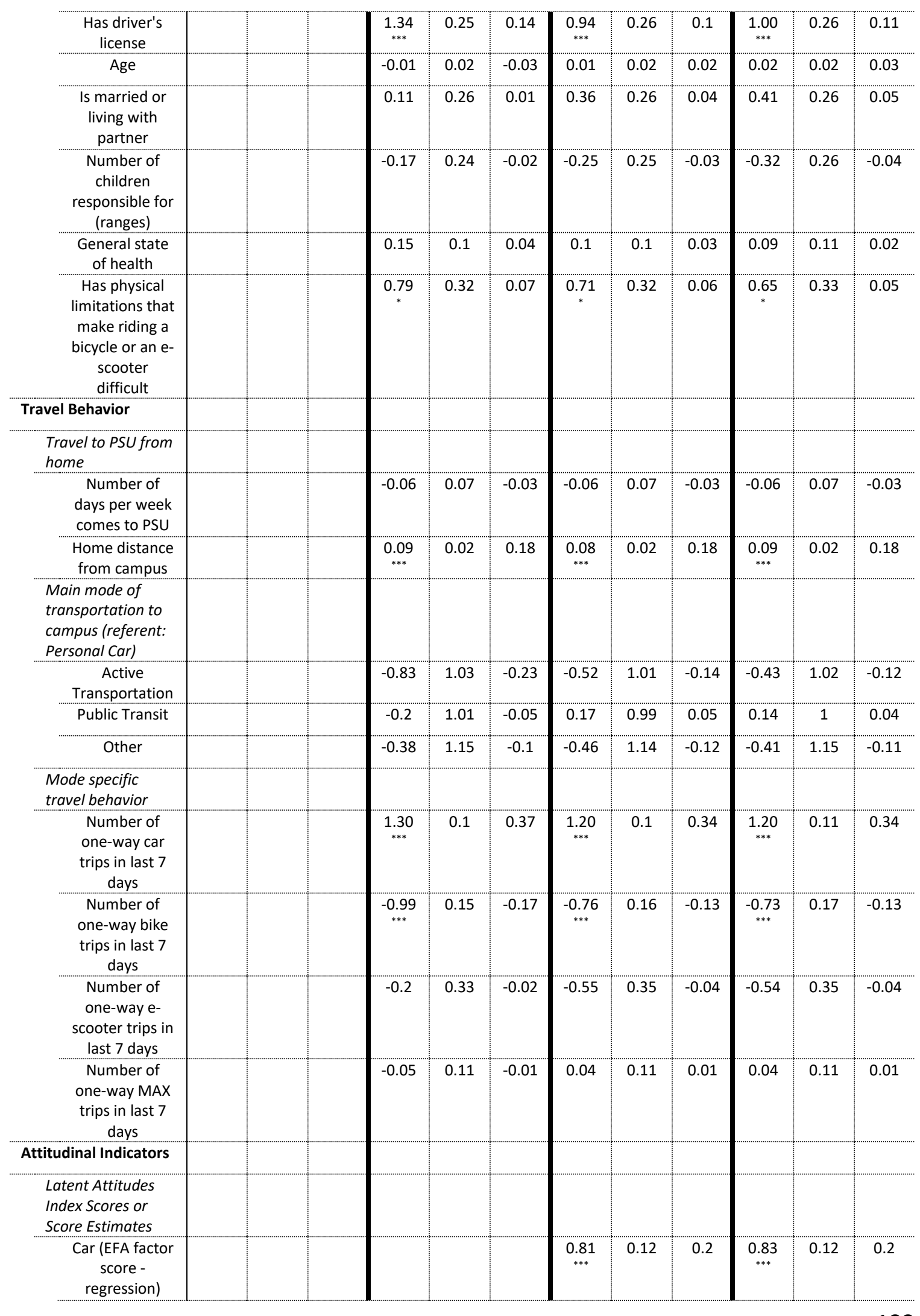




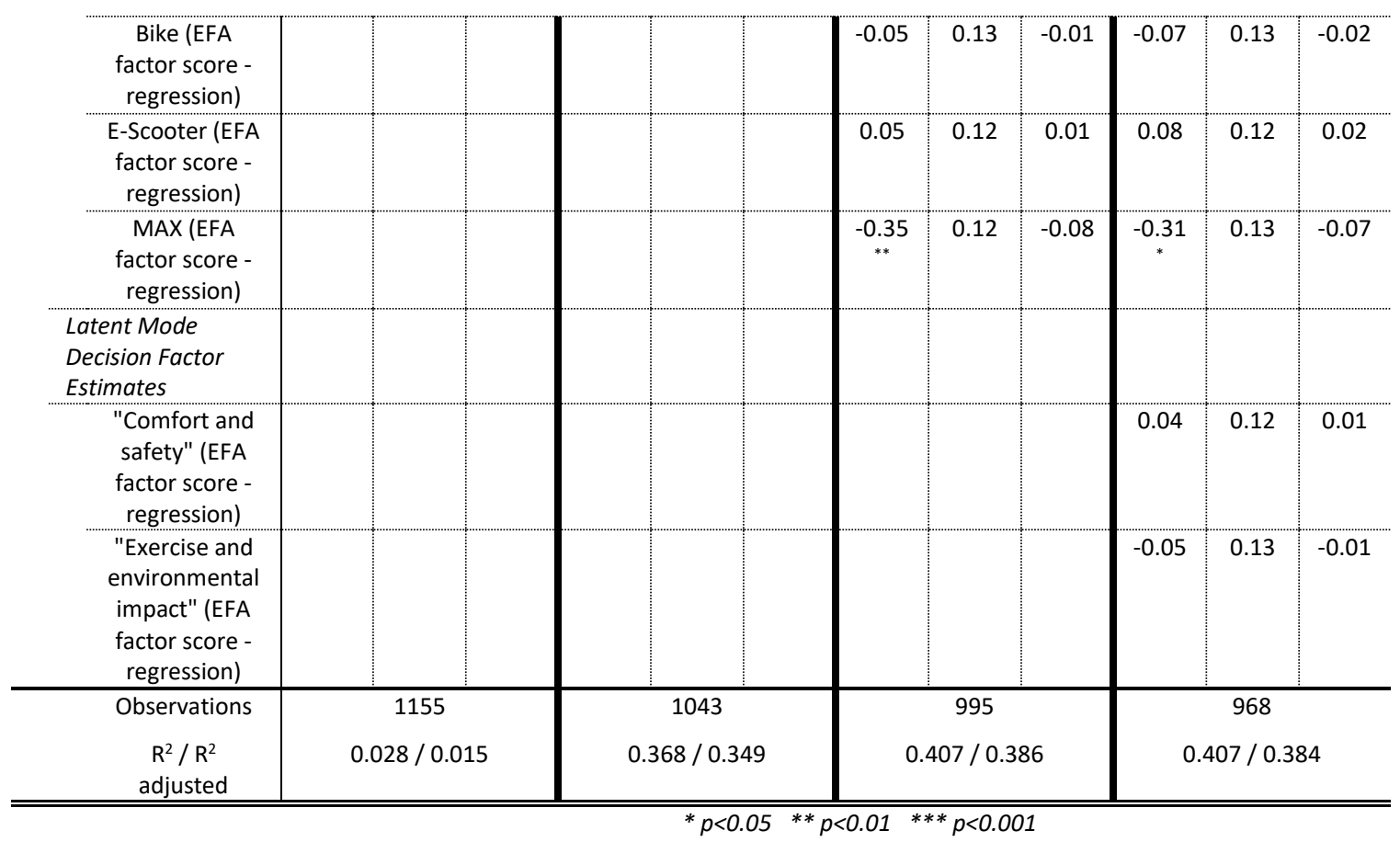




\begin{tabular}{|c|c|c|c|c|c|c|c|c|c|c|c|c|}
\hline \multirow[b]{2}{*}{ Predictors } & \multicolumn{3}{|c|}{$\begin{array}{l}\text { 1. Propensity to switch } \\
\text { to Bike Demographics }\end{array}$} & \multicolumn{3}{|c|}{$\begin{array}{l}\text { 2. Propensity to switch } \\
\text { to Bike Demographics } \\
+ \text { Current travel } \\
\text { behavior }\end{array}$} & \multicolumn{3}{|c|}{$\begin{array}{l}\text { 3. Propensity to switch } \\
\text { to Bike Demographics } \\
+ \text { Current travel } \\
\text { behavior + Mode } \\
\text { Attitudes }\end{array}$} & \multicolumn{3}{|c|}{$\begin{array}{l}\text { 4. Propensity to switch } \\
\text { to Bike Demographics } \\
+ \text { Current travel } \\
\text { behavior + Mode } \\
\text { Attitudes + Decision } \\
\text { factors }\end{array}$} \\
\hline & $\begin{array}{l}\text { Estim } \\
\text { ates }\end{array}$ & $\begin{array}{l}\text { std. } \\
\text { Error }\end{array}$ & $\begin{array}{l}\text { std. } \\
\text { Beta }\end{array}$ & $\begin{array}{l}\text { Estim } \\
\text { ates }\end{array}$ & $\begin{array}{l}\text { std. } \\
\text { Error }\end{array}$ & $\begin{array}{l}\text { std. } \\
\text { Beta }\end{array}$ & $\begin{array}{l}\text { Estim } \\
\text { ates }\end{array}$ & $\begin{array}{l}\text { std. } \\
\text { Error }\end{array}$ & $\begin{array}{l}\text { std. } \\
\text { Beta }\end{array}$ & $\begin{array}{l}\text { Estim } \\
\text { ates }\end{array}$ & $\begin{array}{l}\text { std. } \\
\text { Error }\end{array}$ & $\begin{array}{l}\text { std. } \\
\text { Beta }\end{array}$ \\
\hline (Intercept) & $\begin{array}{c}3.56 \\
* * *\end{array}$ & 0.15 & 0 & 1.91 & 0.53 & -0.05 & 2.29 & 0.51 & 0.04 & $\underset{* * *}{2.48}$ & 0.52 & 0.06 \\
\hline \multicolumn{13}{|l|}{ Demographics } \\
\hline \multicolumn{13}{|l|}{$\begin{array}{l}\text { Income (referent: } \\
\text { less than } \$ 25,000)\end{array}$} \\
\hline $\begin{array}{c}\$ 25,000- \\
\$ 49,999\end{array}$ & 0.08 & 0.19 & 0.01 & 0.27 & 0.2 & 0.03 & 0.2 & 0.19 & 0.03 & 0.24 & 0.19 & 0.03 \\
\hline $\begin{array}{l}\$ 50,000- \\
\$ 74,999\end{array}$ & 0.24 & 0.25 & 0.02 & 0.36 & 0.27 & 0.04 & 0.27 & 0.25 & 0.03 & 0.25 & 0.25 & 0.02 \\
\hline $\begin{array}{l}\$ 75,000- \\
\$ 99,999\end{array}$ & -0.22 & 0.34 & -0.02 & -0.1 & 0.35 & -0.01 & 0.04 & 0.32 & 0 & 0.04 & 0.32 & 0 \\
\hline $\begin{array}{l}\$ 100,000- \\
\$ 124,999\end{array}$ & -0.07 & 0.45 & 0 & 0.21 & 0.43 & 0.01 & 0.24 & 0.41 & 0.01 & 0.28 & 0.42 & 0.02 \\
\hline $\begin{array}{c}\text { Greater than } \\
\$ 125,000\end{array}$ & -0.52 & 0.42 & -0.03 & -0.81 & 0.43 & -0.05 & -0.47 & 0.41 & -0.03 & -0.44 & 0.42 & -0.03 \\
\hline \multicolumn{13}{|l|}{$\begin{array}{l}\text { Race and Ethnicity } \\
\text { (referent: White } \\
\text { only) }\end{array}$} \\
\hline $\begin{array}{c}\text { American } \\
\text { Indian or } \\
\text { Alaska Native } \\
\text { only }\end{array}$ & -0.31 & 0.91 & -0.01 & 0.26 & 0.93 & 0.01 & 0.18 & 0.93 & 0 & 0.1 & 0.92 & 0 \\
\hline Asian only & -0.24 & 0.21 & -0.03 & -0.2 & 0.2 & -0.02 & 0.02 & 0.19 & 0 & 0.06 & 0.2 & 0.01 \\
\hline Black only & -0.43 & 0.49 & -0.02 & -0.16 & 0.47 & -0.01 & -0.1 & 0.45 & -0.01 & -0.09 & 0.45 & 0 \\
\hline $\begin{array}{l}\text { Hispanic or } \\
\text { Latinx/Latino } \\
\text { /Latina only }\end{array}$ & -0.51 & 0.22 & -0.06 & -0.18 & 0.21 & -0.02 & -0.18 & 0.2 & -0.02 & -0.2 & 0.2 & -0.02 \\
\hline $\begin{array}{l}\text { More than } \\
\text { one race or } \\
\text { ethnicity }\end{array}$ & 0 & 0.21 & 0 & 0.15 & 0.2 & 0.02 & 0.33 & 0.19 & 0.04 & 0.32 & 0.19 & 0.04 \\
\hline $\begin{array}{l}\text { Native } \\
\text { Hawaiian or } \\
\text { Pacific } \\
\text { Islander only }\end{array}$ & -0.95 & 0.91 & -0.03 & -0.6 & 0.86 & -0.02 & -1.1 & 0.79 & -0.03 & -1.24 & 0.79 & -0.03 \\
\hline Other only & -1.16 & 0.67 & -0.04 & -0.55 & 0.61 & -0.02 & -0.41 & 0.58 & -0.02 & -0.22 & 0.58 & -0.01 \\
\hline \multicolumn{13}{|l|}{$\begin{array}{l}\text { Gender (referent: } \\
\text { Male) }\end{array}$} \\
\hline Female & -0.96 & 0.15 & -0.17 & -0.68 & 0.14 & -0.12 & -0.57 & 0.14 & -0.1 & -0.52 & 0.14 & -0.09 \\
\hline Non-Binary & -0.27 & 0.37 & -0.02 & 0.19 & 0.37 & 0.01 & -0.45 & 0.35 & -0.03 & -0.32 & 0.35 & -0.02 \\
\hline Other & -0.5 & 0.92 & -0.01 & -0.2 & 0.83 & -0.01 & -0.02 & 0.77 & 0 & -0.16 & 0.81 & 0 \\
\hline \multicolumn{13}{|l|}{$\begin{array}{l}\text { Other } \\
\text { Demographics }\end{array}$} \\
\hline $\begin{array}{l}\text { Has driver's } \\
\text { license }\end{array}$ & & & & -0.19 & 0.19 & -0.02 & -0.18 & 0.19 & -0.02 & -0.22 & 0.19 & -0.03 \\
\hline Age & & & & 0.02 & 0.01 & 0.05 & 0.01 & 0.01 & 0.02 & 0 & 0.01 & 0.01 \\
\hline
\end{tabular}




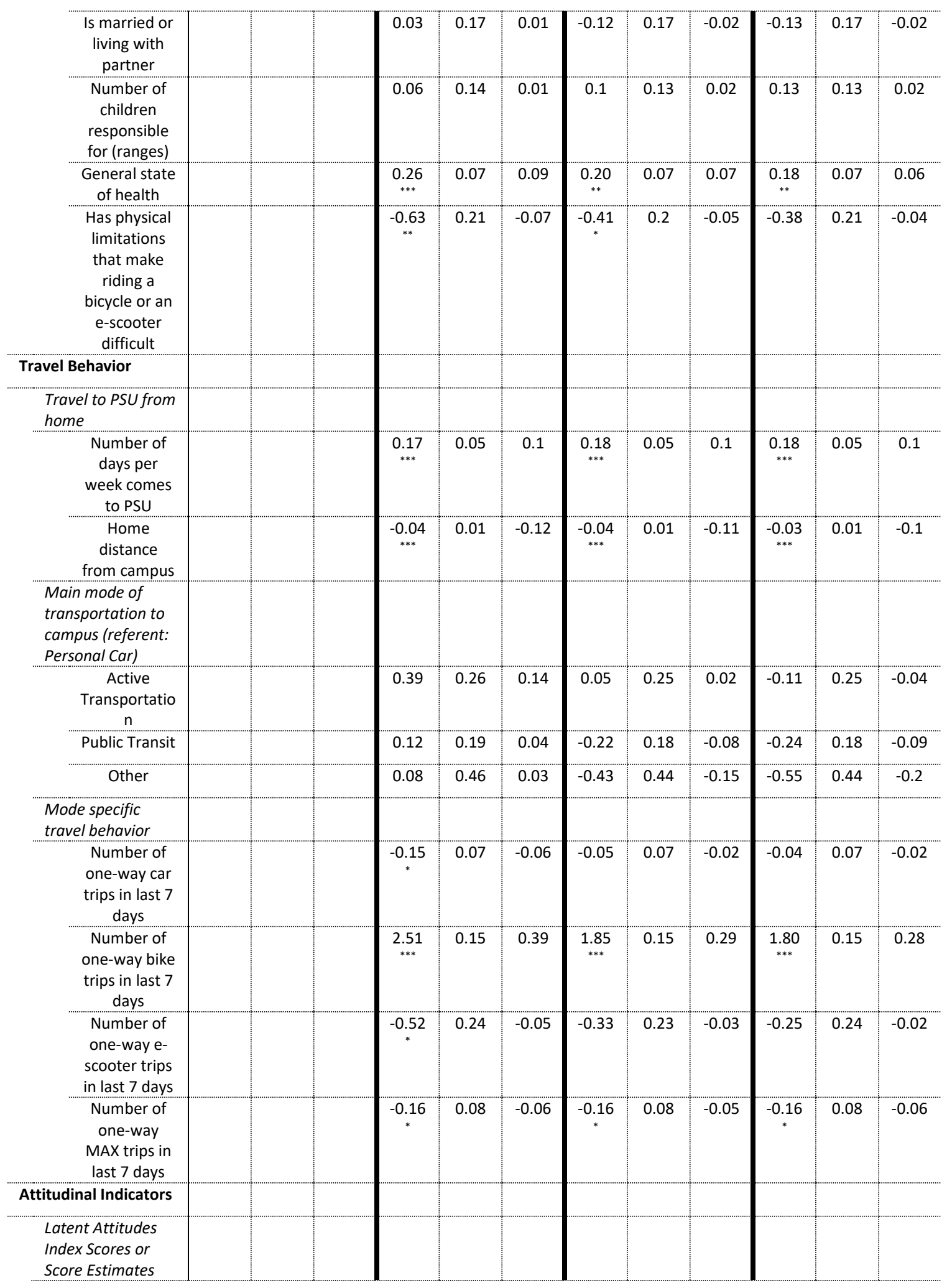




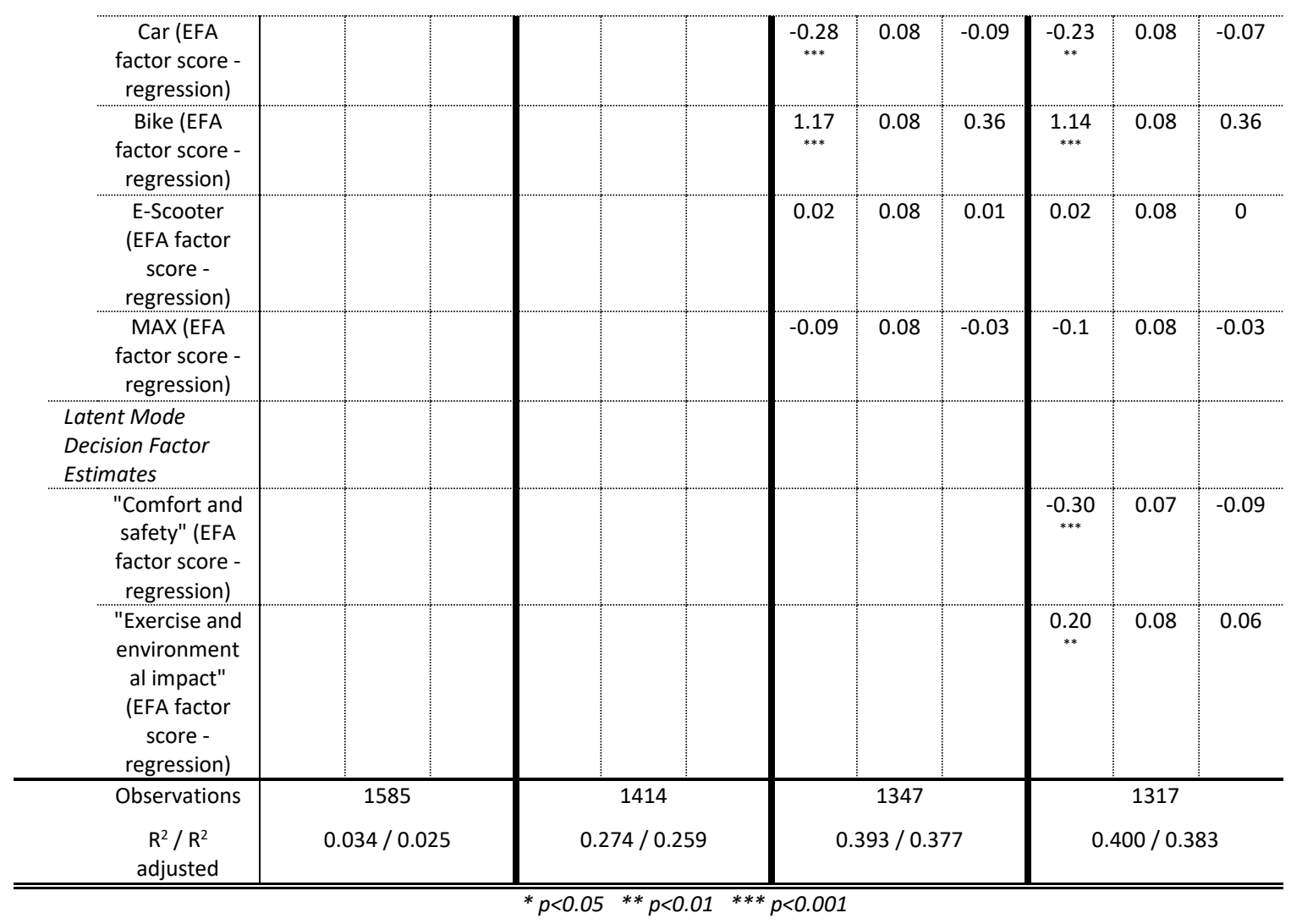




\begin{tabular}{|c|c|c|c|c|c|c|c|c|c|c|c|c|}
\hline \multirow[b]{2}{*}{ Predictors } & \multicolumn{3}{|c|}{$\begin{array}{l}\text { 1. Propensity to switch } \\
\text { to E-Scooter } \\
\text { Demographics }\end{array}$} & \multicolumn{3}{|c|}{$\begin{array}{l}\text { 2. Propensity to switch } \\
\text { to E-Scooter } \\
\text { Demographics + } \\
\text { Current travel } \\
\text { behavior }\end{array}$} & \multicolumn{3}{|c|}{$\begin{array}{l}\text { 3. Propensity to switch } \\
\text { to E-Scooter } \\
\text { Demographics + } \\
\text { Current travel } \\
\text { behavior + Mode } \\
\text { Attitudes }\end{array}$} & \multicolumn{3}{|c|}{$\begin{array}{l}\text { 4. Propensity to switch } \\
\text { to E-Scooter } \\
\text { Demographics + } \\
\text { Current travel } \\
\text { behavior + Mode } \\
\text { Attitudes + Decision } \\
\text { factors }\end{array}$} \\
\hline & $\begin{array}{l}\text { Estim } \\
\text { ates }\end{array}$ & $\begin{array}{l}\text { std. } \\
\text { Error }\end{array}$ & $\begin{array}{l}\text { std. } \\
\text { Beta }\end{array}$ & $\begin{array}{l}\text { Estim } \\
\text { ates }\end{array}$ & $\begin{array}{l}\text { std. } \\
\text { Error }\end{array}$ & $\begin{array}{l}\text { std. } \\
\text { Beta }\end{array}$ & $\begin{array}{c}\text { Estim } \\
\text { ates }\end{array}$ & $\begin{array}{l}\text { std. } \\
\text { Error }\end{array}$ & $\begin{array}{l}\text { std. } \\
\text { Beta }\end{array}$ & $\begin{array}{c}\text { Estim } \\
\text { ates }\end{array}$ & $\begin{array}{l}\text { std. } \\
\text { Error }\end{array}$ & $\begin{array}{l}\text { std. } \\
\text { Beta }\end{array}$ \\
\hline (Intercept) & 1.96 & 0.1 & 0 & 2.24 & 0.38 & -0.06 & 2.17 & 0.37 & -0.03 & 2.25 & 0.37 & -0.01 \\
\hline \multicolumn{13}{|l|}{ Demographics } \\
\hline \multicolumn{13}{|l|}{$\begin{array}{l}\text { Income (referent: } \\
\text { less than } \$ 25,000 \text { ) }\end{array}$} \\
\hline $\begin{array}{c}\$ 25,000- \\
\$ 49,999\end{array}$ & 0.19 & 0.13 & 0.04 & 0.43 & 0.14 & 0.08 & 0.39 & 0.14 & 0.07 & 0.38 & 0.14 & 0.07 \\
\hline $\begin{array}{l}\$ 50,000- \\
\$ 74,999\end{array}$ & 0.1 & 0.17 & 0.01 & 0.36 & 0.19 & 0.05 & 0.32 & 0.18 & 0.05 & 0.27 & 0.18 & 0.04 \\
\hline $\begin{array}{l}\$ 75,000- \\
\$ 99,999\end{array}$ & -0.21 & 0.23 & -0.02 & 0.34 & 0.24 & 0.04 & 0.24 & 0.23 & 0.03 & 0.23 & 0.23 & 0.03 \\
\hline $\begin{array}{l}\$ 100,000- \\
\$ 124,999\end{array}$ & -0.46 & 0.3 & -0.04 & 0.09 & 0.3 & 0.01 & 0.08 & 0.29 & 0.01 & 0.08 & 0.29 & 0.01 \\
\hline $\begin{array}{c}\text { Greater than } \\
\$ 125,000\end{array}$ & -0.47 & 0.28 & -0.04 & 0.22 & 0.3 & 0.02 & 0.25 & 0.29 & 0.02 & 0.26 & 0.29 & 0.02 \\
\hline \multicolumn{13}{|l|}{$\begin{array}{l}\text { Race and Ethnicity } \\
\text { (referent: White } \\
\text { only) }\end{array}$} \\
\hline $\begin{array}{c}\text { American } \\
\text { Indian or } \\
\text { Alaska Native } \\
\text { only }\end{array}$ & -0.48 & 0.6 & -0.02 & 0.29 & 0.62 & 0.01 & -0.01 & 0.62 & 0 & 0.03 & 0.62 & 0 \\
\hline Asian only & 0.24 & 0.15 & 0.04 & 0.01 & 0.15 & 0 & 0.07 & 0.14 & 0.01 & 0.09 & 0.14 & 0.02 \\
\hline Black only & 0.21 & 0.34 & 0.02 & 0.19 & 0.33 & 0.01 & -0.01 & 0.32 & 0 & 0 & 0.32 & 0 \\
\hline $\begin{array}{l}\text { Hispanic or } \\
\text { Latinx/Latino } \\
\text { /Latina only }\end{array}$ & 0.01 & 0.15 & 0 & 0.04 & 0.15 & 0.01 & -0.05 & 0.15 & -0.01 & -0.06 & 0.15 & -0.01 \\
\hline $\begin{array}{l}\text { More than } \\
\text { one race or } \\
\text { ethnicity }\end{array}$ & 0.2 & 0.15 & 0.03 & 0.17 & 0.14 & 0.03 & 0.18 & 0.14 & 0.03 & 0.16 & 0.14 & 0.03 \\
\hline $\begin{array}{l}\text { Native } \\
\text { Hawaiian or } \\
\text { Pacific } \\
\text { Islander only }\end{array}$ & 0.36 & 0.64 & 0.01 & -0.46 & 0.62 & -0.02 & -0.72 & 0.58 & -0.03 & -0.75 & 0.57 & -0.03 \\
\hline Other only & -0.39 & 0.47 & -0.02 & 0.03 & 0.44 & 0 & -0.03 & 0.42 & 0 & -0.01 & 0.42 & 0 \\
\hline \multicolumn{13}{|l|}{$\begin{array}{l}\text { Gender (referent: } \\
\text { Male) }\end{array}$} \\
\hline Female & -0.17 & 0.1 & -0.04 & -0.08 & 0.1 & -0.02 & -0.03 & 0.1 & -0.01 & -0.07 & 0.1 & -0.02 \\
\hline Non-Binary & -0.69 & 0.25 & -0.07 & $\underset{*}{-0.56}$ & 0.26 & -0.06 & -0.41 & 0.25 & -0.04 & -0.47 & 0.25 & -0.05 \\
\hline Other & 0.69 & 0.64 & 0.03 & 0.87 & 0.59 & 0.04 & 1.13 & 0.56 & 0.05 & 1.37 & 0.59 & 0.06 \\
\hline \multicolumn{13}{|l|}{$\begin{array}{l}\text { Other } \\
\text { Demographics }\end{array}$} \\
\hline $\begin{array}{l}\text { Has driver's } \\
\text { license }\end{array}$ & & & & 0.14 & 0.14 & 0.03 & 0.09 & 0.14 & 0.02 & 0.08 & 0.14 & 0.01 \\
\hline Age & & & & -0.01 & 0.01 & -0.04 & 0 & 0.01 & 0 & 0 & 0.01 & -0.01 \\
\hline
\end{tabular}




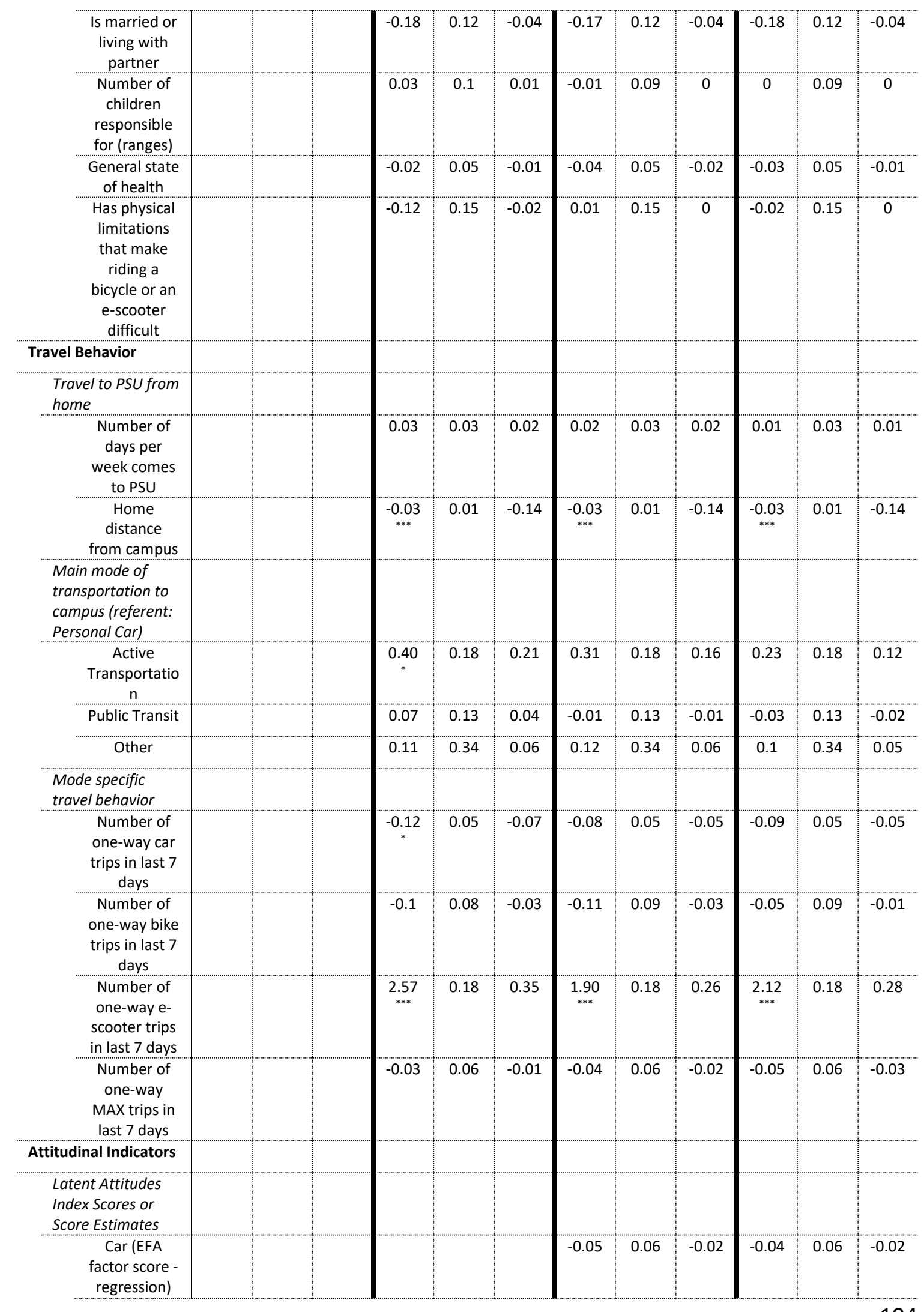




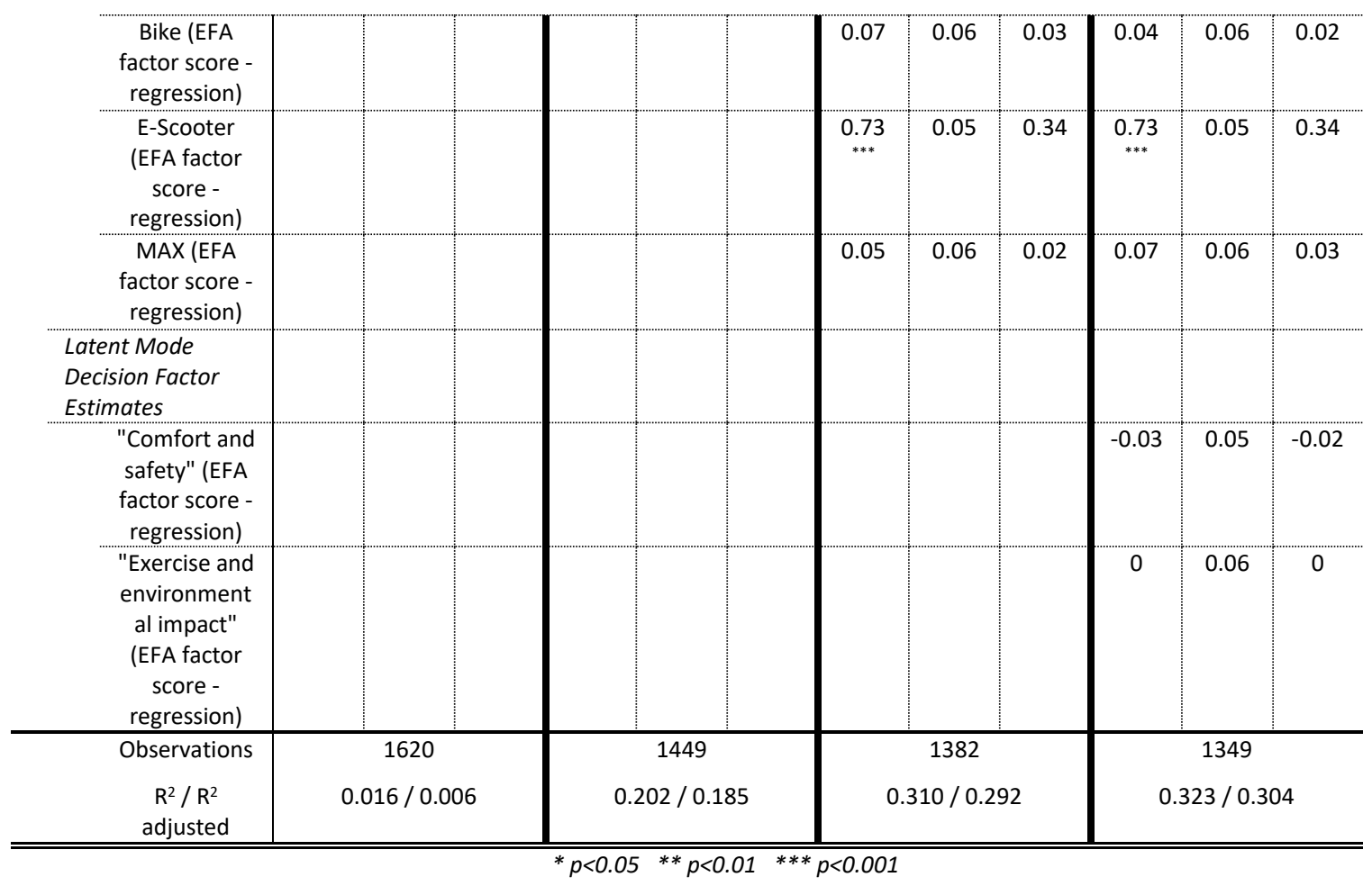




\begin{tabular}{|c|c|c|c|c|c|c|c|c|c|c|c|c|}
\hline \multirow[b]{2}{*}{ Predictors } & \multicolumn{3}{|c|}{$\begin{array}{l}\text { 1. Propensity to switch } \\
\text { to MAX Demographics }\end{array}$} & \multicolumn{3}{|c|}{$\begin{array}{l}\text { 2. Propensity to switch } \\
\text { to MAX Demographics } \\
\text { + Current travel } \\
\text { behavior }\end{array}$} & \multicolumn{3}{|c|}{$\begin{array}{l}\text { 3. Propensity to switch } \\
\text { to MAX Demographics } \\
+ \text { Current travel } \\
\text { behavior + Mode } \\
\text { Attitudes }\end{array}$} & \multicolumn{3}{|c|}{$\begin{array}{l}\text { 4. Propensity to } \\
\text { switch to MAX } \\
\text { Demographics + } \\
\text { Current travel } \\
\text { behavior + Mode } \\
\text { Attitudes + Decision } \\
\text { factors }\end{array}$} \\
\hline & $\begin{array}{l}\text { Estim } \\
\text { ates }\end{array}$ & $\begin{array}{l}\text { std. } \\
\text { Error }\end{array}$ & $\begin{array}{l}\text { std. } \\
\text { Beta }\end{array}$ & $\begin{array}{c}\text { Estim } \\
\text { ates }\end{array}$ & $\begin{array}{l}\text { std. } \\
\text { Error }\end{array}$ & $\begin{array}{l}\text { std. } \\
\text { Beta }\end{array}$ & $\begin{array}{c}\text { Estim } \\
\text { ates }\end{array}$ & $\begin{array}{l}\text { std. } \\
\text { Error }\end{array}$ & $\begin{array}{l}\text { std. } \\
\text { Beta }\end{array}$ & $\begin{array}{l}\text { Estim } \\
\text { ates }\end{array}$ & $\begin{array}{l}\text { std. } \\
\text { Error }\end{array}$ & $\begin{array}{l}\text { std. } \\
\text { Beta }\end{array}$ \\
\hline (Intercept) & $\begin{array}{c}6.45 \\
* * *\end{array}$ & 0.21 & 0 & 7.18 & 0.85 & 0.23 & 8.06 & 0.86 & 0.32 & $\begin{array}{c}8.59 \\
* * *\end{array}$ & 0.88 & 0.31 \\
\hline \multicolumn{13}{|l|}{ Demographics } \\
\hline \multicolumn{13}{|l|}{$\begin{array}{l}\text { Income (referent: } \\
\text { less than } \$ 25,000)\end{array}$} \\
\hline $\begin{array}{c}\$ 25,000- \\
\$ 49,999\end{array}$ & -0.53 & 0.28 & -0.06 & -0.31 & 0.31 & -0.03 & -0.35 & 0.31 & -0.04 & -0.34 & 0.31 & -0.04 \\
\hline $\begin{array}{l}\$ 50,000- \\
\$ 74,999\end{array}$ & -0.42 & 0.35 & -0.04 & -0.13 & 0.4 & -0.01 & -0.08 & 0.39 & -0.01 & -0.07 & 0.4 & -0.01 \\
\hline $\begin{array}{l}\$ 75,000- \\
\$ 99,999\end{array}$ & -0.74 & 0.46 & -0.05 & -0.51 & 0.51 & -0.03 & -0.5 & 0.5 & -0.03 & -0.42 & 0.5 & -0.03 \\
\hline $\begin{array}{l}\$ 100,000- \\
\$ 124,999\end{array}$ & -0.03 & 0.63 & 0 & -0.1 & 0.67 & 0 & -0.17 & 0.66 & -0.01 & -0.12 & 0.66 & -0.01 \\
\hline $\begin{array}{c}\text { Greater than } \\
\$ 125,000\end{array}$ & -0.49 & 0.58 & -0.03 & -0.31 & 0.66 & -0.02 & 0.11 & 0.67 & 0.01 & 0.14 & 0.67 & 0.01 \\
\hline \multicolumn{13}{|l|}{$\begin{array}{l}\text { Race and Ethnicity } \\
\text { (referent: White } \\
\text { only) }\end{array}$} \\
\hline $\begin{array}{c}\text { American } \\
\text { Indian or } \\
\text { Alaska Native } \\
\text { only }\end{array}$ & -1.71 & 1.27 & -0.04 & -1.07 & 1.35 & -0.02 & -0.46 & 1.45 & -0.01 & -0.55 & 1.45 & -0.01 \\
\hline Asian only & 0.52 & 0.33 & 0.05 & 0.2 & 0.35 & 0.02 & 0.28 & 0.35 & 0.03 & 0.19 & 0.36 & 0.02 \\
\hline Black only & 1.49 & 0.74 & 0.06 & 1.03 & 0.77 & 0.04 & 1.15 & 0.8 & 0.04 & 1.21 & 0.79 & 0.05 \\
\hline $\begin{array}{l}\text { Hispanic or } \\
\text { Latinx/Latino/L } \\
\text { atina only }\end{array}$ & 0.73 & 0.32 & 0.07 & 0.44 & 0.33 & 0.04 & 0.42 & 0.33 & 0.04 & 0.37 & 0.34 & 0.04 \\
\hline $\begin{array}{l}\text { More than one } \\
\text { race or } \\
\text { ethnicity }\end{array}$ & 0.51 & 0.3 & 0.05 & 0.49 & 0.3 & 0.05 & 0.61 & 0.31 & 0.06 & 0.63 & 0.3 & 0.06 \\
\hline $\begin{array}{c}\text { Native } \\
\text { Hawaiian or } \\
\text { Pacific Islander } \\
\text { only }\end{array}$ & -0.24 & 1.27 & -0.01 & 0.91 & 1.32 & 0.02 & 1.09 & 1.3 & 0.03 & 1.28 & 1.29 & 0.03 \\
\hline Other only & 0.37 & 0.98 & 0.01 & 1.05 & 0.98 & 0.03 & 1.37 & 1.01 & 0.04 & 1.21 & 1.01 & 0.04 \\
\hline \multicolumn{13}{|l|}{$\begin{array}{l}\text { Gender (referent: } \\
\text { Male) }\end{array}$} \\
\hline Female & 0.21 & 0.22 & 0.03 & 0.14 & 0.22 & 0.02 & 0.17 & 0.22 & 0.02 & 0.13 & 0.22 & 0.02 \\
\hline Non-Binary & 0.28 & 0.53 & 0.02 & 0 & 0.57 & 0 & -0.62 & 0.59 & -0.03 & -0.85 & 0.6 & -0.05 \\
\hline Other & -1.56 & 1.28 & -0.04 & -2.17 & 1.26 & -0.05 & -1.18 & 1.24 & -0.03 & -0.55 & 1.34 & -0.01 \\
\hline \multicolumn{13}{|l|}{$\begin{array}{l}\text { Other } \\
\text { Demographics }\end{array}$} \\
\hline $\begin{array}{l}\text { Has driver's } \\
\text { license }\end{array}$ & & & & -0.48 & 0.32 & -0.05 & -0.3 & 0.32 & -0.03 & -0.35 & 0.32 & -0.04 \\
\hline Age & & & & -0.02 & 0.02 & -0.05 & -0.03 & 0.02 & -0.07 & -0.04 & 0.02 & -0.08 \\
\hline
\end{tabular}




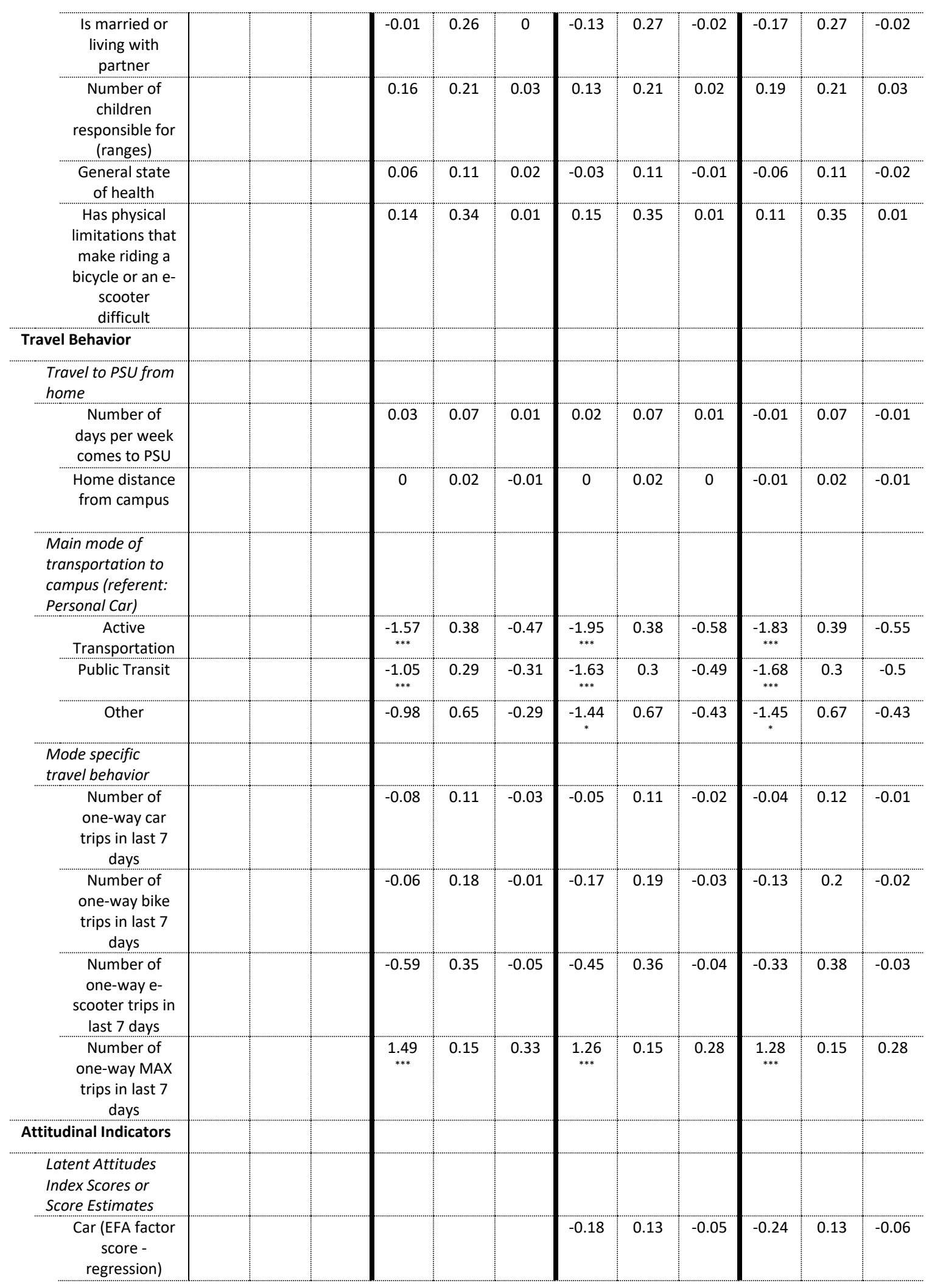




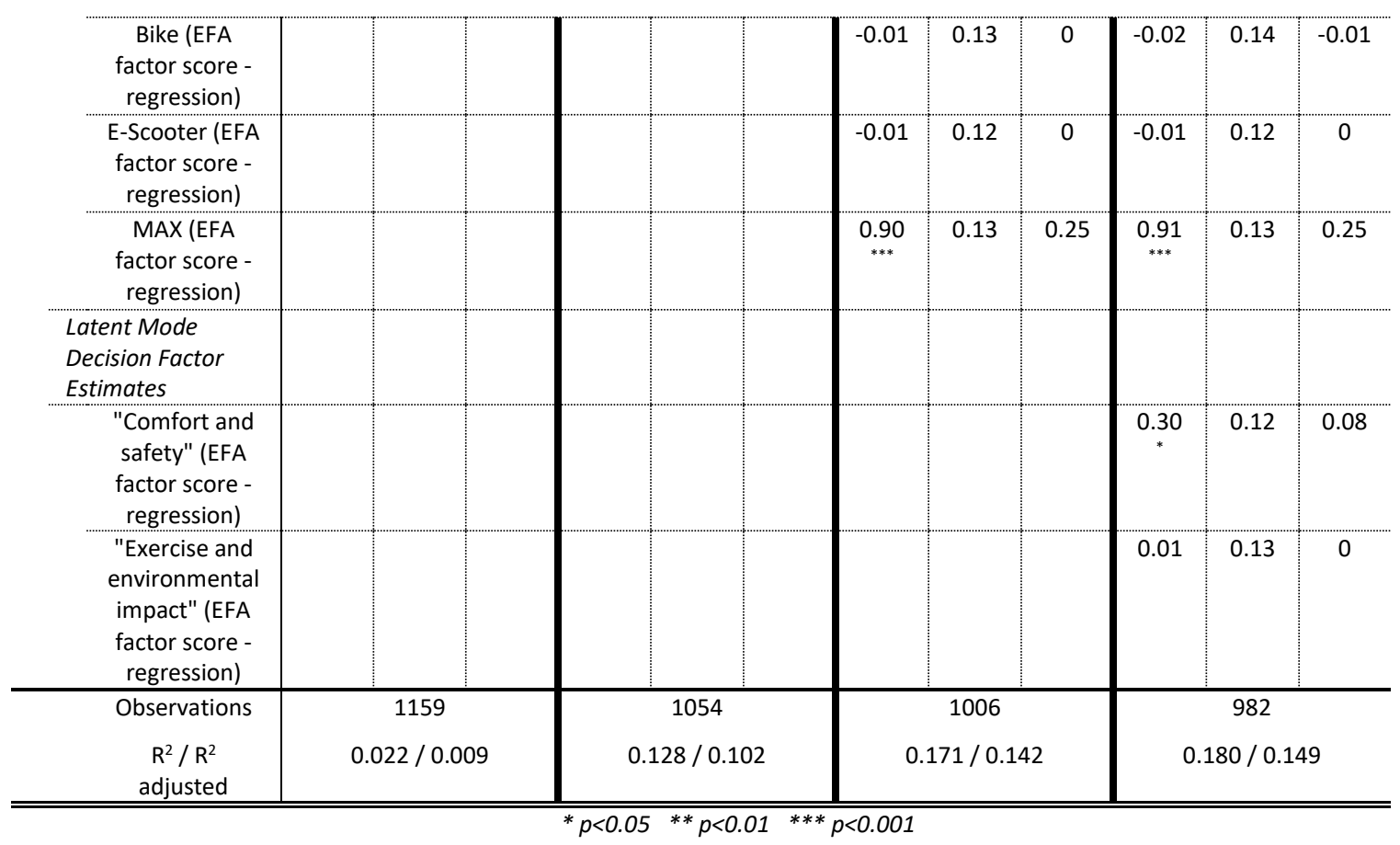




\section{Full Logit Models}

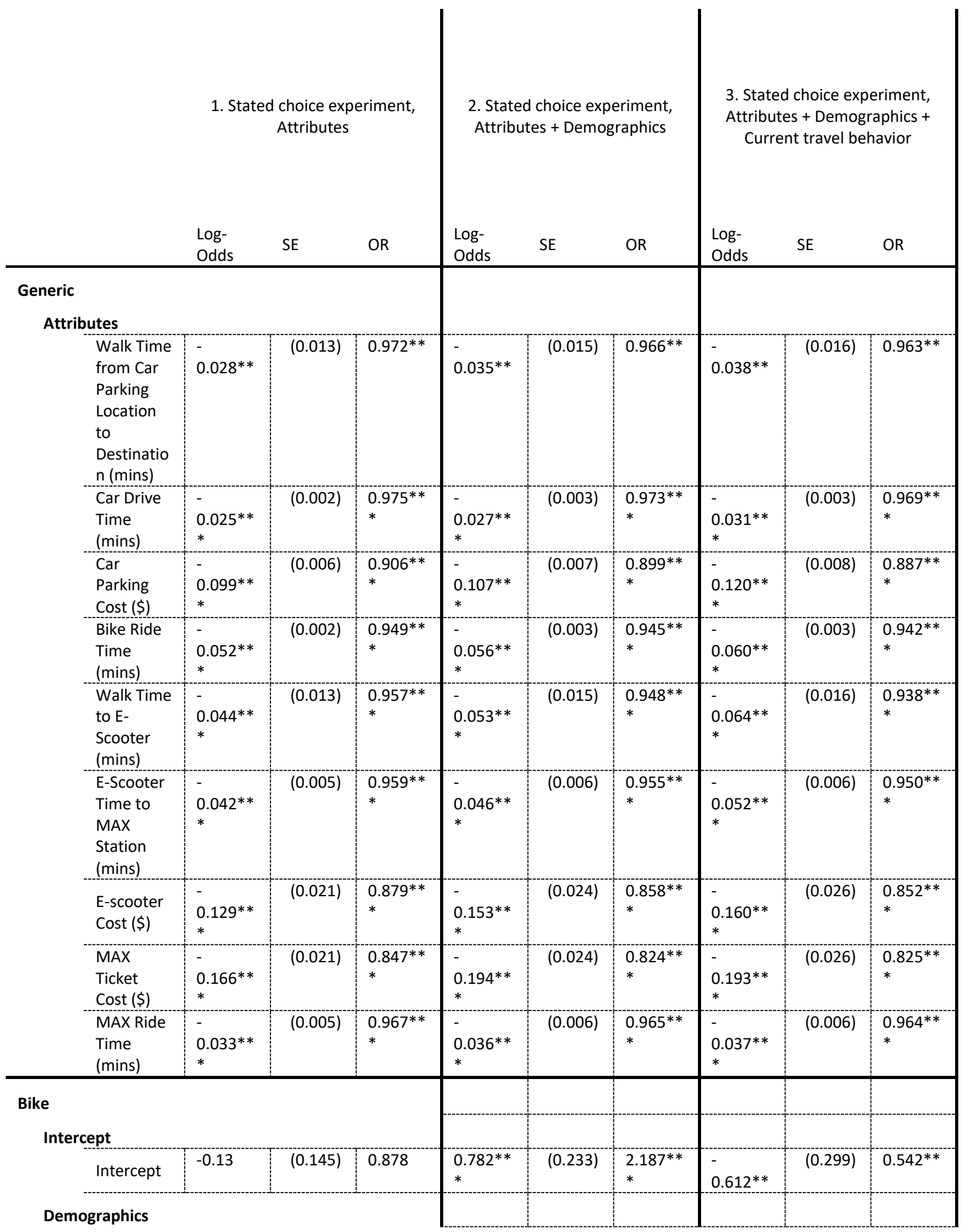




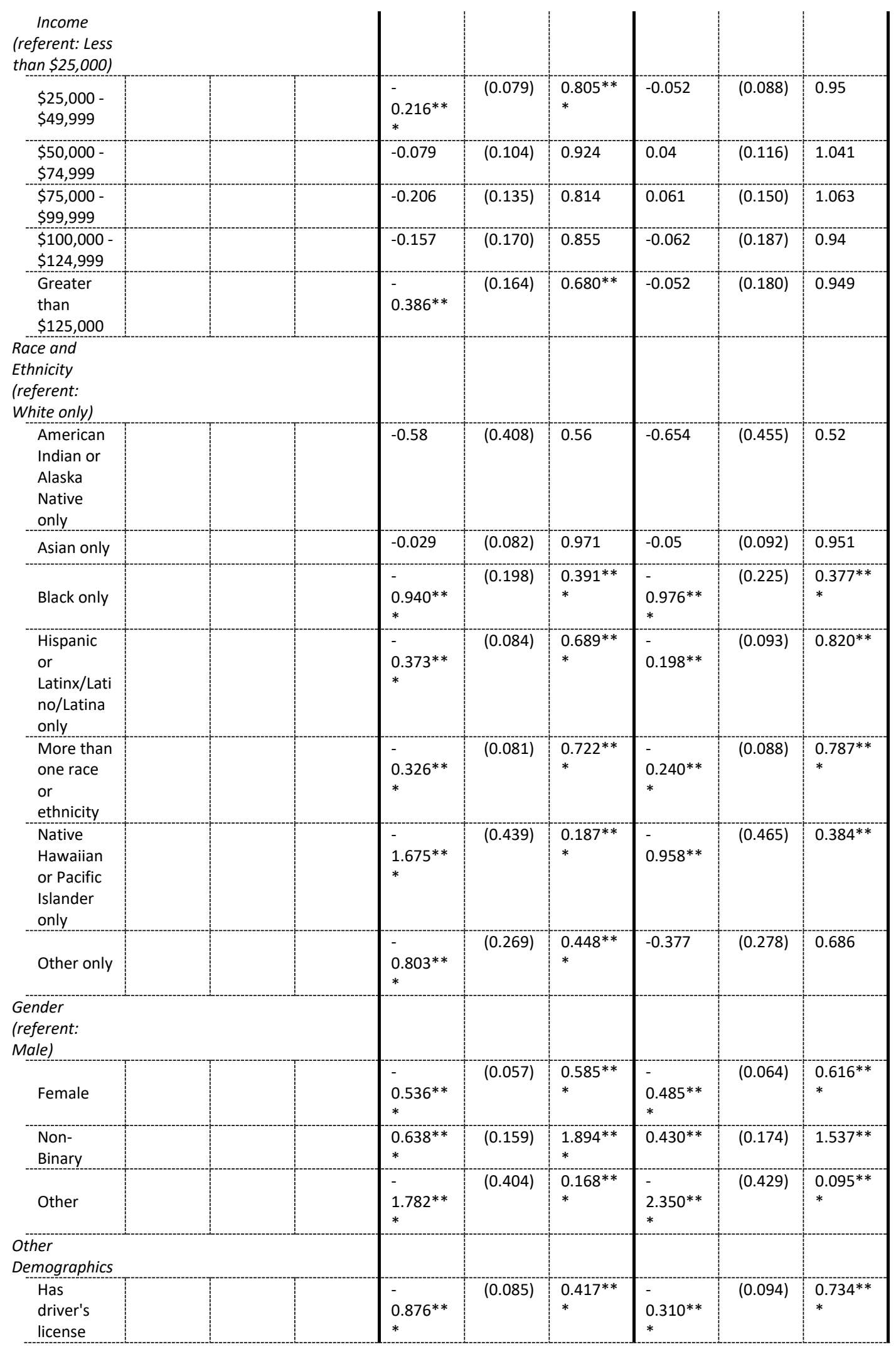




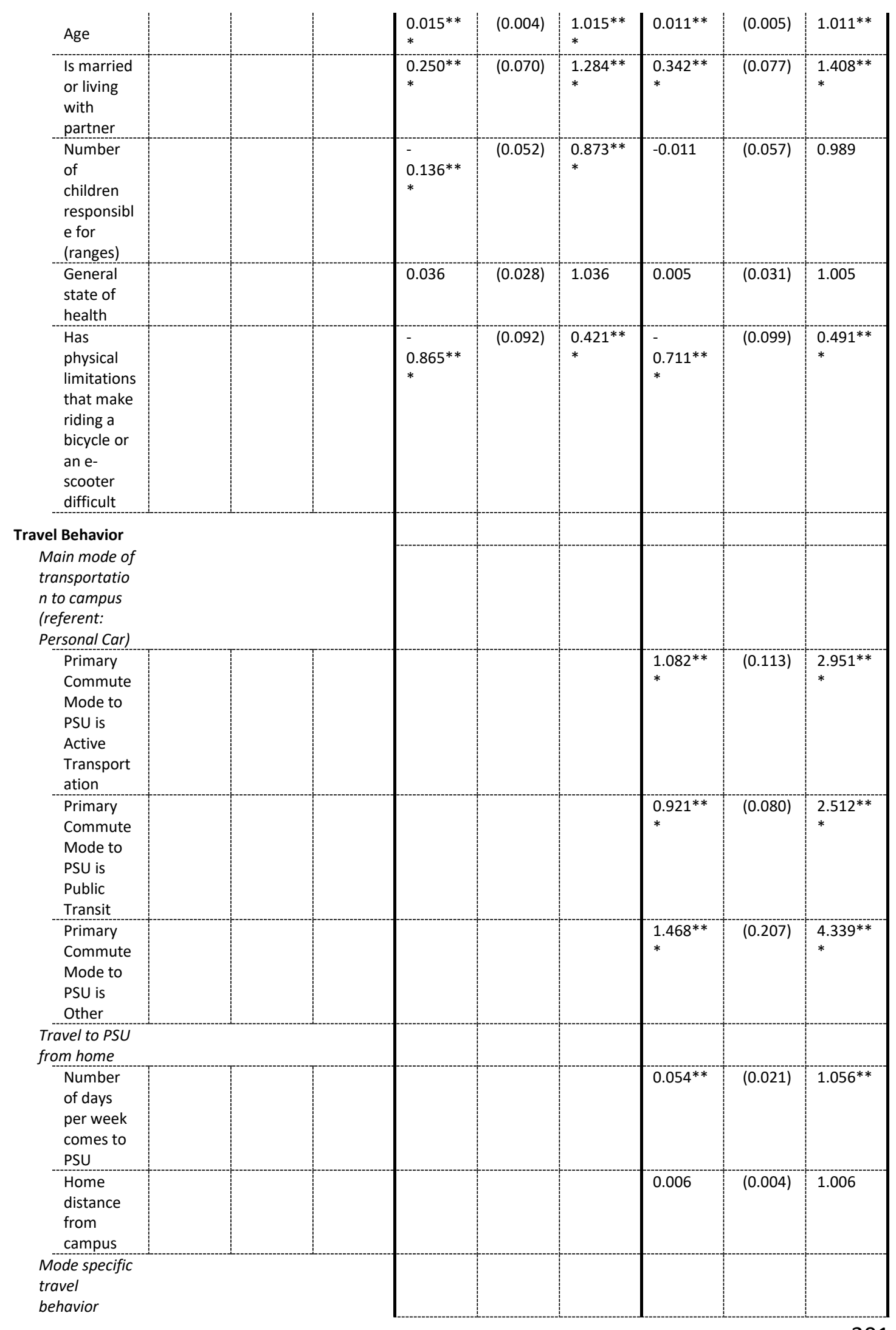




\begin{tabular}{|c|c|c|c|c|c|c|c|c|c|}
\hline $\begin{array}{l}\text { Number } \\
\text { of one- } \\
\text { way car } \\
\text { trips in } \\
\text { last } 7 \text { days }\end{array}$ & & & & & & & $\begin{array}{l}- \\
0.215^{* *} \\
*\end{array}$ & $(0.031)$ & $\begin{array}{l}0.807^{* *} \\
*\end{array}$ \\
\hline $\begin{array}{l}\text { Number } \\
\text { of one- } \\
\text { way bike } \\
\text { trips in } \\
\text { last } 7 \text { days }\end{array}$ & & & & & & & $\begin{array}{l}1.176^{* *} \\
*\end{array}$ & $(0.089)$ & $\begin{array}{l}3.242^{* *} \\
*\end{array}$ \\
\hline $\begin{array}{l}\text { Number } \\
\text { of one- } \\
\text { way e- } \\
\text { scooter } \\
\text { trips in } \\
\text { last } 7 \text { days }\end{array}$ & & & & & & & -0.155 & $(0.124)$ & 0.857 \\
\hline $\begin{array}{l}\text { Number } \\
\text { of one- } \\
\text { way MAX } \\
\text { trips in } \\
\text { last } 7 \text { days } \\
\end{array}$ & & & & & & & 0.043 & $(0.036)$ & 1.044 \\
\hline \multicolumn{10}{|l|}{ E-Scooter + MAX } \\
\hline \multicolumn{10}{|l|}{ Intercept } \\
\hline Intercept & -0.053 & $(0.214)$ & 0.948 & $\begin{array}{l}1.553^{* *} \\
*\end{array}$ & $(0.299)$ & $\begin{array}{l}4.727^{* *} \\
*\end{array}$ & -0.422 & $(0.363)$ & 0.656 \\
\hline \multicolumn{10}{|l|}{ Demographics } \\
\hline \multicolumn{10}{|l|}{$\begin{array}{l}\text { Income } \\
\text { (referent: Less } \\
\text { than } \$ 25,000)\end{array}$} \\
\hline $\begin{array}{l}\$ 25,000- \\
\$ 49,999\end{array}$ & & & & $\begin{array}{l}- \\
0.287^{* *} \\
*\end{array}$ & $(0.084)$ & $\begin{array}{l}0.751^{* *} \\
*\end{array}$ & -0.119 & $(0.093)$ & 0.888 \\
\hline $\begin{array}{l}\$ 50,000- \\
\$ 74,999\end{array}$ & & & & $\begin{array}{l}0.413^{* *} \\
*\end{array}$ & $(0.117)$ & $\begin{array}{l}0.661^{* *} \\
*\end{array}$ & $-0.247^{*}$ & $(0.129)$ & $0.781^{*}$ \\
\hline $\begin{array}{l}\$ 75,000- \\
\$ 99,999\end{array}$ & & & & -0.176 & $(0.145)$ & 0.839 & 0.248 & $(0.159)$ & 1.282 \\
\hline $\begin{array}{r}\$ 100,000 \\
-\$ 124,999\end{array}$ & & & & -0.175 & $(0.183)$ & 0.839 & -0.084 & $(0.204)$ & 0.92 \\
\hline $\begin{array}{l}\text { Greater } \\
\text { than } \\
\$ 125,000\end{array}$ & & & & -0.27 & $(0.180)$ & 0.764 & 0.118 & $(0.196)$ & 1.125 \\
\hline \multicolumn{10}{|l|}{$\begin{array}{l}\text { Race and } \\
\text { Ethnicity } \\
\text { (referent: } \\
\text { White only) }\end{array}$} \\
\hline $\begin{array}{l}\text { American } \\
\text { Indian or } \\
\text { Alaska } \\
\text { Native } \\
\text { only }\end{array}$ & & & & 0.284 & $(0.356)$ & 1.328 & $0.773^{* *}$ & $(0.381)$ & $2.166^{* *}$ \\
\hline $\begin{array}{l}\text { Asian } \\
\text { only }\end{array}$ & & & & $\begin{array}{l}0.280^{* *} \\
*\end{array}$ & $(0.083)$ & $\begin{array}{l}1.323^{* *} \\
*\end{array}$ & 0.057 & $(0.095)$ & 1.059 \\
\hline Black only & & & & 0.074 & $(0.169)$ & 1.077 & -0.243 & $(0.194)$ & 0.784 \\
\hline $\begin{array}{l}\text { Hispanic } \\
\text { or } \\
\text { Latinx/Lati } \\
\text { no/Latina } \\
\text { only }\end{array}$ & & & & -0.101 & $(0.086)$ & 0.904 & -0.03 & $(0.097)$ & 0.97 \\
\hline
\end{tabular}




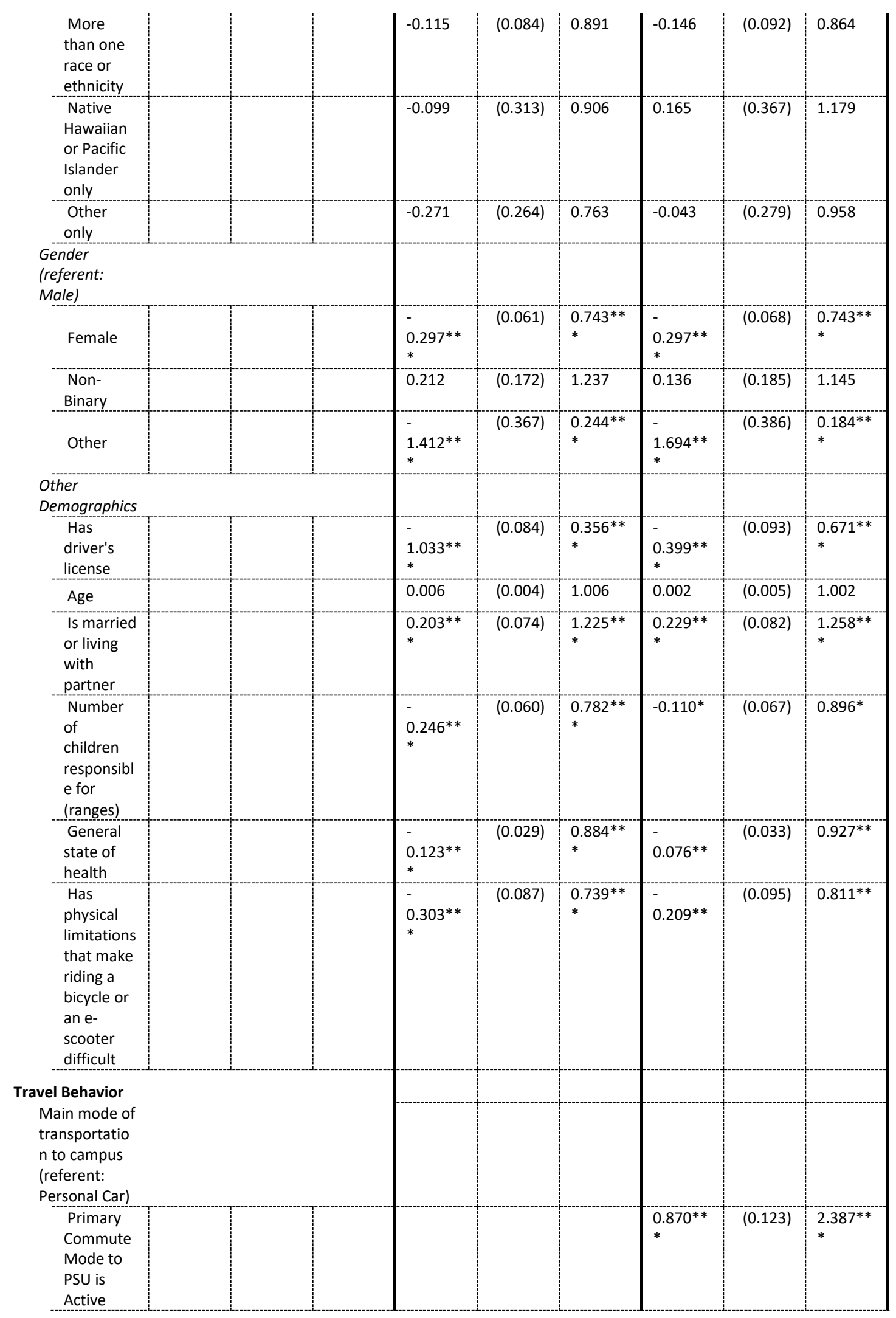




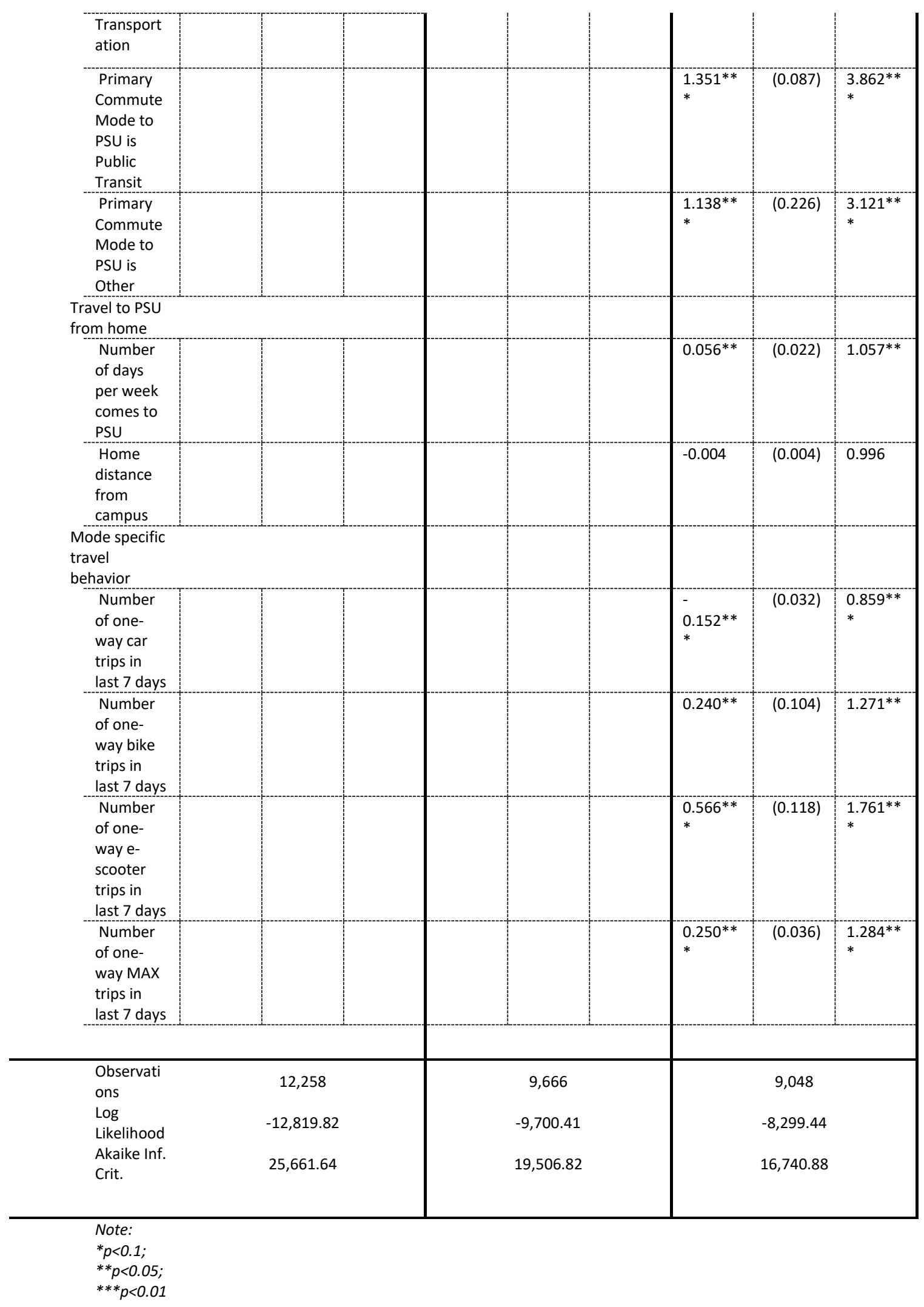




\begin{tabular}{|c|c|c|c|c|c|c|}
\hline & $\begin{array}{l}\text { 4. Stated } \\
\text { Attributes } \\
\text { Current tra }\end{array}$ & $\begin{array}{l}\text { choice exp } \\
\text { + Demog } \\
\text { vel behav } \\
\text { Attitudes }\end{array}$ & $\begin{array}{l}\text { periment, } \\
\text { graphics + } \\
\text { jior + Mode }\end{array}$ & $\begin{array}{l}\text { 5. Stated } \\
\text { Attributes } \\
\text { Current tra } \\
\text { Attitudes }\end{array}$ & $\begin{array}{l}\text { choice ex } \\
\text { + Demog } \\
\text { vel behav } \\
\text { + Decisio }\end{array}$ & $\begin{array}{l}\text { kperiment, } \\
\text { graphics + } \\
\text { vior + Mode } \\
\text { on factors }\end{array}$ \\
\hline & Log-Odds & SE & OR & Log-Odds & SE & OR \\
\hline \multicolumn{7}{|l|}{ Generic } \\
\hline Walk Time from Car Parking Location to Destination (mins) & $-0.034 *$ & $(0.018)$ & $0.967^{*}$ & $-0.035^{* *}$ & $(0.018)$ & $0.965^{*} *$ \\
\hline Car Drive Time (mins) & $-0.037^{* * *}$ & $(0.003)$ & $0.964^{* * *}$ & $-0.037^{* * *}$ & $(0.003)$ & $0.964^{* * *}$ \\
\hline Car Parking Cost $(\$)$ & $-0.139 * * *$ & $(0.009)$ & $0.871^{* * *}$ & $-0.138 * * *$ & $(0.009)$ & $0.871^{* * *}$ \\
\hline Bike Ride Time (mins) & $-0.067^{* * *}$ & $(0.003)$ & $0.935^{* * *}$ & $-0.068^{* * *}$ & $(0.003)$ & $0.934 * * *$ \\
\hline Walk Time to E-Scooter (mins) & $0.069 * * *$ & $(0.017)$ & $0.933^{* * *}$ & $-0.070^{* * *}$ & $(0.017)$ & $0.932 * * *$ \\
\hline E-Scooter Time to MAX Station (mins) & $-0.056^{* * *}$ & $(0.007)$ & $0.945^{* * *}$ & $-0.055^{* * *}$ & $(0.007)$ & $0.946^{* * *}$ \\
\hline E-scooter Cost $(\$)$ & $-0.172^{* * *}$ & $(0.027)$ & $0.842 * * *$ & $-0.168 * * *$ & $(0.028)$ & $0.846^{* * *}$ \\
\hline MAX Ticket Cost (\$) & $0.184^{* * *}$ & $(0.027)$ & $0.832 * * *$ & $-0.181^{* * *}$ & $(0.027)$ & $0.835^{* * *}$ \\
\hline MAX Ride Time (mins) & $-0.040^{* * *}$ & $(0.007)$ & $0.961^{* * *}$ & $-0.040 * * *$ & $(0.007)$ & $0.961^{* * *}$ \\
\hline \multicolumn{7}{|l|}{ Bike } \\
\hline \multicolumn{7}{|l|}{ Intercept } \\
\hline Intercept & -0.334 & $(0.330)$ & 0.716 & -0.519 & $(0.340)$ & 0.595 \\
\hline \multicolumn{7}{|l|}{ Demographics } \\
\hline \multicolumn{7}{|l|}{ Income (referent: Less than $\$ 25,000$ ) } \\
\hline$\$ 25,000-\$ 49,999$ & -0.096 & $(0.097)$ & 0.909 & -0.091 & $(0.098)$ & 0.913 \\
\hline$\$ 50,000-\$ 74,999$ & -0.11 & $(0.127)$ & 0.895 & -0.157 & $(0.130)$ & 0.855 \\
\hline$\$ 75,000-\$ 99,999$ & 0.071 & $(0.168)$ & 1.074 & 0.038 & $(0.171)$ & 1.039 \\
\hline$\$ 100,000-\$ 124,999$ & -0.251 & $(0.215)$ & 0.778 & $-0.375^{*}$ & $(0.221)$ & $0.687^{*}$ \\
\hline Greater than $\$ 125,000$ & -0.033 & $(0.201)$ & 0.967 & -0.012 & $(0.204)$ & 0.988 \\
\hline \multicolumn{7}{|l|}{ Race and Ethnicity (referent: White only) } \\
\hline American Indian or Alaska Native only & -0.53 & $(0.530)$ & 0.589 & -0.615 & $(0.532)$ & 0.541 \\
\hline
\end{tabular}




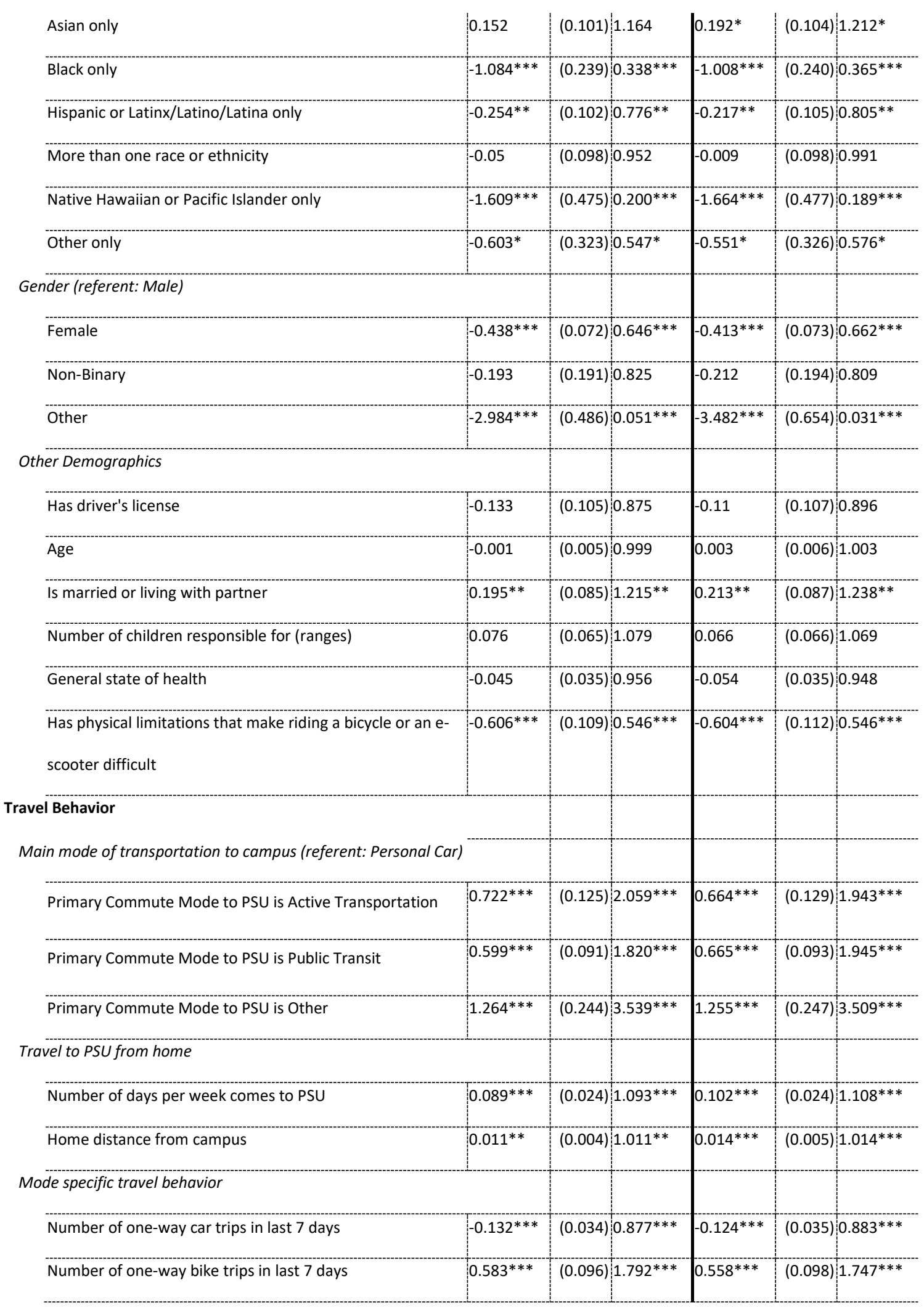




\begin{tabular}{|c|c|c|c|c|c|c|}
\hline Number of one-way e-scooter trips in last 7 days & 0.086 & $(0.132)$ & 1.09 & -0.05 & $(0.139)$ & 0.951 \\
\hline Number of one-way MAX trips in last 7 days & -0.023 & $(0.040)$ & 0.978 & -0.047 & $(0.041)$ & 0.954 \\
\hline \multicolumn{7}{|l|}{ Attitudinal Indicators } \\
\hline \multicolumn{7}{|l|}{ Latent Attitudes Index Score Estimates } \\
\hline Car (EFA factor score - regression) & $-0.546 * * *$ & $(0.043)$ & $0.579 * * *$ & $-0.514 * * *$ & $(0.044)$ & $0.598^{* * *}$ \\
\hline Bike (EFA factor score - regression) & $1.087^{* * *}$ & $(0.046)$ & $2.965^{* * *}$ & $1.097^{* * *}$ & $(0.048)$ & $2.995^{* * *}$ \\
\hline E-scooter (EFA factor score - regression) & $-0.095^{* *}$ & $(0.039)$ & $0.910^{* *}$ & $-0.114 * * *$ & $(0.040)$ & $0.892 * * *$ \\
\hline MAX (EFA factor score - regression) & $0.150^{* * *}$ & $(0.041)$ & $1.161^{* * *}$ & $0.134 * * *$ & $(0.042)$ & $1.143^{* * *}$ \\
\hline \multicolumn{7}{|l|}{ Latent Mode Decision Factor Estimates } \\
\hline "Comfort and safety" (EFA factor score - regression) & & & & $-0.164 * * *$ & $(0.039)$ & $0.849^{* * *}$ \\
\hline $\begin{array}{l}\text { "Exercise and environmental impact" (EFA factor score - } \\
\text { regression) }\end{array}$ & & & & $0.102^{* * *}$ & $(0.039)$ & $1.107^{* * *}$ \\
\hline \multicolumn{7}{|l|}{ E-Scooter + MAX } \\
\hline \multicolumn{7}{|l|}{ Intercept } \\
\hline Intercept & 0.023 & $(0.388)$ & 1.024 & -0.044 & $(0.397)$ & 0.957 \\
\hline \multicolumn{7}{|l|}{ Demographics } \\
\hline \multicolumn{7}{|l|}{ Income (referent: Less than $\$ 25,000$ ) } \\
\hline$\$ 25,000-\$ 49,999$ & -0.138 & $(0.100)$ & 0.871 & -0.161 & $(0.101)$ & 0.851 \\
\hline$\$ 50,000-\$ 74,999$ & $-0.310^{* *}$ & $(0.137)$ & $0.733^{* *}$ & $-0.412^{* * *}$ & $(0.140)$ & $0.663^{* * *}$ \\
\hline$\$ 75,000-\$ 99,999$ & 0.238 & $(0.170)$ & 1.269 & 0.208 & $(0.172)$ & 1.231 \\
\hline$\$ 100,000-\$ 124,999$ & -0.08 & $(0.222)$ & 0.923 & -0.06 & $(0.224)$ & 0.942 \\
\hline Greater than $\$ 125,000$ & 0.157 & $(0.211)$ & 1.169 & 0.226 & $(0.214)$ & 1.254 \\
\hline \multicolumn{7}{|l|}{ Race and Ethnicity (referent: White only) } \\
\hline American Indian or Alaska Native only & $1.366^{* * *}$ & $(0.438)$ & $3.920 * * *$ & $1.378^{* * *}$ & $(0.440)$ & $3.967^{* * *}$ \\
\hline Asian only & 0.11 & $(0.100)$ & 1.116 & 0.153 & $(0.103)$ & 1.165 \\
\hline Black only & $-0.622^{* * *}$ & $(0.210)$ & $0.537 * * *$ & $-0.603 * * *$ & $(0.211)$ & $0.547^{* * *}$ \\
\hline Hispanic or Latinx/Latino/Latina only & -0.157 & $(0.103)$ & 0.855 & -0.146 & $(0.106)$ & 0.864 \\
\hline More than one race or ethnicity & -0.078 & $(0.100)$ & 0.925 & -0.06 & $(0.100)$ & 0.941 \\
\hline Native Hawaiian or Pacific Islander only & -0.14 & $(0.372)$ & 0.869 & -0.118 & $(0.375)$ & 0.889 \\
\hline
\end{tabular}




\begin{tabular}{|c|c|c|c|c|c|c|}
\hline Other only & -0.087 & $(0.298)$ & 0.917 & -0.072 & $(0.300)$ & 0.931 \\
\hline \multicolumn{7}{|l|}{ Gender (referent: Male) } \\
\hline Female & $-0.329 * * *$ & $(0.073)$ & $0.719 * * *$ & $-0.311 * * *$ & $(0.075)$ & $0.733^{* * *}$ \\
\hline Non-Binary & $-0.334^{*}$ & $(0.201)$ & $0.716^{*}$ & -0.306 & $(0.202)$ & 0.736 \\
\hline Other & $-1.813^{* * *}$ & $(0.426)$ & $0.163^{* * *}$ & $-1.830^{* * *}$ & $(0.434)$ & $0.160^{* * *}$ \\
\hline \multicolumn{7}{|l|}{ Other Demographics } \\
\hline Has driver's license & $-0.208^{* *}$ & $(0.102)$ & $0.812^{* *}$ & $-0.212^{* *}$ & $(0.103)$ & $0.809 * *$ \\
\hline Age & -0.008 & $(0.005)$ & 0.992 & -0.006 & $(0.006)$ & 0.994 \\
\hline Is married or living with partner & 0.082 & $(0.088)$ & 1.085 & 0.112 & $(0.090)$ & 1.119 \\
\hline Number of children responsible for (ranges) & -0.064 & $(0.072)$ & 0.938 & -0.085 & $(0.073)$ & 0.918 \\
\hline General state of health & $-0.135^{* * *}$ & $(0.036)$ & $0.874^{* * *}$ & $-0.134 * * *$ & $(0.036)$ & $0.874 * * *$ \\
\hline $\begin{array}{l}\text { Has physical limitations that make riding a bicycle or an e- } \\
\text { scooter difficult }\end{array}$ & -0.165 & $(0.102)$ & 0.848 & -0.132 & $(0.104)$ & 0.876 \\
\hline \multicolumn{7}{|l|}{ Travel Behavior } \\
\hline \multicolumn{7}{|l|}{ Main mode of transportation to campus (referent: Personal Car) } \\
\hline Primary Commute Mode to PSU is Active Transportation & $0.521^{* * *}$ & $(0.132)$ & $1.683^{* * *}$ & $0.483^{* * *}$ & $(0.136)$ & $1.621^{* * *}$ \\
\hline Primary Commute Mode to PSU is Public Transit & $1.025^{* * *}$ & $(0.095)$ & $2.787^{* * *}$ & $1.007^{* * *}$ & $(0.096)$ & $2.737^{* * *}$ \\
\hline Primary Commute Mode to PSU is Other & $1.172^{* * *}$ & $(0.256)$ & $3.228^{* * *}$ & $1.190 * * *$ & $(0.258)$ & $3.286^{* * *}$ \\
\hline \multicolumn{7}{|l|}{ Travel to PSU from home } \\
\hline Number of days per week comes to PSU & $0.071^{* * *}$ & $(0.024)$ & $1.073^{* * *}$ & $0.062 * *$ & $(0.024)$ & $1.064 * *$ \\
\hline Home distance from campus & -0.002 & $(0.005)$ & 0.998 & -0.002 & $(0.005)$ & 0.998 \\
\hline \multicolumn{7}{|l|}{ Mode specific travel behavior } \\
\hline Number of one-way car trips in last 7 days & $-0.105^{* * *}$ & $(0.035)$ & $0.901^{* * *}$ & $-0.114 * * *$ & $(0.035)$ & $0.892^{* * *}$ \\
\hline Number of one-way bike trips in last 7 days & 0.068 & $(0.109)$ & 1.071 & 0.071 & $(0.111)$ & 1.074 \\
\hline Number of one-way e-scooter trips in last 7 days & $0.453^{* * *}$ & $(0.126)$ & $1.573^{* * *}$ & $0.431 * * *$ & $(0.131)$ & $1.539 * * *$ \\
\hline Number of one-way MAX trips in last 7 days & $0.117^{* * *}$ & $(0.039)$ & $1.124^{* * *}$ & $0.121^{* * *}$ & $(0.040)$ & $1.128^{* * *}$ \\
\hline \multicolumn{7}{|l|}{ Attitudinal Indicators } \\
\hline \multicolumn{7}{|l|}{ Latent Attitudes Index Score Estimates } \\
\hline Car (EFA factor score - regression) & $-0.525 * * *$ & $(0.044)$ & $0.591 * * *$ & $-0.517^{* * *}$ & $(0.045)$ & $0.596 * * *$ \\
\hline
\end{tabular}




\begin{tabular}{|c|c|c|c|c|c|c|}
\hline Bike (EFA factor score - regression) & $0.181 * * *$ & $(0.045) 1$ & $1.199 * * *$ & $0.167^{* * *}$ & (0.046) & $1.182^{* * *}$ \\
\hline E-scooter (EFA factor score - regression) & $0.306 * * *$ & $(0.041) 1$ & $1.358 * * *$ & $0.303^{* * *}$ & $(0.042)$ & $1.354 * * *$ \\
\hline MAX (EFA factor score - regression) & $0.503^{* * *}$ & $(0.042) 1$ & $1.654^{* * *}$ & $0.521 * * *$ & $(0.043)$ & $1.683^{* * *}$ \\
\hline \multicolumn{7}{|l|}{ Latent Mode Decision Factor Estimates } \\
\hline "Comfort and safety" (EFA factor score - regression) & & & & -0.025 & $(0.040)$ & 0.976 \\
\hline $\begin{array}{l}\text { "Exercise and environmental impact" (EFA factor score - } \\
\text { regression) }\end{array}$ & & & & -0.012 & $(0.041)$ & 0.988 \\
\hline Observations & & 8,592 & & & 8,382 & \\
\hline Log Likelihood & & $-7,186.68$ & & & $-6,984.92$ & \\
\hline Akaike Inf. Crit. & & $14,531.36$ & & & $14,135.83$ & \\
\hline
\end{tabular}

Note: ${ }^{*} p<0.1 ;{ }^{* *} p<0.05 ;{ }^{* * *} p<0.01$ 


\begin{tabular}{|c|c|c|c|c|c|c|c|c|}
\hline \multirow[b]{2}{*}{ Predictors } & \multicolumn{2}{|c|}{$\begin{array}{l}\text { 1. Frequency of trips } \\
\text { in last } 7 \text { days, mode: } \\
\text { E-Scooter. Terms: } \\
\text { Demographics }\end{array}$} & \multicolumn{2}{|c|}{$\begin{array}{l}\text { 2. Frequency of trips in } \\
\text { last } 7 \text { days, mode: E- } \\
\text { Scooter. Terms: } \\
\text { Demographics + } \\
\text { Current travel } \\
\text { behavior }\end{array}$} & \multicolumn{2}{|c|}{$\begin{array}{l}\text { 3. Frequency of trips in } \\
\text { last } 7 \text { days, mode: E- } \\
\text { Scooter. Terms: } \\
\text { Demographics + } \\
\text { Current travel } \\
\text { behavior + Mode } \\
\text { Attitudes }\end{array}$} & \multicolumn{2}{|c|}{$\begin{array}{c}\text { 4. Frequency of trips } \\
\text { in last } 7 \text { days, mode: } \\
\text { E-Scooter. Terms: } \\
\text { Demographics + } \\
\text { Current travel } \\
\text { behavior + Mode } \\
\text { Attitudes + Decision } \\
\text { factors }\end{array}$} \\
\hline & $\begin{array}{l}\text { Odds } \\
\text { Ratios }\end{array}$ & std. Error & $\begin{array}{l}\text { Odds } \\
\text { Ratios }\end{array}$ & std. Error & $\begin{array}{l}\text { Odds } \\
\text { Ratios }\end{array}$ & std. Error & $\begin{array}{l}\text { Odds } \\
\text { Ratios }\end{array}$ & std. Error \\
\hline (Intercept) & $0.09^{* * *}$ & 0.21 & $0.07^{* *}$ & 0.98 & $0.01^{* * *}$ & 1.07 & $0.01^{* * *}$ & 1.15 \\
\hline \multicolumn{9}{|l|}{ Demographics } \\
\hline \multicolumn{9}{|l|}{$\begin{array}{l}\text { Income (referent: } \\
\text { Less than } \$ 25,000 \text { ) }\end{array}$} \\
\hline $\begin{array}{l}\$ 25,000- \\
\$ 49,999\end{array}$ & 0.85 & 0.3 & 1 & 0.36 & 0.88 & 0.4 & 0.88 & 0.41 \\
\hline $\begin{array}{l}\$ 50,000- \\
\$ 74,999\end{array}$ & 0.91 & 0.39 & 1.3 & 0.47 & 1.49 & 0.5 & 1.3 & 0.54 \\
\hline $\begin{array}{l}\$ 75,000- \\
\$ 99,999\end{array}$ & 0.19 & 1.02 & 0.28 & 1.06 & 0.27 & 1.08 & 0.27 & 1.08 \\
\hline \multicolumn{9}{|l|}{$\begin{array}{l}\text { Race and Ethnicity } \\
\text { (referent: White } \\
\text { only) }\end{array}$} \\
\hline Asian only & 1.53 & 0.29 & 1.73 & 0.33 & 1.69 & 0.37 & 1.88 & 0.39 \\
\hline Black only & 2.34 & 0.56 & 1.26 & 0.76 & 0.7 & 0.86 & 0.66 & 0.89 \\
\hline $\begin{array}{l}\text { Hispanic or } \\
\text { Latinx/Latino/L } \\
\text { atina only }\end{array}$ & 0.96 & 0.36 & 1.41 & 0.38 & 1.17 & 0.41 & 1.34 & 0.42 \\
\hline $\begin{array}{l}\text { More than one } \\
\text { race or } \\
\text { ethnicity }\end{array}$ & 1.03 & 0.35 & 1.1 & 0.36 & 0.72 & 0.41 & 0.82 & 0.41 \\
\hline $\begin{array}{l}\text { Native } \\
\text { Hawaiian or } \\
\text { Pacific Islander } \\
\text { only }\end{array}$ & $8.56^{* *}$ & 0.73 & $9.62^{* *}$ & 0.83 & 6.75 & 1.02 & 5.67 & 1.07 \\
\hline \multicolumn{9}{|l|}{$\begin{array}{l}\text { Gender (referent: } \\
\text { Male) }\end{array}$} \\
\hline Female & $0.55^{* *}$ & 0.22 & $0.58^{*}$ & 0.24 & 0.77 & 0.27 & 0.84 & 0.28 \\
\hline \multicolumn{9}{|l|}{$\begin{array}{l}\text { Other } \\
\text { Demographics }\end{array}$} \\
\hline $\begin{array}{l}\text { Has driver's } \\
\text { license }\end{array}$ & & & 0.79 & 0.31 & 0.65 & 0.36 & 0.66 & 0.37 \\
\hline Age & & & 0.98 & 0.02 & 1.02 & 0.02 & 1.02 & 0.02 \\
\hline $\begin{array}{l}\text { Is married or } \\
\text { living with } \\
\text { partner }\end{array}$ & & & 1.04 & 0.33 & 0.85 & 0.37 & 0.85 & 0.38 \\
\hline $\begin{array}{l}\text { Number of } \\
\text { children } \\
\text { responsible for } \\
\text { (ranges) }\end{array}$ & & & 1.26 & 0.31 & 1.25 & 0.31 & 1.3 & 0.32 \\
\hline
\end{tabular}




\begin{tabular}{|c|c|c|c|c|c|c|}
\hline $\begin{array}{l}\text { General state } \\
\text { of health }\end{array}$ & 1.22 & 0.12 & 1.28 & 0.14 & 1.24 & 0.14 \\
\hline $\begin{array}{l}\text { Has physical } \\
\text { limitations } \\
\text { that make } \\
\text { riding a bicycle } \\
\text { or an e-scooter } \\
\text { difficult }\end{array}$ & 1.85 & 0.37 & $2.34^{*}$ & 0.41 & $2.60^{*}$ & 0.42 \\
\hline \multicolumn{7}{|l|}{ Travel Behavior } \\
\hline \multicolumn{7}{|l|}{$\begin{array}{l}\text { Travel to PSU from } \\
\text { home }\end{array}$} \\
\hline $\begin{array}{l}\text { Number of } \\
\text { days per week } \\
\text { comes to PSU }\end{array}$ & 1.08 & 0.09 & 1.05 & 0.1 & 1.07 & 0.1 \\
\hline $\begin{array}{l}\text { Home distance } \\
\text { from campus }\end{array}$ & $0.95^{*}$ & 0.02 & $0.94^{* *}$ & 0.02 & $0.94^{* *}$ & 0.02 \\
\hline \multicolumn{7}{|l|}{$\begin{array}{l}\text { Main mode of } \\
\text { transportation to } \\
\text { campus (referent: } \\
\text { Personal Car) }\end{array}$} \\
\hline $\begin{array}{l}\text { Active } \\
\text { Transportation }\end{array}$ & 1.17 & 0.41 & 1.08 & 0.46 & 0.94 & 0.48 \\
\hline Public Transit & 1.07 & 0.32 & 1.23 & 0.37 & 1.32 & 0.38 \\
\hline Other & 0.53 & 1.08 & 0.47 & 1.18 & 0.3 & 1.3 \\
\hline \multicolumn{7}{|l|}{ Attitudinal Indicators } \\
\hline \multicolumn{7}{|l|}{$\begin{array}{l}\text { Latent Attitudes } \\
\text { Factor Score } \\
\text { Estimates }\end{array}$} \\
\hline $\begin{array}{l}\text { Car (EFA factor } \\
\text { score - } \\
\text { regression) }\end{array}$ & & & 0.95 & 0.17 & 0.95 & 0.17 \\
\hline $\begin{array}{l}\text { Bike (EFA } \\
\text { factor score - } \\
\text { regression) }\end{array}$ & & & $0.64^{* *}$ & 0.17 & $0.67^{*}$ & 0.18 \\
\hline $\begin{array}{l}\text { E-Scooter (EFA } \\
\text { factor score - } \\
\text { regression) }\end{array}$ & & & $5.35^{* * *}$ & 0.19 & $5.47^{* * * *}$ & 0.2 \\
\hline $\begin{array}{l}\text { MAX (EFA } \\
\text { factor score - } \\
\text { regression) }\end{array}$ & & & 0.75 & 0.16 & 0.76 & 0.16 \\
\hline \multicolumn{7}{|l|}{$\begin{array}{l}\text { Latent Mode } \\
\text { Decision Factor } \\
\text { Estimates }\end{array}$} \\
\hline $\begin{array}{l}\text { "Comfort and } \\
\text { safety" (EFA } \\
\text { factor score - } \\
\text { regression) }\end{array}$ & & & & & 0.75 & 0.16 \\
\hline $\begin{array}{l}\text { "Exercise and } \\
\text { environmental } \\
\text { impact" (EFA } \\
\text { factor score - } \\
\text { regression) }\end{array}$ & & & & & 1 & 0.17 \\
\hline
\end{tabular}




\begin{tabular}{l|l|l|l|l|}
\hline $\begin{array}{l}\text { Observations } \\
\mathrm{R}^{2} \text { Tjur }\end{array}$ & 1485 & $\begin{array}{l}1347 \\
0.02\end{array}$ & 0.044 & $\begin{array}{l}1283 \\
0.197\end{array}$ \\
\hline \hline
\end{tabular}




\begin{tabular}{|c|c|c|c|c|c|c|c|c|}
\hline \multirow[b]{2}{*}{ Predictors } & \multicolumn{2}{|c|}{$\begin{array}{c}\text { 1. Frequency of trips } \\
\text { in last } 7 \text { days, mode: } \\
\text { MAX. Terms: } \\
\text { Demographics }\end{array}$} & \multicolumn{2}{|c|}{$\begin{array}{l}\text { 2. Frequency of trips in } \\
\text { last } 7 \text { days, mode: } \\
\text { MAX. Terms: } \\
\text { Demographics + } \\
\text { Current travel } \\
\text { behavior }\end{array}$} & \multicolumn{2}{|c|}{$\begin{array}{l}\text { 3. Frequency of trips in } \\
\text { last } 7 \text { days, mode: } \\
\text { MAX. Terms: } \\
\text { Demographics + } \\
\text { Current travel } \\
\text { behavior + Mode } \\
\text { Attitudes }\end{array}$} & \multicolumn{2}{|c|}{$\begin{array}{l}\text { 4. Frequency of trips } \\
\text { in last } 7 \text { days, mode: } \\
\text { MAX. Terms: } \\
\text { Demographics + } \\
\text { Current travel } \\
\text { behavior + Mode } \\
\text { Attitudes + Decision } \\
\text { factors }\end{array}$} \\
\hline & $\begin{array}{c}\text { Odds } \\
\text { Ratios }\end{array}$ & std. Error & $\begin{array}{c}\text { Odds } \\
\text { Ratios }\end{array}$ & std. Error & $\begin{array}{l}\text { Odds } \\
\text { Ratios }\end{array}$ & std. Error & $\begin{array}{l}\text { Odds } \\
\text { Ratios }\end{array}$ & std. Error \\
\hline $\begin{array}{l}0 \text { trips|1-4 } \\
\text { trips }\end{array}$ & $0.64^{* * *}$ & 0.1 & $10.39^{* * *}$ & 0.41 & $7.00^{* * *}$ & 0.43 & $8.00^{* * *}$ & 0.45 \\
\hline $\begin{array}{l}1-4 \text { trips } \mid 5-10 \\
\text { trips }\end{array}$ & $2.49^{* * *}$ & 0.1 & $66.02^{* * *}$ & 0.42 & $47.92^{* * *}$ & 0.44 & $54.30^{* * *}$ & 0.45 \\
\hline $\begin{array}{l}5-10 \\
\text { trips|More } \\
\text { than } 10 \text { trips }\end{array}$ & $10.03^{* * *}$ & 0.12 & $348.39^{* * *}$ & 0.43 & $260.20^{* * *}$ & 0.45 & $294.89^{* * *}$ & 0.47 \\
\hline \multicolumn{9}{|l|}{ Demographics } \\
\hline \multicolumn{9}{|l|}{$\begin{array}{l}\text { Income (referent: } \\
\text { Less than } \$ 25,000)\end{array}$} \\
\hline $\begin{array}{l}\$ 25,000- \\
\$ 49,999\end{array}$ & $0.70^{* *}$ & 0.13 & 0.85 & 0.16 & 0.89 & 0.17 & 0.87 & 0.17 \\
\hline $\begin{array}{l}\$ 50,000- \\
\$ 74,999\end{array}$ & $0.64^{* *}$ & 0.17 & 0.79 & 0.22 & 0.83 & 0.23 & 0.85 & 0.23 \\
\hline $\begin{array}{l}\$ 75,000- \\
\$ 99,999\end{array}$ & $0.46^{* * *}$ & 0.23 & 0.89 & 0.29 & 0.98 & 0.29 & 0.94 & 0.3 \\
\hline $\begin{array}{l}\$ 100,000- \\
\$ 124,999\end{array}$ & 0.81 & 0.31 & 1.5 & 0.36 & 1.35 & 0.38 & 1.36 & 0.39 \\
\hline $\begin{array}{l}\text { Greater than } \\
\$ 125,000\end{array}$ & $0.57^{*}$ & 0.28 & 1.29 & 0.35 & 1.33 & 0.38 & 1.36 & 0.38 \\
\hline \multicolumn{9}{|l|}{$\begin{array}{l}\text { Race and Ethnicity } \\
\text { (referent: White } \\
\text { only) }\end{array}$} \\
\hline $\begin{array}{l}\text { American } \\
\text { Indian or } \\
\text { Alaska Native } \\
\text { only }\end{array}$ & 0.92 & 0.62 & 0.98 & 0.68 & 1.84 & 0.72 & 2.02 & 0.72 \\
\hline Asian only & $1.94^{* * *}$ & 0.13 & 1.33 & 0.16 & $1.39^{*}$ & 0.16 & $1.39^{*}$ & 0.17 \\
\hline Black only & $3.06^{* * *}$ & 0.32 & $2.99^{* *}$ & 0.35 & $2.83^{* *}$ & 0.36 & $2.89^{* *}$ & 0.36 \\
\hline $\begin{array}{l}\text { Hispanic or } \\
\text { Latinx/Latino/L } \\
\text { atina only }\end{array}$ & 1.32 & 0.14 & 1.09 & 0.17 & 1.03 & 0.17 & 1.08 & 0.18 \\
\hline $\begin{array}{l}\text { More than one } \\
\text { race or } \\
\text { ethnicity }\end{array}$ & 1 & 0.14 & 0.95 & 0.16 & 0.91 & 0.17 & 0.9 & 0.17 \\
\hline $\begin{array}{l}\text { Native } \\
\text { Hawaiian or } \\
\text { Pacific Islander } \\
\text { only }\end{array}$ & 0.78 & 0.67 & 0.92 & 0.74 & 1.07 & 0.72 & 1.07 & 0.73 \\
\hline Other only & 0.65 & 0.49 & 0.67 & 0.56 & 0.83 & 0.58 & 0.82 & 0.58 \\
\hline \multicolumn{9}{|l|}{$\begin{array}{l}\text { Gender (referent: } \\
\text { Male) }\end{array}$} \\
\hline Female & 0.92 & 0.1 & 1.02 & 0.11 & 0.98 & 0.12 & 0.98 & 0.12 \\
\hline Non-Binary & 1.05 & 0.24 & 1.06 & 0.28 & 0.92 & 0.29 & 0.86 & 0.3 \\
\hline
\end{tabular}




\begin{tabular}{|c|c|c|c|c|c|c|c|c|}
\hline Other & 1.87 & 0.7 & 1.99 & 0.72 & 2.47 & 0.69 & 2.4 & 0.76 \\
\hline \multicolumn{9}{|l|}{$\begin{array}{l}\text { Other } \\
\text { Demographics }\end{array}$} \\
\hline $\begin{array}{l}\text { Has driver's } \\
\text { license }\end{array}$ & & & 0.81 & 0.14 & 0.86 & 0.15 & 0.85 & 0.15 \\
\hline Age & & & 1 & 0.01 & 0.99 & 0.01 & 0.99 & 0.01 \\
\hline $\begin{array}{l}\text { Is married or } \\
\text { living with } \\
\text { partner }\end{array}$ & & & 0.77 & 0.14 & $0.72^{*}$ & 0.15 & $0.74^{*}$ & 0.15 \\
\hline $\begin{array}{l}\text { Number of } \\
\text { children } \\
\text { responsible for } \\
\text { (ranges) }\end{array}$ & & & 0.91 & 0.12 & 0.91 & 0.13 & 0.89 & 0.13 \\
\hline $\begin{array}{l}\text { General state } \\
\text { of health }\end{array}$ & & & 1.01 & 0.06 & 0.99 & 0.06 & 1 & 0.06 \\
\hline $\begin{array}{l}\text { Has physical } \\
\text { limitations } \\
\text { that make } \\
\text { riding a bicycle } \\
\text { or an e-scooter } \\
\text { difficult }\end{array}$ & & & 1.03 & 0.17 & 1.08 & 0.18 & 1.04 & 0.19 \\
\hline \multicolumn{9}{|c|}{ Travel Behavior } \\
\hline \multicolumn{9}{|l|}{$\begin{array}{l}\text { Travel to PSU from } \\
\text { home }\end{array}$} \\
\hline $\begin{array}{l}\text { Number of } \\
\text { days per week } \\
\text { comes to PSU }\end{array}$ & & & $1.23^{* * *}$ & 0.04 & $1.22^{* * *}$ & 0.04 & $1.24^{* * * *}$ & 0.04 \\
\hline $\begin{array}{l}\text { Home distance } \\
\text { from campus }\end{array}$ & & & $1.05^{* * *}$ & 0.01 & $1.05^{* * *}$ & 0.01 & $1.05^{* * * *}$ & 0.01 \\
\hline \multicolumn{9}{|l|}{$\begin{array}{l}\text { Main mode of } \\
\text { transportation to } \\
\text { campus (referent: } \\
\text { Personal Car) }\end{array}$} \\
\hline $\begin{array}{l}\text { Active } \\
\text { Transportation }\end{array}$ & & & $5.70^{* * *}$ & 0.19 & $5.30^{* * *}$ & 0.21 & $5.21^{* * * *}$ & 0.22 \\
\hline Public Transit & & & $17.31^{* * * *}$ & 0.15 & $14.22^{* * *}$ & 0.16 & $14.46^{* * *}$ & 0.16 \\
\hline Other & & & $6.24^{* * *}$ & 0.36 & $5.98^{* * *}$ & 0.38 & $5.88^{* * *}$ & 0.38 \\
\hline \multicolumn{9}{|c|}{ Attitudinal Indicators } \\
\hline \multicolumn{9}{|l|}{$\begin{array}{l}\text { Latent Attitudes } \\
\text { Factor Score } \\
\text { Estimates }\end{array}$} \\
\hline $\begin{array}{l}\text { Car (EFA factor } \\
\text { score - } \\
\text { regression) }\end{array}$ & & & & & 0.93 & 0.07 & 0.93 & 0.07 \\
\hline $\begin{array}{l}\text { Bike (EFA } \\
\text { factor score - } \\
\text { regression) }\end{array}$ & & & & & $0.83^{* *}$ & 0.07 & $0.86^{*}$ & 0.07 \\
\hline $\begin{array}{l}\text { E-Scooter (EFA } \\
\text { factor score - } \\
\text { regression) }\end{array}$ & & & & & 1.06 & 0.06 & 1.05 & 0.06 \\
\hline $\begin{array}{l}\text { MAX (EFA } \\
\text { factor score - } \\
\text { regression) }\end{array}$ & & & & & $1.56^{* * *}$ & 0.07 & $1.57^{* * * *}$ & 0.07 \\
\hline
\end{tabular}




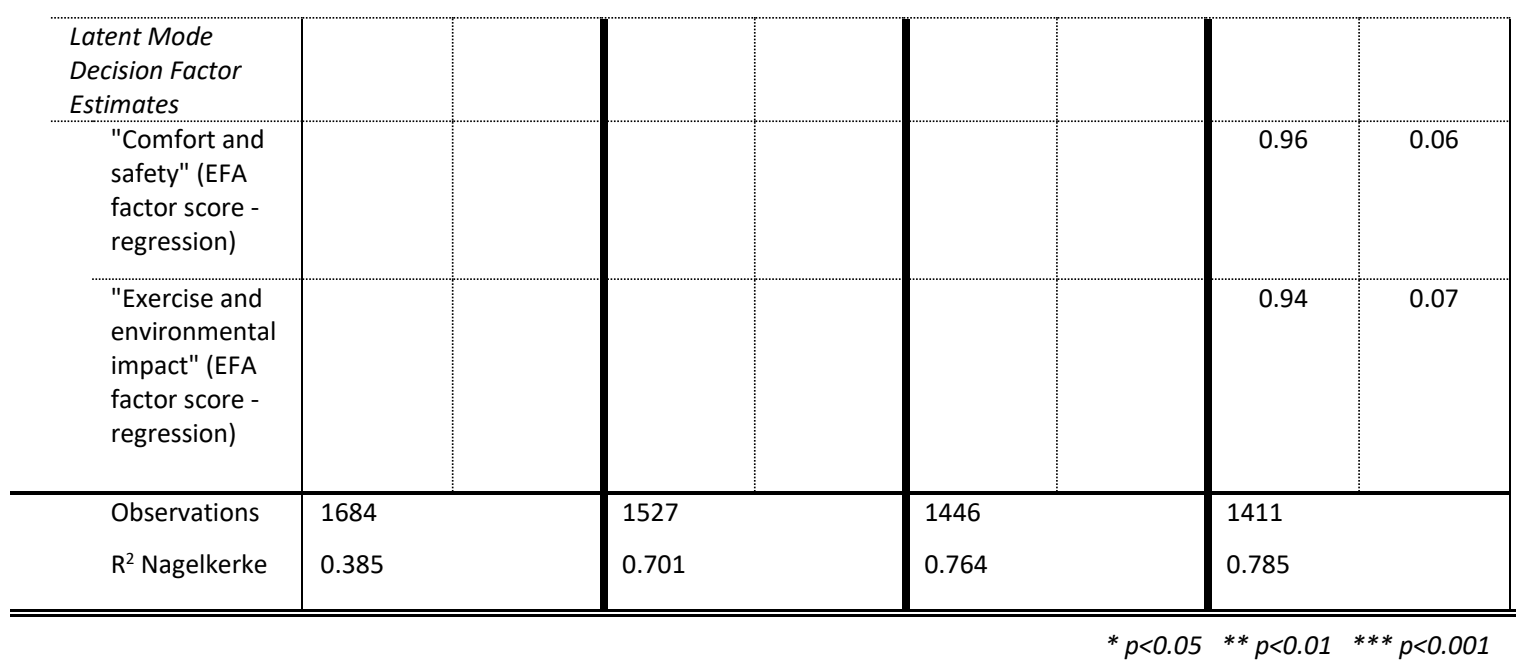




\section{E. Full MNL Models}

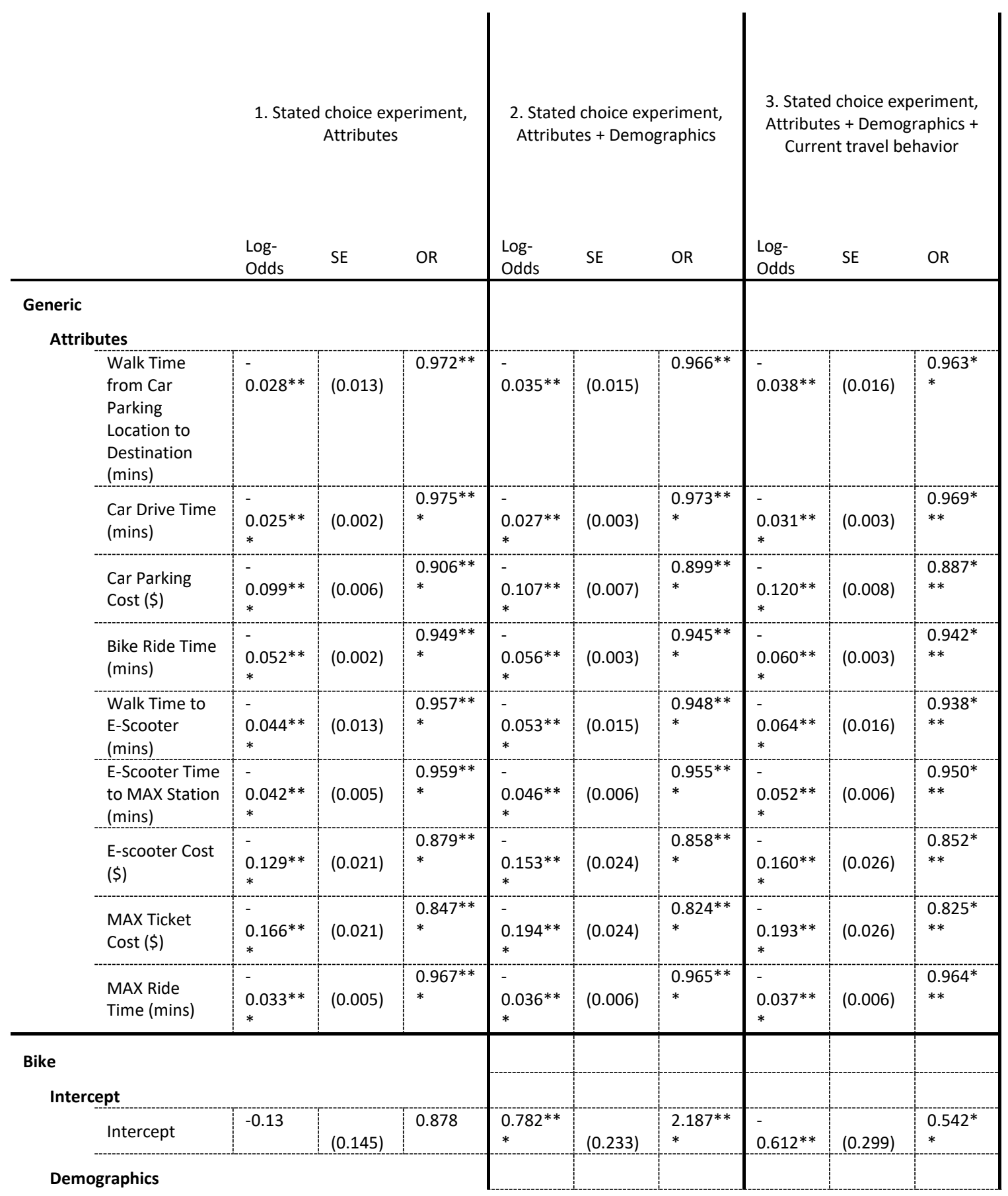




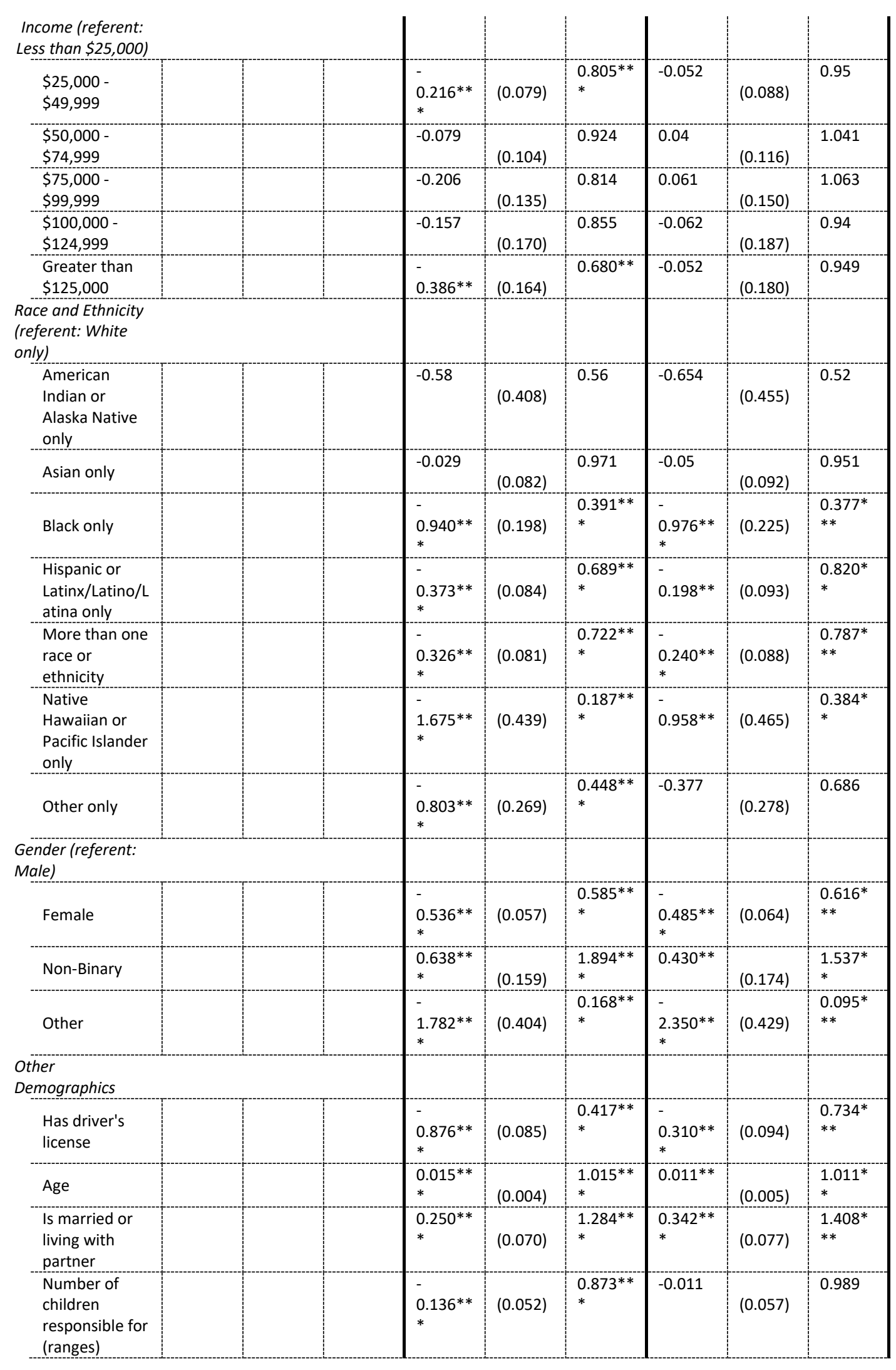




\begin{tabular}{|c|c|c|c|c|c|c|c|c|c|}
\hline $\begin{array}{l}\text { General state } \\
\text { of health }\end{array}$ & & & & 0.036 & $(0.028)$ & 1.036 & 0.005 & $(0.031)$ & 1.005 \\
\hline $\begin{array}{l}\text { Has physical } \\
\text { limitations } \\
\text { that make } \\
\text { riding a bicycle } \\
\text { or an e-scooter } \\
\text { difficult }\end{array}$ & & & & $0.865 * *$ & $(0.092)$ & $\begin{array}{l}0.421^{* *} \\
*\end{array}$ & $0.711^{* *}$ & (0.099) & $\begin{array}{l}0.491^{*} \\
* *\end{array}$ \\
\hline \multicolumn{10}{|l|}{ Travel Behavior } \\
\hline \multicolumn{10}{|l|}{$\begin{array}{l}\text { Main mode of } \\
\text { transportation to } \\
\text { campus (referent: } \\
\text { Personal Car) }\end{array}$} \\
\hline $\begin{array}{l}\text { Primary } \\
\text { Commute } \\
\text { Mode to PSU is } \\
\text { Active } \\
\text { Transportation }\end{array}$ & & & & & & & $\begin{array}{l}1.082^{* *} \\
*\end{array}$ & $(0.113)$ & $\begin{array}{l}2.951^{*} \\
* *\end{array}$ \\
\hline $\begin{array}{l}\text { Primary } \\
\text { Commute } \\
\text { Mode to PSU is } \\
\text { Public Transit }\end{array}$ & & & & & & & $\begin{array}{l}0.921^{* *} \\
*\end{array}$ & $(0.080)$ & $\begin{array}{l}2.512^{*} \\
* *\end{array}$ \\
\hline $\begin{array}{l}\text { Primary } \\
\text { Commute } \\
\text { Mode to PSU is } \\
\text { Other }\end{array}$ & & & & & & & $\begin{array}{l}1.468^{* *} \\
*\end{array}$ & $(0.207)$ & $\begin{array}{l}4.339 * \\
* *\end{array}$ \\
\hline \multicolumn{10}{|l|}{$\begin{array}{l}\text { Travel to PSU from } \\
\text { home }\end{array}$} \\
\hline $\begin{array}{l}\text { Number of } \\
\text { days per week } \\
\text { comes to PSU }\end{array}$ & & & & & & & $0.054^{* *}$ & $(0.021)$ & $\begin{array}{l}1.056^{*} \\
*\end{array}$ \\
\hline $\begin{array}{l}\text { Home distance } \\
\text { from campus }\end{array}$ & & & & & & & 0.006 & $(0.004)$ & 1.006 \\
\hline \multicolumn{10}{|l|}{$\begin{array}{l}\text { Mode specific } \\
\text { travel behavior }\end{array}$} \\
\hline $\begin{array}{l}\text { Number of } \\
\text { one-way car } \\
\text { trips in last } 7 \\
\text { days }\end{array}$ & & & & & & & $0.215^{* *}$ & $(0.031)$ & $\begin{array}{l}0.807^{*} \\
* *\end{array}$ \\
\hline $\begin{array}{l}\text { Number of } \\
\text { one-way bike } \\
\text { trips in last } 7 \\
\text { days }\end{array}$ & & & & & & & $\begin{array}{l}1.176^{* *} \\
*\end{array}$ & $(0.089)$ & $\begin{array}{l}3.242^{*} \\
* *\end{array}$ \\
\hline $\begin{array}{l}\text { Number of } \\
\text { one-way e- } \\
\text { scooter trips in } \\
\text { last } 7 \text { days }\end{array}$ & & & & & & & -0.155 & $(0.124)$ & 0.857 \\
\hline $\begin{array}{l}\text { Number of } \\
\text { one-way MAX } \\
\text { trips in last } 7 \\
\text { days }\end{array}$ & & & & & & & 0.043 & $(0.036)$ & 1.044 \\
\hline \multicolumn{10}{|l|}{ E-Scooter + MAX } \\
\hline \multicolumn{10}{|l|}{ Intercept } \\
\hline Intercept & -0.053 & $(0.214)$ & 0.948 & $\begin{array}{l}1.553^{* *} \\
*\end{array}$ & $(0.299)$ & $\begin{array}{l}4.727^{* *} \\
*\end{array}$ & -0.422 & $(0.363)$ & 0.656 \\
\hline \multicolumn{10}{|l|}{ Demographics } \\
\hline $\begin{array}{l}\text { Income (referent: } \\
\text { Less than } \$ 25,000 \text { ) }\end{array}$ & & & & & & & & & \\
\hline
\end{tabular}




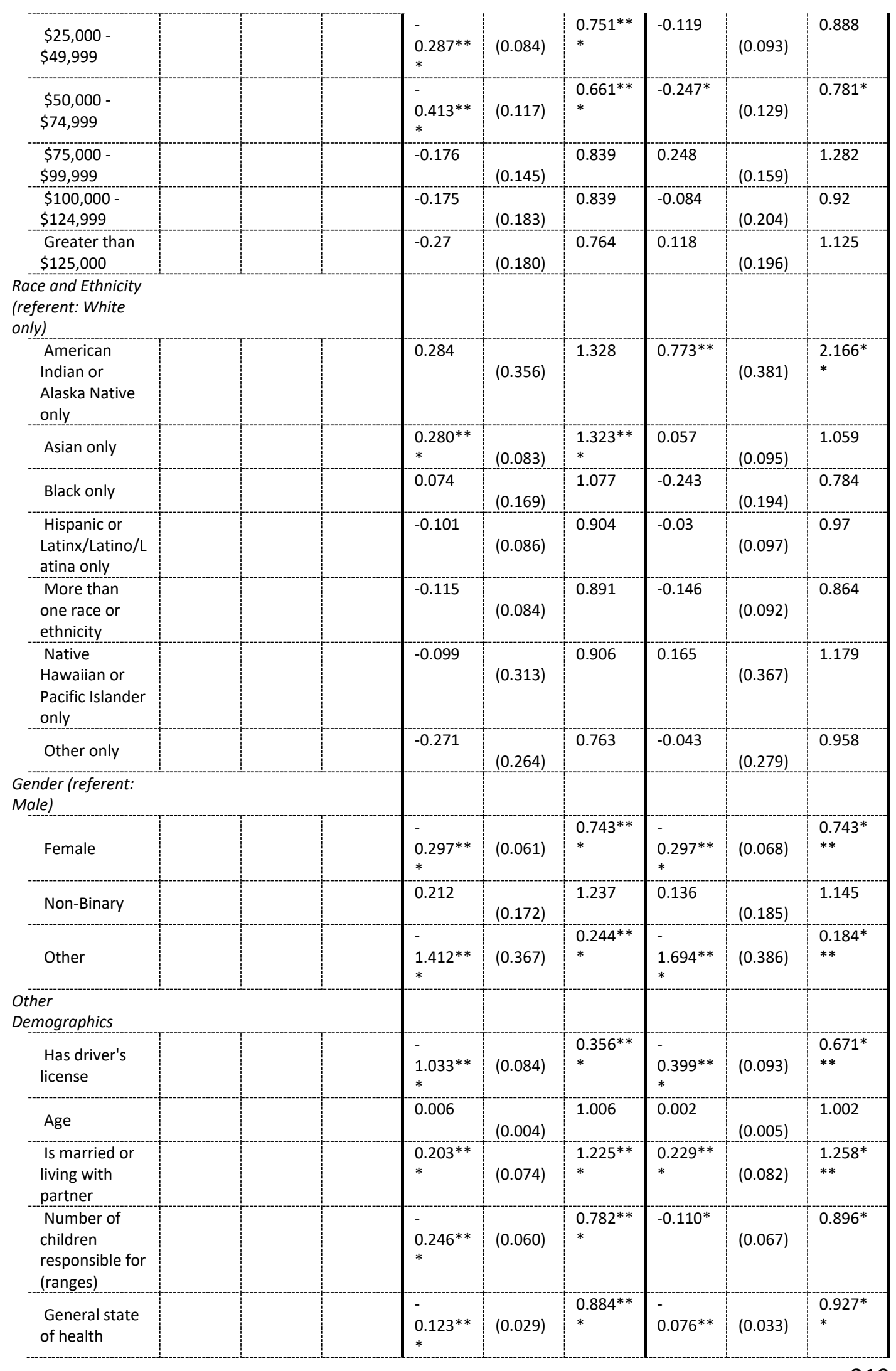




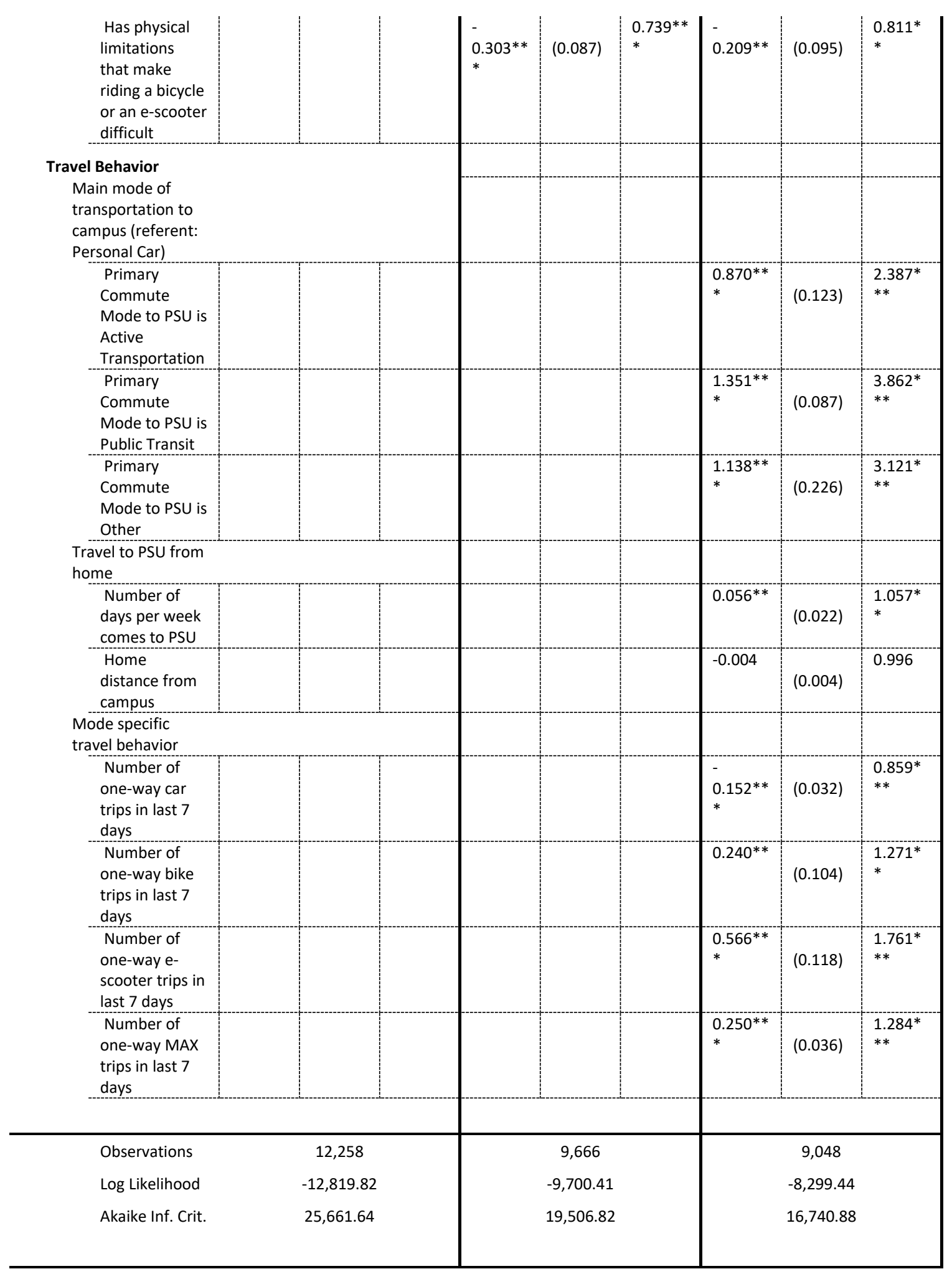

Note: ${ }^{*} p<0.1 ;{ }^{* *} p<0.05 ;{ }^{* * *} p<0.01$ 


\begin{tabular}{|c|c|c|c|c|c|c|}
\hline & \multicolumn{3}{|c|}{$\begin{array}{l}\text { 4. Stated choice experiment, Attributes } \\
\text { + Demographics + Current travel } \\
\text { behavior + Mode Attitudes }\end{array}$} & \multicolumn{3}{|c|}{$\begin{array}{c}\text { 5. Stated choice experiment, Attributes } \\
+ \text { Demographics + Current travel } \\
\text { behavior + Mode Attitudes + Decision } \\
\text { factors }\end{array}$} \\
\hline & Log-Odds & SE & OR & Log-Odds & SE & OR \\
\hline \multicolumn{7}{|l|}{ Generic } \\
\hline \multicolumn{7}{|l|}{ Attributes } \\
\hline $\begin{array}{l}\text { Walk Time from Car Parking } \\
\text { Location to Destination (mins) }\end{array}$ & $-0.034^{*}$ & $(0.018)$ & $0.967^{*}$ & $-0.035^{* *}$ & $(0.018)$ & $0.965 * *$ \\
\hline Car Drive Time (mins) & $-0.037 * * *$ & $(0.003)$ & $0.964^{* * *}$ & $-0.037^{* * *}$ & $(0.003)$ & $0.964^{* * *}$ \\
\hline Car Parking Cost (\$) & $-0.139 * * *$ & $(0.009)$ & $0.871^{* * *}$ & $-0.138^{* * *}$ & $(0.009)$ & $0.871^{* * *}$ \\
\hline Bike Ride Time (mins) & $-0.067 * * *$ & $(0.003)$ & $0.935 * * *$ & $-0.068 * * *$ & $(0.003)$ & $0.934^{* * *}$ \\
\hline Walk Time to E-Scooter (mins) & $-0.069 * * *$ & $(0.017)$ & $0.933^{* * *}$ & $-0.070^{* * *}$ & $(0.017)$ & $0.932 * * *$ \\
\hline $\begin{array}{l}\text { E-Scooter Time to MAX Station } \\
\text { (mins) }\end{array}$ & $-0.056^{* * *}$ & $(0.007)$ & $0.945^{* * *}$ & $-0.055^{* * *}$ & $(0.007)$ & $0.946^{* * *}$ \\
\hline E-scooter Cost (\$) & $-0.172^{* * *}$ & $(0.027)$ & $0.842 * * *$ & $-0.168 * * *$ & $(0.028)$ & $0.846 * * *$ \\
\hline MAX Ticket Cost (\$) & $-0.184^{* * *}$ & $(0.027)$ & $0.832 * * *$ & $-0.181^{* * *}$ & $(0.027)$ & $0.835^{* * *}$ \\
\hline MAX Ride Time (mins) & $-0.040 * * *$ & $(0.007)$ & $0.961^{* * *}$ & $-0.040 * * *$ & $(0.007)$ & $0.961^{* * *}$ \\
\hline \multicolumn{7}{|l|}{ Bike } \\
\hline \multicolumn{7}{|l|}{ Intercept } \\
\hline Intercept & -0.334 & $(0.330)$ & 0.716 & -0.519 & $(0.340)$ & 0.595 \\
\hline \multicolumn{7}{|l|}{ Demographics } \\
\hline \multicolumn{7}{|l|}{$\begin{array}{l}\text { Income (referent: Less than } \\
\$ 25,000)\end{array}$} \\
\hline$\$ 25,000-\$ 49,999$ & -0.096 & $(0.097)$ & 0.909 & -0.091 & $(0.098)$ & 0.913 \\
\hline$\$ 50,000-\$ 74,999$ & -0.11 & $(0.127)$ & 0.895 & -0.157 & $(0.130)$ & 0.855 \\
\hline$\$ 75,000-\$ 99,999$ & 0.071 & $(0.168)$ & 1.074 & 0.038 & $(0.171)$ & 1.039 \\
\hline$\$ 100,000-\$ 124,999$ & -0.251 & $(0.215)$ & 0.778 & $-0.375^{*}$ & $(0.221)$ & $0.687^{*}$ \\
\hline Greater than $\$ 125,000$ & -0.033 & $(0.201)$ & 0.967 & -0.012 & $(0.204)$ & 0.988 \\
\hline \multicolumn{7}{|l|}{$\begin{array}{l}\text { Race and Ethnicity (referent: White } \\
\text { only) }\end{array}$} \\
\hline $\begin{array}{l}\text { American Indian or Alaska } \\
\text { Native only }\end{array}$ & -0.53 & $(0.530)$ & 0.589 & -0.615 & $(0.532)$ & 0.541 \\
\hline Asian only & 0.152 & $(0.101)$ & 1.164 & $0.192^{*}$ & $(0.104)$ & $1.212^{*}$ \\
\hline Black only & $-1.084^{* * *}$ & $(0.239)$ & $0.338^{* * *}$ & $-1.008^{* * *}$ & $(0.240)$ & $0.365^{* * *}$ \\
\hline $\begin{array}{l}\text { Hispanic or } \\
\text { Latinx/Latino/Latina only }\end{array}$ & $-0.254 * *$ & $(0.102)$ & $0.776^{* *}$ & $-0.217^{* *}$ & $(0.105)$ & $0.805^{* *}$ \\
\hline $\begin{array}{l}\text { More than one race or } \\
\text { ethnicity }\end{array}$ & -0.05 & $(0.098)$ & 0.952 & -0.009 & $(0.098)$ & 0.991 \\
\hline $\begin{array}{l}\text { Native Hawaiian or Pacific } \\
\text { Islander only }\end{array}$ & $-1.609 * * *$ & $(0.475)$ & $0.200^{* * *}$ & $-1.664 * * *$ & $(0.477)$ & $0.189 * * *$ \\
\hline
\end{tabular}




\begin{tabular}{|c|c|c|c|c|c|c|}
\hline Other only & $-0.603 *$ & $(0.323)$ & $0.547^{*}$ & $-0.551^{*}$ & $(0.326)$ & $0.576^{*}$ \\
\hline \multicolumn{7}{|l|}{ Gender (referent: Male) } \\
\hline Female & $-0.438^{* * *}$ & $(0.072)$ & $0.646^{* * *}$ & $-0.413^{* * *}$ & $(0.073)$ & $0.662^{* * *}$ \\
\hline Non-Binary & -0.193 & $(0.191)$ & 0.825 & -0.212 & $(0.194)$ & 0.809 \\
\hline Other & $-2.984^{* * *}$ & $(0.486)$ & $0.051^{* * *}$ & $-3.482^{* * *}$ & $(0.654)$ & $0.031^{* * *}$ \\
\hline \multicolumn{7}{|l|}{ Other Demographics } \\
\hline Has driver's license & -0.133 & $(0.105)$ & 0.875 & -0.11 & $(0.107)$ & 0.896 \\
\hline Age & -0.001 & $(0.005)$ & 0.999 & 0.003 & $(0.006)$ & 1.003 \\
\hline $\begin{array}{l}\text { Is married or living with } \\
\text { partner }\end{array}$ & $0.195^{* *}$ & $(0.085)$ & $1.215^{* *}$ & $0.213^{* *}$ & $(0.087)$ & $1.238^{* *}$ \\
\hline $\begin{array}{l}\text { Number of children } \\
\text { responsible for (ranges) }\end{array}$ & 0.076 & $(0.065)$ & 1.079 & 0.066 & $(0.066)$ & 1.069 \\
\hline General state of health & -0.045 & $(0.035)$ & 0.956 & -0.054 & $(0.035)$ & 0.948 \\
\hline $\begin{array}{l}\text { Has physical limitations that } \\
\text { make riding a bicycle or an e- } \\
\text { scooter difficult }\end{array}$ & $-0.606^{* * *}$ & $(0.109)$ & $0.546^{* * *}$ & $-0.604^{* * *}$ & $(0.112)$ & $0.546^{* * *}$ \\
\hline \multicolumn{7}{|l|}{ Travel Behavior } \\
\hline \multicolumn{7}{|l|}{$\begin{array}{l}\text { Main mode of transportation to } \\
\text { campus (referent: Personal Car) }\end{array}$} \\
\hline $\begin{array}{l}\text { Primary Commute Mode to } \\
\text { PSU is Active Transportation }\end{array}$ & $0.722^{* * *}$ & $(0.125)$ & $2.059 * * *$ & $0.664^{* * *}$ & $(0.129)$ & $1.943^{* * *}$ \\
\hline $\begin{array}{l}\text { Primary Commute Mode to } \\
\text { PSU is Public Transit }\end{array}$ & $0.599 * * *$ & $(0.091)$ & $1.820^{* * *}$ & $0.665^{* * *}$ & $(0.093)$ & $1.945^{* * *}$ \\
\hline $\begin{array}{l}\text { Primary Commute Mode to } \\
\text { PSU is Other }\end{array}$ & $1.264^{* * *}$ & $(0.244)$ & $3.539 * * *$ & $1.255^{* * *}$ & $(0.247)$ & $3.509 * * *$ \\
\hline \multicolumn{7}{|l|}{ Travel to PSU from home } \\
\hline $\begin{array}{l}\text { Number of days per week } \\
\text { comes to PSU }\end{array}$ & $0.089 * * *$ & $(0.024)$ & $1.093^{* * *}$ & $0.102^{* * *}$ & $(0.024)$ & $1.108^{* * *}$ \\
\hline Home distance from campus & $0.011^{* *}$ & $(0.004)$ & $1.011^{* *}$ & $0.014^{* * *}$ & $(0.005)$ & $1.014^{* * *}$ \\
\hline \multicolumn{7}{|l|}{ Mode specific travel behavior } \\
\hline $\begin{array}{l}\text { Number of one-way car trips in } \\
\text { last } 7 \text { days }\end{array}$ & $-0.132 * * *$ & $(0.034)$ & $0.877^{* * *}$ & $-0.124 * * *$ & $(0.035)$ & $0.883^{* * *}$ \\
\hline $\begin{array}{l}\text { Number of one-way bike trips } \\
\text { in last } 7 \text { days }\end{array}$ & $0.583^{* * *}$ & $(0.096)$ & $1.792^{* * *}$ & $0.558^{* * *}$ & $(0.098)$ & $1.747^{* * *}$ \\
\hline $\begin{array}{l}\text { Number of one-way e-scooter } \\
\text { trips in last } 7 \text { days }\end{array}$ & 0.086 & $(0.132)$ & 1.09 & -0.05 & $(0.139)$ & 0.951 \\
\hline $\begin{array}{l}\text { Number of one-way MAX trips } \\
\text { in last } 7 \text { days }\end{array}$ & -0.023 & $(0.040)$ & 0.978 & -0.047 & $(0.041)$ & 0.954 \\
\hline \multicolumn{7}{|l|}{ Attitudinal Indicators } \\
\hline \multicolumn{7}{|l|}{$\begin{array}{l}\text { Latent Attitudes Index Score } \\
\text { Estimates }\end{array}$} \\
\hline $\begin{array}{l}\text { Car (EFA factor score - } \\
\text { regression) }\end{array}$ & $-0.546 * * *$ & $(0.043)$ & $0.579^{* * *}$ & $-0.514^{* * *}$ & $(0.044)$ & $0.598^{* * *}$ \\
\hline $\begin{array}{l}\text { Bike (EFA factor score - } \\
\text { regression) }\end{array}$ & $1.087^{* * *}$ & $(0.046)$ & $2.965^{* * *}$ & $1.097^{* * *}$ & $(0.048)$ & $2.995^{* * *}$ \\
\hline $\begin{array}{l}\text { E-scooter (EFA factor score - } \\
\text { regression) }\end{array}$ & $-0.095 * *$ & $(0.039)$ & $0.910^{* *}$ & $-0.114^{* * *}$ & $(0.040)$ & $0.892^{* * *}$ \\
\hline $\begin{array}{l}\text { MAX (EFA factor score - } \\
\text { regression) }\end{array}$ & $0.150^{* * *}$ & $(0.041)$ & $1.161^{* * *}$ & $0.134^{* * *}$ & $(0.042)$ & $1.143^{* * *}$ \\
\hline $\begin{array}{l}\text { Latent Mode Decision Factor } \\
\text { Estimates }\end{array}$ & & & & & & \\
\hline
\end{tabular}




\begin{tabular}{|c|c|c|c|c|c|c|}
\hline $\begin{array}{l}\text { "Comfort and safety" (EFA } \\
\text { factor score - regression) }\end{array}$ & & & & $-0.164 * * *$ & $(0.039)$ & $0.849 * * *$ \\
\hline $\begin{array}{l}\text { "Exercise and environmental } \\
\text { impact" (EFA factor score - } \\
\text { regression) }\end{array}$ & & & & $0.102^{* * *}$ & $(0.039)$ & $1.107^{* * *}$ \\
\hline \multicolumn{7}{|l|}{ E-Scooter + MAX } \\
\hline \multicolumn{7}{|l|}{ Intercept } \\
\hline Intercept & 0.023 & $(0.388)$ & 1.024 & -0.044 & $(0.397)$ & 0.957 \\
\hline \multicolumn{7}{|l|}{ Demographics } \\
\hline \multicolumn{7}{|l|}{$\begin{array}{l}\text { Income (referent: Less than } \\
\$ 25,000)\end{array}$} \\
\hline$\$ 25,000-\$ 49,999$ & -0.138 & $(0.100)$ & 0.871 & -0.161 & $(0.101)$ & 0.851 \\
\hline$\$ 50,000-\$ 74,999$ & $-0.310^{* *}$ & $(0.137)$ & $0.733^{* *}$ & $-0.412 * * *$ & $(0.140)$ & $0.663^{* * *}$ \\
\hline$\$ 75,000-\$ 99,999$ & 0.238 & $(0.170)$ & 1.269 & 0.208 & $(0.172)$ & 1.231 \\
\hline$\$ 100,000-\$ 124,999$ & -0.08 & $(0.222)$ & 0.923 & -0.06 & $(0.224)$ & 0.942 \\
\hline Greater than $\$ 125,000$ & 0.157 & $(0.211)$ & 1.169 & 0.226 & $(0.214)$ & 1.254 \\
\hline \multicolumn{7}{|l|}{$\begin{array}{l}\text { Race and Ethnicity (referent: White } \\
\text { only) }\end{array}$} \\
\hline $\begin{array}{l}\text { American Indian or Alaska } \\
\text { Native only }\end{array}$ & $1.366^{* * *}$ & $(0.438)$ & $3.920^{* * *}$ & $1.378^{* * *}$ & $(0.440)$ & $3.967^{* * *}$ \\
\hline Asian only & 0.11 & $(0.100)$ & 1.116 & 0.153 & $(0.103)$ & 1.165 \\
\hline Black only & $-0.622^{* * *}$ & $(0.210)$ & $0.537^{* * *}$ & $-0.603^{* * *}$ & $(0.211)$ & $0.547^{* * *}$ \\
\hline $\begin{array}{l}\text { Hispanic or } \\
\text { Latinx/Latino/Latina only }\end{array}$ & -0.157 & $(0.103)$ & 0.855 & -0.146 & $(0.106)$ & 0.864 \\
\hline $\begin{array}{l}\text { More than one race or } \\
\text { ethnicity }\end{array}$ & -0.078 & $(0.100)$ & 0.925 & -0.06 & $(0.100)$ & 0.941 \\
\hline $\begin{array}{l}\text { Native Hawaiian or Pacific } \\
\text { Islander only }\end{array}$ & -0.14 & $(0.372)$ & 0.869 & -0.118 & $(0.375)$ & 0.889 \\
\hline Other only & -0.087 & $(0.298)$ & 0.917 & -0.072 & $(0.300)$ & 0.931 \\
\hline \multicolumn{7}{|l|}{ Gender (referent: Male) } \\
\hline Female & $-0.329^{* * *}$ & $(0.073)$ & $0.719^{* * *}$ & $-0.311^{* * *}$ & $(0.075)$ & $0.733^{* * *}$ \\
\hline Non-Binary & $-0.334^{*}$ & $(0.201)$ & $0.716^{*}$ & -0.306 & $(0.202)$ & 0.736 \\
\hline Other & $-1.813^{* * *}$ & $(0.426)$ & $0.163^{* * *}$ & $-1.830^{* * *}$ & $(0.434)$ & $0.160^{* * *}$ \\
\hline \multicolumn{7}{|l|}{ Other Demographics } \\
\hline Has driver's license & $-0.208^{* *}$ & $(0.102)$ & $0.812^{* *}$ & $-0.212^{* *}$ & $(0.103)$ & $0.809^{* *}$ \\
\hline Age & -0.008 & $(0.005)$ & 0.992 & -0.006 & $(0.006)$ & 0.994 \\
\hline $\begin{array}{l}\text { Is married or living with } \\
\text { partner }\end{array}$ & 0.082 & $(0.088)$ & 1.085 & 0.112 & $(0.090)$ & 1.119 \\
\hline $\begin{array}{l}\text { Number of children } \\
\text { responsible for (ranges) }\end{array}$ & -0.064 & $(0.072)$ & 0.938 & -0.085 & $(0.073)$ & 0.918 \\
\hline General state of health & $-0.135^{* * *}$ & $(0.036)$ & $0.874^{* * *}$ & $-0.134^{* * *}$ & $(0.036)$ & $0.874^{* * *}$ \\
\hline $\begin{array}{l}\text { Has physical limitations that } \\
\text { make riding a bicycle or an e- } \\
\text { scooter difficult }\end{array}$ & -0.165 & $(0.102)$ & 0.848 & -0.132 & $(0.104)$ & 0.876 \\
\hline \multicolumn{7}{|l|}{ Travel Behavior } \\
\hline $\begin{array}{l}\text { Main mode of transportation to } \\
\text { campus (referent: Personal Car) }\end{array}$ & & & & & & \\
\hline
\end{tabular}




\begin{tabular}{|c|c|c|c|c|c|c|}
\hline $\begin{array}{l}\text { Primary Commute Mode to } \\
\text { PSU is Active Transportation }\end{array}$ & $0.521 * * *$ & $(0.132)$ & $1.683^{* * *}$ & $0.483^{* * *}$ & $(0.136)$ & $1.621^{* * *}$ \\
\hline $\begin{array}{l}\text { Primary Commute Mode to } \\
\text { PSU is Public Transit }\end{array}$ & $1.025^{* * *}$ & $(0.095)$ & $2.787^{* * *}$ & $1.007^{* * *}$ & $(0.096)$ & $2.737^{* * *}$ \\
\hline $\begin{array}{l}\text { Primary Commute Mode to } \\
\text { PSU is Other }\end{array}$ & $1.172^{* * *}$ & $(0.256)$ & $3.228 * * *$ & $1.190 * * *$ & $(0.258)$ & $3.286 * * *$ \\
\hline \multicolumn{7}{|l|}{ Travel to PSU from home } \\
\hline $\begin{array}{l}\text { Number of days per week } \\
\text { comes to PSU }\end{array}$ & $0.071^{* * *}$ & $(0.024)$ & $1.073^{* * *}$ & $0.062^{* *}$ & $(0.024)$ & $1.064^{* *}$ \\
\hline Home distance from campus & -0.002 & $(0.005)$ & 0.998 & -0.002 & $(0.005)$ & 0.998 \\
\hline \multicolumn{7}{|l|}{ Mode specific travel behavior } \\
\hline $\begin{array}{l}\text { Number of one-way car trips } \\
\text { in last } 7 \text { days }\end{array}$ & $-0.105^{* * *}$ & $(0.035)$ & $0.901^{* * *}$ & $-0.114 * * *$ & $(0.035)$ & $0.892 * * *$ \\
\hline $\begin{array}{l}\text { Number of one-way bike trips } \\
\text { in last } 7 \text { days }\end{array}$ & 0.068 & $(0.109)$ & 1.071 & 0.071 & $(0.111)$ & 1.074 \\
\hline $\begin{array}{l}\text { Number of one-way e-scooter } \\
\text { trips in last } 7 \text { days }\end{array}$ & $0.453^{* * *}$ & $(0.126)$ & $1.573^{* * *}$ & $0.431^{* * *}$ & $(0.131)$ & $1.539 * * *$ \\
\hline $\begin{array}{l}\text { Number of one-way MAX trips } \\
\text { in last } 7 \text { days }\end{array}$ & $0.117^{* * *}$ & $(0.039)$ & $1.124^{* * *}$ & $0.121^{* * *}$ & $(0.040)$ & $1.128^{* * *}$ \\
\hline \multicolumn{7}{|l|}{ Attitudinal Indicators } \\
\hline \multicolumn{7}{|l|}{$\begin{array}{l}\text { Latent Attitudes Index Score } \\
\text { Estimates }\end{array}$} \\
\hline $\begin{array}{l}\text { Car (EFA factor score - } \\
\text { regression) }\end{array}$ & $-0.525^{* * *}$ & $(0.044)$ & $0.591^{* * *}$ & $-0.517^{* * *}$ & $(0.045)$ & $0.596 * * *$ \\
\hline $\begin{array}{l}\text { Bike (EFA factor score - } \\
\text { regression) }\end{array}$ & $0.181^{* * *}$ & $(0.045)$ & $1.199 * * *$ & $0.167^{* * *}$ & $(0.046)$ & $1.182^{* * *}$ \\
\hline $\begin{array}{l}\text { E-scooter (EFA factor score - } \\
\text { regression) }\end{array}$ & $0.306^{* * *}$ & $(0.041)$ & $1.358^{* * *}$ & $0.303^{* * *}$ & $(0.042)$ & $1.354^{* * *}$ \\
\hline $\begin{array}{l}\text { MAX (EFA factor score - } \\
\text { regression) }\end{array}$ & $0.503^{* * *}$ & $(0.042)$ & $1.654^{* * *}$ & $0.521^{* * *}$ & $(0.043)$ & $1.683^{* * *}$ \\
\hline \multicolumn{7}{|l|}{$\begin{array}{l}\text { Latent Mode Decision Factor } \\
\text { Estimates }\end{array}$} \\
\hline $\begin{array}{l}\text { "Comfort and safety" (EFA } \\
\text { factor score - regression) }\end{array}$ & & & & -0.025 & $(0.040)$ & 0.976 \\
\hline $\begin{array}{l}\text { "Exercise and environmental } \\
\text { impact" (EFA factor score - } \\
\text { regression) }\end{array}$ & & & & -0.012 & $(0.041)$ & 0.988 \\
\hline Observations & & 8,592 & & & 8,382 & \\
\hline Log Likelihood & & $-7,186.68$ & & & $-6,984.92$ & \\
\hline Akaike Inf. Crit. & & $14,531.36$ & & & $14,135.83$ & \\
\hline $\begin{array}{l}\text { Note: }{ }^{*} p<0.1 \\
{ }^{* *} p<0.05 \\
* * * p<0.01\end{array}$ & & & & & & \\
\hline
\end{tabular}


F. Survey Instrument

(This page was intentionally left blank) 
Introduction

\section{PS Portland State}

Welcome!

Thank you for participating in this brief transportation survey. It should take 10-15 minutes to complete.

Upon completion, you can enter a raffle to win one of three $\$ 50$ Amazon gift cards!

\section{amazon $s 5$

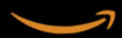

We are interested in understanding what motivates you to choose your means of transportation.

This survey consists of four parts:

- Part I: Questions about your current travel choice to PSU

- Part 2: Questions about your usage and opinions of various transportation options

- Part 3: A game with six hypothetical scenarios

- Part 4: Questions about your demographics

The findings from this survey will be used by a Masters student at the Maseeh College of Engineering and Computer Science towards the completion of a Masters thesis.

To participate in this study, we require that you read and accept the terms of informed consent. Your responses will remain completely anonymous.

Click here to view the terms

By clicking "Accept," you affirm that you are over the age of 18 and agree to the terms.
Aceept
Decline 
How are you affiliated with Portland State University? (Select all that apply)

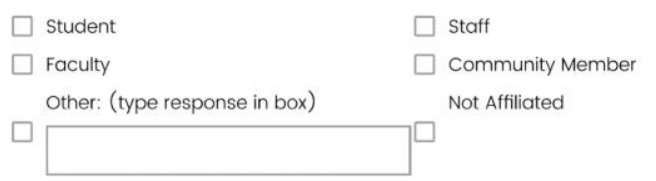

Section 1: Current Commute

Section 1: Current Transportation Options to PSU

The following questions are about your current travel to PSU.

How many days per week do you normally come to PSU?

What is your primary means of transportation to PSU? Please select the mode you take most frequently or for the longest part of your journey.
Walk/Wheelchair
Bike (bike that I own)
Bike Share (BIKETOWN)
E-Bike (that I own)
Bus
MAX (Light Rail)
Portland Streetcar

\begin{tabular}{l} 
Shared E-Scooter (Lime, Bolt, Skip, Bird) \\
Private E-Scooter (e-scooter I own) \\
Drive alone \\
Carpool (two or more persons) \\
Dropped off (Uber/Lytt/Taxi) \\
Motorcycle/Moped \\
Other: (type response in box) \\
\hline
\end{tabular} 
How far do you live from campus (approximately)?

Drag to slider to
Ilive on campus
$\begin{gathered}\text { indicate how far in } \\ \text { miles you live from } \\ \text { campus }\end{gathered}$
$\begin{aligned} & \text { Miles from } \\ & \text { campus }\end{aligned}$

\begin{tabular}{|c|c|c|c|c|c|}
\hline & $\begin{array}{l}\text { Not at all } \\
\text { important }\end{array}$ & $\begin{array}{l}\text { Slightly } \\
\text { important }\end{array}$ & $\begin{array}{l}\text { Moderately } \\
\text { important }\end{array}$ & $\begin{array}{l}\text { Very } \\
\text { important }\end{array}$ & $\begin{array}{l}\text { Extremely } \\
\text { important }\end{array}$ \\
\hline $\begin{array}{l}\text { Obtaining exercise or } \\
\text { physical activity }\end{array}$ & O & $\mathrm{O}$ & O & $\mathrm{O}$ & $\mathrm{O}$ \\
\hline My physical ability & $\mathrm{O}$ & O & $\mathrm{O}$ & $\mathrm{O}$ & $\mathrm{O}$ \\
\hline $\begin{array}{l}\text { Opportunity to shower } \\
\text { at destination }\end{array}$ & O & 0 & $\mathrm{O}$ & 0 & O \\
\hline $\begin{array}{l}\text { Arriving on time to } \\
\text { destination }\end{array}$ & $\mathrm{O}$ & O & $\mathrm{O}$ & 0 & 0 \\
\hline $\begin{array}{r}\text { Frequency of transit } \\
\text { departures }\end{array}$ & 0 & 0 & 0 & 0 & $\mathrm{O}$ \\
\hline $\begin{array}{l}\text { Flexible time of } \\
\text { departure }\end{array}$ & $\mathrm{O}$ & O & $\mathrm{O}$ & $\mathrm{O}$ & $\mathrm{O}$ \\
\hline Travel cost/price & O & 0 & $\mathrm{O}$ & $\mathrm{O}$ & $\mathrm{O}$ \\
\hline Travel time & $\mathrm{O}$ & O & $\mathrm{O}$ & $\mathrm{O}$ & $\mathrm{O}$ \\
\hline Flexible travel route & $\mathrm{O}$ & $\mathrm{O}$ & $\mathrm{O}$ & $\mathrm{O}$ & $\mathrm{O}$ \\
\hline $\begin{array}{l}\text { Personal safety and } \\
\text { security }\end{array}$ & $\mathrm{O}$ & $\mathrm{O}$ & $\mathrm{O}$ & 0 & 0 \\
\hline Traffic safety & $\mathrm{O}$ & $\mathrm{O}$ & $\mathrm{O}$ & $\mathrm{O}$ & $\mathrm{O}$ \\
\hline $\begin{array}{r}\text { The current weather } \\
\text { conditions }\end{array}$ & $\mathrm{O}$ & $\mathrm{O}$ & 0 & $\mathrm{O}$ & D \\
\hline
\end{tabular}


Section 2: Transportation Mode Opinions

Section 2: Transportation Mode Opinions

In this section, we will ask you some questions about your experience with different transportation modes.

Each mode will first be introduced, followed by some questions.

Personal Car

This refers to a typical passenger car or truck.
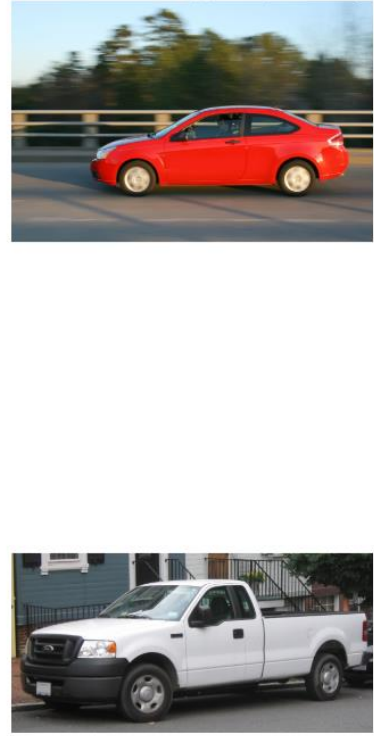

Do you have a driver's license?

Yes

No

Do you have access to a personal car (car, truck, etc.) that you can use for your trip to PSU (either as a driver or a passenger)?

Yes

No

Think about your experience with personal cars. How many one- 
way trips did you take using a personal car (as a driver or passenger) in the last 7 days?

(ex: If I drove from home to the library, checked out a book, and then I drove back, I would have taken 2 trips.)

What prevents you from driving more often? (select all that apply)

$\begin{array}{ll}\square \text { I can't afford car maintenance costs } & \square \text { I do not drive due to my physical } \\ \text { abilities } \\ \square \text { I can't afford gasoline for a car } & \square \text { I can't afford to own or lease a car } \\ \square \text { I can't afford to park downtown during } & \square \text { I don't have a place to park a car at } \\ \text { the week } & \text { home } \\ \begin{array}{l}\text { I am satisfied with my current amount } \\ \text { of driving }\end{array} \\ \text { I don't currently own or lease a car } \\ \begin{array}{l}\text { I don't have a place to park a car at } \\ \text { work }\end{array}\end{array}$

Please indicate to what extent you agree or disagree with the following statements:

\begin{tabular}{|c|c|c|c|c|c|}
\hline & $\begin{array}{l}\text { Strongly } \\
\text { Disagree }\end{array}$ & Disagree & Neutral & Agree & $\begin{array}{c}\text { Strongly } \\
\text { Agree }\end{array}$ \\
\hline $\begin{array}{r}\text { I feel comfortable riding } \\
\text { in a car (Temperature, } \\
\text { seat, space, etc.) }\end{array}$ & $\bigcirc$ & $\bigcirc$ & $\bigcirc$ & $\mathrm{O}$ & $\mathrm{O}$ \\
\hline Driving is cool & $\mathrm{O}$ & $\bigcirc$ & $\mathrm{O}$ & $\bigcirc$ & $\mathrm{O}$ \\
\hline $\begin{array}{r}\text { I think that cars are } \\
\text { harmful to the } \\
\text { environment }\end{array}$ & $\mathrm{O}$ & 0 & $\bigcirc$ & 0 & $\mathrm{O}$ \\
\hline $\begin{array}{l}\text { I don't mind searching } \\
\text { for a parking spot }\end{array}$ & $\mathrm{O}$ & $\mathrm{O}$ & $\mathrm{O}$ & 0 & 0 \\
\hline Cars are convenient & 0 & 0 & 0 & 0 & $\mathrm{O}$ \\
\hline I feel safe in a car & 0 & 0 & 0 & 0 & O \\
\hline $\begin{array}{r}\text { Even if I get delayed by } \\
\text { traffic, l'd still prefer to } \\
\text { take a car }\end{array}$ & 0 & $\mathrm{O}$ & O & $\mathrm{O}$ & 0 \\
\hline I enjoy driving & 0 & $\bigcirc$ & 0 & 0 & 0 \\
\hline
\end{tabular}

Bike

This is a personally-owned, pedal-powered bicycle. 


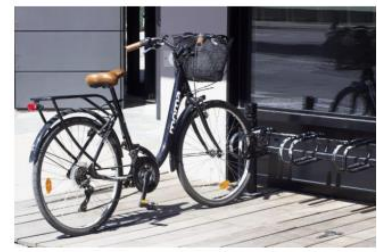

Think about your experience with riding a personal bikes. How many one-way trips did you take using a personal bike in the last 7 days?

(ex: If I rode from home to the library, checked out a book, and then I rode back home, I would have taken 2 trips.)

On the next screen, we will ask about personal reasons and neighborhood reasons that prevent you from biking more

frequently

What personal reasons prevent you from biking more frequently? (select all that apply)

\begin{tabular}{|c|c|}
\hline $\begin{array}{l}\text { I can't afford maintenance costs for a } \\
\text { bike }\end{array}$ & $\square^{\text {I can't afford to buy a bike }}$ \\
\hline $\begin{array}{l}\text { I am satisfied with my current amount } \\
\text { of cycling }\end{array}$ & $\square$ I have never tried riding a bike before \\
\hline Riding a bike makes me too sweaty & $\square$ I often travel with multiple people \\
\hline $\begin{array}{l}\text { Bikes are not well adapted to my } \\
\text { physical ability level }\end{array}$ & 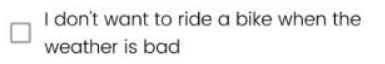 \\
\hline I don't have a place to store a bike & $\square \begin{array}{l}\text { I often travel with too many items to } \\
\text { carry in a backpack or small bag }\end{array}$ \\
\hline Bikes are too slow & $\square$ I don't own a bike \\
\hline Other: (type response in box) & \\
\hline
\end{tabular}


How does the neighborhood where you live prevent you from biking more frequently? (select all that apply)

$\square$ I am satisfied with my current amount
of cycling
$\square$ I'can't count on a bike share bike being
around when I need it
$\square$ Not enough bike parking my bike will be stolen
$\square$ Too many hills
Other: (type response in box)
$\square$ There's not enough transit service to act
as back up plan

Please indicate to what extent you agree or disagree with the following statements:

\begin{tabular}{|c|c|c|c|c|c|}
\hline & $\begin{array}{l}\text { Strongly } \\
\text { Disagree }\end{array}$ & Disagree & Neutral & Agree & $\begin{array}{l}\text { Strongly } \\
\text { Agree }\end{array}$ \\
\hline I enjoy riding a bike & O & ○ & O & O & O \\
\hline I am a bike advocate & ○ & $\bigcirc$ & $\bigcirc$ & O & 0 \\
\hline $\begin{array}{r}\text { I consider myself a bike } \\
\text { commuter }\end{array}$ & ○ & $\bigcirc$ & O & O & 0 \\
\hline Bikes are convenient & 0 & O & O & O & O \\
\hline $\begin{array}{l}\text { I think that riding a bike } \\
\text { helps the environment }\end{array}$ & O & O & O & O & ○ \\
\hline Riding a bike is cool & O & ○ & O & O & ○ \\
\hline I feel safe riding a bike & 0 & ○ & ○ & O & ○ \\
\hline $\begin{array}{r}\text { | will not ride } \\
\text { somewhere if there are } \\
\text { no bike lanes }\end{array}$ & O & $\bigcirc$ & $\bigcirc$ & O & 0 \\
\hline $\begin{array}{l}\text { Most cyclists ride } \\
\text { recklessly }\end{array}$ & O & O & ○ & O & O \\
\hline $\begin{array}{l}\text { Cyclists cause unsafe } \\
\text { situations for } \\
\text { pedestrians }\end{array}$ & 0 & $\bigcirc$ & O & O & 0 \\
\hline
\end{tabular}




\section{E-scooters}

These are battery-powered two wheel devices that can be unlocked with a phone application and ridden in a bike lane or path.

You may have seen e-scooters of different brands (such as Lime, Bolt, Razor, Spin, and Bird) in use throughout Portland.

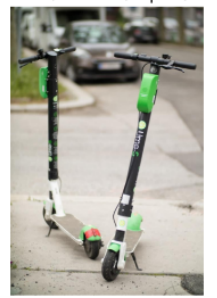

Think about your experience with e-scooters. How many one-way trips did you take using an e-scooter in the last 7 days?

(ex: If I rode from home to the library, checked out a book, and then I rode back, I would have taken 2 trips.)

On the next screen, we will ask about personal reasons and neighborhood reasons that prevent you from riding e-scooters more frequently. 
What personal reasons prevent you from using an e-scooter more frequently? (select all that apply)

\begin{tabular}{|c|c|}
\hline E-scooters are too slow & $\begin{array}{l}\text { I don't have a credit card or debit card } \\
\text { that I can use to pay for an e-scooter }\end{array}$ \\
\hline $\begin{array}{l}\text { I'm not sure how to sign up for an } \\
\text { e-scooter system }\end{array}$ & $\square \begin{array}{l}\text { I often travel with too many items to } \\
\text { carry in a backpack or small bag }\end{array}$ \\
\hline $\begin{array}{l}\text { I have never tried riding an e-scooter } \\
\text { before }\end{array}$ & $\square^{\text {I often travel with multiple people }}$ \\
\hline $\begin{array}{l}\text { I am satisfied with my current amount } \\
\text { of e-scooter use }\end{array}$ & $\square^{\text {I don't feel comfortable riding in traffic }}$ \\
\hline $\begin{array}{l}\text { I cant afford to ride e-scooters } \\
\text { regularly }\end{array}$ & $\square \begin{array}{l}\text { E-scooters are not well adapted to my } \\
\text { physical ability level }\end{array}$ \\
\hline I don't want to ride an e-scooter when & Other: (type response in box) \\
\hline
\end{tabular}

How does the neighborhood where you live prevent you from using an e-scooter more frequently? (select all that apply)

$\square \begin{aligned} & \text { My destinations are outside an } \\ & \text { e-scooter service area }\end{aligned} \quad \begin{aligned} & \text { I can't count on an e-scooter being } \\ & \text { around when I need it }\end{aligned}$
$\square \begin{aligned} & \text { There's not enough transit service to act } \\ & \text { as a plan B }\end{aligned} \begin{aligned} & \text { I am satisfied with my current amount } \\ & \text { of e-scooter use }\end{aligned}$
$\square$ Too much traffic
I live outside of an e-scooter service
$\square$ area

Do you have an e-scooter application installed on your phone?

yes

no 
Please indicate to what extent you agree or disagree with the following statements:

Ifeel safe riding an
e-scooter
E-scooters are ugly
I am an e-scooter
commuter
I will not ride

(Last mode!)

\section{MAX Light Rail}

This is an electric train that connects Hillsboro, Beaverton,

Gresham, Milwaukie, Clackamas Town Center, and the Airport to Downtown Portland. It is operated by Trimet.

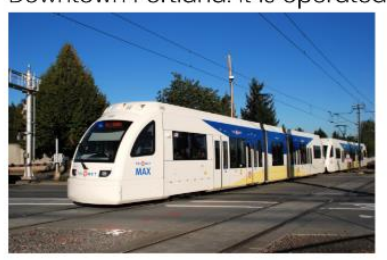

Think about your experience with MAX. How many one-way trips did you take using MAX in the last 7 days?

(ex: If I rode MAX from home to the library, checked out a book, and then I rode MAX back, I would have taken 2 trips.) 
On the next screen, we will ask about personal reasons and neighborhood reasons that prevent you riding MAX more frequently.

What personal reasons prevent you from riding MAX more frequently? (select all that apply)

$\square$ MAX does not run during times when I $\square$ Im not sure how to buy a ticket to ride
need to use it
MAX is too slow
$\square$ I I often travel with multiple people
MAX
$\square$ I often travel with too many items to
carry in a backpack or small bag
$\square$ MAX is not well adapted to my physical $\square$ I Ion't have a credit card or debit card
ability level
MAX is too expensive


How does the neighborhood where you live prevent you from riding MAX more frequently? (Select all that apply)

$\square$ I am satisfied with how frequently I ride $\square$ There is not a safe way for me to walk
or bike to the MAX station
$\quad$ I live too far from a MAX station
$\square$

Please indicate to what extent you agree or disagree with the following statements:

I enjoy riding MAX
Riding MAX is cool
MAX comes frequently
enough for me to use it
$\begin{gathered}\text { I feel safe riding MAX } \\ \text { I think that riding MAX } \\ \text { helps the environment } \\ \text { MAX is convenient } \\ \text { I am glad to have the } \\ \text { time to do other things } \\ \text { while riding MAX } \\ \text { I am a transit } \\ \text { commuter }\end{gathered}$
$\begin{array}{r}\text { I feel comfortable while } \\ \text { riding MAX } \\ \text { (Temperature, seat, } \\ \text { space, etc.) }\end{array}$
$\begin{array}{r}\text { Transit is primarily for } \\ \text { people with lower } \\ \text { inmmoc }\end{array}$


If your primary means of transportation to PSU was unavailable, how likely is it that you would choose to take one of the following modes to PSU?

\begin{tabular}{|c|c|c|c|c|c|c|c|c|c|}
\hline & \multicolumn{5}{|c|}{ Not at all likely } & \multicolumn{4}{|c|}{ Extremely likely } \\
\hline 1 & 2 & 3 & 4 & 6 & 6 & 7 & 8 & 9 & 10 \\
\hline \multicolumn{10}{|l|}{ Personal car } \\
\hline \multicolumn{10}{|l|}{ Bike (personal) } \\
\hline & & & & $\mathrm{O}$ & & & & & \\
\hline \multicolumn{10}{|l|}{ E-scooter } \\
\hline MAX Light Rail & & & & & & & & & \\
\hline
\end{tabular}

\section{Section 3: Stated Preference}

\section{Section 3: Stated Preference}

The next section will ask you to play a game.

Imagine that you are living in a different area of Portland than you do now, and it is too far to walk to PSU.

For the next six questions, you will be asked to choose one of three different transportation options to PSU:

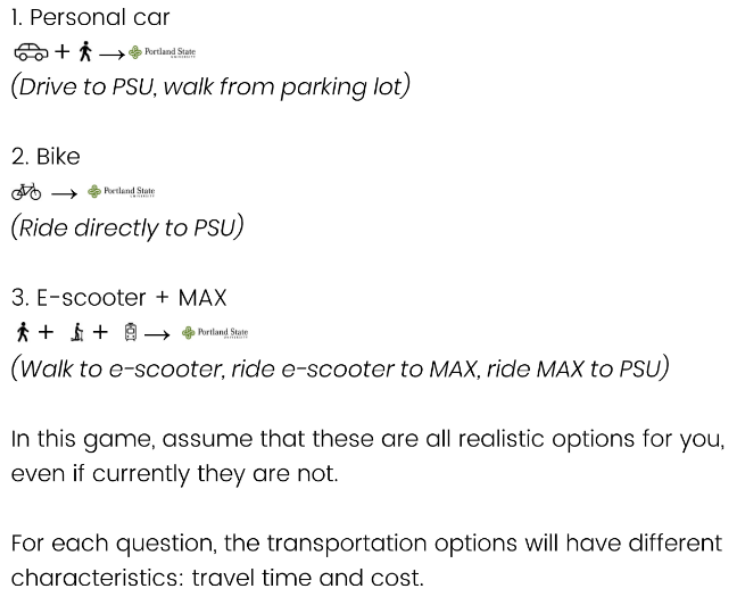


to the time it takes to access or leave the vehicle.

In order for the questions in this section to display properly, please rotate your device so that it is vertical.

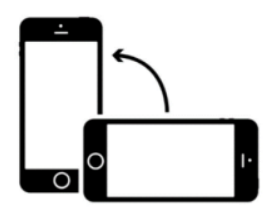

Experiment Block 1

Based upon these attributes, which one of the three transportation options to PSU do you prefer?

Note that the attributes will change each time.

\begin{tabular}{|c|c|c|c|c|c|c|c|c|}
\hline \multicolumn{2}{|c|}{ Personal Car } & Totals: & \multicolumn{2}{|c|}{ Bike } & Totals: & \multicolumn{2}{|c|}{ E-Scooter + MAX } & Totals: \\
\hline $\begin{array}{l}\text { Drive } \\
\text { time: }\end{array}$ & $25 \mathrm{~min}$ & \multirow{2}{*}{$25 \mathrm{~min}$} & $\begin{array}{l}\text { Walking } \\
\text { time: }\end{array}$ & $\underset{\min }{0}$ & & $\begin{array}{l}\text { Walking } \\
\text { time: }\end{array}$ & $2 \mathrm{~min}$ & \multirow{3}{*}{$42 \min$} \\
\hline $\begin{array}{l}\text { Walking } \\
\text { time: }\end{array}$ & $0 \mathrm{~min}$ & & $\begin{array}{l}\text { Bike } \\
\text { time: }\end{array}$ & $\begin{array}{l}45 \\
\text { min }\end{array}$ & mins & $\begin{array}{l}\text { E-Scooter } \\
\text { time: }\end{array}$ & $\begin{array}{c}10 \\
\min \end{array}$ & \\
\hline $\begin{array}{l}\text { Parking } \\
\text { Cost: }\end{array}$ & $\$ 15.00$ & $\$ 15.00$ & Cost: & Free & Free & $\begin{array}{l}\text { MAX } \\
\text { time: }\end{array}$ & $\begin{array}{l}30 \\
\text { min }\end{array}$ & \\
\hline & & & & & & $\begin{array}{l}\text { E-scooter } \\
\text { cost: }\end{array}$ & $\$ 0.50$ & \multirow{2}{*}{$\$ 4.25$} \\
\hline & 0 & & & 0 & & $\begin{array}{l}\text { MAX } \\
\text { cost: }\end{array}$ & $\$ 3.75$ & \\
\hline
\end{tabular}

Note: Only one choice set has been included here to save space. In total, there were 24 different choice sets. 


\section{Section 4: Demographics}

Almost done!

In the last section, we will ask you some basic questions about yourself

Do you consider yourself (check all that apply)...

$\begin{array}{ll}\square \text { American Indian or Alaska Native } & \square \text { Native Hawaiian or other Pacific Islander } \\ \square \text { Asian } & \square \text { Hispanic or Latinx/Latino/Latina } \\ \square \text { Black or African American } & \square \text { Prefer not to say } \\ \quad \square \quad & \text { Other: (type response in box) } \\ \square & \square\end{array}$

What is your age?

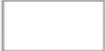

What gender do you identify as?

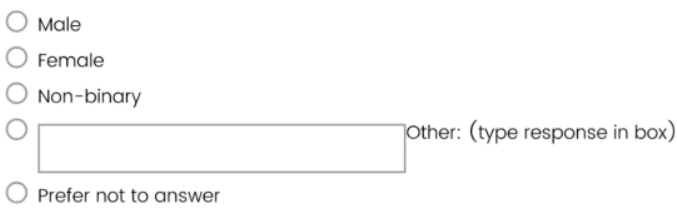

Are you married or living with a partner?

Yes

No

Prefer notto answer

How many children live with you that you are responsible for? 
What is the approximate annual income of you and your partners?

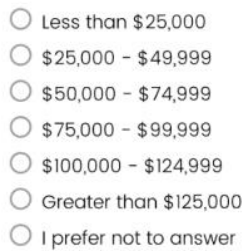

How would you describe your general state of health?
Poor
Fair
Good
Very Good
Excellent I prefer not to
○
O
○
O
○
answer

Do you have any physical limitation that make riding a bicycle or an e-scooter difficult for you?

$\mathrm{O}$ Yes

No

Prefer not to answer

What is an intersection near your home (e.g. SW Broadway and sW Yamhill St.)? 